\title{
WestVirginiaUniversity
}

THE RESEARCH REPOSITORY @ WVU

Graduate Theses, Dissertations, and Problem Reports

2013

\section{Nanoclay-Based Solid-Amine Adsorbents for Carbon Dioxide Capture}

\author{
Elliot A. Roth \\ West Virginia University
}

Follow this and additional works at: https://researchrepository.wvu.edu/etd

\section{Recommended Citation}

Roth, Elliot A., "Nanoclay-Based Solid-Amine Adsorbents for Carbon Dioxide Capture" (2013). Graduate Theses, Dissertations, and Problem Reports. 279.

https://researchrepository.wvu.edu/etd/279

This Dissertation is protected by copyright and/or related rights. It has been brought to you by the The Research Repository @ WVU with permission from the rights-holder(s). You are free to use this Dissertation in any way that is permitted by the copyright and related rights legislation that applies to your use. For other uses you must obtain permission from the rights-holder(s) directly, unless additional rights are indicated by a Creative Commons license in the record and/ or on the work itself. This Dissertation has been accepted for inclusion in WVU Graduate Theses, Dissertations, and Problem Reports collection by an authorized administrator of The Research Repository @ WVU.

For more information, please contact researchrepository@mail.wvu.edu. 


\title{
Nanoclay-Based Solid-Amine Adsorbents for Carbon Dioxide Capture
}

\author{
Elliot A. Roth
}

Dissertation submitted to the

Benjamin M. Statler College of Engineering and Mineral Resources at West Virginia University in partial fulfillment of the requirements for the degree of

Doctor of Philosophy

in

Chemical Engineering

\author{
Rakesh Gupta, Ph.D., Chair \\ Sushant Agarwal, Ph.D. \\ Charter Stinespring, Ph.D. \\ Evan Granite, Ph.D. \\ Karl Haider, Ph.D.
}

Department of Chemical Engineering

Morgantown, West Virginia

2013

Keywords: Carbon Dioxide Capture; Amine; Solid Adsorbent Copyright 2013 Elliot A. Roth 


\section{ABSTRACT \\ Nanoclay-Based Solid-Amine Adsorbents for Carbon Dioxide Capture}

\section{Elliot A. Roth}

The objective of this research was to develop an efficient, low cost, recyclable solid sorbent for carbon dioxide adsorption from large point sources, such as coal-fired power plants. The current commercial way to adsorb $\mathrm{CO}_{2}$ is to use a liquid amine or ammonia process. These processes are used in industry in the "sweetening" of natural gas, but liquid based technologies are not economically viable in the adsorption of $\mathrm{CO}_{2}$ from power plants due to the extremely large volume of $\mathrm{CO}_{2}$ and the inherent high regeneration costs of cycling the sorbent. Therefore, one of the main objectives of this research was to develop a novel sorbent that can be cycled and uses very little energy for regeneration.

The sorbent developed here is composed of a nanoclay (montmorillonite), commonly used in the production of polymer nanocomposites, grafted with commercially available amines. (3-aminopropyl) trimethoxysilane (APTMS) was chemically grafted to the edge hydroxyl groups of the clay. While another amine, polyethylenimine (PEI), was attached to the surface of the clay by electrostatic interactions. To confirm the attachment of amines to the clay, the samples were characterized using FTIR and the corresponding peaks for amines were observed. The amount of amine loaded onto the support was determined by TGA techniques. The treated clay was initially analyzed for $\mathrm{CO}_{2}$ adsorption in a pure $\mathrm{CO}_{2}$ stream. The adsorption temperatures that had the highest adsorption capacity were determined to be between $75^{\circ} \mathrm{C}$ and $100^{\circ} \mathrm{C}$ for all of the samples tested at atmospheric pressure. The maximum $\mathrm{CO}_{2}$ adsorption capacity observed was with nanoclay treated with both APTMS and PEI at $85^{\circ} \mathrm{C}$. In a more realistic flue gas of $10 \% \mathrm{CO}_{2}$ and $90 \% \mathrm{~N}_{2}$, the adsorbents had essentially the same overall $\mathrm{CO}_{2}$ adsorption capacity indicating that the presence of nitrogen did not hinder the adsorption of $\mathrm{CO}_{2}$. Adsorption studies in pure $\mathrm{CO}_{2}$ at room temperature under pressure from 40-300 PSI were also conducted. The average adsorption capacity for the adsorbents did not change significantly over the range of pressures studied, indicating that the uptake of $\mathrm{CO}_{2}$ was due mainly to chemical reaction and not to the physical absorption of $\mathrm{CO}_{2}$. The average $\mathrm{CO}_{2}$ adsorption capacity at 300 psi and room temperature for clay treated with APTMS alone was 7.6 wt\% $\mathrm{CO}_{2}$. The combination of APTMS and PEI treatment increased the average adsorption capacity to $11.4 \mathrm{wt} \% \mathrm{CO}_{2}$.

The regeneration method for the majority of the adsorption tests employed pure $\mathrm{N}_{2}$ at $100^{\circ} \mathrm{C}$ as a sweep gas, and it was successful in regenerating the adsorbent. The regeneration of the adsorbent was also studied with pure and humid $\mathrm{CO}_{2}$ at $155^{\circ} \mathrm{C}$. Using $\mathrm{CO}_{2}$ as a sweep gas for regeneration is more commercially relevant and was able to regenerate the sorbents. 
Vacuum regeneration and the stability of the adsorbents to water vapor were also studied. Our studies showed that the developed adsorbents were able to adsorb $\mathrm{CO}_{2}$ at atmospheric conditions using pure $\mathrm{CO}_{2}$ as well as $10 \% \mathrm{CO}_{2}$ and $90 \%$ nitrogen. Additionally, the adsorbents developed have the potential to be cycled using commercially applicable regeneration schemes. While these results are comparable to results of other emerging $\mathrm{CO}_{2}$ adsorption technologies, our adsorbent has the benefit of a very cheap support, and it could provide a commercially useful $\mathrm{CO}_{2}$ adsorbent. 


\section{ACKNOWLEDGEMENT}

I would like to thank my advisor, Dr. Rakesh Gupta, for all of his enthusiasm, advice, motivation, and help he provided me with throughout my graduate studies. He helped me with not only my research and classwork, but also helped me become a better person in general. I would like to thank Dr. Sushant Agarwal for all of his expertise in the laboratory, and his help with everyday problems that tend to occur with experimental research. I would like to thank Dr. Evan Granite for his unwavering support, enthusiasm, and advice with my research, and giving me a chance to see his laboratory at the Department of Energy, which was very exciting in many ways. My appreciations are extended to Dr. Karl Haider who helped organize my internship at Bayer MaterialScience, and provide a vast amount of knowledge with the chemistry and other areas of my research. I would also like to thank Dr. Charter Stinespring for his advice and guidance during my studies.

My sincere gratitude goes out to Dr. John Zondlo and Dr. Gloria Oporto for allowing me to use their equipment and laboratory space, which was instrumental to my research. Additionally, I would like to thank Adam Finniss, Matthew Thompson, Jeremy Hardinger, and everyone else who helped me with laboratory techniques, with technical problems, and with proofreading anything that I needed. Finally I would like to thank the Bayer Foundation for the fellowship it provided me for the duration of my studies, and Center for Advanced Separation Technology (CAST) for funding. 


\section{Table of Contents}

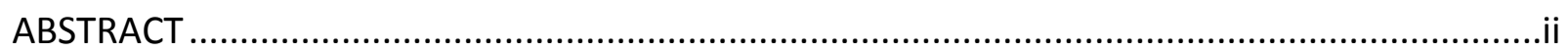

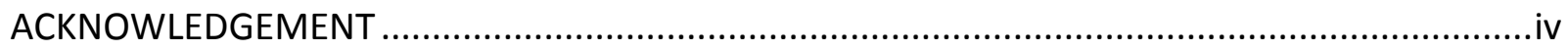

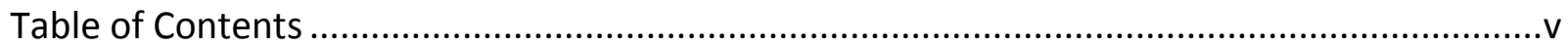

List of Figures................................................................................................................

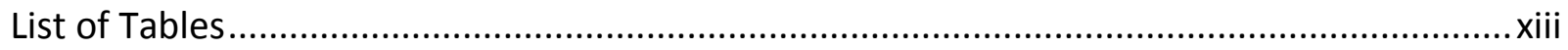

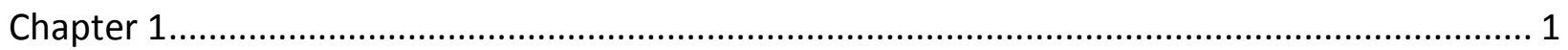

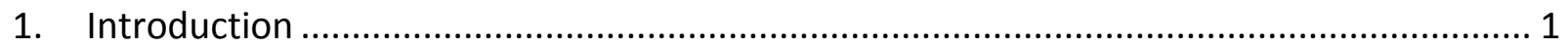

1.1 Coal-fired Power Plants and Carbon Dioxide Emissions ................................................ 2

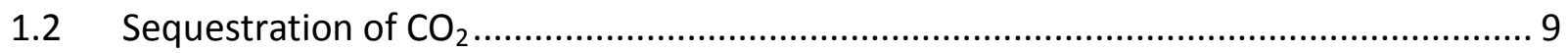

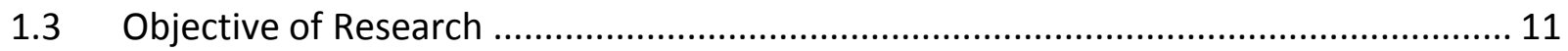

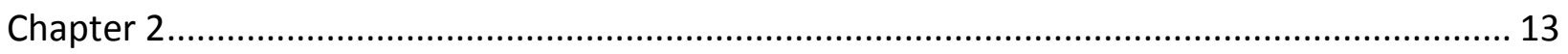

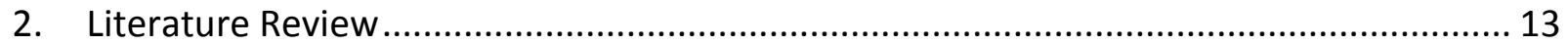

2.1 Physical and Chemical Solvents for $\mathrm{CO}_{2}$ Capture .................................................. 13

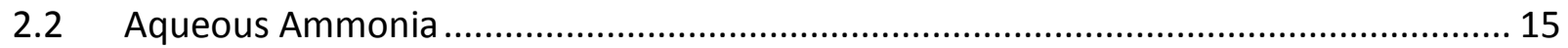

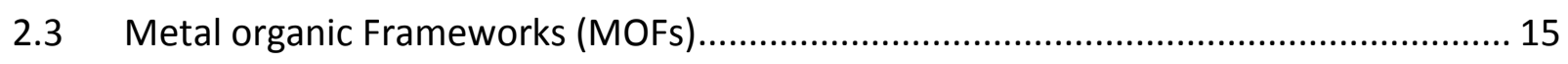

2.4 Zeolites and compounds composed of alkali and alkali earth metals .......................... 17

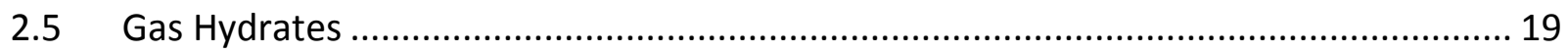

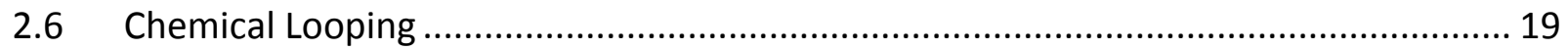

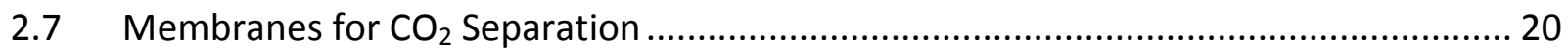

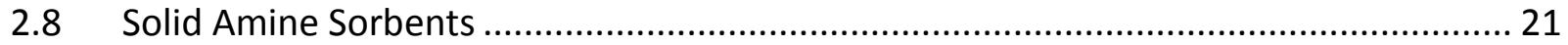

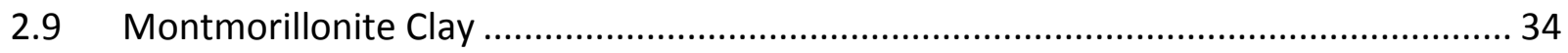

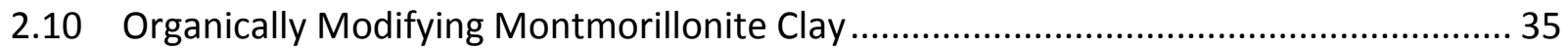

2.11 Methods for Attaching APTMS and PEI to Montmorillonite Clay ................................ 37

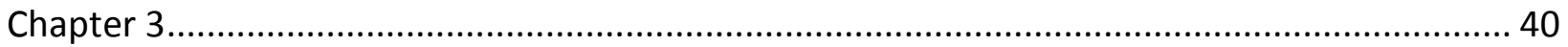

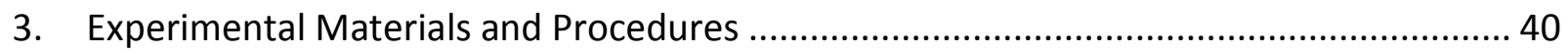

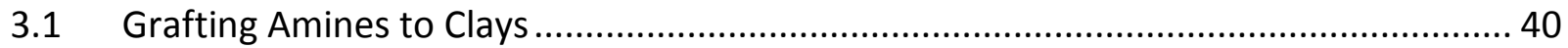

3.2 Thermogravimetric Analysis for Amine Content on Clay ................................................ 41

3.3 High Pressure $\mathrm{CO}_{2}$ Adsorption and Desorption Tests ................................................ 42

3.4 Thermogravimetric Analysis for $\mathrm{CO}_{2}$ Adsorption and Desorption ................................ 43 


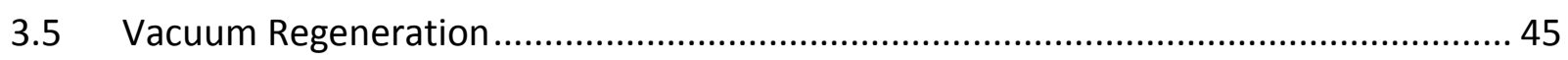

3.6 Fourier Transform Infrared Spectroscopy (FTIR) Characterization ................................. 46

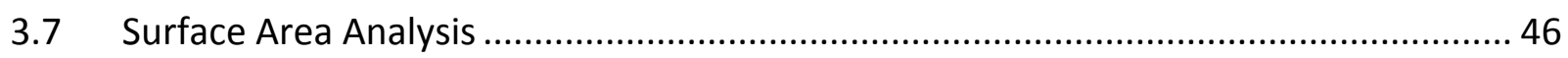

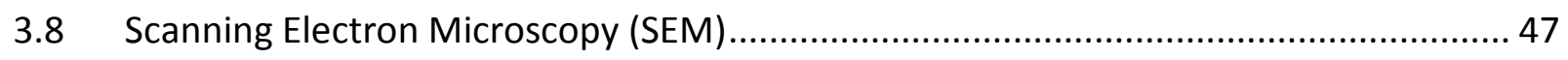

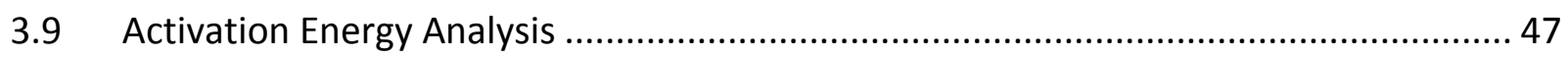

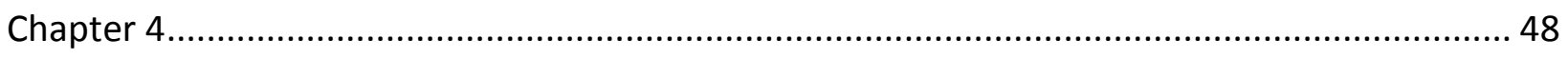

4. Results of Grafting APTMS and PEI onto Montmorillonite Clay ...................................... 48

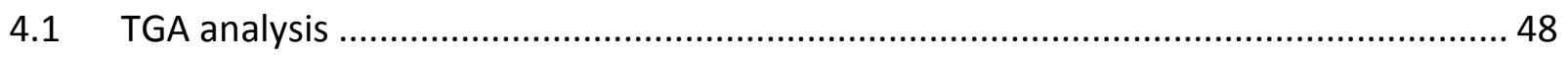

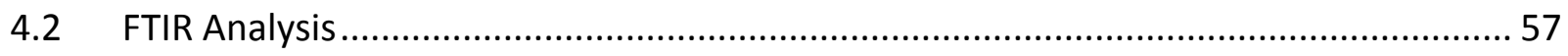

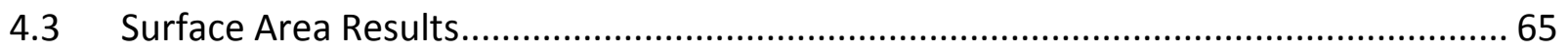

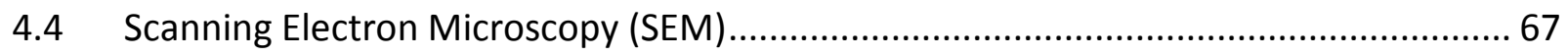

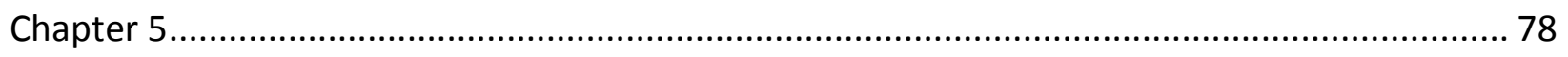

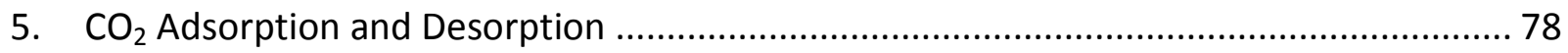

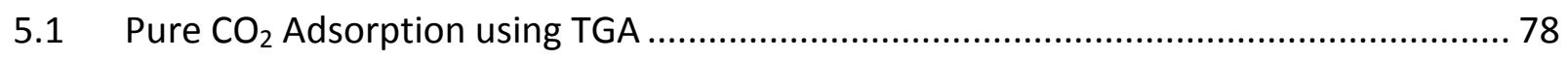

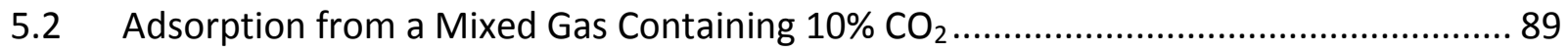

5.3 Regeneration of Adsorbents using Pure Nitrogen ...................................................... 91

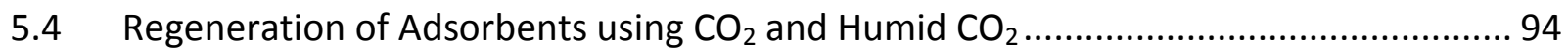

5.5 Regeneration of Adsorbents using Vacuum............................................................. 101

$5.6 \mathrm{CO}_{2}$ Adsorption at High Pressure ................................................................... 108

5.7 Stability of the Adsorbent after Long Exposure to Water Vapor ................................. 120

5.8 Activation Energy Results ...................................................................................... 127

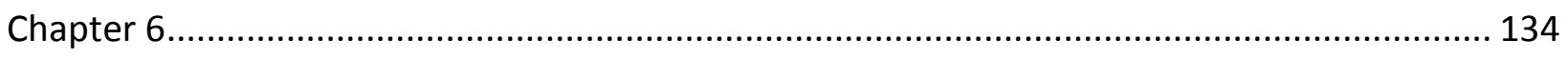

6. Conclusions and Future Work .................................................................................. 134

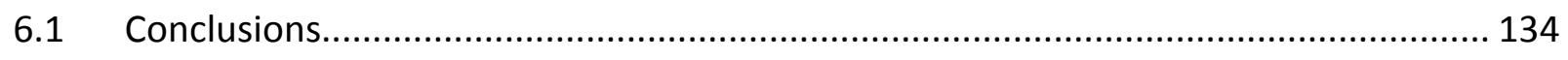

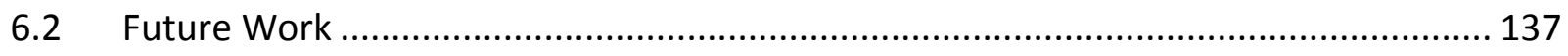

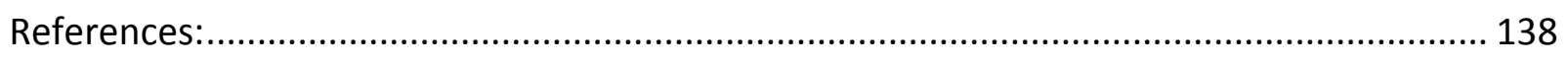

Appendix A: Tabulated Data for Graphs ...................................................................... 143 


\section{List of Figures}

Figure 1-1: World $\mathrm{CO}_{2}$ emissions by sector in 2009; Other, includes commercial/public services, agriculture/forestry, fishing and other emissions not specified elsewhere. ${ }^{[2]}$ 3

Figure 1-2: U.S. projection of $\mathrm{CO}_{2}$ emissions for existing coal-fired power plants versus new coal-fired power plants ${ }^{[6]}$ 5

Figure 2-1: Single crystal structure of Mg-MOF-74, formed by reaction of the DOT linker with

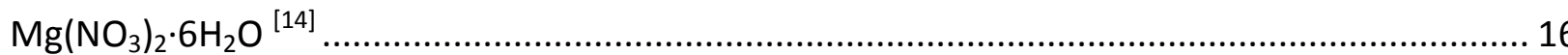

Figure 2-2: Structures of different zeolite frameworks (a) silicalite, (b) $13 \mathrm{X}$ and (c) $5 \mathrm{~A}^{[19]} \ldots \ldots \ldots 17$

Figure 2-3: Schematic of direct coal combustion using chemical looping with iron. ${ }^{[23]}$............... 20

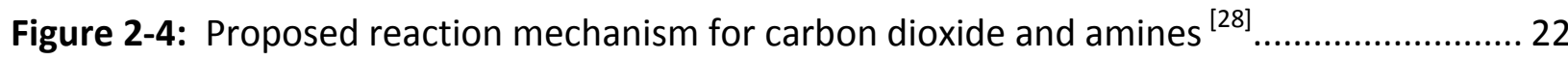

Figure 2-5: a) Class 1 amine impregnated solid amine adsorbent, b) Class 2 covalently attached solid amine adsorbent, c) Class 3 polymerized solid amine adsorbent ${ }^{[40]}$ 23 Figure 2-6: $\mathrm{MCM}-41$ loaded with PEl cycles at $75^{\circ} \mathrm{C}$; a) dry pure $\mathrm{CO}_{2}$ and nitrogen, b) humid $\mathrm{CO}_{2}$ and nitrogen $(6 \% \mathrm{RH})^{[59}$ 31

Figure 2-7: $\mathrm{CO}_{2}$ adsorption and desorption at $70^{\circ} \mathrm{C}$ using TRI-PE-MCM- 41 with dry gases (TRI-

70/70-d) and humid gases (7\% RH) (TRI-70/70-h) ${ }^{[60]}$ 32

Figure 2-8: Proposed scheme of urea formation using amine sorbents ${ }^{[60]} \ldots \ldots \ldots \ldots \ldots \ldots \ldots \ldots \ldots \ldots \ldots . . . . . . . . . . . . . . . .33$

Figure 2-9: Schematic of 2:1 layered clay; $d_{001}$ refers to basal plane spacing. ${ }^{[63]} \ldots \ldots \ldots \ldots \ldots \ldots \ldots \ldots . . . . . . . . . .35$

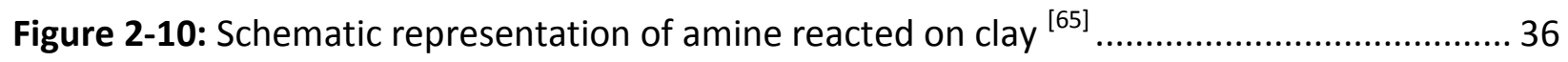

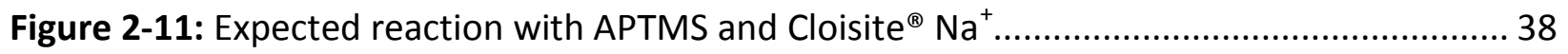

Figure 4-1: TGA Curve of clay treated with 0.4g APTMS/g Clay in nitrogen ............................... 49

Figure 4-2: TGA curve of untreated Cloisite ${ }^{\circledR} \mathrm{Na}^{+}$in nitrogen.................................................. 50 
Figure 4-3: TGA curve of untreated Cloisite ${ }^{\circledR} \mathrm{Na}^{+}$ramped to $900^{\circ} \mathrm{C}$ in nitrogen....... 51

Figure 4-4: Average amount of amine grafted using different solvents "dry method" 52

Figure 4-5: Comparison of the dry method versus the slurry method using DMF ..... 53

Figure 4-6: Percent amine grafted versus the concentration of APTMS "slurry method" 54

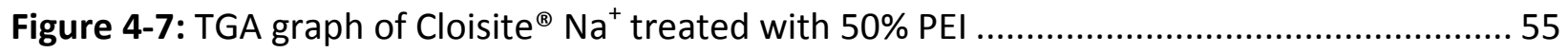

Figure 4-8: Comparison of the amount of amine grafted versus treatment .......................... 56

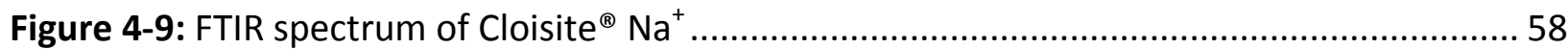

Figure 4-10: FTIR spectra of Cloisite $\mathrm{Na}^{\circledR}:$ (a) spectrum of the initial sample at room

temperature, (b) spectrum of the sample at $100^{\circ} \mathrm{C},(\mathrm{c})$ spectrum of the sample at $200^{\circ} \mathrm{C},(\mathrm{d})$

spectrum of the sample at room temperature immediately after cooling, (e) spectrum of the sample at room temperature after $70 \mathrm{~h}$, and (f) spectrum of the sample at room temperature

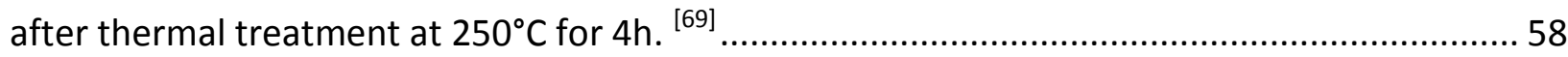

Figure 4-11: FTIR spectrum: (a) untreated clay, (b) untreated clay heated to $900^{\circ} \mathrm{C}$ in $\mathrm{N}_{2} \ldots \ldots . .59$

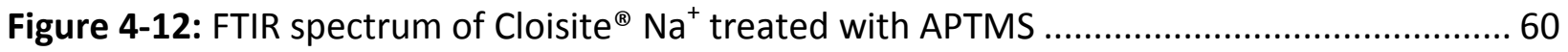

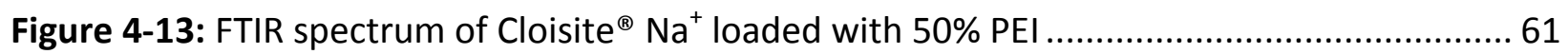

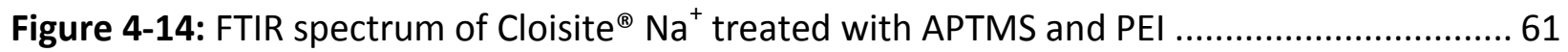

Figure 4-15: FTIR Spectra comparing the differences in amine treatments: (a) untreated clay, (b) clay treated with PEI, (c) clay treated with APTMS, (d) clay treated with APTMS+PEI 62

Figure 4-16: FTIR Spectra: (a) untreated clay, (b) clay treated with APTMS and, (c) clay treated with APTMS after $\mathrm{CO}_{2}$ adsorption in TGA at $85^{\circ} \mathrm{C}$ in pure $\mathrm{CO}_{2}$.... 64

Figure 4-17: FTIR Spectra from $1800 \mathrm{~cm}^{-1}-800 \mathrm{~cm}^{-1}$ : (a) untreated clay, (b) clay treated with APTMS, and (c) clay treated with APTMS after $\mathrm{CO}_{2}$ adsorption in TGA at $85^{\circ} \mathrm{C}$ in pure $\mathrm{CO}_{2} \ldots \ldots . .65$ 
Figure 4-18: SEM image of untreated clay magnified 200 times, with a working distance of

$12.8 \mathrm{~mm}$, using $5.0 \mathrm{kV}$ and both detectors

Figure 4-19: SEM image of untreated clay magnified 25,000 times, with a working distance of

$12.7 \mathrm{~mm}$, using $5.0 \mathrm{kV}$ and both detectors.

Figure 4-20: SEM image of untreated clay magnified 1,000 times, with a working distance of $12.8 \mathrm{~mm}$, using $5.0 \mathrm{kV}$ and the lower detector 70

Figure 4-21: SEM image of treated clay with APTMS magnified 200 times, with a working distance of $12.7 \mathrm{~mm}$, using $5.0 \mathrm{kV}$ and the lower detector

Figure 4-22: SEM image of treated clay with APTMS magnified 100,000 times, with a working distance of $12.7 \mathrm{~mm}$, using $5.0 \mathrm{kV}$ and the both detectors 72

Figure 4-23: SEM image of treated clay with APTMS magnified 350 times, with a working distance of $12.7 \mathrm{~mm}$, using $5.0 \mathrm{kV}$ and the lower detector

Figure 4-24: SEM image of treated clay with 50\% PEI magnified 200 times, with a working distance of $15.0 \mathrm{~mm}$, using $5.0 \mathrm{kV}$ and both detectors. 73

Figure 4-25: SEM image of treated clay with 50\% PEI magnified 1,800 times, with a working distance of $12.7 \mathrm{~mm}$, using $5.0 \mathrm{kV}$ and the lower detector

Figure 4-26: SEM image of 20 treated clay with APTMS and 50\% PEI magnified 50 times, with a working distance of $12.1 \mathrm{~mm}$, using $5.0 \mathrm{kV}$ and both detectors. 75 Figure 4-27: SEM image of 2L treated clay with APTMS and 50\% PEI magnified 50 times, with a working distance of $12.5 \mathrm{~mm}$, using $5.0 \mathrm{kV}$ and both detectors. The blisters and holes are due to the carbon tape not the sample 76 
Figure 4-28: SEM image of 2L treated clay with APTMS and 50\% PEI magnified 500 times, with a working distance of $12.4 \mathrm{~mm}$, using $5.0 \mathrm{kV}$ and both detectors ......................................... 76

Figure 4-29: SEM image of 20 treated clay with APTMS and 50\% PEI magnified 2,500 times, with a working distance of $12.4 \mathrm{~mm}$, using $5.0 \mathrm{kV}$ and both detectors ................................... 77

Figure 5-1: TGA graph of untreated clay for $\mathrm{CO}_{2}$ adsorption at $85^{\circ} \mathrm{C}$ in pure $\mathrm{CO}_{2} \ldots \ldots \ldots \ldots \ldots \ldots . \ldots . \ldots . \ldots$

Figure 5-2: TGA graph of clay treated with PEI, pure $\mathrm{CO}_{2}$ adsorption at $85^{\circ} \mathrm{C} \ldots \ldots \ldots \ldots \ldots \ldots \ldots . . . . . . . . . . . .80$

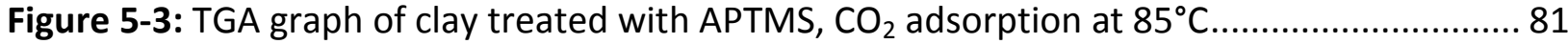

Figure 5-4: TGA graph of clay treated with APTMS and PEI, $\mathrm{CO}_{2}$ adsorption at $85^{\circ} \mathrm{C} \ldots \ldots \ldots \ldots . . . . . .82$

Figure 5-5: Carbon dioxide adsorption capacity as a function of adsorption temperature at

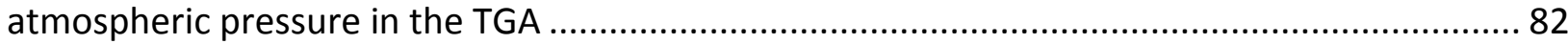

Figure 5-6: Time versus percent $\mathrm{CO}_{2}$ adsorbed based on a 90 minute adsorption run ............. 84

Figure 5-7: $\mathrm{TGA} \mathrm{CO}_{2}$ adsorption graph at $85^{\circ} \mathrm{C}$ of clay loaded with $50 \%$ PEI $\mathrm{Mn} 1200 \ldots \ldots \ldots \ldots . . . .86$

Figure 5-8: $\mathrm{TGA} \mathrm{CO}_{2}$ adsorption graph at $85^{\circ} \mathrm{C}$ for clay loaded with $50 \%$ PEI $\mathrm{Mn} 60,000 \ldots \ldots \ldots . . .87$

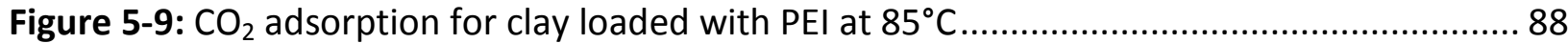

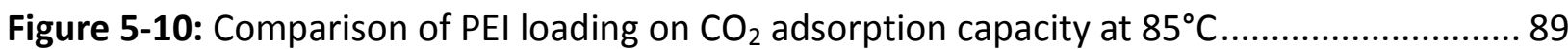

Figure 5-11: $\mathrm{CO}_{2}$ adsorption using $10 \% \mathrm{CO}_{2}$ and $90 \% \mathrm{~N}_{2}$, clay treated with APTMS ................. 90

Figure 5-12: $\mathrm{CO}_{2}$ adsorption capacity in pure $\mathrm{CO}_{2}$ and $10 \% \mathrm{CO}_{2}$ balanced with nitrogen .......... 91

Figure 5-13: Percent regeneration using pure nitrogen at $100^{\circ} \mathrm{C}$ in a TGA........................... 93

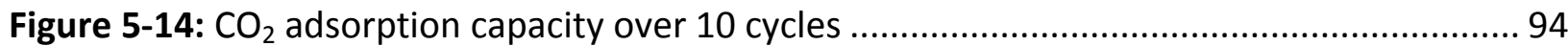

Figure 5-15: TGA graph clay treated with APTMS pure $\mathrm{CO}_{2}$ temperature study ..................... 95

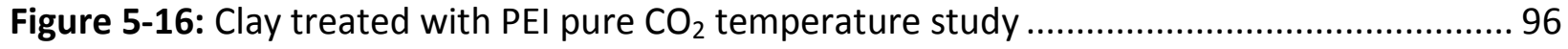


Figure 5-17: Clay treated with $\mathrm{PEI}$, initially in pure nitrogen at $100^{\circ} \mathrm{C}$ then switched to pure $\mathrm{CO}_{2}$ for adsorption at $85^{\circ} \mathrm{C}$ and desorption at $155^{\circ} \mathrm{C}$

Figure 5-18: Percent carbon dioxide cycled at $85^{\circ} \mathrm{C}$ in the TGA using pure $\mathrm{CO}_{2}$ at $155^{\circ} \mathrm{C}$ for 30 minutes for regeneration 98

Figure 5-19: Schematic of the addition of water to the reaction gas 99

Figure 5-20: Percent $\mathrm{CO}_{2}$ cycled using humid $\mathrm{CO}_{2}$ at $155^{\circ} \mathrm{C}$ for 30 minutes 100

Figure 5-21: Clay treated with APTMS initial $\mathrm{CO}_{2}$ adsorption run for vacuum study 101

Figure 5-22: TGA graph of clay treated with APTMS after the $2^{\text {nd }}$ vacuum desorption step..... 103

Figure 5-23: TGA graph of clay treated with $\mathrm{PEI}$ initial $\mathrm{CO}_{2}$ adsorption at $85^{\circ} \mathrm{C}$ 106

Figure 5-24: TGA graph of clay treated with PEI after first vacuum desorption step 106

Figure 5-25: Vacuum regeneration results for $85^{\circ} \mathrm{C}$ vacuum desorption in the vacuum oven.. 108

Figure 5-26: $\mathrm{CO}_{2}$ sorption at pressure using clay treated with APTMS 110

Figure 5-27: $\mathrm{CO}_{2}$ sorption at pressure using clay treated with $\mathrm{PEI}$ 110

Figure 5-28: $\mathrm{CO}_{2}$ sorption at pressure using clay treated with APTMS+PEI 111

Figure 5-29: $\mathrm{CO}_{2}$ sorption at pressure using untreated clay 112

Figure 5-30: $\mathrm{CO}_{2}$ sorption at different pressures with 24 hours adsorption time 113

Figure 5-31: $\mathrm{CO}_{2}$ adsorption at 300psi for 24 hours at room temperature and at $50^{\circ} \mathrm{C}$. 114

Figure 5-32: Temperature comparison at 300psi for a 24 hours adsorption time 116

Figure 5-33: Weight percent $\mathrm{CO}_{2}$ adsorbed at 300 psi for at least 2 hours and weight percent desorbed under vacuum at $85^{\circ} \mathrm{C}$ at $93 \mathrm{kPa}$ 118

Figure 5-34: Vacuum regeneration with adsorption at $50^{\circ} \mathrm{C}$ at $300 \mathrm{psi}$ 119

Figure 5-35: Comparison of amine treatments on $\mathrm{CO}_{2}$ adsorption 124 
Figure 5-36: Comparison of the PEl loading on $\mathrm{CO}_{2}$ adsorption

Figure 5-37: $\mathrm{CO}_{2}$ adsorption of clay loaded with $66 \% \mathrm{PEI}$ after exposure to the environment chamber 126

Figure 5-38: $\mathrm{CO}_{2}$ adsorption for clay treated with APTMS and PEI after exposure to the environment chamber 126

Figure 5-39: TGA overlay graph of sample clay treated with $\mathrm{PEI}$ 129

Figure 5-40: Logarithm of heating rate vs. reciprocal absolute temperature. 129

Figure 5-41: Activation energy of clay treated with PEI versus weight fraction ..... 130

Figure 5-42: Clay treated with APTMS overlay TGA graph 131

Figure 5-43: Clay treated with APTMS activation energy versus weight fraction....... 131

Figure 5-44: Desorption of $\mathrm{CO}_{2}$ on clay treated with APTMS in nitrogen 133 


\section{List of Tables}

Table 1-1: Typical process conditions for combustion and gasification of coal in a $500 \mathrm{MW}$

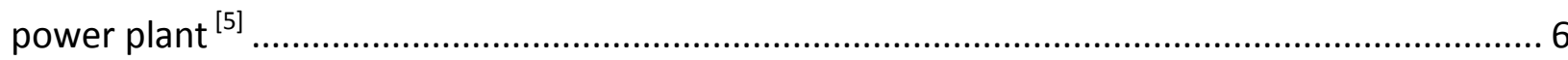

Table 1-2: Typical Composition of Coal Combustion Flue Gas and Gasification Fuel Gas ${ }^{[5]}$......... 7

Table 1-3: Theoretical gas compositions for a $500 \mathrm{MW}$ power plant flue gas for Air-Blown versus

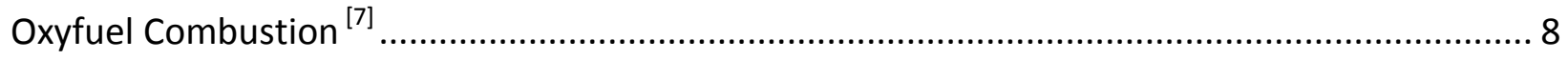

Table 2-1: $\mathrm{CO}_{2}$ adsorption capacities for amine grafted adsorbents at atmospheric pressure ... 28

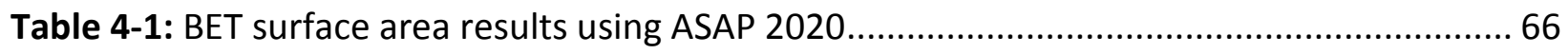

Table 5-1: Time to reach different $\mathrm{CO}_{2}$ adsorption percentages based on a 90 minute adsorption

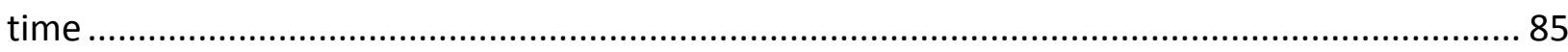

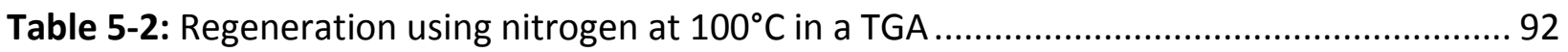

Table 5-3: Weight of clay treated with APTMS during different steps of the vacuum study .... 102

Table 5-4: Comparison of the beginning TGA weight with the TGA weight right before the

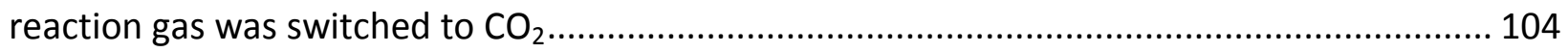

Table 5-5: Sample of clay loaded with 50\% PEI comparison of $\mathrm{CO}_{2}$ adsorption capacities ....... 105

Table 5-6: $\mathrm{CO}_{2}$ adsorption capacity after exposure to the environmental chamber ............... 125

Table A-1: Data for Figure 4-5, Comparison of "dry method" versus "slurry method" ............ 143

Table A-2: Data for Figure 4-6, Percent amine grafted versus the concentration of APTMS

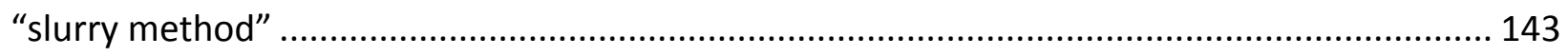

Table A-3: Data for Figure 4-8, Comparison of amount amine grafted versus treatment ........ 143

Table A-4: Data for Figure 5-5, Carbon dioxide adsorption capacity as a function of adsorption temperature at atmospheric pressure in the TGA 
Table A-5: Data for Figure 5-6, Time versus percent $\mathrm{CO}_{2}$ adsorbed based on a 90 minute adsorption run 144

Table A-6: Data for Figure 5-9, $\mathrm{CO}_{2}$ adsorption for clay loaded with $\mathrm{PEI}$ at $85^{\circ} \mathrm{C}$

Table A-7: Data for Figure 5-10, Comparison of PEl loading versus $\mathrm{CO}_{2}$ adsorption capacity at $85^{\circ} \mathrm{C}$

Table A-8: Data for Figure 5-12, $\mathrm{CO}_{2}$ adsorption capacity in pure $\mathrm{CO}_{2}$ and $10 \% \mathrm{CO}_{2}$ balanced with nitrogen

Table A-9: Data for Figure 5-13, Percent regeneration using pure nitrogen at $100^{\circ} \mathrm{C}$ 145

Table A-10: Data for Figure 5-14, $\mathrm{CO}_{2}$ adsorption capacity over 10 cycles. 145

Table A-11: Data for Figure 5-18, Percent $\mathrm{CO}_{2}$ cycled using pure $\mathrm{CO}_{2}$ at $155^{\circ} \mathrm{C}$ for 30 minutes for regeneration 145

Table A-12: Data for Figure 5-20, Percent $\mathrm{CO}_{2}$ cycled using humid $\mathrm{CO}_{2}$ at $155^{\circ} \mathrm{C}$ for 30 minutes for regeneration. 145

Table A-13: Data for Figure 5-25, Vacuum regeneration results for $85^{\circ} \mathrm{C}$ vacuum desorption in the vacuum oven 146

Table A-14: Data for Figures 5-26-30, Pure $\mathrm{CO}_{2}$ adsorption at pressure 146

Table A-15: Data for Figures 5-31-32, Pure $\mathrm{CO}_{2}$ adsorption at pressure and temperature. 146

Table A-16: Data for Figure 5-33, $\mathrm{CO}_{2}$ adsorption and vacuum desorption results ..... 147

Table A-17: Data for Figure 5-34, $\mathrm{CO}_{2}$ adsorption and vacuum desorption results..... 147

Table A-18: Data for Figures 5-35-36, $\mathrm{CO}_{2}$ adsorption before and after water stability test .... 147 


\section{Chapter 1}

\section{Introduction}

Almost all the energy produced in the world comes from the burning of fossil fuels such as oil, coal and natural gas. Since no clean and renewable energy source, (i.e. solar, wind, hydro, geothermal) seems likely to make a major impact in world energy demands in the near future, it is foreseeable that the amount of anthropogenic (i.e., human caused) carbon dioxide emission is only going to rise. The growing concern with global warming and its effects on climate change is almost certain to drive government regulation to reduce the amount of greenhouse gases allowed to be emitted into the atmosphere. Although $\mathrm{CO}_{2}$ is not the worst greenhouse gas, it is by far the most released with the current world-wide emission rate of approximately 28 gigatonnes of $\mathrm{CO}_{2}$ per year. ${ }^{[1]}$

The most logical way to capture vast amounts of $\mathrm{CO}_{2}$ is by focusing on large point sources like coal-fired power plants. Commercially available $\mathrm{CO}_{2}$ capture processes exist due to industrial processes which require the removal of $\mathrm{CO}_{2}$ from natural gas streams or from hydrogen production streams. These typically use either liquid physical solvents, which absorb $\mathrm{CO}_{2}$ without reactions, or liquid chemical solvents, which are usually amines that react with $\mathrm{CO}_{2}$. One problem with both of these processes is that they require a large amount of energy to regenerate the sorbent.

Solid sorbents have also been studied for adsorption of $\mathrm{CO}_{2}$ and typically use a porous support material which can adsorb $\mathrm{CO}_{2}$ itself. Alternatively a chemical that can adsorb $\mathrm{CO}_{2}$ (usually an amine) is either attached to the surface of the substrate by chemical reaction or is 
impregnated into the pores. Once the amine is attached to the support material, the sorbent can adsorb $\mathrm{CO}_{2}$ by reacting with the attached amines. After the sorbent has adsorbed the $\mathrm{CO}_{2}$ from the gas stream, it can then be regenerated by thermal treatment, reduction in pressure, or a combination of both processes. This cycle can be repeated multiple times. Some possible advantages that solid amines have over conventional liquid amines are reduced energy requirement for regeneration, less corrosion problems, and less environmental impacts from loss of evaporated toxic amines.

\subsection{Coal-fired Power Plants and Carbon Dioxide Emissions}

There has been a growing concern with the rise in the amount of $\mathrm{CO}_{2}$ in the atmosphere and its possible effects on the environment over the past several years. One possible reason for this sharp increase in the amount of atmospheric $\mathrm{CO}_{2}$ could be the enormous amount of $\mathrm{CO}_{2}$ that is released into the atmosphere from the burning of fossil fuels for energy. Electricity and heat generation produced $41 \%$ of the world $\mathrm{CO}_{2}$ emissions in 2009 with transport and industry

contributing the majority of the other $\mathrm{CO}_{2}$ emissions. ${ }^{[2]}$ Figure $1-1$ is a representation of the amount of $\mathrm{CO}_{2}$ emissions produced from different sources in 2009. 


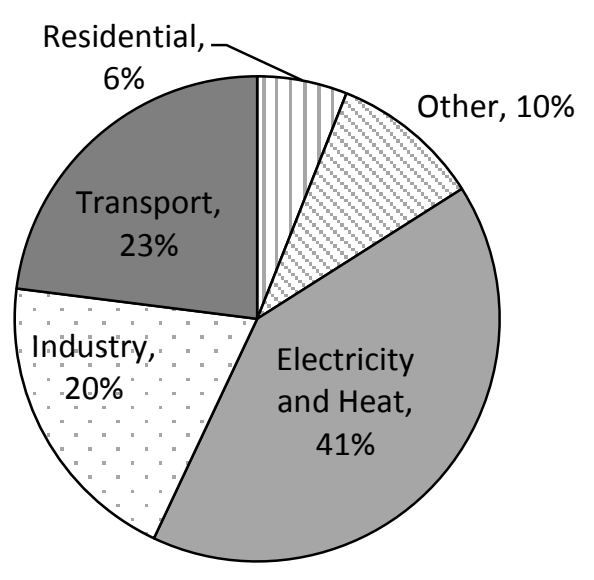

Figure 1-1: World $\mathrm{CO}_{2}$ emissions by sector in 2009; Other, includes commercial/public services, agriculture/forestry, fishing and other emissions not specified elsewhere. ${ }^{[2]}$

Processes where large amounts of $\mathrm{CO}_{2}$ are released at a single point source would seem to be the most logical and easiest place to start to explore the possibility for $\mathrm{CO}_{2}$ capture and sequestration. Some important information to consider is that approximately $25 \%$ of the world's primary energy demand is satisfied by coal, and about $50 \%$ of the power produced in the United States comes from coal-fired power plants. ${ }^{[3]}$ Recently the decrease in natural gas prices has decreased the amount of electricity being produced from coal. In August 2012 only $39 \%$ of the power produced in the U.S. came from coal. ${ }^{[4]}$ Worldwide, approximately 12.5 billion metric tons of $\mathrm{CO}_{2}$ is produced from the combustion of coal which is about $43 \%$ of the world's $\mathrm{CO}_{2}$ emissions in 2009. ${ }^{[2]}$ Since coal $\mathrm{CO}_{2}$ emissions are so large and the equivalent of one hundred $500 \mathrm{MW}$ coal-fired power plants are built in China each year, $\mathrm{CO}_{2}$ capture at coalfired power plants is an ideal place to reduce emissions. ${ }^{[5]} \mathrm{CO}_{2}$ capture at this point source would obviously result in significant reduction of the anthropogenic $\mathrm{CO}_{2}$ emitted each year. 
For each ton of coal burned, over 3 tons of $\mathrm{CO}_{2}$ are produced, and this generates about $3 \mathrm{MM}$ ton/year of $\mathrm{CO}_{2}$ for a $500 \mathrm{MW}$ power plant. ${ }^{[5]} \mathrm{A} \$ 25$ per ton target cost for capturing $\mathrm{CO}_{2}$ would imply about $\$ 75$ in additional costs per ton of coal burned, which is close to the cost of

coal itself. ${ }^{[5]}$ With the equivalent of about five hundred $500 \mathrm{MW}$ coal-fired power plants in the U.S. it can be seen that to capture all of the $\mathrm{CO}_{2}$ emitted by coal-fired power plants in the U.S. would amount to billions of dollars per year in $\mathrm{CO}_{2}$ capture cost. Therefore a low cost, efficient, and robust technology is needed for $\mathrm{CO}_{2}$ capture in the quantities needed at coal-fired power plants.

\subsubsection{Post-combustion capture of $\mathrm{CO}_{2}$}

The majority of coal-fired power plants in the U.S. traditionally burn coal with excess air to create heat. This process creates a flue gas stream of mostly nitrogen and carbon dioxide, with some leftover oxygen, water, acid gases and other impurities. Traditional coal combustion creates a flue stream with a huge volumetric flow rate, at about atmospheric pressure, and relatively low temperature as compared to other coal combustion technologies. As a result, it is necessary to capture $\mathrm{CO}_{2}$ by the use of post-combustion technology, and it would be ideal to develop a $\mathrm{CO}_{2}$ sorbent and process that can be retrofitted onto these existing plants. Figure 1-2 shows the estimated amount of $\mathrm{CO}_{2}$ released from existing coal-fired power plants versus coalfired power plants being built. 


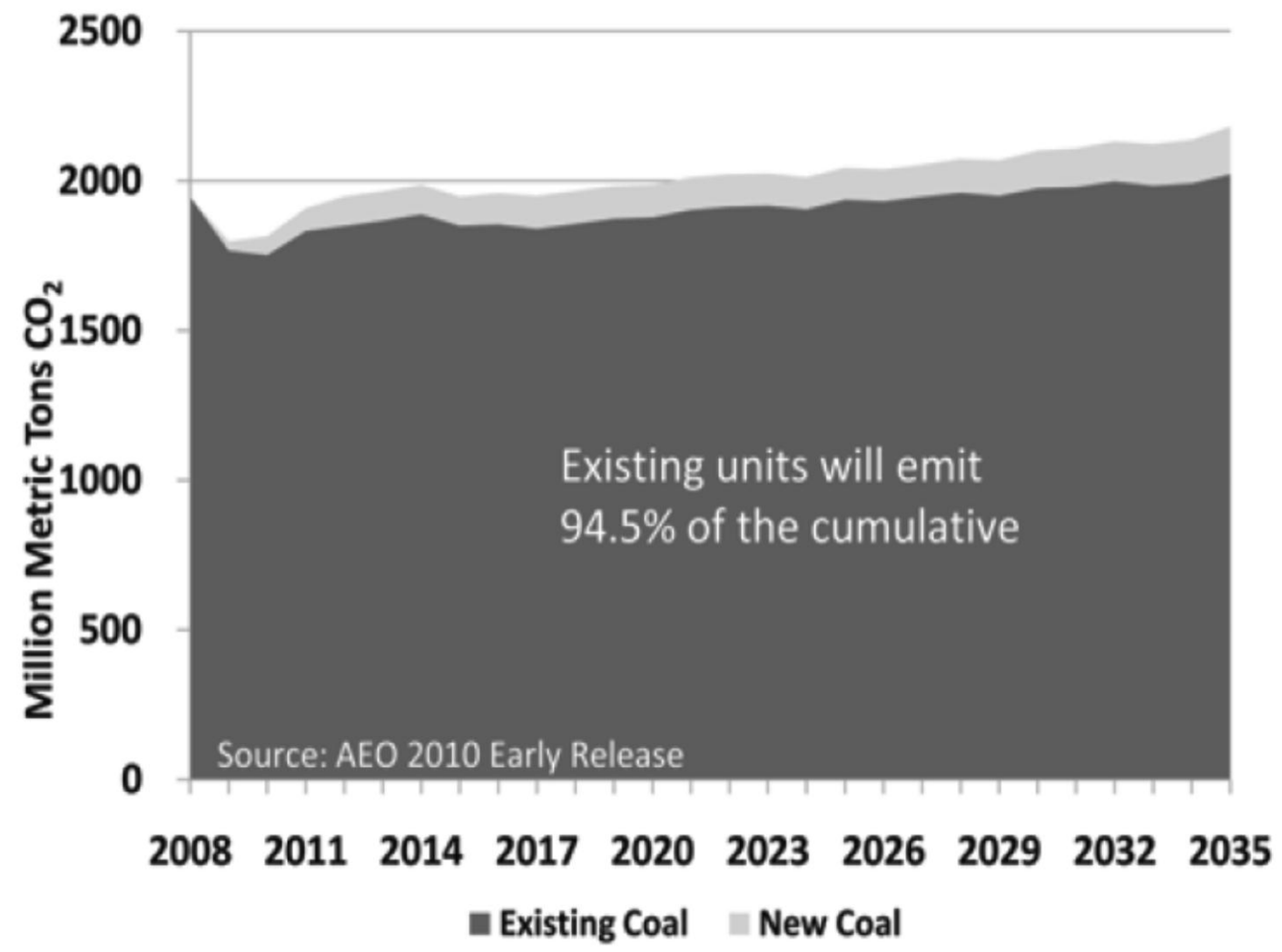

Figure 1-2: U.S. projection of $\mathrm{CO}_{2}$ emissions for existing coal-fired power plants versus new coal-fired power plants ${ }^{[6]}$

From Figure 1-2, it can be seen that the vast amount of $\mathrm{CO}_{2}$ emission from coal-fired power plants is projected to occur from existing plants in the United States. Therefore it is necessary to develop a sorbent for the conditions that occur in pre-existing plants. The conditions and composition of the flue gas in post-combustion power plants are compared with other technologies in section 1.1.2.

\subsubsection{Pre-Combustion capture of $\mathrm{CO}_{2}$}

In pre-combustion capture of $\mathrm{CO}_{2}$ the coal is first gasified to create a synthesis gas composed of $\mathrm{CO}$ and $\mathrm{H}_{2}$. The $\mathrm{CO}$ is then converted to $\mathrm{CO}_{2}$ by a shift reaction, which produces more $\mathrm{H}_{2}$. The $\mathrm{CO}_{2}$ would then be removed before the burning of $\mathrm{H}_{2}$. Integrated gasification combined cycle (IGCC) is a process in which $\mathrm{CO}_{2}$ can be captured before the combustion of coal. 
In an IGCC process, the coal is reacted with $\mathrm{H}_{2} \mathrm{O}$ and $\mathrm{O}_{2}$. The reaction of coal and the $\mathrm{H}_{2} \mathrm{O}$ produces the syngas. The combustion reaction with $\mathrm{O}_{2}$ and coal is used to produce heat to drive the predominantly endothermic gasification reactions ${ }^{[7]}$. The main reactions that occur in the gasification of coal are shown in Equations 1-4. ${ }^{[7]}$

$$
\begin{array}{ll}
\mathrm{C}+\mathrm{O}_{2} \rightarrow \mathrm{CO}_{2} & \Delta \mathrm{H}_{\mathrm{rxn}}=-394 \mathrm{~kJ} / \mathrm{mol} \\
\mathrm{C}+1 / 2 \mathrm{O}_{2} \rightarrow \mathrm{CO} & \Delta \mathrm{H}_{\mathrm{rxn}}=-111 \mathrm{~kJ} / \mathrm{mol} \\
\mathrm{C}+\mathrm{H}_{2} \mathrm{O} \rightarrow \mathrm{CO}+\mathrm{H}_{2} & \Delta \mathrm{H}_{\mathrm{rxn}}=-131 \mathrm{~kJ} / \mathrm{mol} \\
\mathrm{C}+\mathrm{CO}_{2} \rightarrow 2 \mathrm{CO} & \Delta \mathrm{H}_{\mathrm{rxn}}=173 \mathrm{~kJ} / \mathrm{mol}
\end{array}
$$

Table 1-1 lists typical conditions for a $500 \mathrm{MW}$ coal fired power plant using traditional postcombustion technology versus the conditions from pre-combustion capture fuel stream.

Table 1-1: Typical process conditions for combustion and gasification of coal in a $500 \mathrm{MW}$ power plant ${ }^{[5]}$

\begin{tabular}{|l|l|l|}
\hline & Post-Combustion & $\begin{array}{l}\text { Gasification or Pre- } \\
\text { Combustion }\end{array}$ \\
\hline Coal Feed $(\mathrm{kg} / \mathrm{h})$ & 284,000 & 228,000 \\
\hline Gas Mass Flow $(\mathrm{kg} / \mathrm{h})$ & $3,210,000$ & 607,000 \\
\hline Pressure $($ bar) & $1-1.5$ & $25-100$ \\
\hline Temperature $\left({ }^{\circ} \mathrm{C}\right)$ & $40-160$ & $40-300$ \\
\hline Volumetric Flow Rate $\left(\mathrm{m}^{3} / \mathrm{h}\right)$ & $2,568,000$ & 21,274 \\
\hline
\end{tabular}


The typical gas composition of a coal combustion flue stream versus pre-combustion fuel stream is shown in Table 1-2. The pre-combustion fuel stream has a greater concentration in $\mathrm{CO}_{2}$ and $\mathrm{H}_{2}$ while simultaneously having a significantly smaller concentration of $\mathrm{N}_{2}$.

Table 1-2: Typical Composition of Coal Combustion Flue Gas and Gasification Fuel Gas [5]

\begin{tabular}{|c|c|c|c|}
\hline & & Post-Combustion & $\begin{array}{c}\text { Gasification or Pre- } \\
\text { combustion }\end{array}$ \\
\hline Composition & $\mathrm{MW}$ & Volume $\%$ & Volume \% \\
\hline $\mathrm{H}_{2}$ & 2 & 15 & 10 \\
\hline $\mathrm{H}_{2} \mathrm{O}$ & 18 & 65 & 4 \\
\hline $\mathrm{N}_{2}$ & 28 & 4 & 0 \\
\hline $\mathrm{O}_{2}$ & 32 & 0.06 & 0.5 \\
\hline $\mathrm{NO}$ & 32 & 0 & 35.5 \\
\hline $\mathrm{H}_{2} \mathrm{~S}$ & 34 & 14.8 & 0 \\
\hline $\mathrm{CO}_{2}$ & 44 & 0.14 & Some \\
\hline $\mathrm{SO}_{2}$ & 64 & Some & 0 \\
\hline Hydrocarbon & Various & & 0.5 \\
\hline
\end{tabular}

In pre-combustion capture of $\mathrm{CO}_{2}$, the gas stream is at considerably higher pressures, has a higher concentration of $\mathrm{CO}_{2}$, and has a much lower flow rate than post-combustion capture. This is the preferred technology for coal efficiency, but there are few IGCC power plants operating at present.

\subsubsection{Oxy-fuel Combustion}

Oxy-fuel combustion is a process where pure oxygen is used instead of air to burn the coal. This technology creates a flue gas with almost no $\mathrm{N}_{2}$ and a very high concentration of $\mathrm{CO}_{2}$. 
Using this combustion process would produce an almost sequestration-ready $\mathrm{CO}_{2}$ flue gas with drying probably being the only separation needed. ${ }^{[7]}$ Problems with this process are that it requires an expensive air separation unit, and concerns with conventional boilers and gas turbines handling the high flame temperature of coal burned in pure $\mathrm{O}_{2} \cdot{ }^{[7]}$ To alleviate the high flame temperature caused by burning in a pure oxygen environment, $\mathrm{CO}_{2}$ could possibly be recycled and mixed with the pure $\mathrm{O}_{2}$ and coal prior to combustion in existing coal-fired power plants. Theoretical gas compositions for a $500 \mathrm{MW}$ power plant for this process are compared with air-blown combustion in Table 1-3.

Table 1-3: Theoretical gas compositions for a $500 \mathrm{MW}$ power plant flue gas for Air-Blown versus Oxyfuel Combustion ${ }^{[7]}$

\begin{tabular}{|c|c|c|}
\hline & Air-Blown & Oxyfuel $\left(99 \% \mathrm{O}_{2} / 1 \% \mathrm{CO}_{2}\right)$ \\
\hline Flue Gas Flow Rate (kg/s) & 552 & 0.6 \\
\hline Nitrogen (\% v/v) & 74 & 63 \\
\hline Carbon Dioxide (\%v/v) & 14 & 32 \\
\hline Water (\% v/v) & 8 & 4.5 \\
\hline Oxygen (\% v/v) & 3 & 0.3 \\
\hline Argon (\% v/v) & 1 & 0.3 \\
\hline Sulfur Oxides (\% v/v) & 0.07 & 0.07 \\
\hline Nitrogen Oxides (\% v/v) & 0.02 & \\
\hline
\end{tabular}

Table 1-3 shows that the combustion of coal in pure oxygen would possibly create a flue gas stream that would only need the removal of water to be sequestered. If this technology could 
be economically achieved it would greatly reduce the need for an adsorbent that could capture $\mathrm{CO}_{2}$ from post-combustion coal-fired power plants.

\subsection{Sequestration of $\mathrm{CO}_{2}$}

The capture of $\mathrm{CO}_{2}$ is a challenging and expensive problem, but it is only the first step in the process of carbon capture and sequestration. ${ }^{[6]}$ After the capture of $\mathrm{CO}_{2}$, the next step is to transport the $\mathrm{CO}_{2}$ through a pipeline for sequestration. The three major geologic formations considered to be good candidates for $\mathrm{CO}_{2}$ sequestration are depleted oil and gas reservoirs, deep unmineable coal seams, and saline formations. ${ }^{[1]}$ With the large amount of $\mathrm{CO}_{2}$ that could be potentially captured from coal-fired power plants, an enormous amount of storage capacity is needed. Fortunately the estimated worldwide capacity of $\mathrm{CO}_{2}$ in geologic formations is in the range of $100-10,000$ gigatonnes. ${ }^{[8]}$

\subsubsection{Storage of $\mathrm{CO}_{2}$ in Oil and Gas Reservoirs}

Storage of $\mathrm{CO}_{2}$ in oil and gas reservoirs is a good place to sequester $\mathrm{CO}_{2}$ because they have contained oil and gas for millions of years with minimum leakage. Also, their geology is well understood and $\mathrm{CO}_{2}$ can be used to help increase the production of oil and gas, which can offset some of the costs of capturing $\mathrm{CO}_{2}$. The process of using $\mathrm{CO}_{2}$ for enhanced oil recovery (EOR) has been shown to work and is currently being conducted. In North Dakota there is a major $\mathrm{CO}_{2}$ pipeline that transports $\mathrm{CO}_{2}$ to the Weyburn enhanced oil recovery (EOR) project in Canada. The $\mathrm{CO}_{2}$ is $95 \%$ pure, has a flow rate of 5,000 tonnes per day and is in the form of a supercritical fluid at a pressure of about $150 \mathrm{~atm} .{ }^{[1]}$ This project shows the possibility for $\mathrm{CO}_{2}$ 
sequestration in oil formations. The estimated capacity for $\mathrm{CO}_{2}$ storage in the U.S. and Canada within oil and gas fields is 138 billion tonnes. ${ }^{[9]}$

\subsubsection{Storage in Unmineable Coal Seams}

Another geologic formation for $\mathrm{CO}_{2}$ sequestration is unmineable coal seams.

Unmineable coal seams are seams that are either too deep or too thin to be mined economically. By sequestering $\mathrm{CO}_{2}$ in coal seams, it is possible to recover methane that is commonly found in coal seams. This process of recovering methane by sequestering $\mathrm{CO}_{2}$ is called enhanced coal-bed methane (ECBM) recovery. Since the geology of coal seams is well known, this process could provide a good option for long term storage for $\mathrm{CO}_{2}$. The rank of the coal determines the amount of $\mathrm{CO}_{2}$ molecules that are adsorbed for each molecule of methane released. The estimation for the capacity of $\mathrm{CO}_{2}$ that can be sequestered in unmineable coal seams is in the range of 60-117 billion metric tons in the U.S and Canada. ${ }^{[10]}$ Just like EOR, sequestration in unmineable coal seams would not only be a good place for long term sequestration, but it could also offset some of the cost for $\mathrm{CO}_{2}$ capture by recovering methane.

\subsubsection{Saline Formations}

Saline formations are layers of porous rock that are saturated in salt water that was either trapped from the ocean during the rock formation or had salt leach into the water from the surrounding rocks. These formations are possibly huge sinks for $\mathrm{CO}_{2}$ sequestration. Unlike oil, gas and coal reservoirs for sequestration, there is no added cost benefit from the recovery of methane or oil. Another disadvantage of saline formations is the limited characterization experience from industry compared to oil and coal reservoirs. All of the saline formations in the U.S. have not been documented, but enough have been documented to form an estimate for 
$\mathrm{CO}_{2}$ storage. In the U.S. there is an estimated $\mathrm{CO}_{2}$ storage capacity of 1,653 to more than 20,213 billion metric tons in saline formations. ${ }^{[10]}$ This is enough storage capacity to sequester more than 450 years of current $\mathrm{CO}_{2}$ emissions. ${ }^{[10]}$

\subsection{Objective of Research}

With billions of tons of $\mathrm{CO}_{2}$ being released into the atmosphere every year from the combustion of fossil fuels to produce electricity, the need for a cheap and efficient process to capture $\mathrm{CO}_{2}$ is key to the reduction of anthropogenic greenhouse gas emissions. Therefore, the objective of the current research is to develop an efficient, low cost, highly recyclable solid sorbent for carbon dioxide adsorption from large point sources, such as coal-fired power plants. The solid support used is to be available in large quantities and be modified using commercial amines. Once the amine is grafted to the support, the amount of amine grafted onto the support and the $\mathrm{CO}_{2}$ adsorption capacity need to be studied.

The sorbent developed here is composed of a nanoclay (montmorillonite), commonly used in the production of polymer nanocomposites, grafted with commercially available amines. The goal was to react (3-aminopropyl) trimethoxysilane to the edge hydroxyl groups of the clay. Additionally polyethylenimine was attached to the flat surface of the clay by electrostatic interactions. The combination of both treatments was also studied to determine if there was an increase in the adsorption of $\mathrm{CO}_{2}$.

For the adsorption of $\mathrm{CO}_{2}$, the objective is to first study the sorbents in a pure $\mathrm{CO}_{2}$ atmosphere to determine the adsorption capacity. Different temperatures and pressures for $\mathrm{CO}_{2}$ adsorption will be used to determine the dependence on each variable and its applicability to post-combustion or pre-combustions conditions. Desorption of the adsorbed $\mathrm{CO}_{2}$ will also 
be tested to determine the ability for multiple $\mathrm{CO}_{2}$ adsorption steps. Additionally a realistic reaction gas with $10 \% \mathrm{CO}_{2}$ will be used to determine the $\mathrm{CO}_{2}$ adsorption capacity in a mixed gas stream.

Once the adsorption and desorption of the adsorbents has been studied the objective is to determine more industrially realistic conditions for cycling of the adsorbent. The stability of the adsorbents in water vapor will be studied and so will the ability to desorb $\mathrm{CO}_{2}$ in an industrially realistic process such as vacuum or temperature swing desorption using a sweep gas. 


\section{Chapter 2}

\section{Literature Review}

Carbon dioxide capture technologies exist due to commercial processes that require separation of $\mathrm{CO}_{2}$, like the purification of natural gas. Commercial purification of natural gas, the possibility of carbon emission taxes or regulations in the U.S., and the possibility of successful carbon capture and sequestration to reduce or stop global warming have created many research opportunities for the capture of $\mathrm{CO}_{2}$. The main research areas are for work on improving existing $\mathrm{CO}_{2}$ capture technologies and creating completely new sorbents to separate or capture $\mathrm{CO}_{2}$. Some of these processes being researched to capture carbon dioxide are conventional physical and chemical solvents, aqueous ammonia, metal organic frame works (MOFs), membranes, solid amine sorbents, zeolites and compounds of alkali and alkali earth metals, hydrates, and chemical-looping. Solid amine adsorbents, which is the category of the adsorbent developed in this research, contain a vast amount of different supports and amines to capture $\mathrm{CO}_{2}$ with various advantages and disadvantages.

\subsection{Physical and Chemical Solvents for $\mathrm{CO}_{2}$ Capture}

Physical solvents capture $\mathrm{CO}_{2}$ by selectively absorbing $\mathrm{CO}_{2}$ from the flue stream without chemical reaction. The amount of $\mathrm{CO}_{2}$ that can be absorbed using physical solvents depends on the partial pressure of $\mathrm{CO}_{2}$ and temperature of the flue gas. Higher loadings are achieved with low temperatures and high partial pressures of $\mathrm{CO}_{2}$. The maximum loading of $\mathrm{CO}_{2}$ for physical solvents are approximately proportional to the partial pressure of $\mathrm{CO}_{2} \cdot{ }^{[1]}$ Henry's law is an approximation for the amount of $\mathrm{CO}_{2}$ that can be absorbed into a physical solvent.

$$
X_{\mathrm{CO}_{2}}=P_{\mathrm{CO}_{2}} \times \frac{1}{\mathrm{H}_{\mathrm{CO}_{2}}(\mathrm{~T})}
$$


Where $X_{\mathrm{CO}_{2}}$ is the mole fraction of $\mathrm{CO}_{2}$ in the liquid phase, $\mathrm{PCO}_{2}$ is the partial pressure of $\mathrm{CO}_{2}$, and $\mathrm{H}_{\mathrm{CO}_{2}}(T)$ is the Henry's constant for $\mathrm{CO}_{2}$ in the solvent at a given temperature. ${ }^{[7]}$ Since the absorption capacity depends on the partial pressure of $\mathrm{CO}_{2}$, physical solvents work best for precombustion capture of carbon dioxide where the pressures are much higher and the concentration of $\mathrm{CO}_{2}$ is higher than post-combustion conditions. Physical solvents are regenerated by either pressure reduction or addition of heat, and since the Van der Waal's forces or electrostatic forces that bind the $\mathrm{CO}_{2}$ molecules to the solvent are much weaker than the chemical bonds with $\mathrm{CO}_{2}$ in chemical solvents, the regeneration energy required for physical solvents is much less than for chemical solvents. ${ }^{[7]} \mathrm{A}$ major problem with physical solvents is that they usually require cooling of the syngas before carbon capture. ${ }^{[1]}$ Two conventional physical processes for acid gas removal are Selexol ${ }^{\mathrm{TM}}$ and Rectisol ${ }^{\oplus}$, which rely on dimethyl ethers of polyethylene glycol (DMPEG) and chilled methanol respectively, as the solvents. ${ }^{[11]}$

Chemical solvents differ from physical solvents in that they chemically react with $\mathrm{CO}_{2}$ to separate $\mathrm{CO}_{2}$ from the flue gas. Chemical solvents can capture carbon dioxide at low partial pressures, and the loading capacity depends on chemical equilibrium and concentration of the amine in the solvent. ${ }^{[1]}$ The ability to capture $\mathrm{CO}_{2}$ at low partial pressures makes chemical solvents capable of capturing $\mathrm{CO}_{2}$ from traditional coal fired power plants. Commonly used amines in chemical solvents are a primary amine, monoethanol amine (MEA), a secondary amine, diethanol amine (DEA), and a tertiary amine, methyl diethanol amine (MDEA), with primary amines forming the strongest bonds with acid gases. Problems with chemical amine solvents are that amine concentration is usually limited to approximately $30 \%$, due to corrosion 
problems, which increases the heat input for regeneration, formation of stable compounds with impurities like $\mathrm{COS}, \mathrm{SO}_{2}, \mathrm{SO}_{3}$, and $\mathrm{NO}_{x}$, degradation of the amine by oxygen in the flue gas, and loss of the amine due to vaporization. Adsorption capacity for MEA processes can reach up to $1.20 \mathrm{~kg} \mathrm{CO}_{2} / \mathrm{kg} \mathrm{NH}_{3}$ or $0.40 \mathrm{~kg} \mathrm{CO}_{2} / \mathrm{kg}$ of MEA based on $30 \%$ amine solution. ${ }^{[12]}$

\subsection{Aqueous Ammonia}

Aqueous ammonia sorbents work in the same way that amine chemical solvents work, but they have the advantage of lower regeneration energy, potential for higher $\mathrm{CO}_{2}$ capacity, and no degradation due to oxygen. Also when reacted with $\mathrm{SO}_{\mathrm{x}}$ and $\mathrm{NO}_{\mathrm{x}}$, ammonium sulfate and ammonium nitrate can be produced and sold as fertilizer. ${ }^{[1]}$ One significant problem is the higher volatility of ammonia compared to MEA, requiring the flue gas to be cooled between 0 -

$25^{\circ} \mathrm{C}{ }^{[1]}$ This technology has not been sufficiently developed for commercial deployment. ${ }^{[7]}$

\subsection{Metal organic Frameworks (MOFs)}

Metal organic frameworks are a class of nanoporous materials that are synthesized using organic linker molecules and metal joints that self-assemble into well-defined crystalline forms with high surface areas. ${ }^{[13]}$ An example of the formation of a MOF is shown in Figure 2-1. Figure 2-1 shows a well-organized structure that is composed of an organic linker and produces a nanoporous material. 

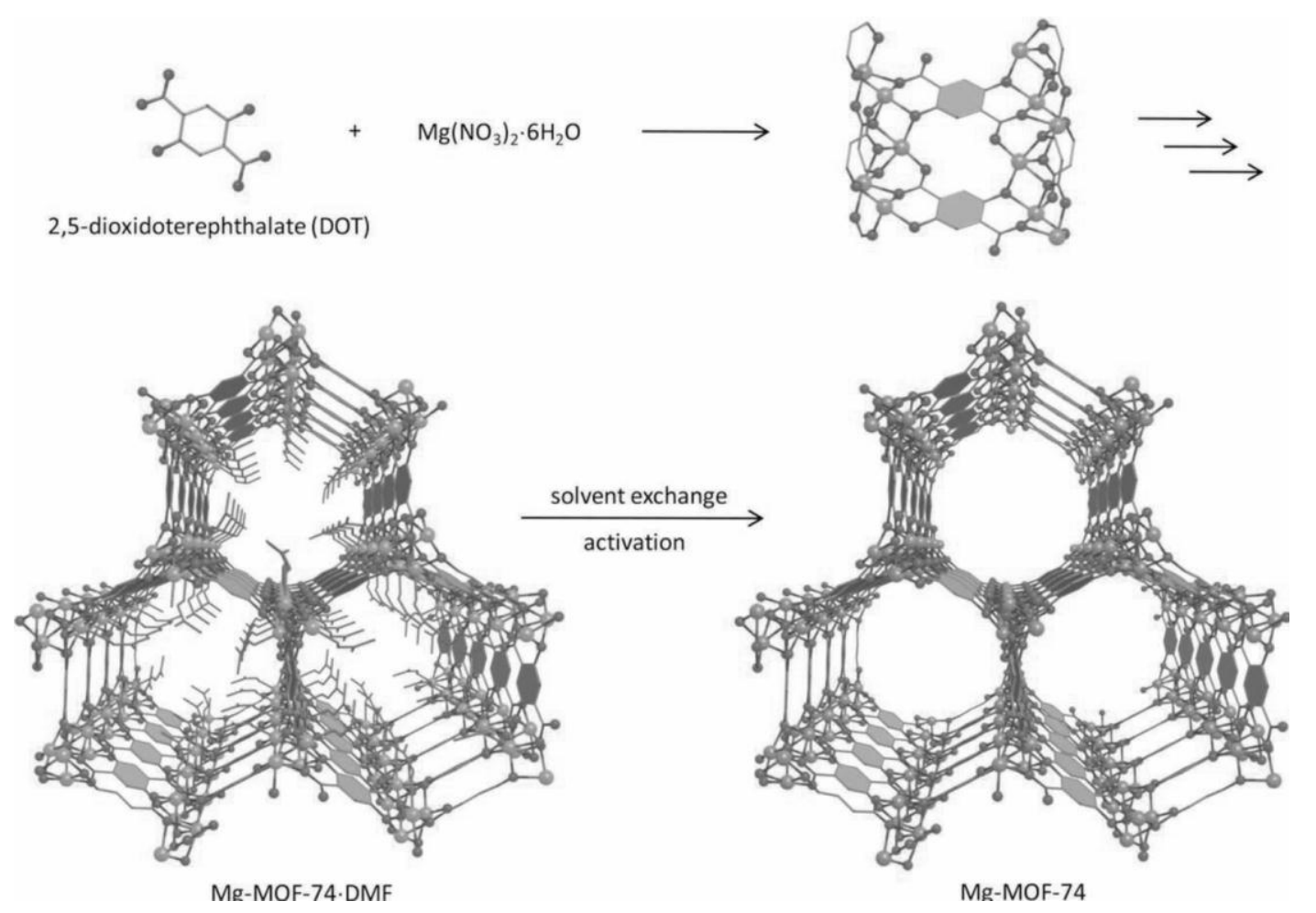

Figure 2-1: Single crystal structure of Mg-MOF-74, formed by reaction of the DOT linker with $\mathrm{Mg}\left(\mathrm{NO}_{3}\right)_{2} \cdot 6 \mathrm{H}_{2} \mathrm{O}^{[14]}$

There are a vast amount of MOFs that can be formed with different chemical functionalities, which potentially make MOFs excellent candidates for $\mathrm{CO}_{2}$ adsorption. ${ }^{[13]}$ With the possibility of thousands of combinations of MOFs, there is a significant potential for modeling and simulation to determine the best MOF for carbon dioxide capture. Therefore, there has been a large amount of research on simulating MOFs for $\mathrm{CO}_{2}$ capture. ${ }^{[13][15],[16]}$ MOFs have been shown to adsorb $\mathrm{CO}_{2}$ at pressures as low as 0.1 bar and at room temperature with an adsorption capacity of $236 \mathrm{mg} \mathrm{CO} / \mathrm{g}$ sorbent (23.6\% wt gain). ${ }^{[15]}$ Problems with MOFs for $\mathrm{CO}_{2}$ capture are low selectivity for $\mathrm{CO}_{2}$ in nitrogen and $\mathrm{CO}_{2}$ streams, unfavorable adsorption isotherms at low pressure, and large reduction of $\mathrm{CO}_{2}$ adsorption with an increase in temperature. 


\subsection{Zeolites and compounds composed of alkali and alkali earth metals}

Zeolites are highly organized microporous crystalline materials that have also been

studied for $\mathrm{CO}_{2}$ capture. The interests of zeolites for carbon dioxide capture are the different adsorption capacities observed based on the pore size, chemical make-up and structure of the zeolite. Zeolites with low $\mathrm{Si} / \mathrm{Al}$ ratio have been reported to have the best $\mathrm{CO}_{2}$ adsorption capacity. ${ }^{[17]}$ One commonly studied zeolite is $13 \mathrm{X}$ and has shown to have a high $\mathrm{CO}_{2}$ adsorption capacity at higher pressures and low temperatures. ${ }^{[18]}$ Figure 2-2 shows a diagram of different frameworks of typical zeolites.

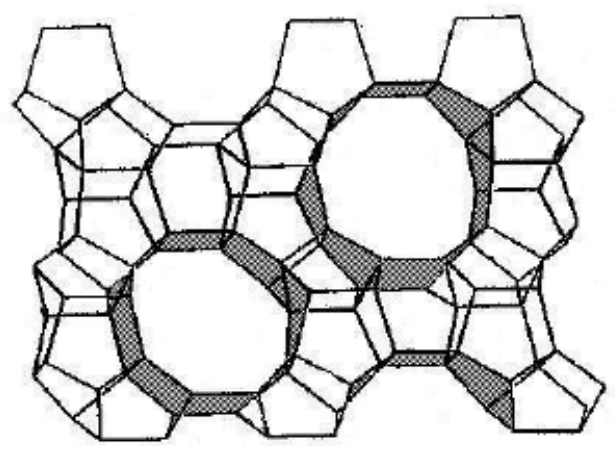

(a)

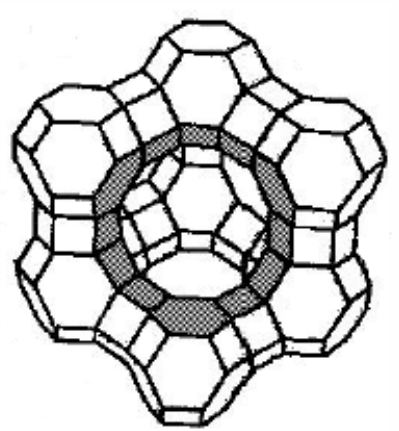

(b)

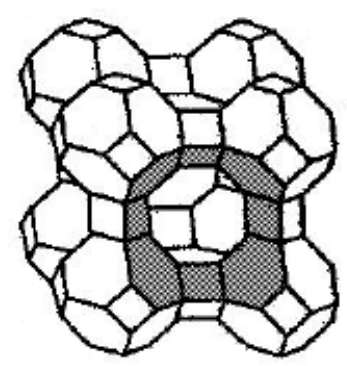

(c)

Figure 2-2: Structures of different zeolite frameworks (a) silicalite, (b) $13 X$ and (c) $5 A^{[19]}$ 
Zeolites consist of tetrahedrons as the primary building units, were a silicon or aluminum atom is surrounded by four oxygen atoms. ${ }^{[19]}$ The internal pore surfaces are made by linkages of secondary building units in different geometries, which can be seen in Figure 2-2 for three different zeolites. ${ }^{[19]}$ The inner surfaces of the zeolites can be made up of triangles, squares, rectangles and regular hexagons, which can also be seen in Figure 2-2. ${ }^{[19]}$ Although zeolites can be tunable, one problem with zeolites is the severe reduction of $\mathrm{CO}_{2}$ adsorption capacity in the presence of water. ${ }^{[20]}$

Compounds of alkali metals can be used to chemically react with $\mathrm{CO}_{2}$. An example of this is an alkali metal carbonate reacting with $\mathrm{CO}_{2}$ and $\mathrm{H}_{2} \mathrm{O}$ to form alkali metal bicarbonate as shown in Equation 5.

$$
\begin{gathered}
\mathrm{X}_{2} \mathrm{CO}_{3}+\mathrm{CO}_{2}+\mathrm{H}_{2} \mathrm{O} \leftrightarrow 2 \mathrm{XHCO}_{3} \\
(\mathrm{X}=\mathrm{Li}, \mathrm{Na}, \mathrm{K}, \text { etc. })
\end{gathered}
$$

Alkaline earth metals react with $\mathrm{CO}_{2}$ to form alkaline earth metal carbonate. Equation 6 is an example of this reaction.

$$
\mathrm{XO}+\mathrm{CO}_{2} \leftrightarrow \mathrm{XCO}_{3}(\mathrm{X}=\mathrm{Mg}, \mathrm{Ca} \text {, etc. })
$$

Alkali metals can react with $\mathrm{CO}_{2}$ in the temperature range of $373-473 \mathrm{~K}$, which is suitable for flue gas carbon capture. The alkaline earth metal $(\mathrm{CaO}, \mathrm{MgO})$ can also react with $\mathrm{CO}_{2}$ in the temperature range of $773-1173 \mathrm{~K}$, which can be utilized in process streams at elevated temperature, such as integrated gasification combined cycle (IGCC). ${ }^{[12]}$ 


\subsection{Gas Hydrates}

Carbon dioxide can also be captured by the formation of hydrates. Gas hydrates are crystalline solids where low molecular weight molecules are trapped inside cages of hydrogenbonded water molecules. ${ }^{[21]}$ In this process the exhaust gas containing $\mathrm{CO}_{2}$ is exposed to water under high pressure and a hydrate is formed, which captures the carbon. The hydrate is separated and dissociated to release the $\mathrm{CO}_{2}$. This process has shown to have a potential energy penalty as small as $6-8 \% .{ }^{[22]}$ This process is an interesting process to capture $\mathrm{CO}_{2}$, but has not been extensively studied as a viable option for $\mathrm{CO}_{2}$ capture from coal-fired power plants.

\subsection{Chemical Looping}

Chemical looping is a process where a particle acts as an oxygen carrier, and is used in place of air to combust the fuel. By using a metal oxide as the oxygen source instead of air, an exhaust stream of $\mathrm{CO}_{2}$ and $\mathrm{H}_{2} \mathrm{O}$ is formed which can easily be separated by drying. The success of chemical looping is strongly dependent on the chemical looping particles or oxygen carrier particles, and it has been used to create hydrogen in industrial processes. ${ }^{[23]}$ The chemical looping process can be applied to combustion (CLC) or gasification (CLG) of carbon-based materials and can be more energetically efficient than conventional power generation processes. ${ }^{[23]}$ Figure 2-3 is a simplified representation of chemical looping in direct combustion of coal using iron as the chemical looping particle. 


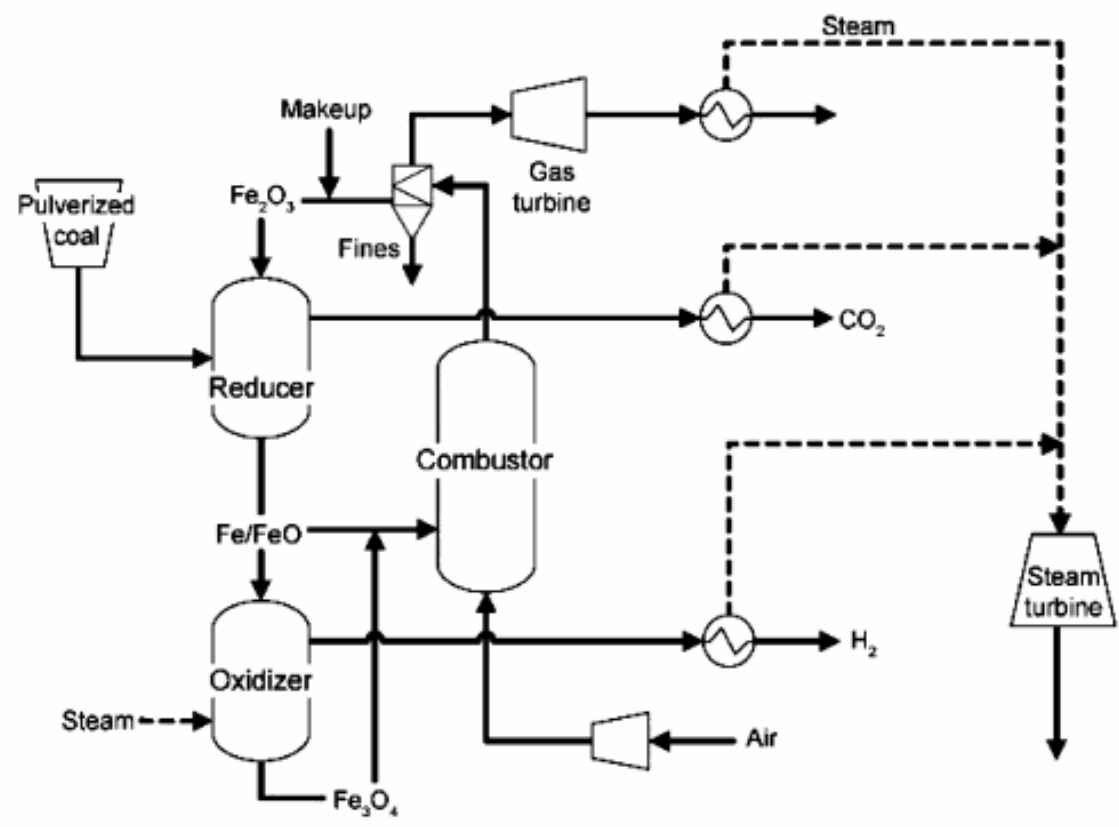

Figure 2-3: Schematic of direct coal combustion using chemical looping with iron. ${ }^{\text {[23] }}$

This technology is an alternative to separating oxygen from nitrogen in air for oxyfuel combustion, and it is a very interesting process for $\mathrm{CO}_{2}$ capture. Using this process a stream of $\mathrm{CO}_{2}$ pure enough for sequestration could possibly be created by simply condensing out water in the flue gas. The reason this process is not in commercial operation is high product cost due to low reactivity and recyclability of the chemical looping particles. ${ }^{[23]}$

\subsection{Membranes for $\mathrm{CO}_{2}$ Separation}

Membranes have been used for many industrial separation applications and have been used to separate $\mathrm{CO}_{2}$ from natural gas. Membranes separate $\mathrm{CO}_{2}$ from other gases by either size exclusion or by chemical affinity. Problems with polymer membranes for $\mathrm{CO}_{2}$ separation include the chemically harsh environment and high temperatures of fuel and flue gases. Also the low pressure of traditional flue does not provide a large driving force for membrane processes. The ideal membrane is one with high permeability and a high selectivity, but a highly 
permeable membrane tends to have a low selectivity and a highly selective membrane tends to have low selectivity. ${ }^{[24]}$ Polyimide based membranes have shown some of the best permeability and selectivity properties for purely polymeric membranes and are resistant to thermal, chemical and plasticization degradation. ${ }^{[24]}$ The development of a membrane process that could separate $\mathrm{CO}_{2}$ from a gas stream with a huge volumetric flow rate at low pressure and a low concentration of $\mathrm{CO}_{2}$ is a very difficult task. If a membrane could be developed for these conditions, this would seem to be a simple commercial system for cheap retrofitting of existing coal-fired power plants and the separation of $\mathrm{CO}_{2}$.

\subsection{Solid Amine Sorbents}

Solid amine adsorbents use an amine to chemically react with $\mathrm{CO}_{2}$ to adsorb $\mathrm{CO}_{2}$. Solid amine sorbents for $\mathrm{CO}_{2}$ capture are usually made up of a porous large surface area support that is either impregnated or reacted with an amine that can absorb $\mathrm{CO}_{2}$. Solid amine sorbents have an advantage over liquid amine processes in that they do not have corrosion problems, and they need less energy to regenerate because they are not diluted in an aqueous solution like liquid amine processes. Some problems with solid amine sorbents that were initially reported are low $\mathrm{CO}_{2}$ capacity, lack of stability over regeneration cycles and poisoning from other flue gases. ${ }^{[25]}$

It has been reported that for a solid $\mathrm{CO}_{2}$ adsorbent to be economically competitive against other technologies, the adsorbent would have to adsorb approximately $2-4 \mathrm{mmol} / \mathrm{g}$ sorbent. ${ }^{[26]}$ Many solid amine sorbents described in the literature have not been able to reach this capacity, but some more recently studied solid amine sorbents have been reported to have a $\mathrm{CO}_{2}$ capture capacity as high as to $5.55 \mathrm{mmol} \mathrm{CO} / \mathrm{g}$ sorbent $\left(24.4 \mathrm{wt} . \% \mathrm{CO}_{2}\right) \cdot{ }^{[27]}$ The ability of 
some solid amine adsorbents to adsorb a relatively large amount of $\mathrm{CO}_{2}$ shows the possibility for these sorbents to work in the $\mathrm{CO}_{2}$ capture from coal-fired power plants. Besides the key requirement for these adsorbents to adsorb $\mathrm{CO}_{2}$, they should also be able to desorb $\mathrm{CO}_{2}$ with minimal amount of energy. The proposed reaction for $\mathrm{CO}_{2}$ using liquid amines is shown in Figure 2-4. It is expected that solid amine adsorbents would follow the same reaction

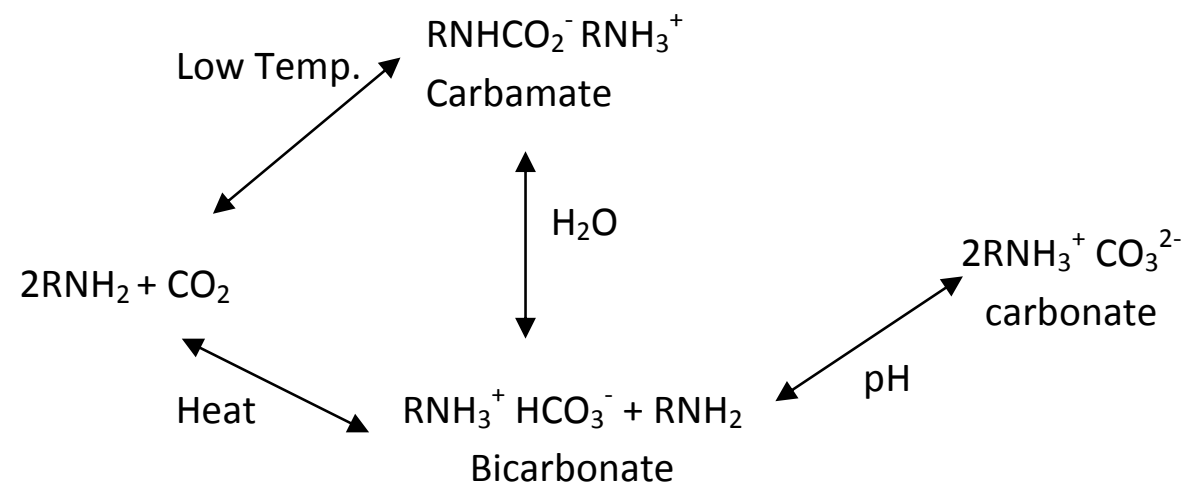

mechanism. ${ }^{[28]}$

\section{Figure 2-4: Proposed reaction mechanism for carbon dioxide and amines ${ }^{[28]}$}

Three different types of solid amine adsorbents have been reported for the capture of

$\mathrm{CO}_{2}$ at relatively low temperatures and atmospheric pressures. The first class of solid amine adsorbents uses a porous support that is impregnated with an amine such as PEI. Significant amount of research for this support was conducted by Song and was first reported in 2002. [29], [30], [31], [32], [33] The second class of solid amine adsorbents is based on amines that are covalently attached to the solid support such as (3-trimethoxysilylpropyl)diethylenetriamine (TRI). Sayari's group published a large amount of the research conducted on this type of adsorbent. [34], [35], [36], ${ }^{\text {[37] }}$ The third class of solid amine adsorbents is aminopolymers that are polymerized in situ onto a porous support. These solid amine adsorbents have been called hyperbranched aminosilicas 
(HAS), and work on them was first published by Drese et al. in 2008. ${ }^{[38],[39],[40]}$ Figure 2-5 is a representation of each class of adsorbent with porous silica as a support.

a)<smiles>CN(C)CC(C)(C)C</smiles>

\section{Class 1}

$R=H, C$

b)
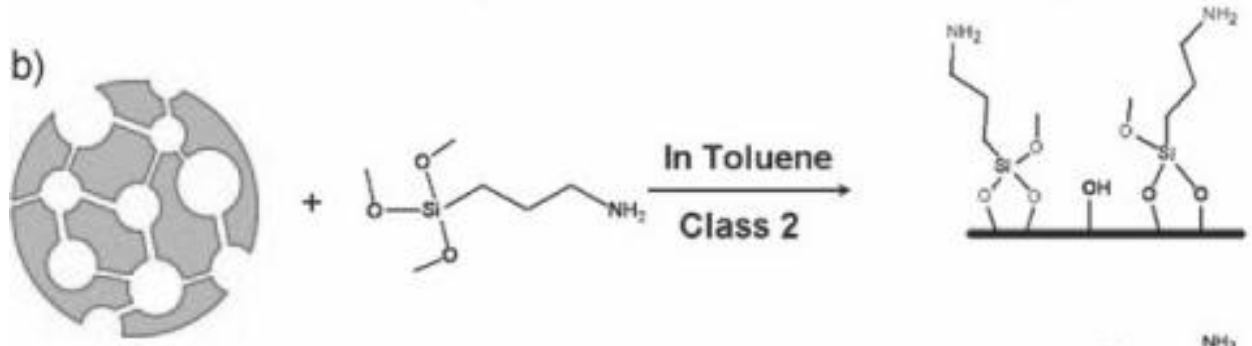

Porous

Silica

c)
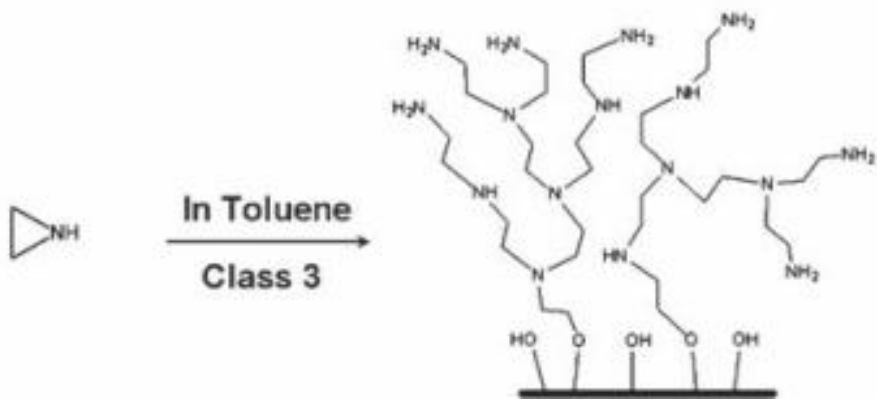

Figure 2-5: a) Class 1 amine impregnated solid amine adsorbent, b) Class 2 covalently attached solid amine adsorbent, c) Class 3 polymerized solid amine adsorbent ${ }^{[40]}$

In Figure 2-5 it can be seen that the class 1 adsorbents are just the physical impregnation of an amine into a porous support, while the class 2 and 3 adsorbents are chemically attached amines. The class 1 adsorbents usually use a porous silica support such as MCM-41 or SBA-15 and impregnate the support with a low molecular weight poly(ethyleneimine) (PEI). ${ }^{[30], ~[41]}$ Class 2 solid amine adsorbents use a variety of aminosilanes such as, 3-[2-(2-aminoethylamino)ethylamino]propyl trimethoxysilane (TRI), grafted to porous silica supports such as MCM-41 or SBA-15. ${ }^{[34],[42]}$ Class 3 amine adsorbents typically use 
aziridine monomer attached to a silica support such as SBA-15. ${ }^{[25]}$ The aziridine is then polymerized to produce amine groups for $\mathrm{CO}_{2}$ capture.

\subsubsection{Amine Impregnated Solid Adsorbents}

Amine impregnated solid adsorbents have been designated as Class 1 amine adsorbents in the literature, and they typically consist of a low molecular weight PEI impregnated into a porous silica support. ${ }^{[43]}$ Song et. al. have conducted a significant amount of work using this type of adsorbent. ${ }^{[29], ~[30], ~[31], ~[32], ~[33] ~ T h i s ~ t y p e ~ o f ~ a d s o r b e n t ~ i s ~ a l s o ~ k n o w n ~ a s ~ a ~ " m o l e c u l a r ~}$ basket", and was initially reported to increase the $\mathrm{CO}_{2}$ adsorption capacity of pure PEI by a factor of 2.3. ${ }^{[30]}$ The increase of the $\mathrm{CO}_{2}$ adsorption capacity of PEI when it was impregnated into a porous silica support indicated that there were some synergistic effects occurring with the incorporation of PEI into the pores. This synergistic effect was the greatest when the support was loaded with $50 \%$ PEI. ${ }^{[30]}$

The procedure described in the literature for impregnating the PEI into the support is to dissolve the PEI in methanol, add the support, and then dry the mixture in a vacuum oven at $70^{\circ} \mathrm{C}$ for 16 hours. ${ }^{[30]}$ The addition of $\mathrm{PEI}$ into the pores of $\mathrm{MCM}-41$ was reported to continually reduce the surface area and pore volume of the support with increased loading of $\mathrm{PEI}$, but resulted in an increased amount of $\mathrm{CO}_{2}$ adsorbed per gram of adsorbent. ${ }^{[30]}$ The highest initial adsorption capacity reported for MCM-41 that was loaded with $75 \%$ PEI was 133 (mg CO $2 /$-adsorbent) in pure $\mathrm{CO}_{2}$ at $75^{\circ} \mathrm{C} .{ }^{[30]}$ Thermal gravimetric analysis (TGA) was used to measure the amount of $\mathrm{CO}_{2}$ adsorbed on the sample; the procedure for $\mathrm{CO}_{2}$ adsorption used was to heat the sample to $100^{\circ} \mathrm{C}$ in nitrogen for 30 minutes, then cool the sample to $75^{\circ} \mathrm{C}$ and switch the reaction gas to pure $\mathrm{CO}_{2} \cdot{ }^{[30]}$ Another interesting finding for $\mathrm{MCM}-41$ impregnated 
with PEI was that the $\mathrm{CO}_{2}$ adsorption capacity increased with increasing temperature up to $75^{\circ} \mathrm{C}{ }^{[44]}$ The authors attributed this phenomenon to a diffusion limited reaction at lower temperatures. ${ }^{[44]}$ The increase of the temperature is suspected to increase the diffusion of $\mathrm{CO}_{2}$ into PEI on the support causing more amine reaction sites to be exposed for $\mathrm{CO}_{2}$ adsorption. To show that the adsorption of $\mathrm{CO}_{2}$ was diffusion limited at lower temperatures, $\mathrm{CO}_{2}$ was adsorbed at $75^{\circ} \mathrm{C}$ and the temperature was then reduced and the $\mathrm{CO}_{2}$ adsorption capacity monitored. ${ }^{[44]}$ When the temperature was reduced, the $\mathrm{CO}_{2}$ adsorption capacity did not decrease to the adsorption capacity recorded at the lower temperatures, but in fact it continued to very slowly increase. This indicated that the $\mathrm{CO}_{2}$ adsorption at lower temperatures was diffusion limited.

The influence of moisture on the $\mathrm{CO}_{2}$ adsorption capacity has been studied using this type adsorbent. ${ }^{[31],[32]}$ In the presence of moisture in the reaction gases, the $\mathrm{CO}_{2}$ adsorption capacity was shown to increase. ${ }^{[31]}$ In one study, the effect of increased moisture concentration on $\mathrm{CO}_{2}$ adsorption capacity was examined. ${ }^{[31]}$ The addition of $6 \%$ moisture to a simulated flue gas that contained $14.9 \% \mathrm{CO}_{2}$ increased the $\mathrm{CO}_{2}$ adsorption capacity by approximately $20 \% .{ }^{[31]}$ Using the same concentration of $\mathrm{CO}_{2}$ and increasing the moisture to $10 \%$, the $\mathrm{CO}_{2}$ adsorption capacity was observed to increase approximately by $40 \%$, but, when the moisture content was $16 \%$, the adsorption capacity only increased $5 \%$ from the adsorption capacity using $10 \%$ moisture. ${ }^{[31]}$ The authors concluded from this study that a moisture content that is the same as the concentration of $\mathrm{CO}_{2}$ had the most influence on enhanced $\mathrm{CO}_{2}$ adsorption. ${ }^{[31]}$ 
Degradation in the presence of acid gases in the flue gas is a concern for all $\mathrm{CO}_{2}$

adsorbents. MCM-41 loaded with 50\% PEI has also been studied using flue gas from a natural gas-fired boiler that contained 7.4-7.7\% $\mathrm{CO}_{2}, 14.6 \% \mathrm{H}_{2} \mathrm{O}$, oxygen, $\mathrm{CO}$, ppm of $\mathrm{NO}_{\mathrm{x}}$, and nitrogen.

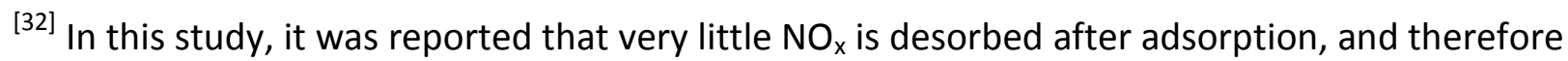
reduces the $\mathrm{CO}_{2}$ adsorption capacity of the adsorbent. ${ }^{[32]}$ This may indicate that the removal of $\mathrm{NO}_{\mathrm{x}}$ is necessary for the commercial use of this type of adsorbent in coal-fired power plants.

Another application of this type of adsorbent has recently been studied in the capture of $\mathrm{CO}_{2}$ from air using a porous silica support (SBA-15) and PEI. ${ }^{[33]}$ In this study SBA-15 was loaded with 50 weight percent $\mathrm{PEI}$ and was able to capture $\mathrm{CO}_{2}$ from a stream containing $1 \% \mathrm{CO}_{2}$ at $75^{\circ} \mathrm{C}$. The $\mathrm{CO}_{2}$ saturation capacity of 63.1 and $66.7 \mathrm{mg} / \mathrm{g}$ adsorbent was achieved and regeneration was stable for 20 cycles using helium purge and heating to $105^{\circ} \mathrm{C} .{ }^{[33]}$ This study indicated that this type of adsorbent could be used for the adsorption of $\mathrm{CO}_{2}$ from coal-fired power plants, and for $\mathrm{CO}_{2}$ adsorption from air.

\subsubsection{Covalently Attached Amines to Solid Sorbents}

Many different amines have been covalently attached to solid supports. Primary, secondary, and tertiary amines have all been used for covalently binding to solid supports. ${ }^{\text {[45] }}$ One of the first reports of an amine grafted support for $\mathrm{CO}_{2}$ capture was an amine attached to a silica gel from Leal et. al. in 1995. ${ }^{[43],[46]}$ Since then some of the typical amines are that are grafted to silica supports are (3-amniopropyl)trimethoxsilane (APTMS) ${ }^{[45],[47]}$, (3trimethoxysilylpropyl)diethylenetriamine $(\mathrm{TRI})^{[48]}$, and $\mathrm{N}$-[3-(trimethoxysily)propyl] ethylenediamine (EDA) ${ }^{[43],[49]}$ These amines are typically attached to porous silica supports such as hexagonal mesoporous silicas $(\mathrm{HMS})^{[47]}$, mesoporous silica MCM-41, ${ }^{[36],[37]}$ pore expanded 
PE-MCM-41, ${ }^{[35]}$ MCM-48, ${ }^{[50]}$ and SBA-15. ${ }^{[51], ~[52] ~ A m i n e ~ g r a f t e d ~ s o r b e n t s ~ h a v e ~ b e e n ~ s t u d i e d ~ i n ~ a ~}$ wide range of conditions, including temperatures from $20-60^{\circ} \mathrm{C},{ }^{[43]}$ various concentrations of $\mathrm{CO}_{2}$ in dry and humid reaction streams, ${ }^{[43]}$ and using different types of stability and regeneration tests. ${ }^{[40],[53],[54]}$

The addition of water in the reaction gas has generally shown an increase in the $\mathrm{CO}_{2}$ adsorption capacity of the sorbent. One study observed an increase in $\mathrm{CO}_{2}$ adsorption from 0.41 to 0.89 ( $\mathrm{mmol} / \mathrm{g})$ when using $100 \%$ relative humidity $(\mathrm{RH})$ in a $\mathrm{CO}_{2}$ stream at room temperature. ${ }^{[55]}$ Similarly, another group observed a $10 \%$ increase in $\mathrm{CO}_{2}$ adsorption from 2.65 $\mathrm{mmol} / \mathrm{g}$ to $2.94 \mathrm{mmol} / \mathrm{g}$ when using a $27 \%$ relative humidity stream consisting of $5 \% \mathrm{CO}_{2}$ balanced with nitrogen. ${ }^{[35]}$ Although typically there is an increase in the $\mathrm{CO}_{2}$ adsorption capacity with the presence of water, it has also been reported in some cases that water had little to no effect on the $\mathrm{CO}_{2}$ adsorption capacities. One study using amines grafted to SBA-15 with a reaction gas of $15 \mathrm{kPa} \mathrm{CO}$ and $12 \mathrm{kPa} \mathrm{H}_{2} \mathrm{O}$ and balance nitrogen at $333 \mathrm{~K}$ showed little to no effect on the $\mathrm{CO}_{2}$ adsorption capacity in the presence of water. ${ }^{[52]}$

Table 2-1 shows some $\mathrm{CO}_{2}$ adsorption capacities for different types of amines and supports used in amine grafted supports. The data in Table 2-1 shows the some of the many different conditions, supports, and amines used to study amine grafted $\mathrm{CO}_{2}$ adsorbents. The highest $\mathrm{CO}_{2}$ adsorption capacity shown in Table $2-1$ is $2.94 \mathrm{mmol} / \mathrm{g}$ or 12.9 weight percent gained. 
Table 2-1: $\mathrm{CO}_{2}$ adsorption capacities for amine grafted adsorbents at atmospheric pressure

\begin{tabular}{|c|c|c|c|c|c|c|}
\hline Support & Amine & $\begin{array}{c}\mathrm{CO}_{2} \text { Capacity } \\
(\mathrm{mmol} / \mathrm{g})\end{array}$ & $\begin{array}{c}\text { Experimental Conditions: } \\
\text { Percent } \mathrm{CO}_{2}\end{array}$ & $\begin{array}{c}\mathrm{T} \\
\left({ }^{\circ} \mathrm{C}\right)\end{array}$ & Reference & Year \\
\hline Silica Gel & APTMS & $0.89(3.9 \mathrm{wt} \%)$ & $100 \%(100 \% \mathrm{RH})$ & 50 & {$[55]$} & 1995 \\
\hline SBA-15 & TRI & $1.80(7.9 \mathrm{wt} \%)$ & $15 \%($ humid $)$ & 60 & {$[52]$} & 2005 \\
\hline MCM-48 & APTMS & $2.3(10.1 \mathrm{wt} \%)$ & $10 \%(100 \% \mathrm{RH})$ & 25 & {$[50]$} & 2003 \\
\hline PE-MCM-41 & TRI & $2.94(12.9 \mathrm{wt} \%)$ & $5 \%(27 \% \mathrm{RH})$ & 25 & {$[35]$} & 2007 \\
\hline SBA-16 & EDA & $1.4(6.2 \mathrm{wt} \%)$ & $100 \%$ & 27 & {$[49]$} & 2007 \\
\hline HMS & APTMS & $1.59(7.0 \mathrm{wt} \%)$ & $90 \%$ & 20 & {$[47]$} & 2005 \\
\hline
\end{tabular}

One significant problem that has been reported for amine grafted materials is loss of $\mathrm{CO}_{2}$ adsorption capacity when the adsorbent is exposed to $\mathrm{SO}_{2}{ }^{\cdot[56], ~[57]}$ It has been reported that the $\mathrm{CO}_{2}$ adsorption capacity of TRI-PE-MCM-41 in a stream of $10 \% \mathrm{CO}_{2}$ at $50^{\circ} \mathrm{C}$ decreased from 6.9 weight percent to 3.9 weight percent after exposure to pure $\mathrm{SO}_{2}$ at $323 \mathrm{~K}$ using vacuum regeneration at $373 \mathrm{~K} .{ }^{[57]}$ Although exposure to pure $\mathrm{SO}_{2}$ is extreme, the degradation of amine grafted adsorbents after exposure to $\mathrm{SO}_{2}$ would indicate that the flue gas from a coal-fired power plant would have to be processed for removal of $\mathrm{SO}_{2}$, or at the least taken into consideration.

Another concern for this type of amine adsorbent and other amine adsorbents is oxidative degradation of the amine. Since coal-fired power plants are typically operated using excess air, the adsorbents will be exposed to oxygen during the adsorption cycle. A study of primary, secondary, and tertiary monoamines, and a primary-secondary diamine was conducted under accelerated oxidation conditions using pure $\mathrm{O}_{2}$ at reaction temperatures of 
$25-135^{\circ} \mathrm{C}$ for 24 hours. ${ }^{[45]}$ In this study, it was reported that primary and tertiary amines on propyl linkers were found to be more stable to accelerated oxidative degradation compared to secondary amines. ${ }^{[45]}$ Additionally, functional groups that had a primary amine separated from a secondary amine ( $\mathrm{RNHCH}{ }_{2} \mathrm{CH}_{2} \mathrm{NH}_{2}$ ), which are seen in poly(ethyleneimine), also showed oxidative degradation. ${ }^{[45]}$ Although this study was conducted under extreme oxidative conditions, the degradation of these types of amines should be considered when adsorbents have to be stable over thousands of cycles in a flue stream that contains oxygen.

\subsubsection{Hyperbranched Aminosilicas}

Hyperbranched aminosilicas to adsorb $\mathrm{CO}_{2}$ were reported in the literature in 2008, and these were prepared by polymerizing aziridine inside the pores of SBA-15. ${ }^{[25]}$ This adsorbent was initially reported as having a $\mathrm{CO}_{2}$ adsorption capacity of $3.11 \mathrm{mmol} / \mathrm{g}$ using a water saturated reaction gas of $10 \% \mathrm{CO}_{2}$ in argon at $25^{\circ} \mathrm{C} .{ }^{[25]} \mathrm{A}$ different study with an increase in the loading of hyperbranched amines reported $\mathrm{CO}_{2}$ adsorption capacity of $4 \mathrm{mmol} / \mathrm{g}$, using humid $10 \% \mathrm{CO}_{2}$ in nitrogen. ${ }^{[27]}$

The effect of the support structure on the $\mathrm{CO}_{2}$ adsorption properties was studied using pore-expanded SBA-15, mesocellular foam, and a large-pore commercial silica. ${ }^{[58]}$ In this study with the larger pore diameter silica, the amount of amine loaded by the polymerization of aziridine was lower than the loading using standard SBA-15, and therefore also had a lower $\mathrm{CO}_{2}$

adsorption capacity. ${ }^{[58]}$ This type of solid amine adsorbent is very interesting and has been shown to have a high $\mathrm{CO}_{2}$ adsorption capacity and could possibly be a better option than the PEl loaded sorbents since the amine is covalently attached to the solid sorbent. 


\subsubsection{Regeneration and Stability of Amine Solid Sorbents}

One of the most important properties of an adsorbent for $\mathrm{CO}_{2}$ capture from coal-fired

power plants, or any commercial or industrial process that would require an enormous amount of $\mathrm{CO}_{2}$ capture, is the stability of the adsorbent over hundreds to thousands of adsorption and desorption cycles. There are typically two different ways to regenerate solid amine adsorbents: one is using a sweep gas and increasing the temperature to remove the $\mathrm{CO}_{2}$, while the other way is to use vacuum. ${ }^{[57]}$ For initial studies of solid amine adsorbents most of the published studies used an inert sweep gas such as nitrogen, argon, or helium to regenerate the adsorbent. [29], [25] [50]

The use of an inert sweep gas is convenient to determine the possibility of regeneration at the lab scale, but it is not practical for commercial applications. This process is not practical in commercial applications because the desorbed $\mathrm{CO}_{2}$ would be contaminated with the inert gas giving an exit stream that would not be much different from the inlet flue gas. The use of vacuum to regenerate the adsorbent is more practical than using an inert sweep gas, but, for sequestration, the $\mathrm{CO}_{2}$ has to be pressurized and therefore the use of vacuum would result in an energy penalty. Two methods that seem to be the most practical ways to regenerate an amine solid sorbent are using low pressure "waste" steam, or using $\mathrm{CO}_{2}$ at elevated temperatures as a sweep gas to regenerate the adsorbent.

There have only been a few studies that showed cycling ability over hundreds of cycles. A recent study that reported a significant amount of cycles using dry nitrogen and $\mathrm{CO}_{2}$ and a humid nitrogen and $\mathrm{CO}_{2}$ stream for cycling PEI impregnated adsorbents showed that there was slight degradation of the adsorbent over many cycles. Figure 2-6 is a graph of the $\mathrm{CO}_{2}$ 
adsorption capacities over many cycles of a PEI impregnated adsorbent using isothermal adsorption and desorption at $75^{\circ} \mathrm{C}^{[59]}$

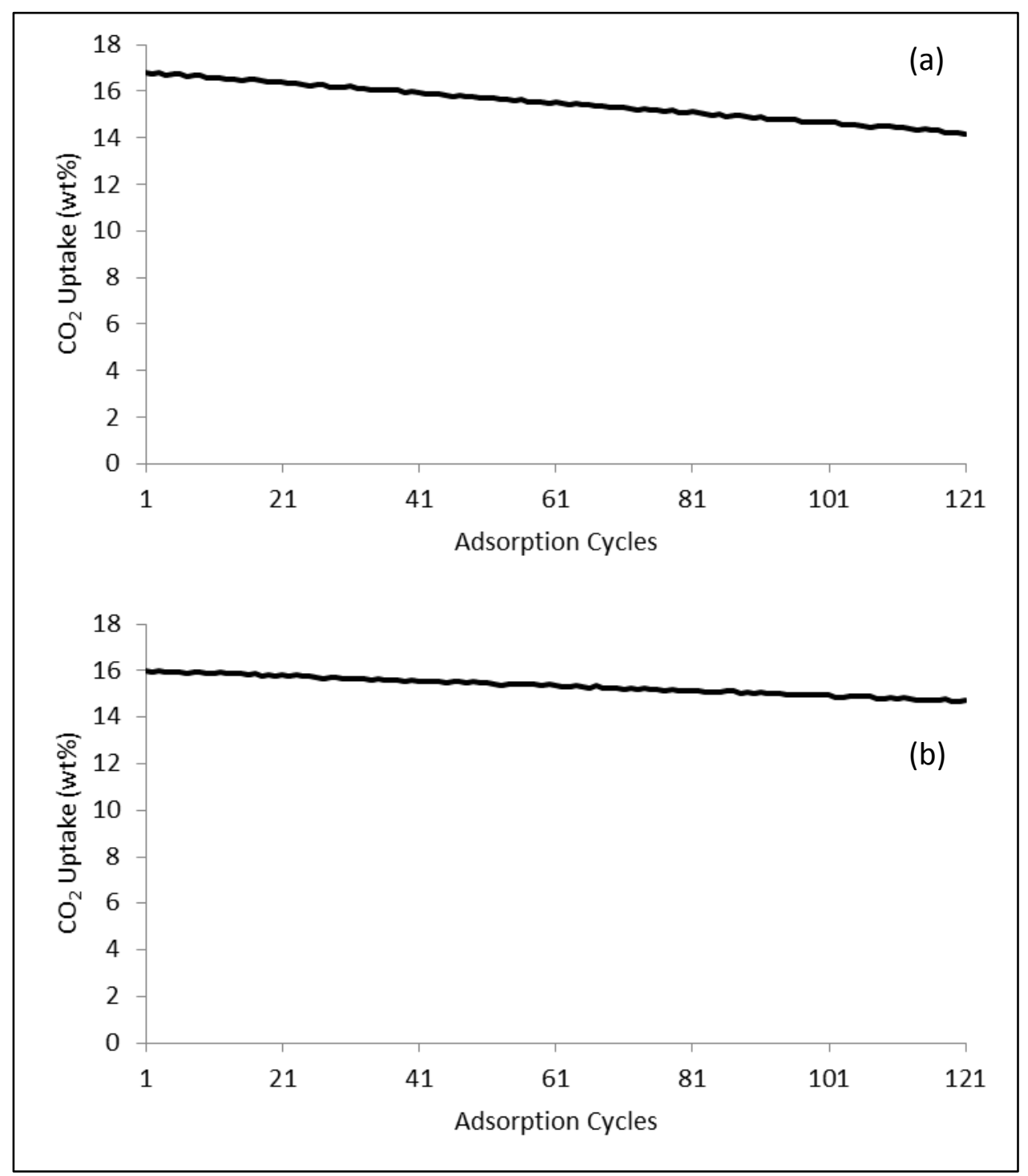

Figure 2-6: $\mathrm{MCM}-41$ loaded with PEI cycles at $75^{\circ} \mathrm{C}$; a) dry pure $\mathrm{CO}_{2}$ and nitrogen, b) humid $\mathrm{CO}_{2}$ and nitrogen $(6 \% \mathrm{RH})^{[59]}$

In Figure 2-6 it is seen that when pure $\mathrm{CO}_{2}$ is adsorbed onto PEI loaded support and desorbed using pure nitrogen, the stability is less than when using humid $\mathrm{CO}_{2}$ and humid nitrogen to regenerate the adsorbent at $75^{\circ} \mathrm{C}$. This is due to the slow formation of urea even at low temperatures when using pure $\mathrm{CO}_{2}$ as the adsorption gas. Figure 2-7 is a graph of the 
adsorption and desorption of a class two amine adsorbent using dry and humid gases at $70^{\circ} \mathrm{C}$ for adsorption and desorption.

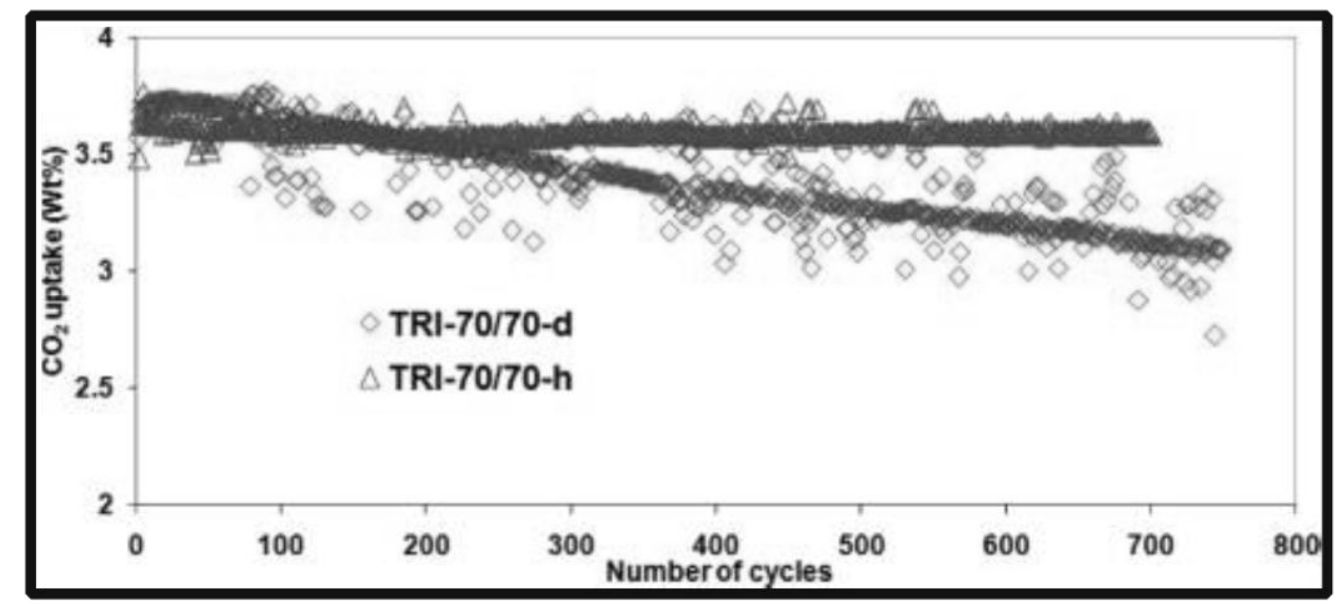

Figure 2-7: $\mathrm{CO}_{2}$ adsorption and desorption at $70^{\circ} \mathrm{C}$ using TRI-PE-MCM-41 with dry gases (TRI70/70-d) and humid gases (7\% RH) (TRI-70/70-h) ${ }^{[60]}$

Again these studies showed that it was possible to regenerate an amine loaded support using dry and humid nitrogen over many cycles, but this is not applicable to commercial operations since they used humid nitrogen for regeneration.

Desorption using pure $\mathrm{CO}_{2}$ at elevated temperatures is an interesting idea, but the concern is that PEI or other amines used will be evaporated or degraded at elevated temperatures. Another concern is the possible formation of stable urea onto the sorbent reducing the adsorption capacity of multiple cycles at elevated temperatures. A study that used an impregnated PEI support found that the adsorbent was not completely regenerated at temperatures under $140^{\circ} \mathrm{C}$ using pure $\mathrm{CO}_{2}$ as a desorption sweep gas, indicating that desorption temperatures would have to be higher than $140^{\circ} \mathrm{C} .{ }^{[61]}$ The proposed scheme for the formation of urea compounds is shown in Figure $2-8$, and this was determined using DRIFTS FTIR. ${ }^{[60]}$ 


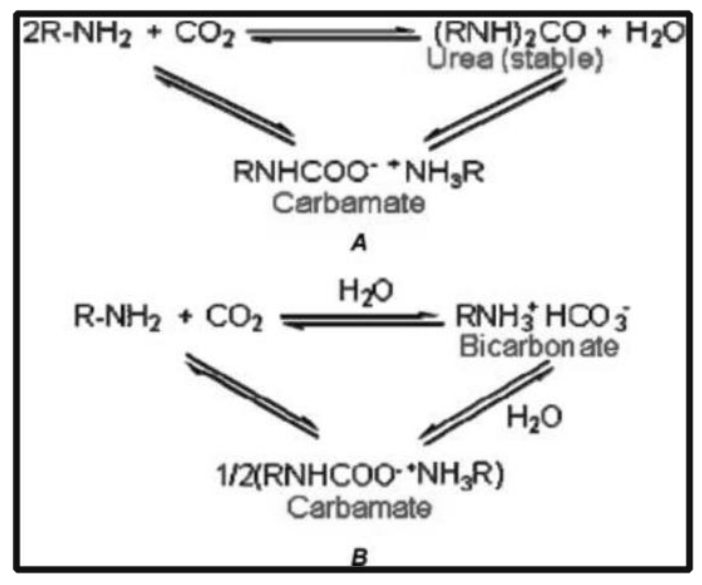

Figure 2-8: Proposed scheme of urea formation using amine sorbents ${ }^{[60]}$

The formation of urea compounds was shown to occur slowly even at relatively low temperatures $\left(70^{\circ} \mathrm{C}\right)$, and this was attributed to the loss of $\mathrm{CO}_{2}$ adsorption in Figure 2-7 over 700 cycles using pure $\mathrm{CO}_{2} \cdot{ }^{[60]}$ The use of humid $\mathrm{CO}_{2}$ is a regeneration method that could be used in commercial applications by recycling the $\mathrm{CO}_{2}$ captured form the flue gas, adding water and using it as a sweep gas. The water could then be condensed out of the stream giving a pure $\mathrm{CO}_{2}$ stream for sequestration. The possibility of this regeneration scheme has shown promise for solid amine sorbents in the literature.

Low pressure steam regeneration for solid amine adsorbents would seem as the most logical sweep gas for $\mathrm{CO}_{2}$ regeneration because low pressure or waste steam is available at coal-fired power plants and water could easily be condensed out of $\mathrm{CO}_{2}$. The regeneration and stability of amine solid sorbents using steam has been reported in only a few articles in the literature. ${ }^{[40],[54]}$ For all three classes of solid amine adsorbents it was shown that steam at $105^{\circ} \mathrm{C}$ was able to fully regenerate the adsorbent over several cycles. ${ }^{[40]}$ This showed promise for a commercially applicable regeneration scheme of solid amine adsorbents. A stability study 
using steam at more extreme conditions used an autoclave to generate steam to test the three different classes of solid amine adsorbents using mesocellular foam MCF as a support. ${ }^{[54]}$ In this study it was reported that all of the adsorbents were degraded after a 24 hour exposure to steam at temperatures from $106-180^{\circ} \mathrm{C}$ in an autoclave with air or nitrogen used as a purge gas. ${ }^{[54]}$ The 24 hour exposure to steam was used to try to simulate hundreds to thousands of cycles using steam. The loss of $\mathrm{CO}_{2}$ adsorption capacity was attributed to structural degradation of the MCF and degradation of the amine. Another interesting finding was that the class 2 adsorbent showed the most degradation upon long exposure to steam. ${ }^{[54]}$ The use of low temperature and pressure steam to regenerate solid amine adsorbent has been shown to be a viable possibility, but the long term stability of solid amine adsorbents should be considered as a concern when using or developing solid amine sorbents.

\subsection{Montmorillonite Clay}

Montmorillonite (MMT) is a cationic smectite clay that consists of stacks of two

tetrahedral silicate layers with a central alumina or magnesia octahedral layer. [62], [63], [64] This 2:1 ratio of tetrahedral to octahedral layers forms one layered sheet of clay with dimensions of about $1 \mathrm{~nm}$ thick by $30 \mathrm{~nm}$ to several microns in lateral dimensions. MMT has a surface area in the range of $750 \mathrm{~m}^{2} / \mathrm{g}$ when the individual platelets are completely separated. [63], [64] Montmorillonite clay is typically used to make polymer nanocomposites and is the most widely used clay for clay polymer nanocomposites because of its ability to swell, its high surface area and its high surface reactivity. ${ }^{[63]}$ Figure 2-9 is a representation of the structure of montmorillonite type clay. 


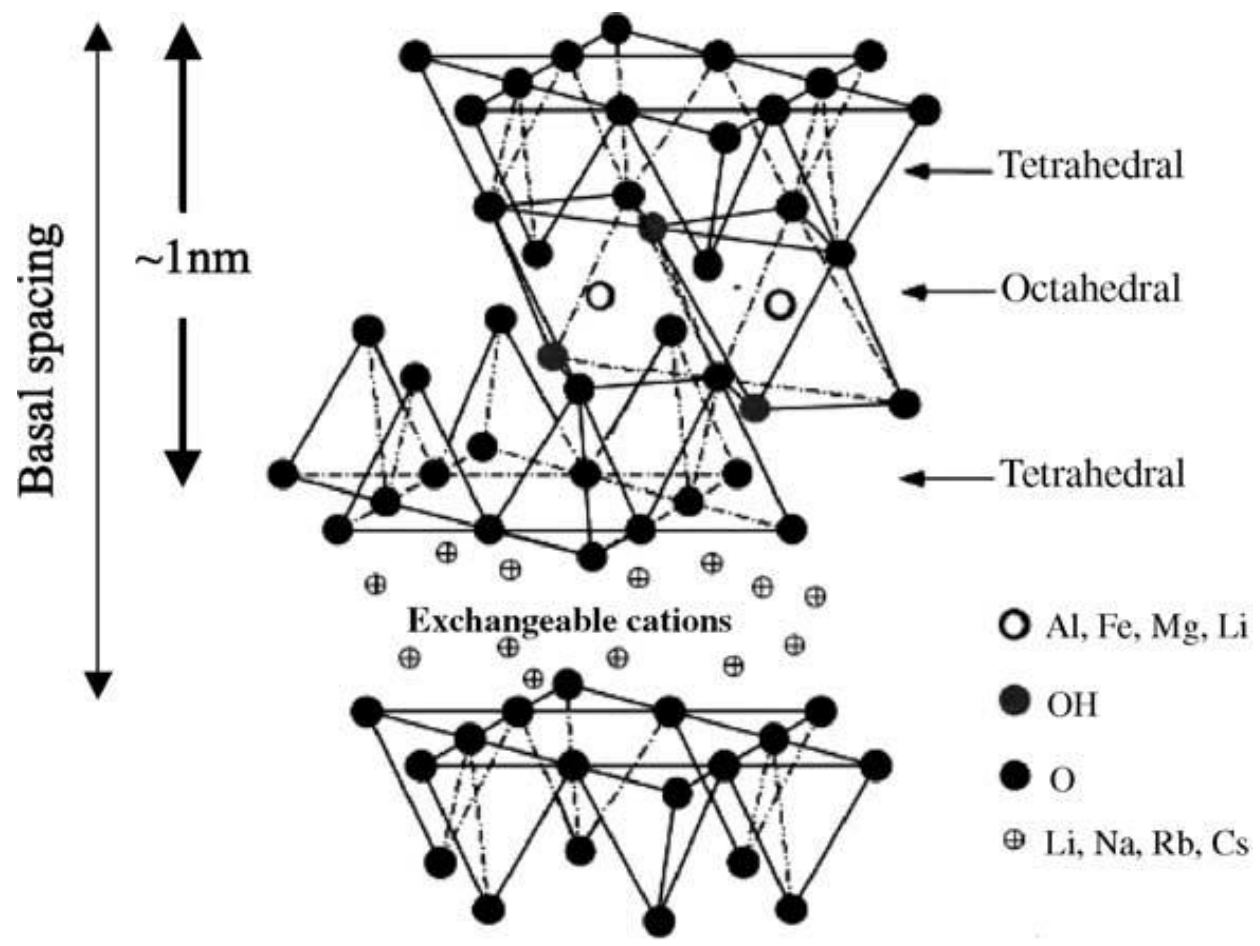

Figure 2-9: Schematic of 2:1 layered clay; $d_{001}$ refers to basal plane spacing. ${ }^{\text {[63] }}$

The individual layers of clay tend to stack in several hundred layers, which are called tactoids, and are micro sized particles. The stacking of these layers leads to a regular van der Waals gap between the layers called the interlayer or gallery. ${ }^{[63]}$ Pristine clay usually has $\mathrm{Na}^{+}$or $\mathrm{Ca}^{+}$in its interlayer gallery, and the amount that can be exchanged with another cation is usually characterized by cation exchange capacity (CEC), and this is generally expressed as mequiv/100 g. ${ }^{[63]}$ The CEC depends on the crystal size, the $\mathrm{pH}$ and the type of exchangeable cation. ${ }^{[62], ~[63], ~[64] ~ S e p a r a t i n g ~ t h e ~ p l a t e l e t s ~ i n t o ~ i n d i v i d u a l ~ s h e e t s ~ w i l l ~ e x p o s e ~ t h e ~ e d g e ~ h y d r o x y l ~}$ groups and utilize the high surface area, but this can be difficult in practice.

\subsection{Organically Modifying Montmorillonite Clay}

While there are many different specific ways to modify MMT with an amine, the main steps are to swell the clay in a liquid and react the hydrophilic end of the amine compound to the edge $\mathrm{OH}$ groups leaving the hydrophobic amine on the outside end to better interact with 
$\mathrm{CO}_{2}$. Figure 2-10 is a representation of this mechanism where first the clay is swelled with water and then the clay is filtered and placed in an organic solvent, acetone, and then an amine, (3aminopropyl) trimethoxysilane (APTMS), is reacted on the edge $\mathrm{OH}$ groups. Figure 2-10 illustrates how the clay platelets are swollen and then separated by the reaction with the amine. When producing a polymer nanocomposite the modified clay is then dispersed into the polymer by melt mixing or a solution process. The difference between the work conducted in the literature and the proposed research is that the work in the literature was conducted in polymers to improve their mechanical, thermal, and physical properties with concentrations of nanoclay around $5 \%$. The proposed research uses this same idea, but uses the amine treated nanoclay for $\mathrm{CO}_{2}$ adsorption experiments.

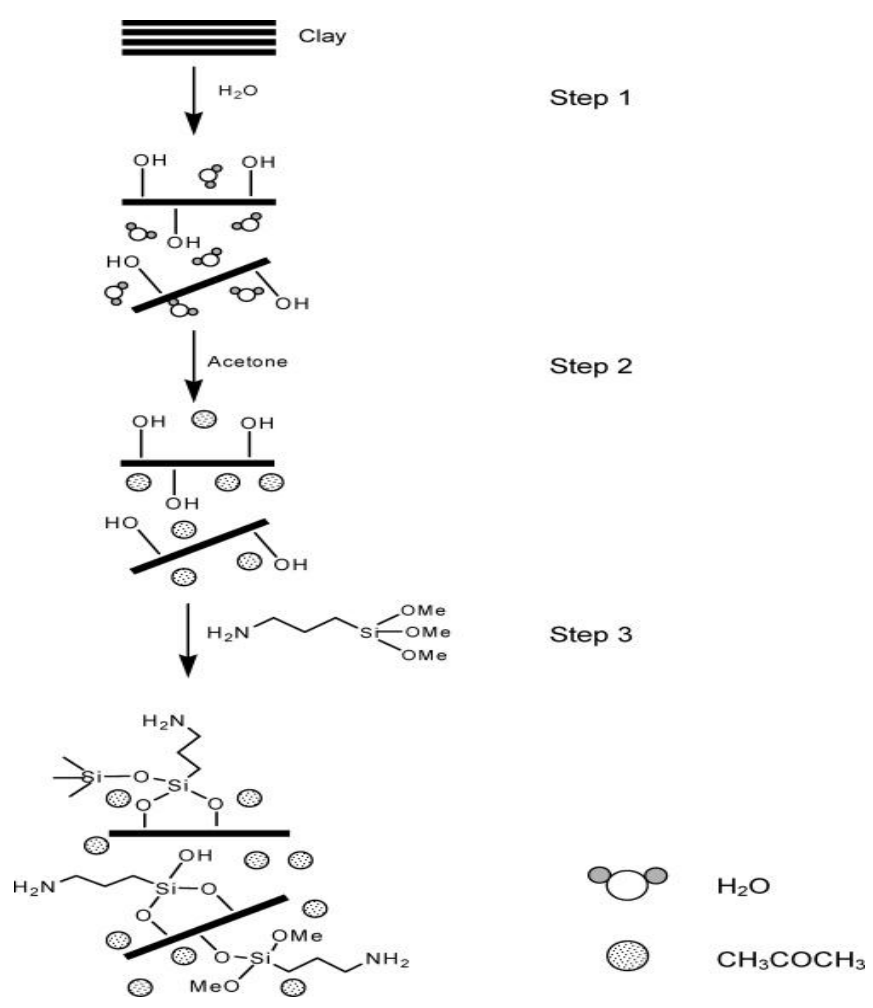

Figure 2-10: Schematic representation of amine reacted on clay ${ }^{[65]}$ 
Figure 2-10 shows a reaction with an aminosiliane. In this reaction, the water is replaced with an organic solvent after the swelling because the aminosiliane can agglomerate by a condensation reaction with the water. Replacing the water is therefore necessary in this reaction, but water is usually much better at swelling the clay than an organic solvent and would be preferred as the medium in the reaction. ${ }^{[65]}$

\subsection{Methods for Attaching APTMS and PEI to Montmorillonite Clay}

Cloisite ${ }^{\circledR} \mathrm{Na}^{+}$is a montmorillonite clay that has $\mathrm{Na}^{+}$cations in-between its layers and

was the clay used in this study. (3-aminopropyl) trimethoxysilane (APTMS) and

Polyethylenimine (PEI) were used as the amines that are attached to the clay. To react APTMS

with the clay, first the clay needs to be swelled in a solvent to separate the aggregated stacked layers into more separated layers of the clay. Then the APTMS is added and the trimethoxy silane group in APTMS reacts with the edge hydroxyl groups on the clay leaving the $\mathrm{CO}_{2}$ adsorbing amine group available for the adsorption of $\mathrm{CO}_{2}$ from the reaction stream. The expected reaction is shown in Figure 2-11. DMF was the solvent that was used extensively throughout the sample preparation experiments. Other solvents were initially used but preliminary results demonstrated that the greatest amount of APTMS grafted onto the clay was achieved using DMF as a solvent. Preliminary studies to determine the concentration of APTMS needed to ensure an excess for the grafting reaction were conducted and we determined that the ratio of clay to APTMS needed to be above 5:6 on mass basis. An excess amount of APTMS was then used for the majority of the experiments to ensure that the grafting reaction was not limited by the amount of APTMS. Water is very good at swelling clays, but it can agglomerate 
APTMS through a condensation reaction. ${ }^{[65]}$ A study with the swelling of the clay with water and then replacing it with an organic solvent to react the APTMS versus just using an organic solvent to swell the clay and react the APTMS was conducted. Figure 2-11 is the expected reaction between the clay and the aminosilane.

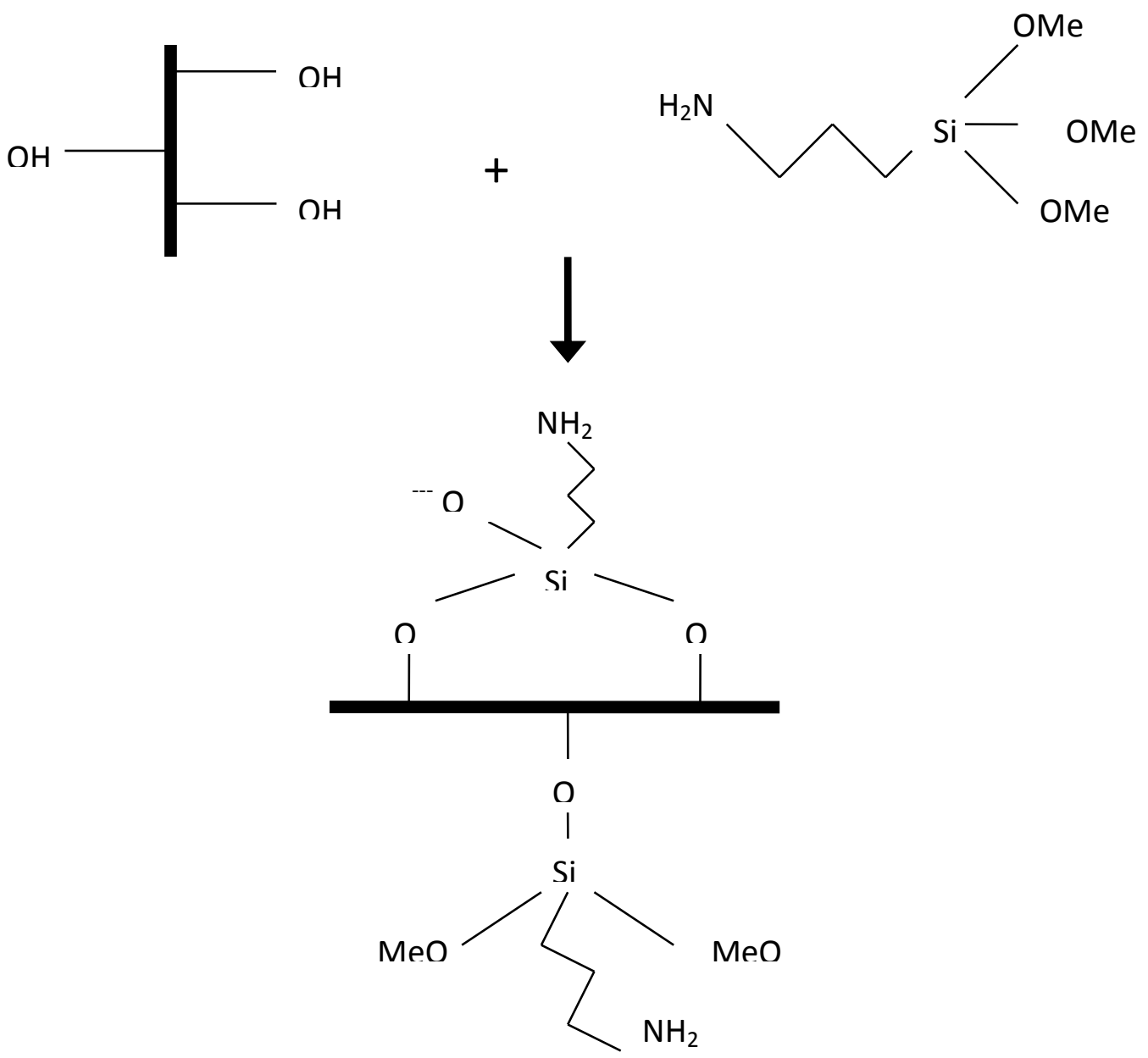

Figure 2-11: Expected reaction with APTMS and Cloisite ${ }^{\circledR} \mathrm{Na}^{+}$

PEI attached to silica supports has been shown to have high values of $\mathrm{CO}_{2}$ adsorption. ${ }^{[30]}$ $\mathrm{PEI}$ is attached to silica supports by a wet impregnation method, where PEI is dissolved in methanol, and then the support is added and mixed well with the PEI/methanol solution and then the methanol is evaporated in an oven. In this method the positively charged PEI is 
attached to the negatively charged clay surface by electrostatic forces. The combination of reacting APTMS to the edge hydroxyl groups and then wet impregnating the PEI onto the surface of the clay was conducted to determine if the combination of the two amines would increase the amount of $\mathrm{CO}_{2}$ adsorbed onto the sample. 


\section{Chapter 3}

\section{Experimental Materials and Procedures}

Cloisite ${ }^{\circledR} \mathrm{Na}^{+}$from Southern Clay products INC., a montmorillonite clay, was used as the support for the adsorbent developed. Ethylenimine, oligomer mixture (PEI) Mn 423 from Sigma Aldrich, and 3-Aminopropyltrimethoxy-silane, 97\% (APTMS) from Sigma Aldrich were the amines used in the study. N,N-Dimethylformamide 99\%, Methanol, and 99\% Acetone ReagentPlus from Sigma Aldrich and deionized water were used for reaction solutions. Other PEls that were used for comparison were Polyethylenimine $50 \mathrm{wt} \%$ solution in water $\mathrm{Mn}$ 60,000, and Polyethylenimine 50 wt\% solution in water $\mathrm{Mn} \mathrm{1,200} \mathrm{and} \mathrm{were} \mathrm{also} \mathrm{purchased}$ from Sigma Aldrich.

\subsection{Grafting Amines to Clays}

The grafting of APTMS onto the clay was performed by two methods. One was called the "dry method". This method started by drying the clay in an oven overnight. Then $0.5 \mathrm{~g}$ of the nanoclay was dispersed in $80 \mathrm{ml}$ of acetone, toluene or dimethylformamide (DMF), and a specified amount of APTMS was then added and the mixture was stirred at room temperature for 24 hours. After the mixture was stirred, the solution was sonicated for 30 seconds at an amplitude of $40 \%$ using a Cole Parmer 750 watt Ultrasonic Processor. The resulting mixture was then filtered using a vacuum filtration system and Fisher Scientific fine porosity P2 qualitative filter paper, washed multiple times with the solvent used, and dried in an oven at $60^{\circ} \mathrm{C}$ overnight. The second method, called the "slurry method", used $15 \mathrm{ml}$ of deionized water to swell $0.5 \mathrm{~g}$ of clay by stirring for 24 hours. $100 \mathrm{ml}$ of DMF was then added to the clay/water suspension and stirred for 24 hours, sonicated for 30 seconds, filtered and washed. The filtered 
clay was then added to $80 \mathrm{ml}$ of DMF and was stirred for approximately 15 minutes to disperse the clay. APTMS was then added in different concentrations. The sample was then stirred for 24 hours, sonicated for 30 seconds, filtered and washed with copious amounts of DMF. The samples where then dried overnight in an oven at $60^{\circ} \mathrm{C}$. After the sample was dried, it was crushed using a mortar and pestle to achieve a fine powder for testing.

For work with PEl, a wet impregnation method was used. This method involved dissolving PEI into methanol at a ratio of 8:1 methanol to PEI. The desired amount of support was added to achieve a specified percent loading of PEI onto the clay, and stir the sample for 24 hours. Samples were loaded with 33\% PEI, 50\% PEI and 66\% PEI. An example of 50\% loaded PEI onto the clay support would be adding 1 gram of clay to 1 gram of PEI dissolved in 8 grams of methanol. The solvent was then evaporated in a vacuum oven at $60^{\circ} \mathrm{C}$ overnight. These samples where easily broken into a powder without the use of a mortar and pestle.

For the samples treated with both APTMS and PEI, the sample was first treated with APTMS using the methods described earlier. The treated clay sample was then crushed using a mortar and pestle. PEI was dissolved into methanol in an 8:1 ratio using the same method as the wet impregnation with untreated clay. The treated clay was then added in a 1:1 ratio, based on the weight of the treated clay, with the PEI to achieve a $50 \%$ loading of PEI onto the treated clay.

\subsection{Thermogravimetric Analysis for Amine Content on Clay}

A TA Instruments TA-Q500 TGA was used to determine the amount of amine content that was grafted onto the samples. The samples were first heated at $20^{\circ} \mathrm{C} /$ minute to $900^{\circ} \mathrm{C}$ in nitrogen at a flow rate of $40 \mathrm{ml} /$ minute. The derivative of temperature weight loss was used to 
determine different weight loss steps. The weight loss that occurred around $100^{\circ} \mathrm{C}$ was

assumed to be adsorbed water or $\mathrm{CO}_{2}$ that was reacted onto the sample. The weight loss after this step was used to calculate the amount of amine grafted onto the clay. Another method used to further investigate different weight loss steps was to heat the sample in nitrogen with a flow rate of $40 \mathrm{ml} /$ minute to $100^{\circ} \mathrm{C}$ and keep the sample at $100^{\circ} \mathrm{C}$ for 30 minutes to remove all of the water. The sample temperature was then ramped to $600^{\circ} \mathrm{C}$ at $20^{\circ} \mathrm{C} /$ minute, and kept at $600^{\circ} \mathrm{C}$ for 30 minutes to remove all of the grafted amine. The weight loss due to water was measured as the weight loss at $100^{\circ} \mathrm{C}$. The weight loss due to the amine was calculated as the weight loss after the $100^{\circ} \mathrm{C}$ step.

\subsection{High Pressure $\mathrm{CO}_{2}$ Adsorption and Desorption Tests}

High pressure $\mathrm{CO}_{2}$ adsorption tests were conducted in a pressure vessel that was approximately 2 inches in diameter and 10 inches long. Up to eleven samples were run at one time. The pressure in the pressure vessel was determined using the secondary pressure gauge on the reaction gas cylinder. During the $\mathrm{CO}_{2}$ adsorption experiments the valve on the gas cylinder was left open to insure that the pressure in the pressure vessel was maintained at the desired value. The temperature for the reaction of $\mathrm{CO}_{2}$ was not altered and left at room temperature for the majority of the tests. The weight of $\mathrm{CO}_{2}$ adsorbed in the high pressure tests was calculated by weighing the sample before it was placed into the reaction vessel. Then, once the sorbents had adsorbed $\mathrm{CO}_{2}$ the sample was removed from the pressure vessel weighed to find the weight difference. After this, desorption and cycle tests were conducted using vacuum.

In order to determine the temperature effects of $\mathrm{CO}_{2}$ adsorption at high pressures, the samples were loaded into the pressure vessel and $\mathrm{CO}_{2}$ was introduced into the vessel. A valve 
on the pressure vessel was then closed and the vessel was placed into a water bath at the desired reaction temperature in an oven at the same temperature for 24 hours. The initial pressure was determined by back calculating the pressure for a final pressure of 300 psi using the ideal gas law for the change in pressure due to the increase in temperature. The water bath was used to help limit any fluctuations in the oven temperature.

The vacuum desorption experiment for the samples exposed to high pressure $\mathrm{CO}_{2}$ used the same procedure as the vacuum desorption for the samples in the TGA, as described in the next section. The procedure for vacuum desorption for the samples in the pressure vessel experiments was to weigh the sample after $\mathrm{CO}_{2}$ adsorption, then place the sample into the vacuum oven at $85^{\circ} \mathrm{C}$ for 1 hour. The samples were then reweighed and the percentage weight loss was calculated and compared to the weight gained during the initial $\mathrm{CO}_{2}$ adsorption experiment. The equation used for weight percent desorbed is given in Equation 3-1.

$$
\left(1-\frac{W_{v a c}}{W_{C O_{2}}}\right) \cdot 100=W_{d e s}
$$

$W_{v a c}$ is the weight of the sample when it is removed from the vacuum oven, $W_{\mathrm{CO}_{2}}$ is the weight of the sample after it is removed from the pressurized $\mathrm{CO}_{2}$ and $W_{\text {des }}$ is the weight percentage regenerated from the vacuum oven experiment.

\subsection{Thermogravimetric Analysis for $\mathrm{CO}_{2}$ Adsorption and Desorption}

Two TGAs were used in these experiments. These were a Thermo Cahn Thermax 500

and a TA Instruments TA-Q500. Samples in the Thermo Cahn were approximately 40-50mg, and this sample weight was used to minimize the noise in the results, but also to conserve the sample for multiple runs. With the TA-Q500, the noise was minimal so a sample size of around 
$10 \mathrm{mg}$ was used for all of the runs. The reaction gas for both TGAs was controlled by a flow controller. Since the sample size and the flow controller were larger in the Thermo Chan TGA, a flow rate of $100 \mathrm{ml} / \mathrm{min}$ was used for all of the experiments. With the TA-Q500 a flow rate of $40 \mathrm{ml} / \mathrm{min}$ for the reaction gas was used. Samples were run on both TGAs to compare results, and these were found to be comparable to each other.

The experimental procedure was the same for all of the samples and included an initial drying step in nitrogen at $100^{\circ} \mathrm{C}$ to remove any moisture or adsorbed $\mathrm{CO}_{2}$ from the sample and to get a good baseline for the calculation of the $\mathrm{CO}_{2}$ adsorbed. The sample was kept at $100^{\circ} \mathrm{C}$ for 30 minutes to achieve a stable weight before the $\mathrm{CO}_{2}$ adsorption experiments. If the adsorption temperature was above $100^{\circ} \mathrm{C}$, such as $125^{\circ} \mathrm{C}$ and $150^{\circ} \mathrm{C}$, the initial drying step was completed using the $\mathrm{CO}_{2}$ adsorption temperature instead of $100^{\circ} \mathrm{C}$. For $\mathrm{CO}_{2}$ adsorption at temperatures lower than $100^{\circ} \mathrm{C}$, the sample was cooled in nitrogen and, once the reactor temperature reached the designated reaction temperature, the reaction gas was switched to $\mathrm{CO}_{2}$.

The adsorption of $\mathrm{CO}_{2}$ was tested at various temperatures to see which temperature would adsorb the most $\mathrm{CO}_{2}$ in a reasonable amount of time. For the samples treated with APTMS, the adsorption of $\mathrm{CO}_{2}$ reached equilibrium very quickly at temperatures above $75^{\circ} \mathrm{C}$, but, for the clay treated with PEI, an adsorption time of 90 minutes was used. This was based on initial results that showed that, although the adsorption of $\mathrm{CO}_{2}$ was still ongoing with increasing time, the increase in the amount of $\mathrm{CO}_{2}$ adsorbed was minimal after 90 minutes. If equilibrium was not reached before 90 minutes, a 90 minute adsorption time was used as the 
standard adsorption time for all of the samples at all of the different temperatures and conditions.

\subsubsection{Multiple cycles in the TGA}

For subjecting a sample to multiple cycles of adsorption and desorption in nitrogen, the reaction gas was switched to pure nitrogen and the sample was heated to $100^{\circ} \mathrm{C}$ and the temperature was kept constant for 30 minutes. Once the sample was regenerated, the TGA reactor was cooled back to the reaction temperature in nitrogen. When the reaction temperature was reached the desired value, the inlet gas stream was switched back to the initial reaction gas for $\mathrm{CO}_{2}$ adsorption.

Cycling the samples in $\mathrm{CO}_{2}$ was similar to cycling in nitrogen, except that the temperature for regeneration was $155^{\circ} \mathrm{C}$ for 30 minutes. The reaction gas was always pure $\mathrm{CO}_{2}$ for all of the experiments during the cycling step. For example when the adsorption temperature of the sample was $85^{\circ} \mathrm{C}$, the reaction gas was kept at pure $\mathrm{CO}_{2}$ during the ramping of the temperature to $155^{\circ} \mathrm{C}$ and during the cooling of the temperature back to $85^{\circ} \mathrm{C}$.

Humid carbon dioxide was also used to regenerate the samples. During this experiment, the reaction gas was bubbled through deionized water that was at room temperature before it went into the reactor. The regeneration temperature was $155^{\circ} \mathrm{C}$ which was the same temperature used during cycling using pure $\mathrm{CO}_{2}$.

\subsection{Vacuum Regeneration}

To regenerate the samples using vacuum, carbon dioxide was reacted onto the sample in either the TGA or in the pressure vessel using the same adsorption methods already described. After $\mathrm{CO}_{2}$ was reacted onto the sample, the sample was placed into the vacuum 
oven at $85^{\circ} \mathrm{C}$. The vacuum pump was then turned on to achieve a vacuum pressure of $93 \mathrm{kPa}$ as measured by a gauge on the vacuum oven. The samples were then removed after a designated period of time and the weight difference was measured. The samples were then placed back into the TGA or pressure vessel to measure the amount of $\mathrm{CO}_{2}$ adsorbed after regeneration. The amount of $\mathrm{CO}_{2}$ initially adsorbed was then compared with the amount adsorbed after the vacuum regeneration step.

\subsection{Fourier Transform Infrared Spectroscopy (FTIR) Characterization}

Fourier transform infrared spectroscopy (FTIR) was used to determine if any amine was attached to the clay support. A Thermo Scientific Nicolet iS10 FTIR with the Attenuated Total Reflectance (ATR) attachment and a diamond crystal was used with a resolution of $1 \mathrm{~cm}^{-1}$ and 40 scans per sample. The procedure was to take a background spectrum before every sample with no sample on crystal surface. If the background spectrum had no unexpected peaks, a small amount of sample was placed onto the crystal surface and the spectrum was then collected.

\subsection{Surface Area Analysis}

To determine the surface area of unmodified Cloisite ${ }^{\circledR} \mathrm{Na}^{+}$, a ASAP 2020 surface analysis machine was used to determine the BET surface area. A sample of fumed silica with a surface area of $250+/-30 \mathrm{~m}^{2} / \mathrm{g}$ was tested in the BET ASAP 2020 surface analysis machine to determine the accuracy of the method. First a sample was placed into the sample tube with an auxiliary sample rod also placed into the tube. A vacuum was place onto the tube and the sample was heated to $120^{\circ} \mathrm{C}$ to remove any moisture in the sample. The vacuum was held for at least 30 minutes or until 100mTorr was observed on the vacuum gauge. Once this was achieved, the vacuum was turned off and nitrogen was allowed to flow into the sample tube. The lid was then 
quickly placed onto the sample tube and the sample was connected to the surface analysis machine for sample analysis. The ASAP 2020 used liquid nitrogen to cool the sample and the BET surface area was calculated using nitrogen adsorption at 77K.

\subsection{Scanning Electron Microscopy (SEM)}

SEM images were taken using a Hitachi S-4700 FE-SEM. The samples were attached to a sample holder using double sided carbon tape. The samples were coated with gold before the images were taken because the samples were not conductive enough for SEM imaging. The procedure for coating the samples was to place the samples into a SPI-MODULE ${ }^{\mathrm{TM}}$ sputter coater. The samples were then evacuated to $400-600$ mTorr. The chamber was then flushed with argon, the vacuum was then restored to $80 \mathrm{mTorr}$, and approximately $3 \mathrm{~nm}$ of gold was sputtered onto the samples. The samples were then placed into the SEM for imaging. SEM images were taken using various magnifications, with a general working distance of 12.1$13.1 \mathrm{~mm}$ and a voltage of $5.0 \mathrm{kV}$.

\subsection{Activation Energy Analysis}

The stability of amines on solid supports is a big concern for the applicability of the amine solid adsorbents in commercial applications. Therefore the activation energy of the degradation of APTMS and PEI on montmorillonite was studied using TGA as described in a

paper by Friedman ${ }^{[66]}$ and similar to other papers on TGA activation energy. ${ }^{[67], ~[68]}$ The procedure was very similar to the procedure for determining the amount of amine grafted to the sample. A sample of approximately $10 \mathrm{mg}$ was placed into the TGA and the temperature was ramped from $5-20^{\circ} \mathrm{C}$ to $900^{\circ} \mathrm{C}$ in nitrogen. The difference in the degradation curves were then used to estimate an activation energy using equations described in the literature. 


\section{Chapter 4}

\section{Results of Grafting APTMS and PEI onto Montmorillonite Clay}

Samples of treated clay were produced using the steps described in the experimental sections for grafting amines to clay. Once these samples were created, the samples were characterized using TGA, FTIR and SEM techniques to determine if an amine was successfully attached to the clay, the amount of amine loaded, and the morphology of the treated samples.

\subsection{TGA analysis}

Samples using Cloisite ${ }^{\circledast} \mathrm{Na}^{+}$and DMF as a solvent were first grafted with APTMS using the "dry method" described in the experimental section. After the sample was filtered washed and dried, the sample was crushed using a mortar and pestle to a fine powder. To determine the amount of amine attached to the sample TGA analysis was conducted. Using methods similar to those described in the literature, the temperature was ramped at $20^{\circ} \mathrm{C} /$ minute to $600^{\circ} \mathrm{C}$ and kept at $600^{\circ} \mathrm{C}$ for 60 minutes. Figure 4-1 is a TGA graph of Cloisite ${ }^{\circledR} \mathrm{Na}^{+}$treated with 0.4g APTMS/g clay using the "dry method". In Figure 4-1 it can be seen that there are multiple weight loss steps when heating the sample to $600^{\circ} \mathrm{C}$ in nitrogen. The first weight loss step that is clearly seen in the derivative weight loss curve in Figure $4-1$ is at a temperature of $25-140^{\circ} \mathrm{C}$, and this is attributed to the loss of water. The remaining weight loss is attributed to the loss of the amine. 


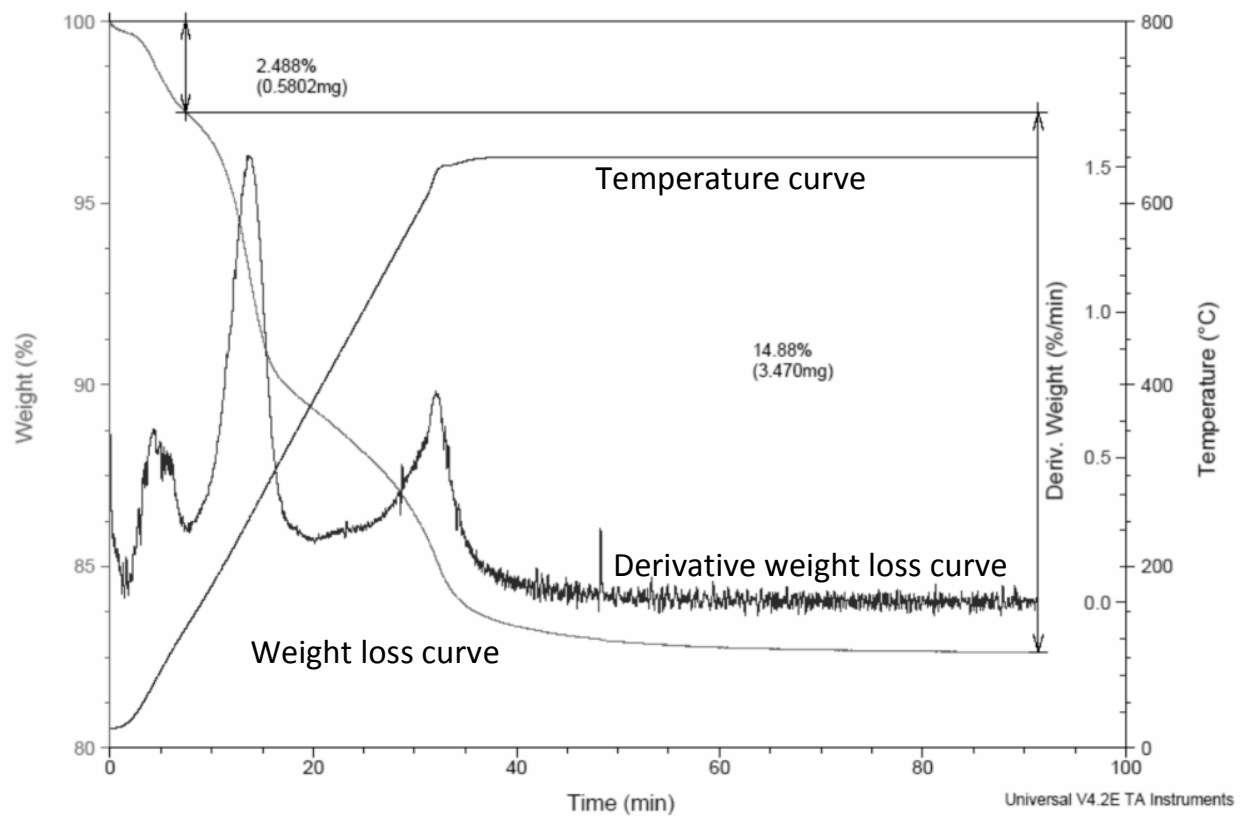

Figure 4-1: TGA Curve of clay treated with 0.4g APTMS/g Clay in nitrogen

This procedure and procedures similarly used in the literature assumed, that after the weight loss due to water and unattached molecules, the remaining weight loss is due to the removal of the attached organic amine from the inorganic support. In order to test this theory the untreated clay was run using the same procedure as a control. The TGA curve for untreated clay ramped to $600^{\circ} \mathrm{C}$ is shown in Figure $4-2$. In this figure it can be seen that there is an initial weight loss step that is attributed to water, similar to the weight loss step seen in the APTMS treated sample. Then there is another weight loss step, in which there is approximately $5.7 \mathrm{wt} \%$ lost. This weight loss is possibly due to the degradation of the clay and possibly weight loss of water entrapped in the intergalleries of the clay. It is obvious that some sort of degradation is happening at high temperatures to the clay since the color of the clay changes from white to dark gray after exposure to high temperatures in nitrogen. 


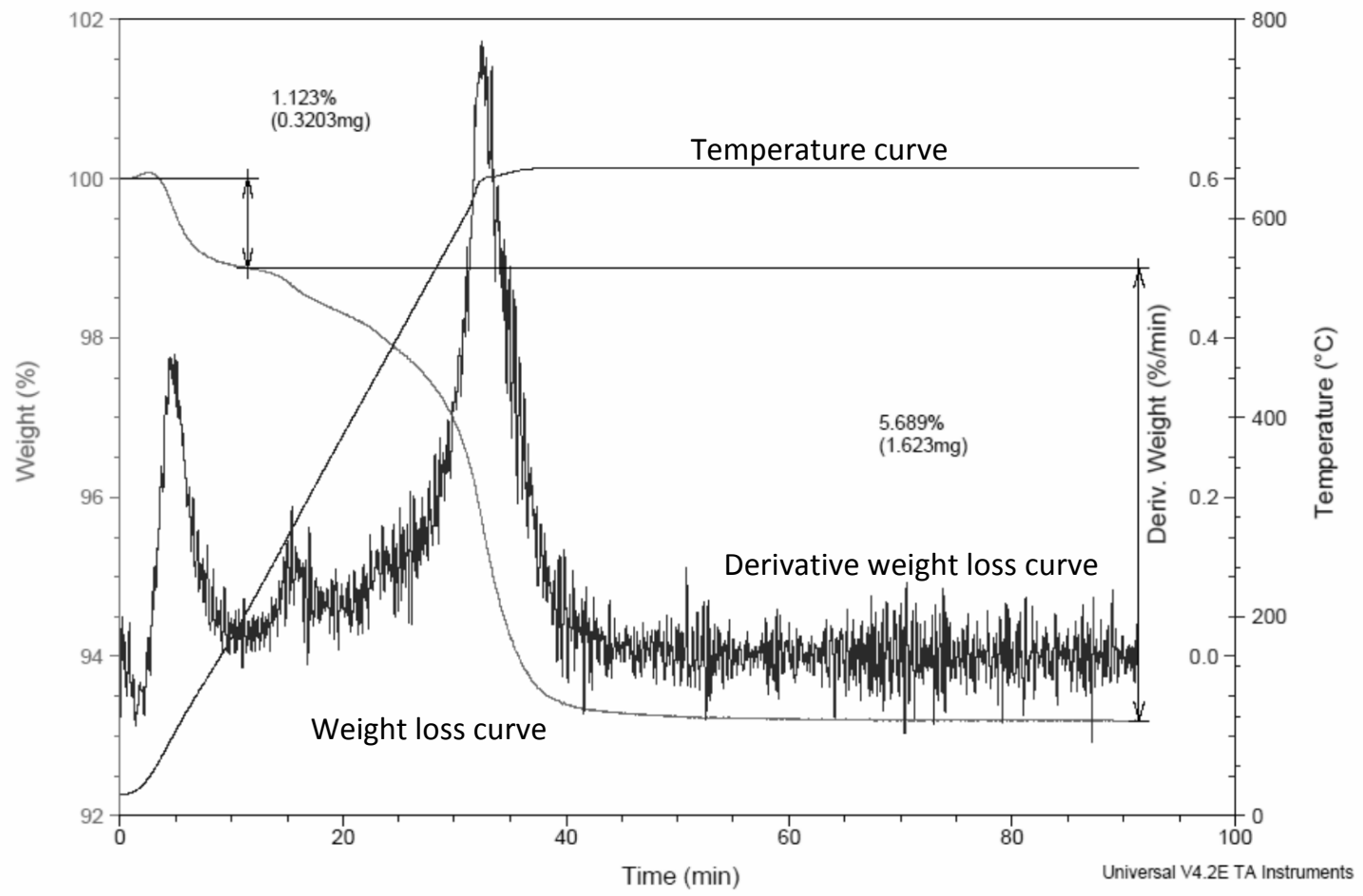

Figure 4-2: TGA curve of untreated Cloisite ${ }^{\circledR} \mathrm{Na}^{+}$in nitrogen.

In order to determine the stability of the clay used in this study, the untreated clay was heated progressively to $900^{\circ} \mathrm{C}$ to determine if there was any more degradation weight loss.

Figure 4-3 is a TGA curve of untreated Cloisite ${ }^{\circledR} \mathrm{Na}^{+}$heated to $900^{\circ} \mathrm{C}$ at $20^{\circ} \mathrm{C} /$ minute in nitrogen. In Figure 4-3 the weight loss is graphed versus temperature and it can be clearly seen that there are two main weight loss steps, one due to the loss of water and the other due to some degradation to the untreated clay. The weight loss due to water is more in Figure 4-3 than in Figure 4-2 using the $600^{\circ} \mathrm{C}$ method. This is due to the amount of moisture that the sample was able to adsorb during that particular day and while the sample was stored. This weight loss is expected to change depending on the humidity during that day and the difference in the two runs is not a concern. The more important weight loss is the weight loss after the desorption of water. This weight loss step is approximately the same using the two different ending 
temperatures. Both procedures were repeated multiple times using untreated clay and showed similar results indicating that the weight loss is the same due to the degradation of clay using an ending temperature of $600^{\circ} \mathrm{C}$ and $900^{\circ} \mathrm{C}$. The average weight loss after desorption of water from the untreated clay was calculated as $5.6 \pm 0.7$. This weight loss should be taken into account when calculating the amount of amine grafted onto the sample.

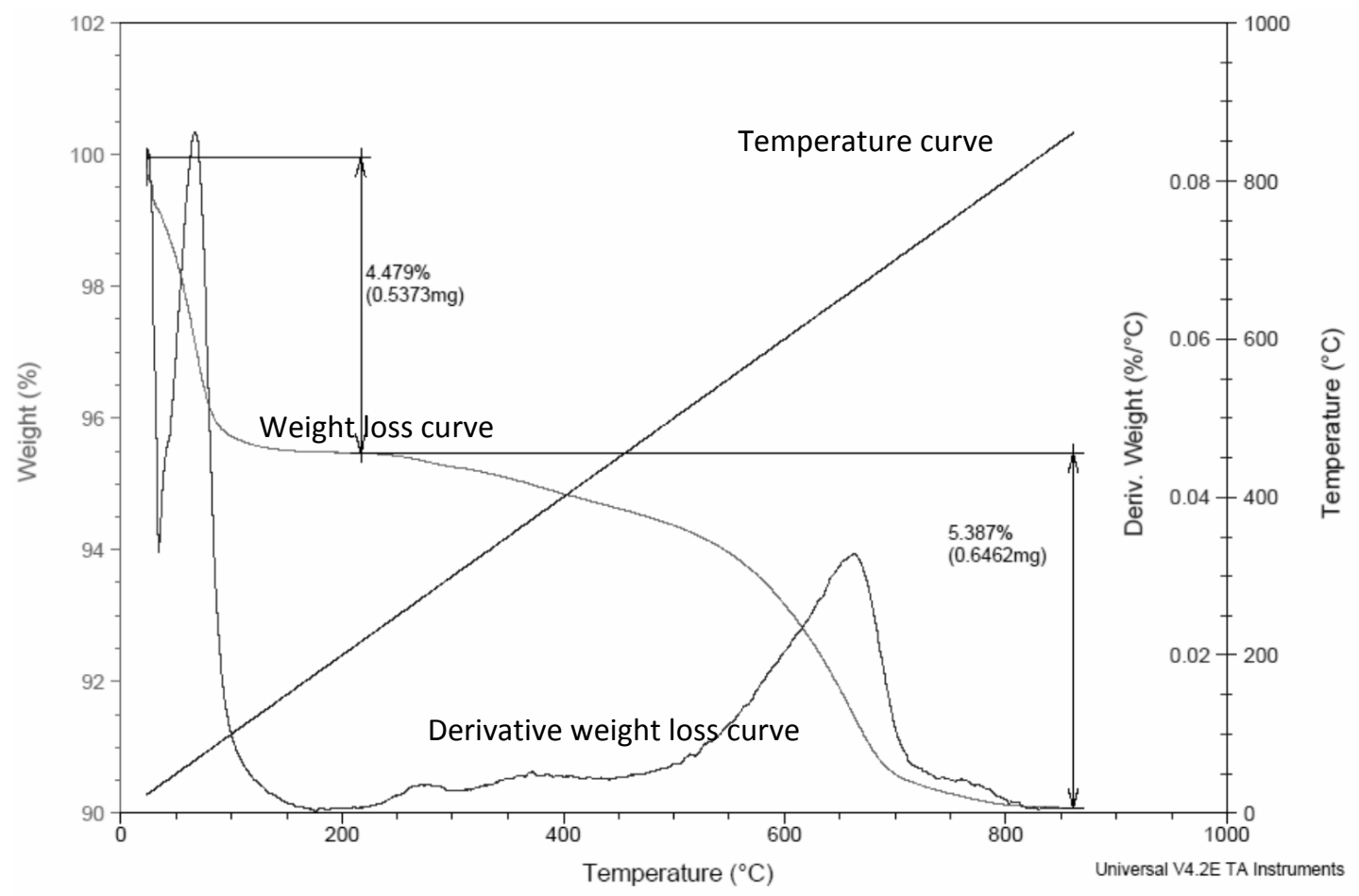

Figure 4-3: TGA curve of untreated Cloisite ${ }^{\circledR} \mathrm{Na}^{+}$ramped to $900^{\circ} \mathrm{C}$ in nitrogen

Experiments were performed to see the effect of various solvents and APTMS concentration on amine grafting. Solvents such as acetone, toluene and DMF vary in their polarity which can affect the nanoclay dispersion. A short study using different solvents and the "dry method" described in the experimental chapter was conducted to quickly determine which solvent allowed the most amine to graft to the clay. Shown in Figure 4-4 are the results of the 
average amount of amine grafted to Cloisite ${ }^{\circledR} \mathrm{Na}^{+}$using the dry method with different liquid media. Although this was a quick study and not enough runs were performed to prove that the differences between the solvents were significant, there was some indication that DMF had the highest amount of amine grafted and therefore was the solvent used in producing all of the additional samples treated with APTMS.

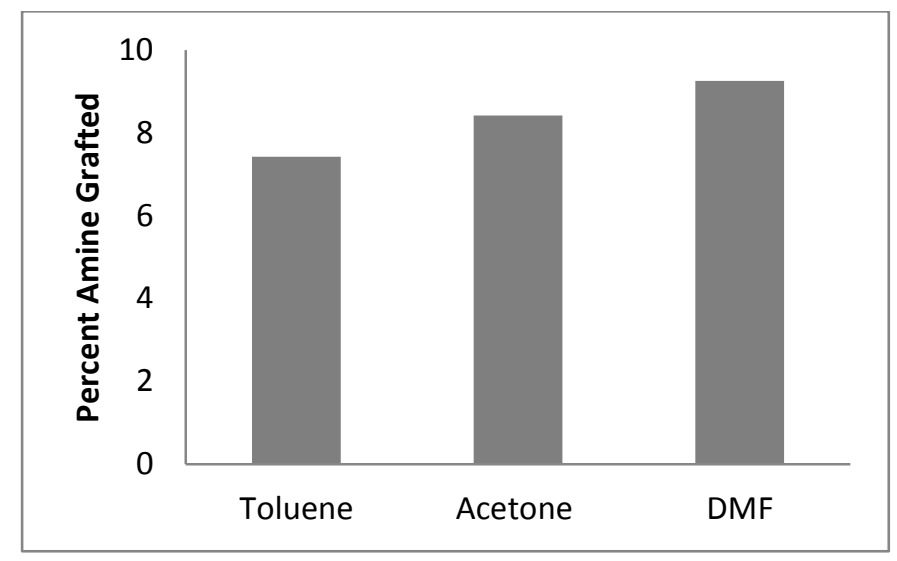

Figure 4-4: Average amount of amine grafted using different solvents "dry method"

Montmorillonite is easily swollen by water which separates the clay platelets and exposes more surface area of the clay for APTMS to react to the edge hydroxyl groups.

Therefore, experiments were conducted by first swelling the clay in water and then adding DMF using the procedure called the "slurry method" which is described in detail in Chapter 4. A comparison of the two methods and the amount of amine grafted to them are shown in Figure 4-5 with two different concentrations of APTMS used. The error bars in Figure 4-5 represent the standard deviation of the repeated runs, for the dry method using a concentration of $0.4 \mathrm{~g}$ APTMS/g clay the standard deviation is 0.1 and is difficult to see in the figure. The data that is shown in Figure 4-5 indicates that on average the slurry method did increase the amount of 
amine grafted onto the sample. Therefore the remaining samples created were produced using the slurry method.

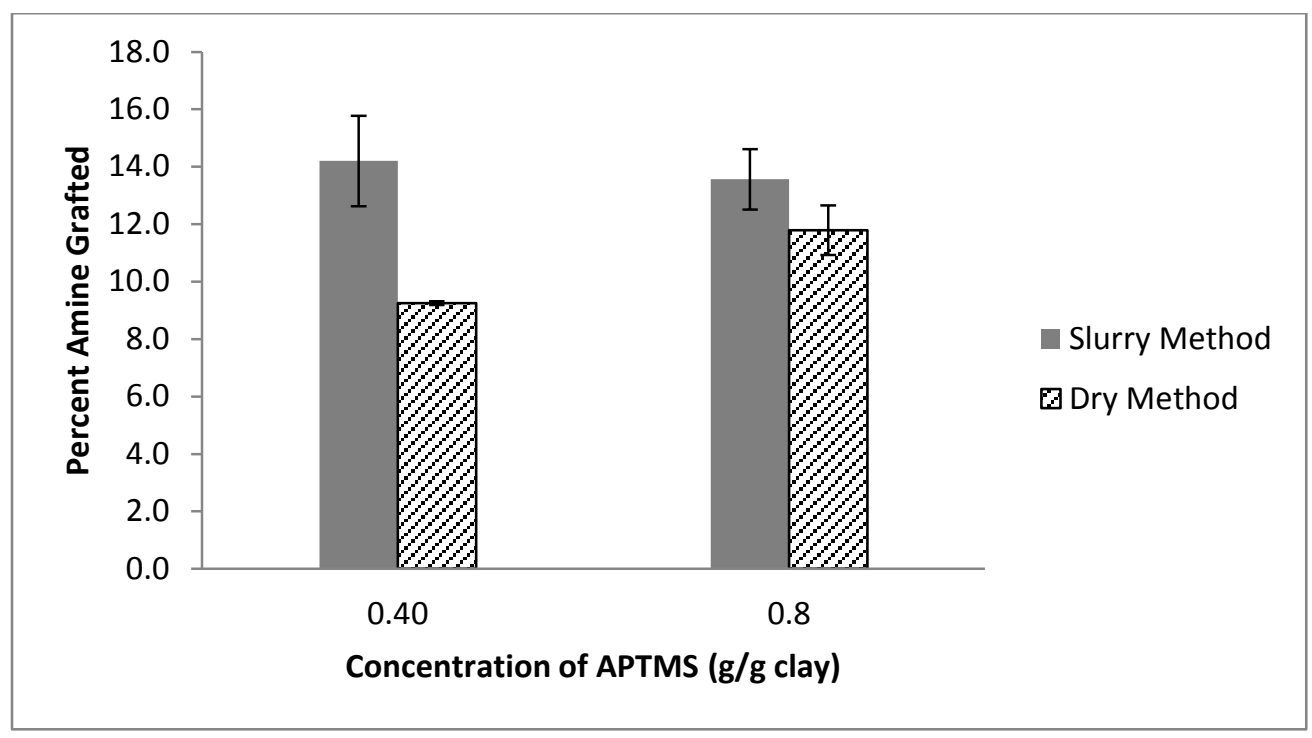

Figure 4-5: Comparison of the dry method versus the slurry method using DMF

The next study was on the concentration of APTMS added compared to the amount of amine that is attached to the clay. Again the slurry method was used since the slurry method showed a greater amount of amine grafted onto the sample. Figure 4-6 shows the effect of the concentration of APTMS on the amount of APTMS grafted to the sample. 


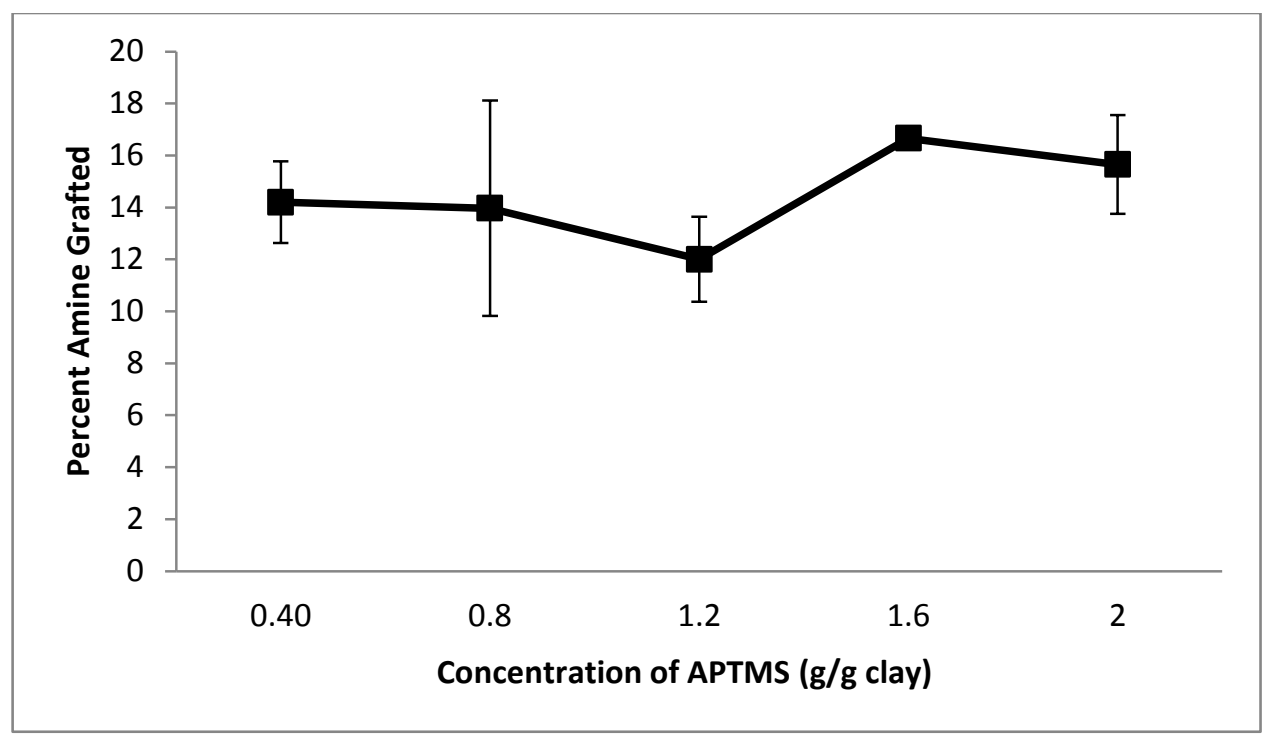

Figure 4-6: Percent amine grafted versus the concentration of APTMS “slurry method"

As the concentration of APTMS is increased, there is no significant change in the amount of amine grafted over the concentrations tested. This would indicate that the concentration of APTMS used is not the limiting step in the amount of APTMS reacted to the clay. In order to ensure that the concentration of APTMS was not the limiting step in the reaction, the highest concentration of $2 \mathrm{~g}$ APTMS/g clay was used for all of the future tests. Samples treated with this concentration of APTMS are labeled C-APTMS-1-2 indicating the ratio of clay to APTMS used in the grafting procedure.

Cloisite ${ }^{\circledR} \mathrm{Na}^{+}$treated with PEI was also studied using the TGA for the amount of amine immobilized. A representative TGA graph for a sample treated with $50 \% \mathrm{PEI}$ is shown in the Figure 4-7. In Figure 4-7 it can be seen that there are a few different weight loss steps. 


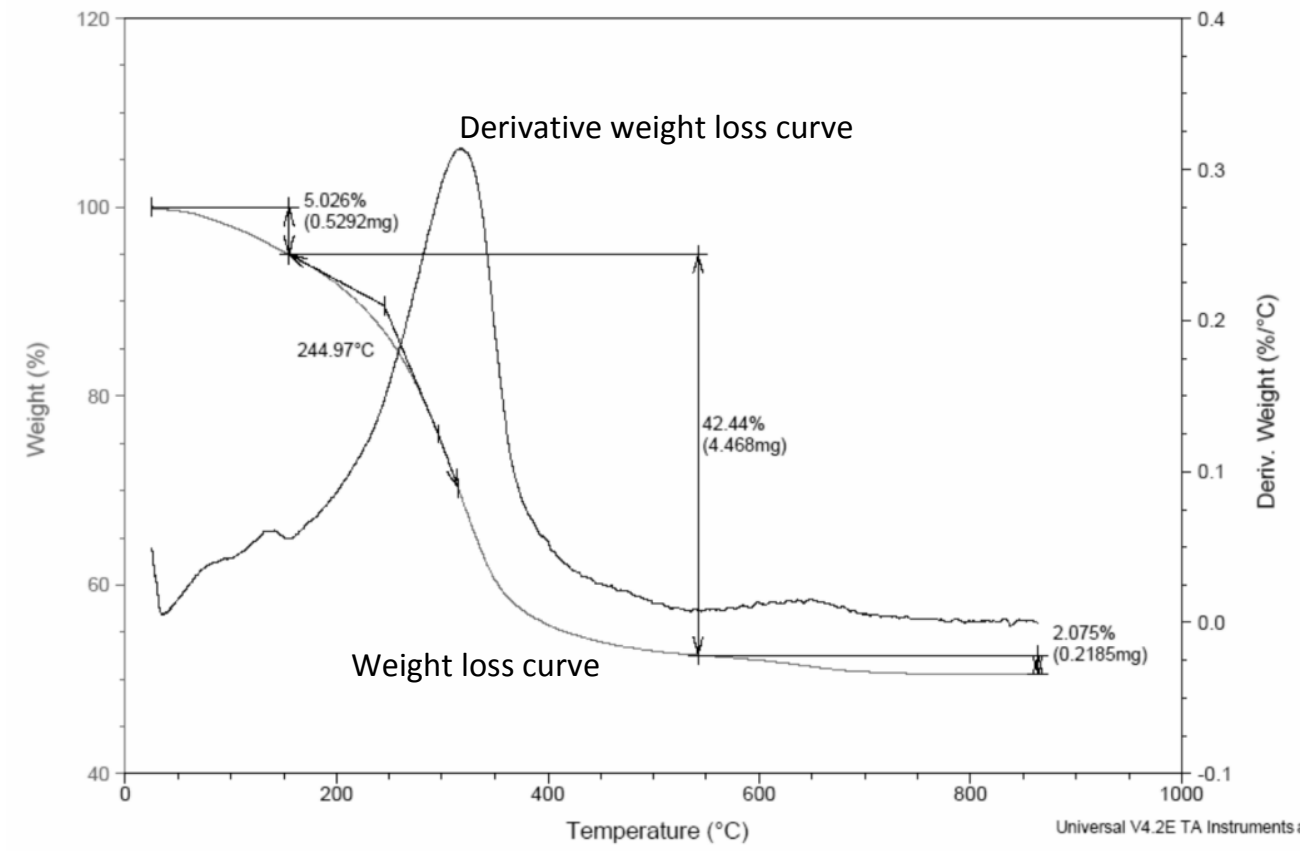

Figure 4-7: TGA graph of Cloisite ${ }^{\circledR} \mathrm{Na}^{+}$treated with $50 \%$ PEI

The initial weight loss step is contributed by the loss of water and is measured at the point where the derivative weight loss is at a minimum around $160^{\circ} \mathrm{C}$. The next weight loss step is clearly seen and is attributed to the loss of PEI from the clay surface. The final weight loss step is contributed by the degradation of the clay which is seen around $600^{\circ} \mathrm{C}$ for the untreated clay samples as well. The amount of amine attached is calculated by taking into account the weight loss after the removal of water and subtracting the average weight loss seen due to the degradation of the untreated clay. The average weight loss attributed to the amount of amine attached to the samples loaded with $50 \%$ PEI using this calculation was $37.4 \pm 1.5$ percent.

Samples were also treated with both APTMS and PEI. The samples were first treated with APTMS using the slurry method and then loaded with $50 \%$ PEI using the same wet impregnation method described in the experimental sections. The same TGA procedures and calculations were used to determine the amount of amine loaded onto the clay. Figure 4-8 
shows the amount of amine grafted for each treatment used. In Figure 4-8 it can be seen that there is only a slight increase in the amount of amine measured on the clay for samples treated with both APTMS and PEI. This was not necessarily expected, but one reason for this is that the APTMS prevents the PEI from attaching to the ends of the clay platelets.

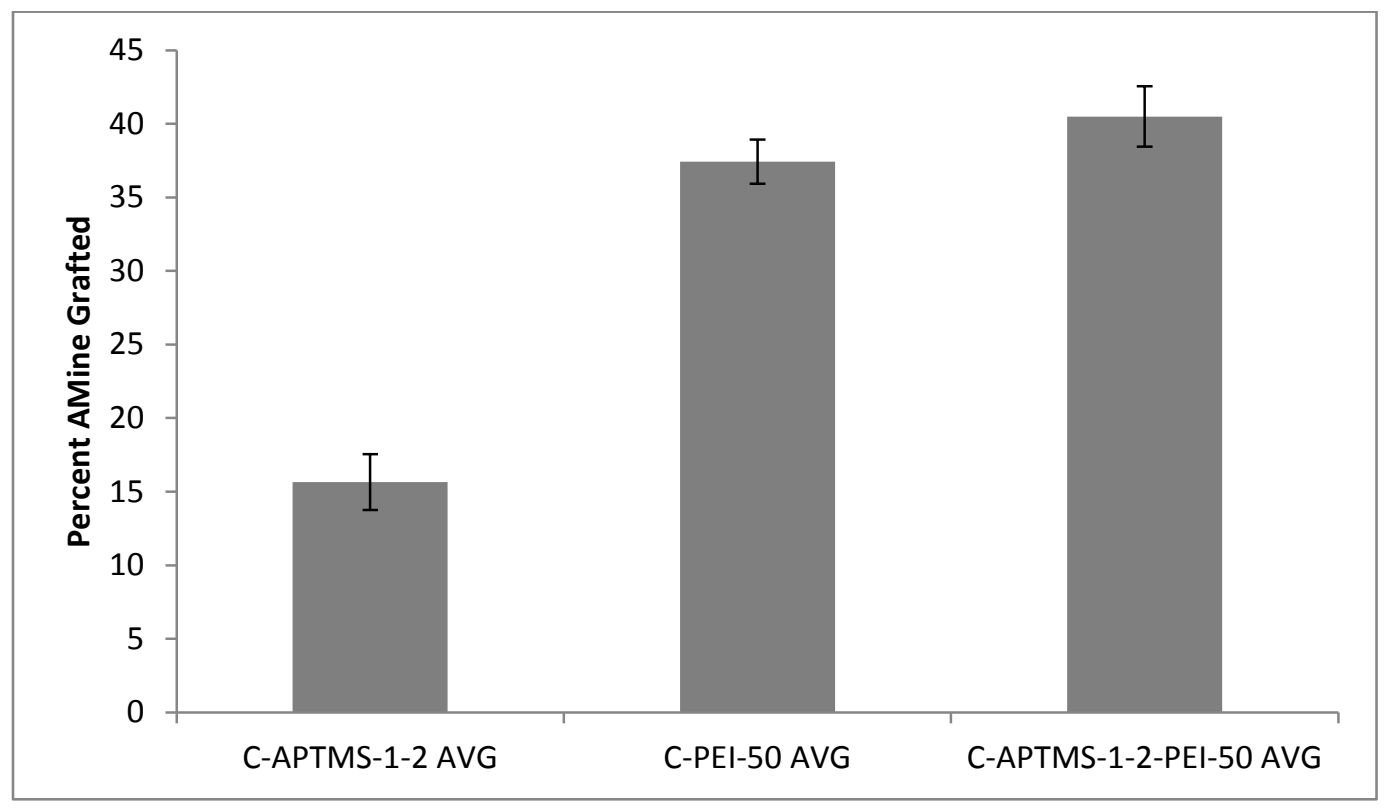

Figure 4-8: Comparison of the amount of amine grafted versus treatment

Additionally the amount of PEI loaded was measured using the weight of the APTMS treated sample and not the theoretical weight of the clay in the treated sample. Using the amount of amine grafted onto the samples treated with only APTMS and only PEI the theoretical amount of amine loaded onto the samples treated with both APTMS and PEI can be calculated based on Equation 4-1.

$$
C_{o} P_{A}+\left(C_{o}-C_{o} P_{A}\right) P_{p}=C_{A+P}
$$

In Equation 4-1 $P_{A}$ is the weight percent of APTMS grafted onto untreated clay (15.7\%), $C_{o}$ is the weight of the untreated clay, $P_{p}$ is the weight percentage of PEl grafted onto untreated 
clay (37.4\%), and $C_{A+P}$ is the weight of amine grafted onto the clay for the combination of APTMS and PEI. Using Equation 4-1 and assuming 1 gram for $C_{o}$ the theoretical weight of amine loaded onto the samples treated with both APTMS and PEI is 0.47 grams or 47 weight percent. However, the amount measured using the TGA is $40.5 \pm 2.05$ weight percent. The difference in the theoretical percentage of the amount of amine attached to the sample and the actual amount measured using the TGA is the result of APTMS blocking some of the surface of the clay for the PEI to attach. Additionally, the treated clay may not disperse as well in methanol as the untreated clay resulting in less area for the PEI to attach to the clay. The ability of the treated clay to disperse into the methanol and PEI solution is a concern based on the consistency of the samples. Some of the APTMS treated samples did not seem to mix as well with the PEI based on visual observations of the samples.

\subsection{FTIR Analysis}

Fourier transform infrared spectroscopy (FTIR) was used to determine if any amine was attached to the clay support. A Thermo Scientific Nicolet iS10 FTIR with the Attenuated Total Reflectance (ATR) attachment was used using a resolution of $1 \mathrm{~cm}^{-1}$ and 40 scans per sample. The untreated Cloisite ${ }^{\circledR} \mathrm{Na}^{+}$was first characterized to determine the peaks of the untreated clay. The untreated clay spectrum was then compared with a sample of Cloisite ${ }^{\circledR} \mathrm{Na}^{+}$treated with APTMS, with PEI, and with APTMS and PEI. Figure 4-9 is a spectrum of Cloisite ${ }^{\circledR} \mathrm{Na}^{+}$ 


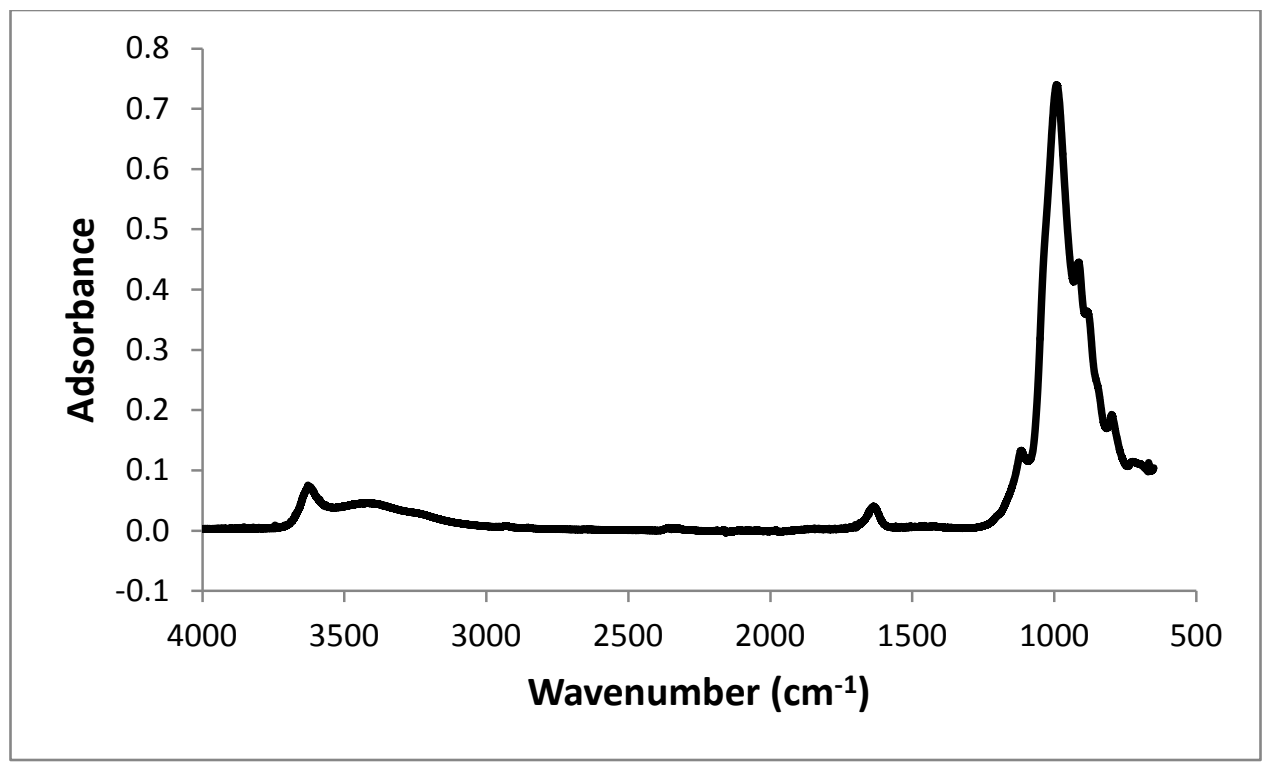

Figure 4-9: FTIR spectrum of Cloisite ${ }^{\circledR} \mathrm{Na}^{+}$

This spectrum was taken at room temperature and compares well with spectra of Cloisite ${ }^{\circledR} \mathrm{Na}^{+}$seen in the literature. ${ }^{[69]}$ Figure 4-10 shows spectra of Cloisite ${ }^{\circledR} \mathrm{Na}^{+}$seen in the literature taken at different temperatures.

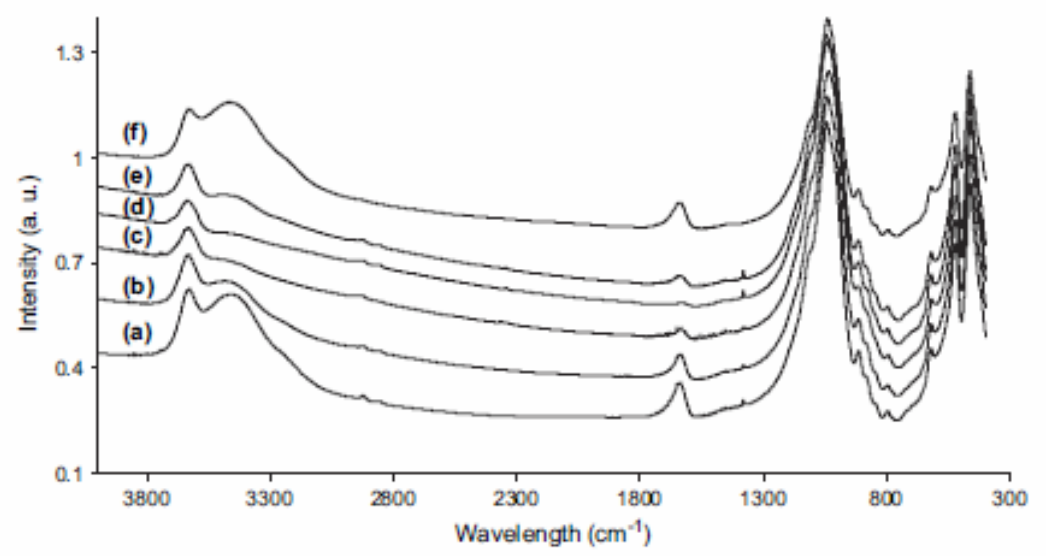

Figure 4-10: FTIR spectra of Cloisite $\mathrm{Na}^{\circledR}$ : (a) spectrum of the initial sample at room temperature, (b) spectrum of the sample at $100^{\circ} \mathrm{C}$, (c) spectrum of the sample at $200^{\circ} \mathrm{C}$, (d) spectrum of the sample at room temperature immediately after cooling, (e) spectrum of the sample at room temperature after $70 \mathrm{~h}$, and (f) spectrum of the sample at room temperature after thermal treatment at $250^{\circ} \mathrm{C}$ for $4 \mathrm{~h} .{ }^{[69]}$ 
The Large peak at $985 \mathrm{~cm}^{-1}$ indicates a Si-O in plane stretching which is similar to results in the literature. The broad peak around $3440 \mathrm{~cm}^{-1}$ that is not seen with much intensity in our spectrum is associated with $\mathrm{O}-\mathrm{H}$ stretching from water that is not bound, but adsorbed on the surface. ${ }^{[69],[70]}$ This would indicate that the clay was dry during the test. The peak around 1659 $\mathrm{cm}^{-1}$ is also associated with $\mathrm{O}-\mathrm{H}$ stretching in water. ${ }^{[69]}$ The peak around $3630 \mathrm{~cm}^{-1}$ is assigned to an asymmetric $\mathrm{H}_{2} \mathrm{O}$ stretching for bound water in the clay. ${ }^{[70]}$ When the untreated clay was heated to $900^{\circ} \mathrm{C}$ there were two weight steps observed. One weight loss step was attributed to the loss of adsorbed water. The weight loss step at high temperatures was attributed to some other degradation to the clay. Figure 4-11 shows the FTIR comparison between untreated clay and untreated clay heated to $900^{\circ} \mathrm{C}$ in nitrogen.

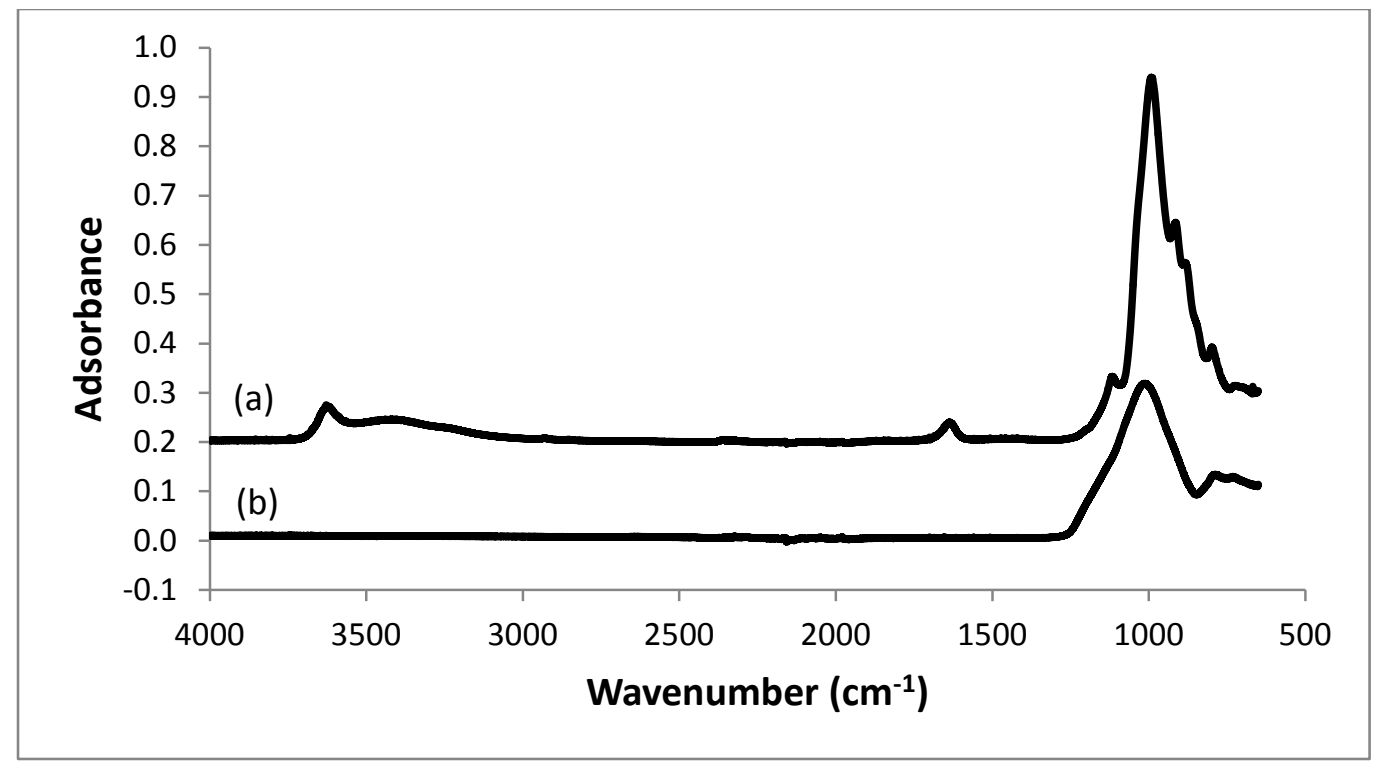

Figure 4-11: FTIR spectrum: (a) untreated clay, (b) untreated clay heated to $900^{\circ} \mathrm{C}$ in $\mathrm{N}_{2}$ In Figure 4-11 it can be clearly seen that the peaks attributed to adsorbed water and bound water are removed when the untreated clay is heated to $900^{\circ} \mathrm{C}$. The only peak that remains for the untreated clay that was heated to $900^{\circ} \mathrm{C}$ is the one attributed to Si-O stretching. 
This is expected since any organic impurities or bound water is expected to be removed at such a high temperature. Comparisons using FTIR untreated clay and the amine treated clay were also conducted. Figure 4-12 is a spectrum of clay treated with APTMS.

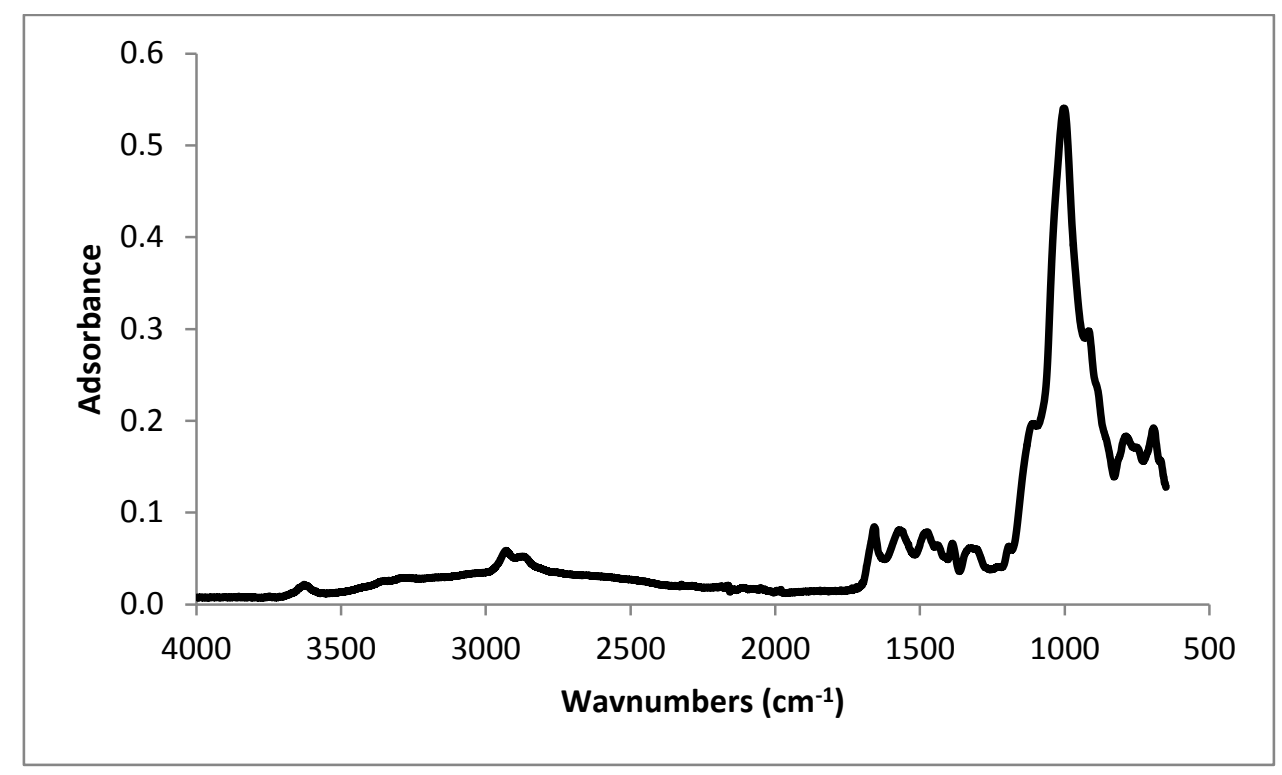

\section{Figure 4-12: FTIR spectrum of Cloisite ${ }^{\circledast} \mathrm{Na}^{+}$treated with APTMS}

Figure 4-12 shows that the $\mathrm{O}-\mathrm{H}$ peak at $3630 \mathrm{~cm}^{-1}$ is still seen, and is the contribution of the bound water in the clay. The peaks around $2870 \mathrm{~cm}^{-1}$ and 2930 represent $\mathrm{C}-\mathrm{H}$ asymmetric and symmetric vibration of the methylene groups on APTMS. ${ }^{[47],[65],[71]}$ The broad peak at 3300 $\mathrm{cm}^{-1}$ is observed with $\mathrm{N}-\mathrm{H}$ stretching from the amine in APTMS. ${ }^{[50]}$ To compare the treatments of APTMS and PEl a spectrum of Cloisite ${ }^{\circledR} \mathrm{Na}^{+}$treated with PEl is shown in Figure 4-13. Additionally, a spectrum of clay treated with the combination of APTMS and PEI are shown in Figure 4-14. 


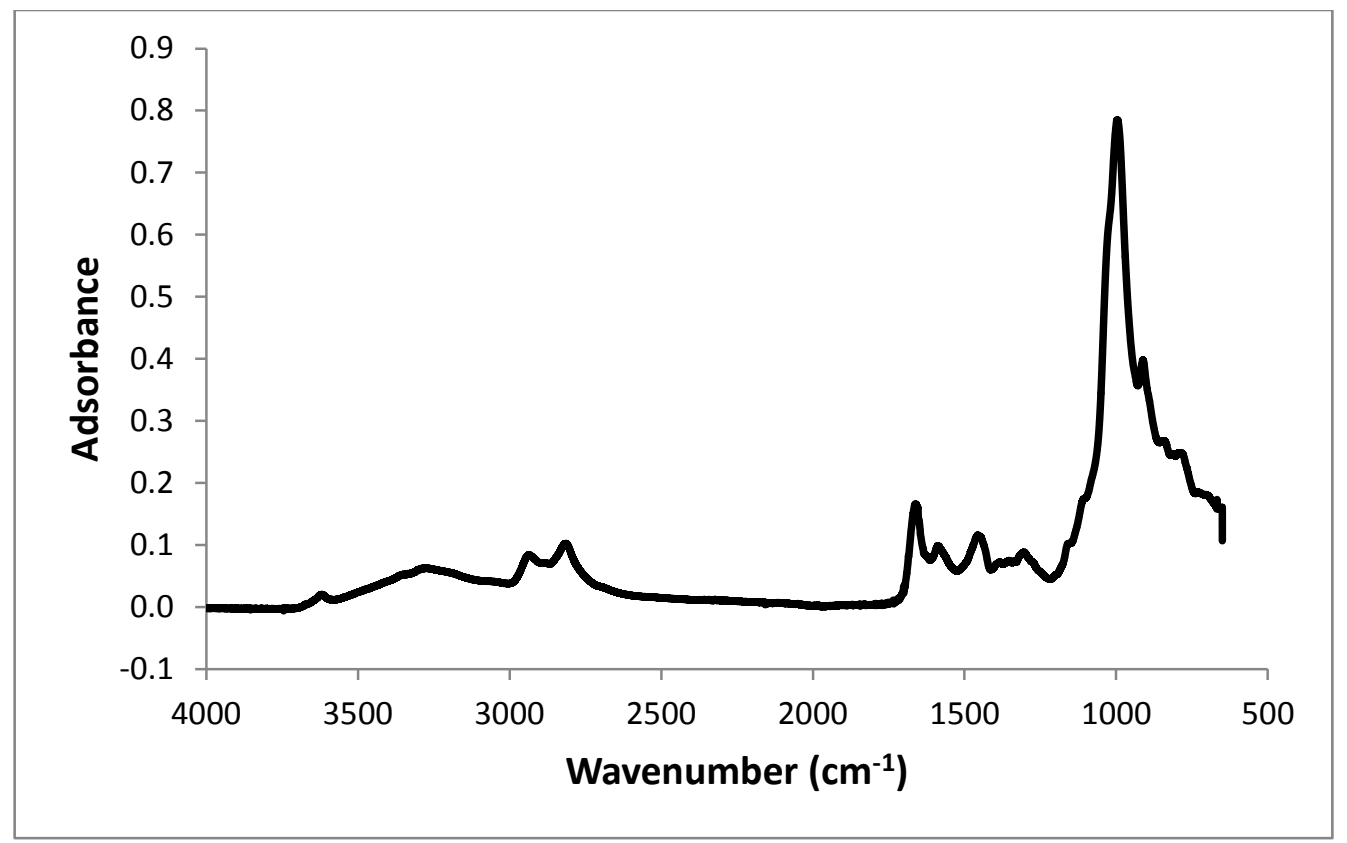

Figure 4-13: FTIR spectrum of Cloisite ${ }^{\circledR} \mathrm{Na}^{+}$loaded with $50 \%$ PEI

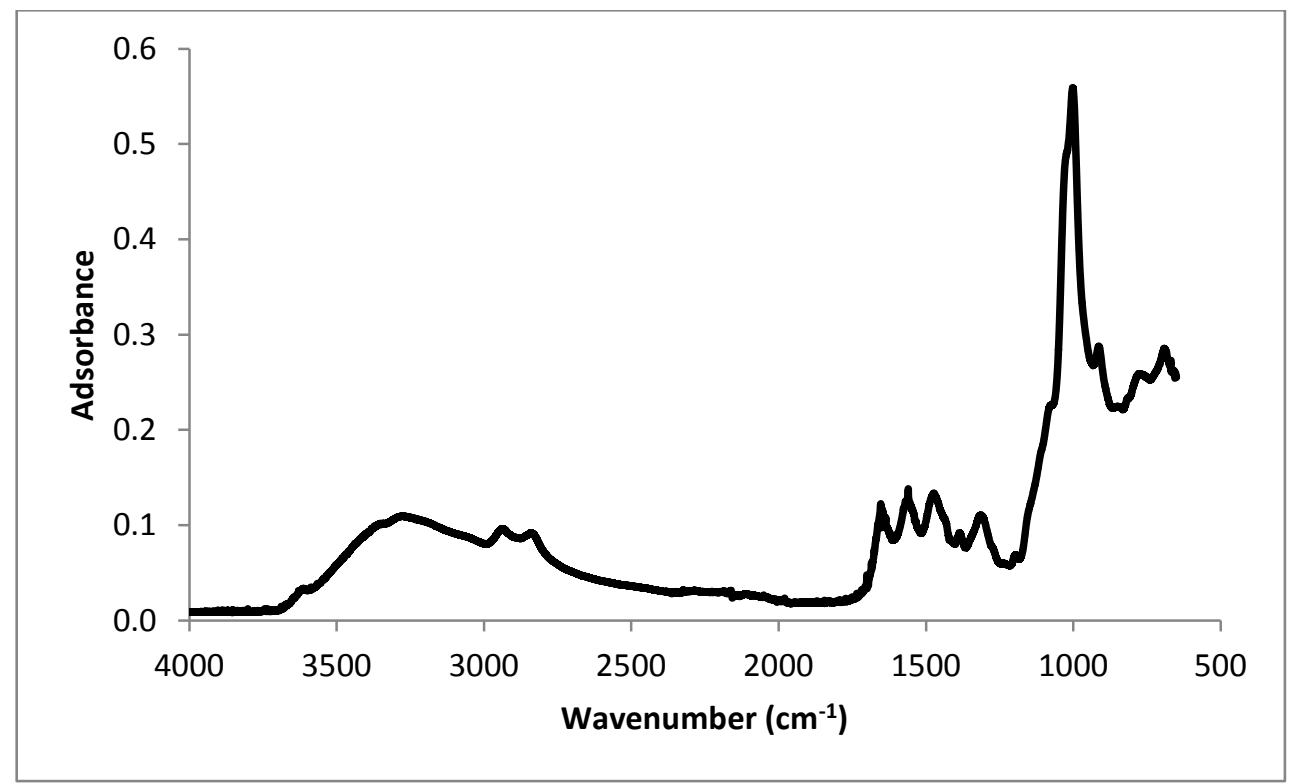

Figure 4-14: FTIR spectrum of Cloisite ${ }^{\circledR} \mathrm{Na}^{+}$treated with APTMS and PEI

In Figures 4-13 and 4-14 the $3275 \mathrm{~cm}^{-1}$ (Broad Peak) is attributed to symmetric $\mathrm{NH}_{2}$ stretching. ${ }^{[50]}$ It can be seen that the samples treated with PEI have a much more intense peak around $3275 \mathrm{~cm}^{-1}$, and this indicates that there are more $\mathrm{NH}$ bonds due to the presence of more 
amine groups. The $2940,2812 \mathrm{~cm}^{-1}$ peak is also more intense with the PEI treated samples indicating that there is more $\mathrm{CH}$ stretching due to the increase in loading of PEI. The peak at $1590 \mathrm{~cm}^{-1}$ for samples treated with only PEI is contributed to $\mathrm{NH}$ scissoring vibration similar to

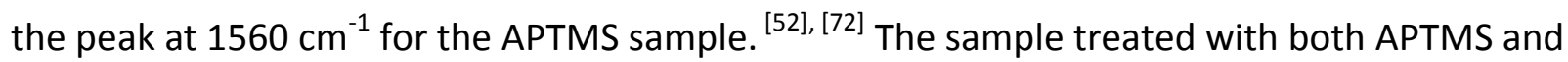
PEI had a more intense peak around $1560 \mathrm{~cm}^{-1}$, and this is attributed to $\mathrm{NH}$ scissoring vibration overlap of APTMS and PEI. ${ }^{[72]}$ The peaks in the $1400 \mathrm{~cm}^{-1}$ region are attributed to $\mathrm{CH}_{3}$ and $\mathrm{CH}_{2}$ deformation. ${ }^{[71]}$ Figure 4-15 is a comparison of the amine treatments compared to the untreated clay.

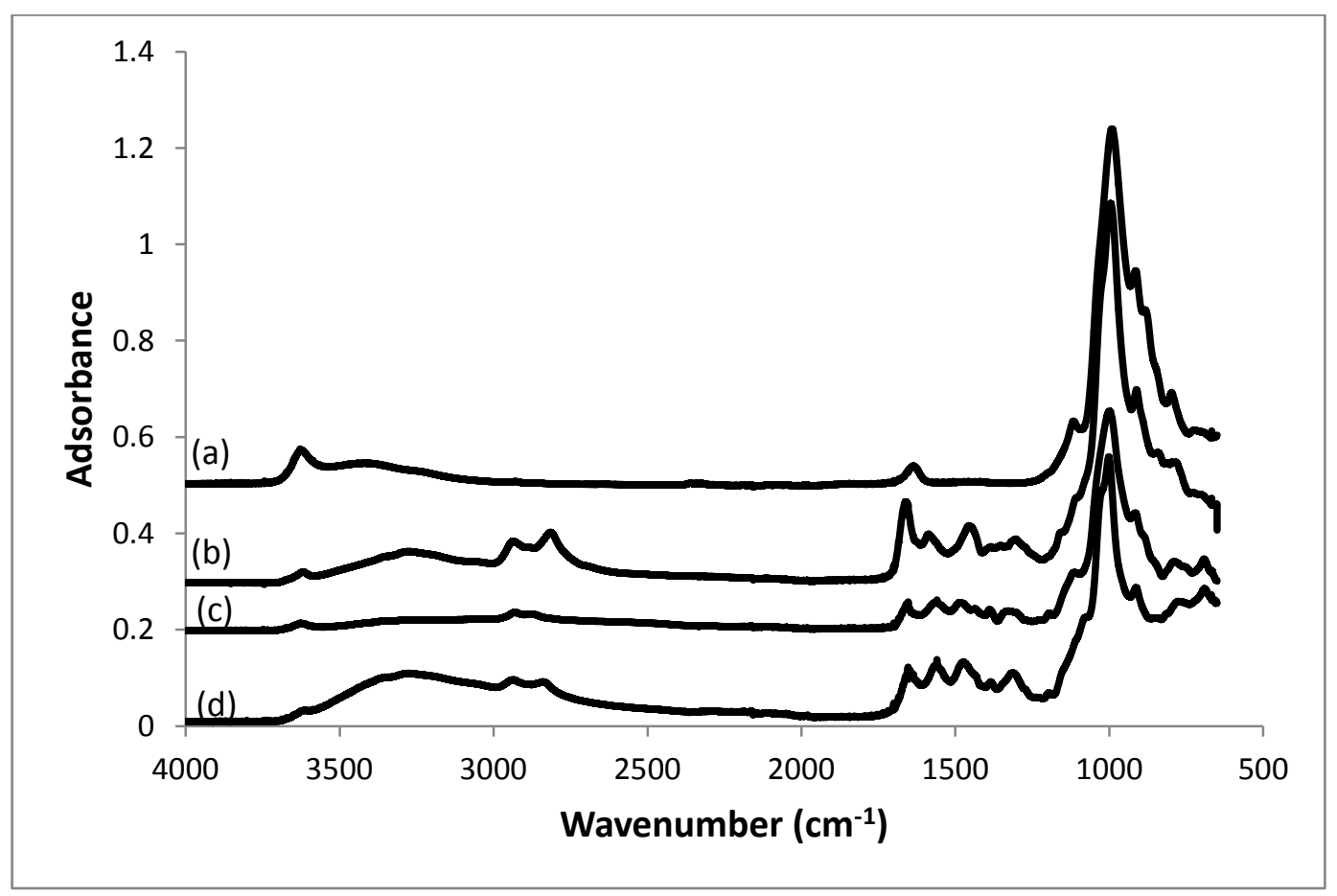

Figure 4-15: FTIR Spectra comparing the differences in amine treatments: (a) untreated clay, (b) clay treated with PEI, (c) clay treated with APTMS, (d) clay treated with APTMS+PEI

From Figure 4-15, it can be easily seen that there are amine and carbon chain vibrations associated with APTMS and PEI attached to the clay. Additionally it is evident that the clay 
treated with both APTMS and PEI has all of the representative peaks of each treatment. This indicates that PEI and APTMS were both attached to the clay.

FTIR spectra were taken of treated samples that had been reacted with $\mathrm{CO}_{2}$ to see if the formation of carbamates could be seen using this method of FTIR. Other researchers have used diffuse reflectance infrared spectroscopy (DRIFTS) to study the adsorption of $\mathrm{CO}_{2}$ on their amine treated supports in real time. ${ }^{[71],[72],[73]}$ One advantage of taking a spectrum while exposing a sample to $\mathrm{CO}_{2}$ is that a spectrum can be taken of the exact same sample immediately before exposure to $\mathrm{CO}_{2}$. This enables one to subtract the spectra to find very minute differences in the spectra of the same sample reacted with $\mathrm{CO}_{2}$. Figure $4-16$ is a comparison of Cloisite ${ }^{\circledR} \mathrm{Na}^{+}$, Cloisite ${ }^{\circledR} \mathrm{Na}^{+}$treated with APTMS and Cloisite ${ }^{\circledR} \mathrm{Na}^{+}$treated with APTMS and reacted with $\mathrm{CO}_{2}$ in the TGA at $85^{\circ} \mathrm{C}$. The sample that was reacted with $\mathrm{CO}_{2}$ was stored in a sample bottle at room temperature until FTIR was conducted. This experiment was studied to see if there was any difference in the sample exposed to $\mathrm{CO}_{2}$ compared to the sample not exposed to $\mathrm{CO}_{2}$. 


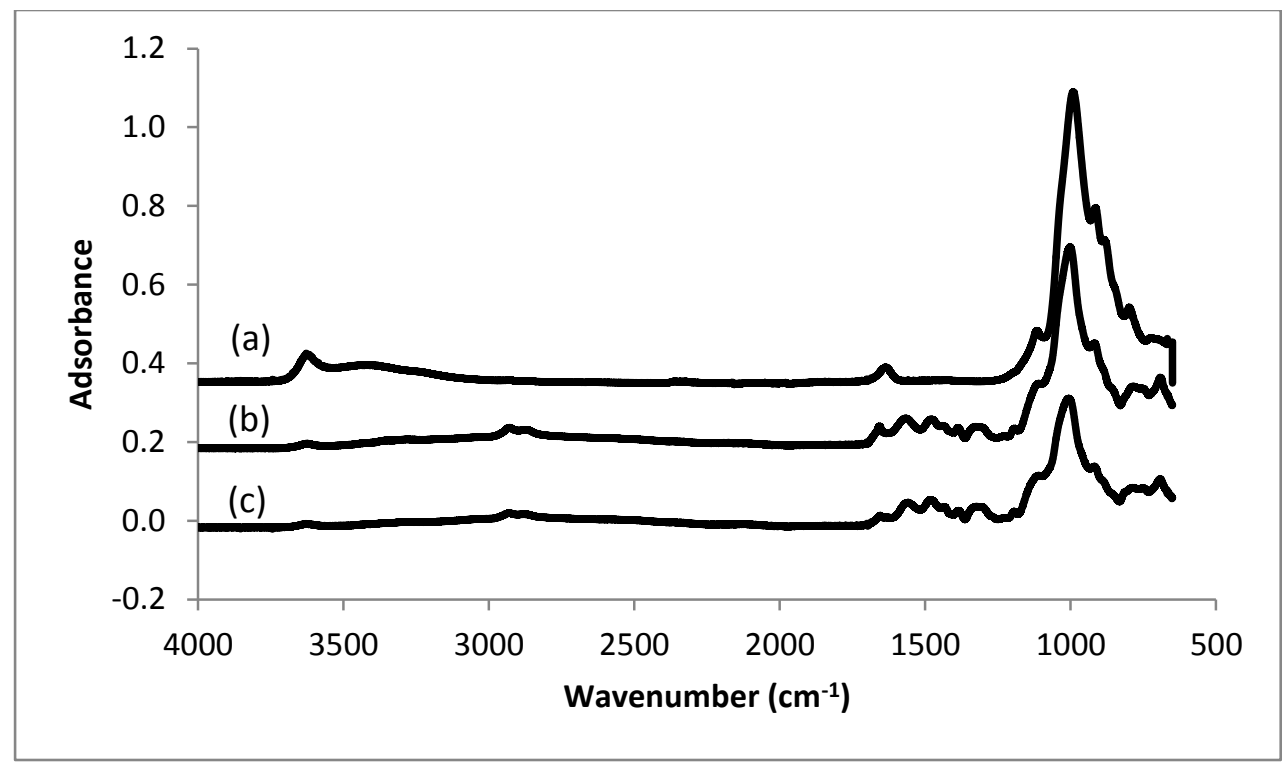

Figure 4-16: FTIR Spectra: (a) untreated clay, (b) clay treated with APTMS and, (c) clay treated with APTMS after $\mathrm{CO}_{2}$ adsorption in TGA at $85^{\circ} \mathrm{C}$ in pure $\mathrm{CO}_{2}$

The spectra in Figure 4-16 are consistent with the previous spectrum taken in Figures 49 and 4-12. The treated clay and the treated clay exposed to the $\mathrm{CO}_{2}$ are very similar indicating that either the reacted $\mathrm{CO}_{2}$ is no longer attached to the amine or the reaction product of $\mathrm{CO}_{2}$ with the amine is difficult to see using this method. Figure 4-17 is a magnified spectrum of Figure 4-16 from $1800 \mathrm{~cm}^{-1}$ to $800 \mathrm{~cm}^{-1}$ to better see the similarities in the spectra. 


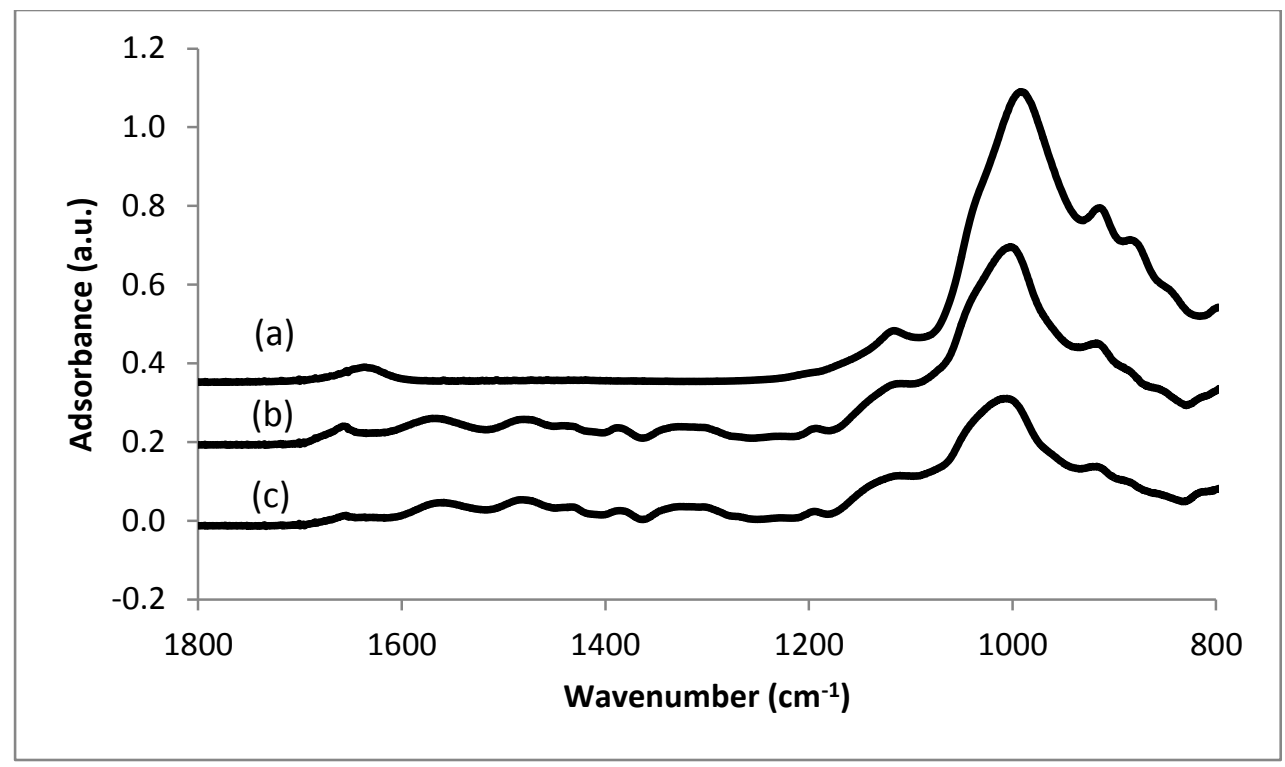

Figure 4-17: FTIR Spectra from $1800 \mathrm{~cm}^{-1}-800 \mathrm{~cm}^{-1}$ : (a) untreated clay, (b) clay treated with APTMS, and (c) clay treated with APTMS after $\mathrm{CO}_{2}$ adsorption in TGA at $85^{\circ} \mathrm{C}$ in pure $\mathrm{CO}_{2}$

In Figure 4-17 there are slight shifts in peaks from $1660-1300 \mathrm{~cm}^{-1}$ which might be due to reacted $\mathrm{CO}_{2}$, but the shifts are slight and might be due to other factors since the sample had to be moved from the TGA where the sample was reacted with $\mathrm{CO}_{2}$ to a different building were the FTIR tests was conducted. Similar observations were made with $\mathrm{CO}_{2}$ reacted PEI samples.

FTIR tests concluded that there is a clear difference between the amine treated samples and the untreated clay. This is contributed to the peaks associated with the amines attached to the clay. FTIR experiments were conducted to try to see the difference between samples exposed to $\mathrm{CO}_{2}$, but the differences in the spectra were slight and could not be conclusively attributed to reacted $\mathrm{CO}_{2}$.

\subsection{Surface Area Results}

If montmorillonite clay could be separated into individual sheets the surface area is expected to be $750 \mathrm{~m}^{2} / \mathrm{g}$. This is according to the material data supplied by the Southern Clay 
Products for Cloisite ${ }^{\circledast} \mathrm{Na}^{+}$. To determine the surface area of unmodified Cloisite ${ }^{\circledast} \mathrm{Na}^{+}$, a ASAP 2020 surface analysis machine was used to determine the BET surface area. A sample of fumed silica with a surface area of $250+/-30 \mathrm{~m}^{2} / \mathrm{g}$ was tested in the BET ASAP 2020 surface analysis machine to determine the accuracy of the method. First, a sample was placed into the sample tube with an auxiliary sample rod also placed into the tube. A vacuum was placed onto the tube and the sample was heated to $120^{\circ} \mathrm{C}$ to remove any moisture in the sample. The vacuum was held for at least 30 minutes or until 100 mtorr was observed on the vacuum gauge. Once this was achieved, the vacuum was turned off and nitrogen was allowed to flow into the sample tube. The lid was then quickly placed onto the sample tube and the sample was connected to the surface analysis machine.

Two consecutive runs were conducted using the same sample without removing the sample from the machine to test the repeatability of the results. The results were 218.9879 $\mathrm{m}^{2} / \mathrm{g}+/-1.9554 \mathrm{~m}^{2} / \mathrm{g}$ and $222.9788 \mathrm{~m}^{2} / \mathrm{g}+/-2.7113 \mathrm{~m}^{2} / \mathrm{g}$, which when averaged fit between the parameters of the surface area reported for the fumed silica. A standard was run before these tests were conducted and the results were satisfactory. This result led us to believe that the numbers obtained from this machine were accurate. The BET surface area results are reported in Table 4-1.

Table 4-1: BET surface area results using ASAP 2020

\begin{tabular}{|l|c|c|c|c|c|}
\hline & $\begin{array}{c}\text { Untreated } \\
\text { Clay }\end{array}$ & C-APTMS-1-2 & C-PEI-50 & C-APTMS-PEI-50 & $\begin{array}{c}\text { Fumed Silica (250 } \\
\left.\mathrm{m}^{2} / \mathrm{g}+/-30 \mathrm{~m}^{2} / \mathrm{g}\right)\end{array}$ \\
\hline $\begin{array}{l}\text { BET Surface } \\
\text { Area } \mathrm{m}^{2} / \mathrm{g}\end{array}$ & 11.66 & 7.26 & 0.10 & 0.35 & 220.98 \\
\hline error $+/-$ & 0.17 & 0.10 & 0.02 & 0.02 & 2.33 \\
\hline
\end{tabular}


The results showed that the untreated Cloisite ${ }^{\circledR} \mathrm{Na}^{+}$had the highest surface area, followed by Cloisite ${ }^{\circledR} \mathrm{Na}^{+}$treated with APTMS, Cloisite ${ }^{\circledR} \mathrm{Na}^{+}$treated with APTMS and PEI, and Cloisite ${ }^{\circledR} \mathrm{Na}^{+}$treated with PEl. The reduction in the surface area when the clay is treated with PEI is expected since the PEI coats the surface and seems to promote agglomeration of the particles. Also when other researchers coated their molecular baskets and other solid supports (SBA-15, MCM-41) with PEI, the surface area went down. This is also assumed to be the reason why the surface area went down with clay treated with APTMS and PEI. The reduction in surface area when the clay was treated with only APTMS is not necessarily expected since it was thought that the APTMS would react with the edge hydroxyl groups and even further separate the clay platelets, resulting in less stacking of the individual platelets and therefore more surface area. The increase in surface area was expected since the surface area for Cloisite ${ }^{\circledR} \mathrm{Na}^{+}$is reported by Southern Clay Products as being $750 \mathrm{~m}^{2} / \mathrm{g}$ when the platelets are fully exfoliated. One possible reason that the surface area did decrease is when the sample is filtered and dried it forms into a hard solid that needs to be crushed back into a powered. This is done by mortar and pestle, and the resulting powder might have to be crushed more finely to achieve a greater surface area.

\subsection{Scanning Electron Microscopy (SEM)}

SEM pictures were taken of the treated and untreated clay to determine the particle size and the general composition of the sorbents. The use of a particle size analyzer was initially attempted, but the particles had to be dispersed in a liquid medium (water). Since water swells the clay, it breaks apart the layers, and this significantly alters the clay particle size. This technique was assumed to give results not representative of the dry powder samples. 
Particle size can be determined using dry powders, but this instrument was not available for use, and since the samples treated with PEI tended to be sticky, the results from this technique would also be questionable.

The samples were placed onto a sample holder using double sided carbon tape. Multiple images were taken of all of the samples in different areas to determine that the images taken were representative of the sample. The images shown in this section were representative of the samples tested, based on all of the images that were taken.

The untreated clay was first imaged at a low magnification to determine the general particle size of the powder. In Figure 4-18 it can be seen that there are a large number of particles with various sizes throughout the image. The large aggregates are indicative of many layers of clay stacked together in large clusters. The smaller particles are not individual platelets, but just smaller stacks of platelets. Other images at this magnification were taken to make sure that this was representative of the sample. An image of the smallest and largest particle of the untreated clay was taken to get a general particle size range for the material, and to see more of the features of the sample at a higher magnification. Figure 4-19 and 4-20 are images of the smallest and largest representative particle in the sample of untreated clay. 


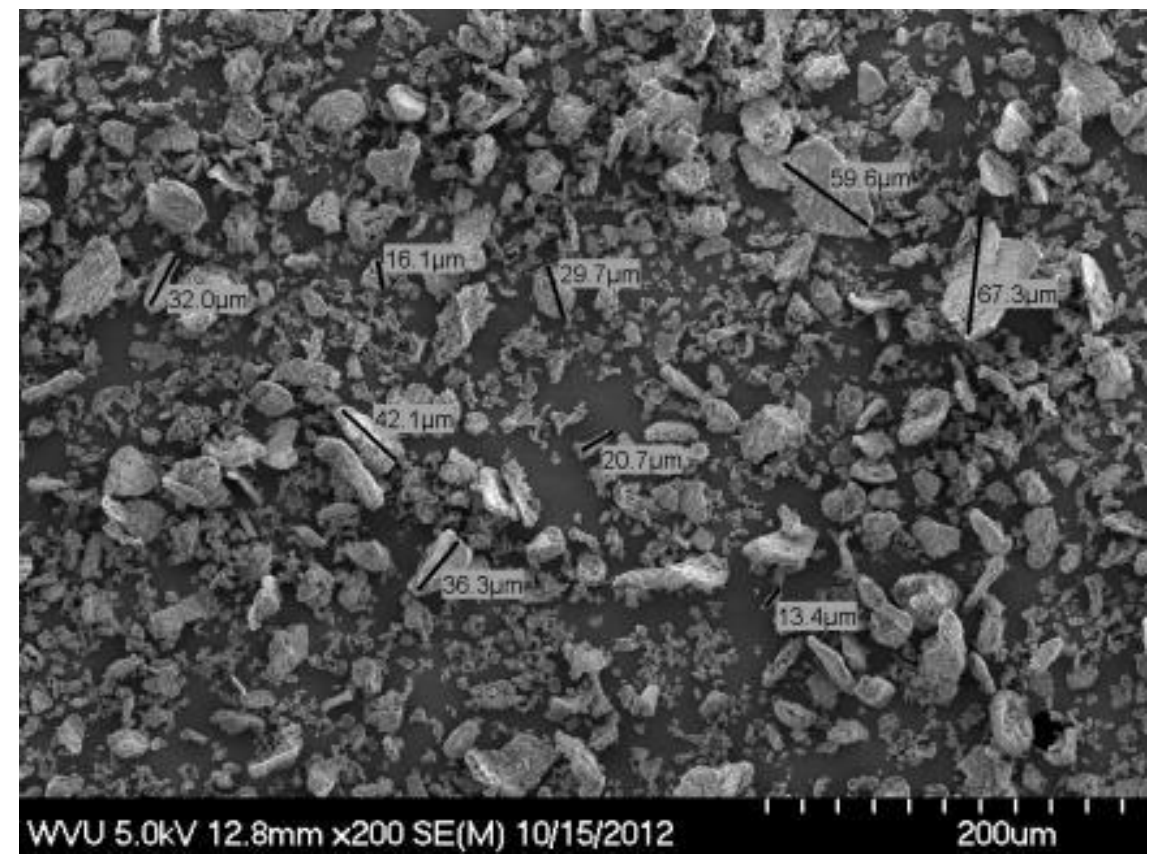

Figure 4-18: SEM image of untreated clay magnified 200 times, with a working distance of $12.8 \mathrm{~mm}$, using $5.0 \mathrm{kV}$ and both detectors

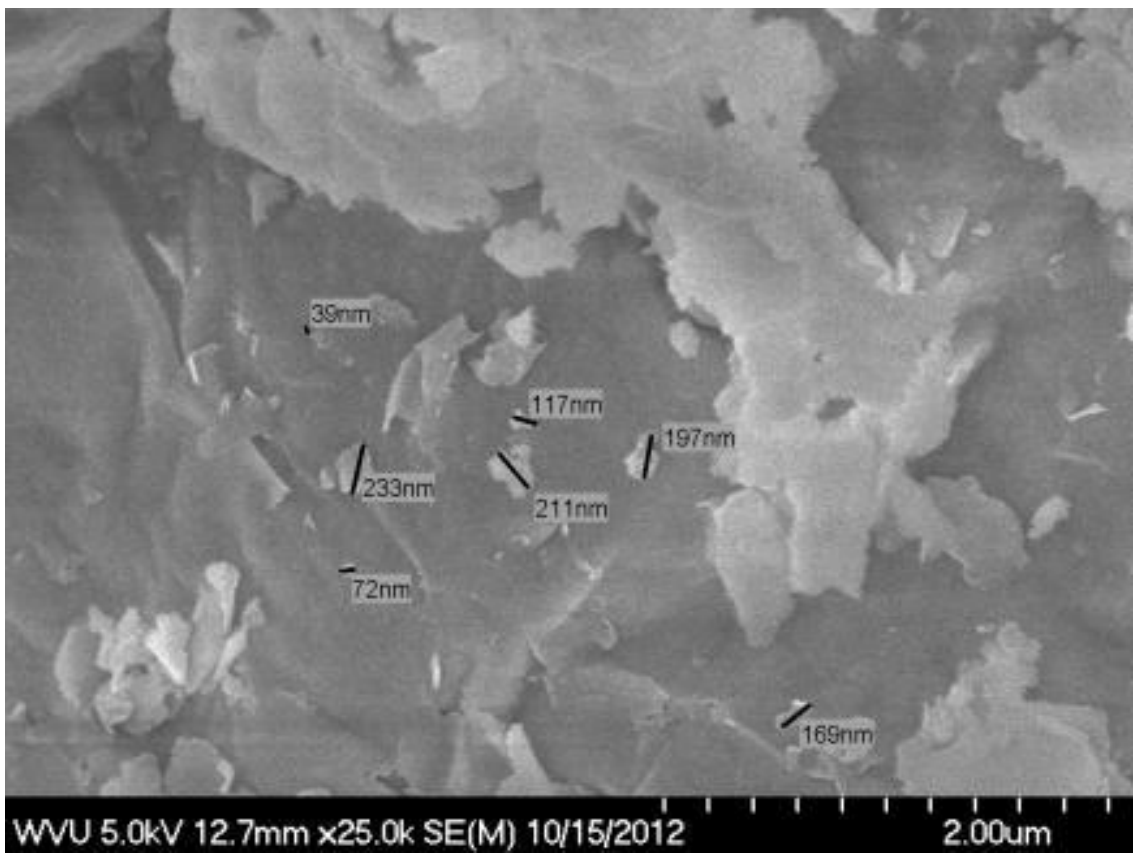

Figure 4-19: SEM image of untreated clay magnified 25,000 times, with a working distance of $12.7 \mathrm{~mm}$, using $5.0 \mathrm{kV}$ and both detectors 


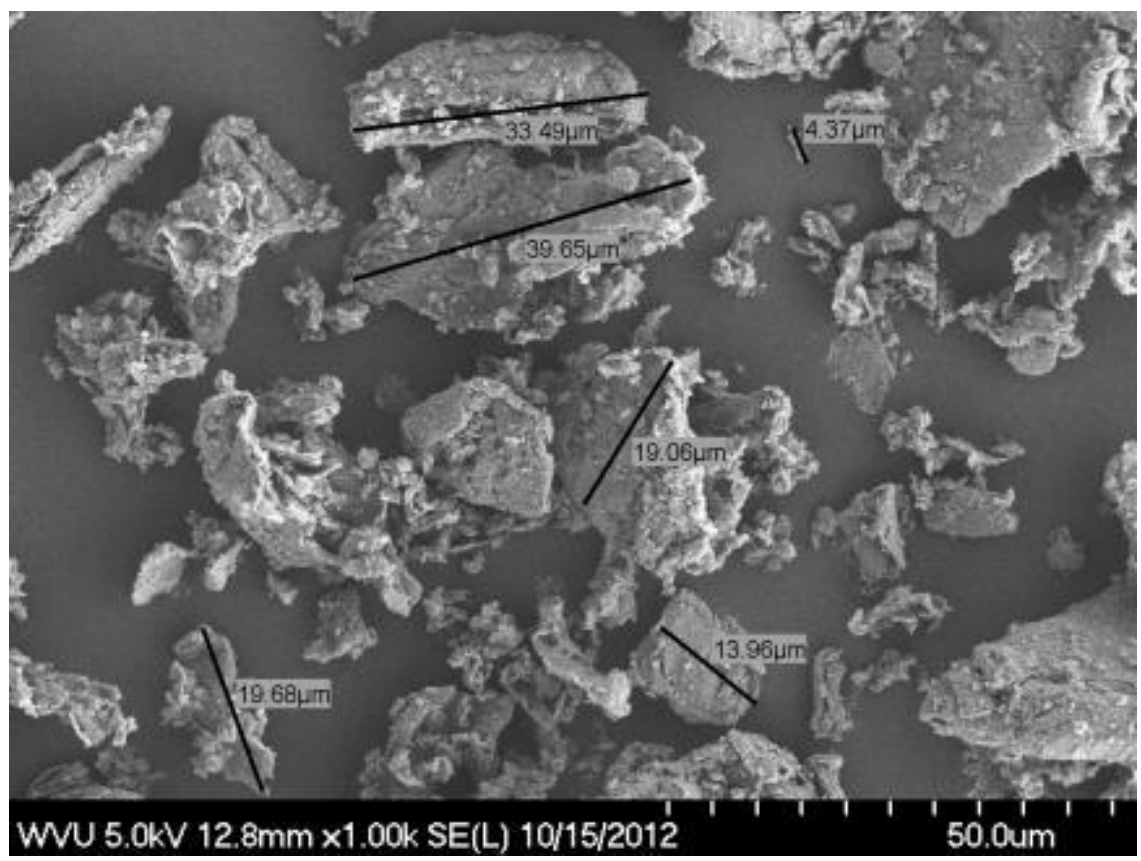

Figure 4-20: SEM image of untreated clay magnified 1,000 times, with a working distance of $12.8 \mathrm{~mm}$, using $5.0 \mathrm{kV}$ and the lower detector

From Figures 4-18-20 it can be seen that the smallest particle that can be imaged using the SEM and untreated clay is $39 \mathrm{~nm}$ and the largest particle is $67.3 \mu \mathrm{m}$. This indicates a wide size range of the untreated clay particles. The smallest particle seen of $39 \mathrm{~nm}$ is close to the expected lateral dimensions of a single clay particle. The majority of the particles are larger than this, which is expected since the clay platelets stack together to form large aggregates.

Clay treated with APTMS using the slurry method was imaged to determine the difference in the treated and untreated clay. The sample was crushed in a mortar and pestle to form a fine powder. Figure 4-21 is an image at low magnification to get a general representation of the sample. In Figure 4-21 it can be seen that there are larger particles in the clay sample treated with APTMS than with the untreated clay. Similarly to the untreated clay sample there is a wide range of particle sizes. This indicates that the clay is still stacked in large clusters of individual sheets. 


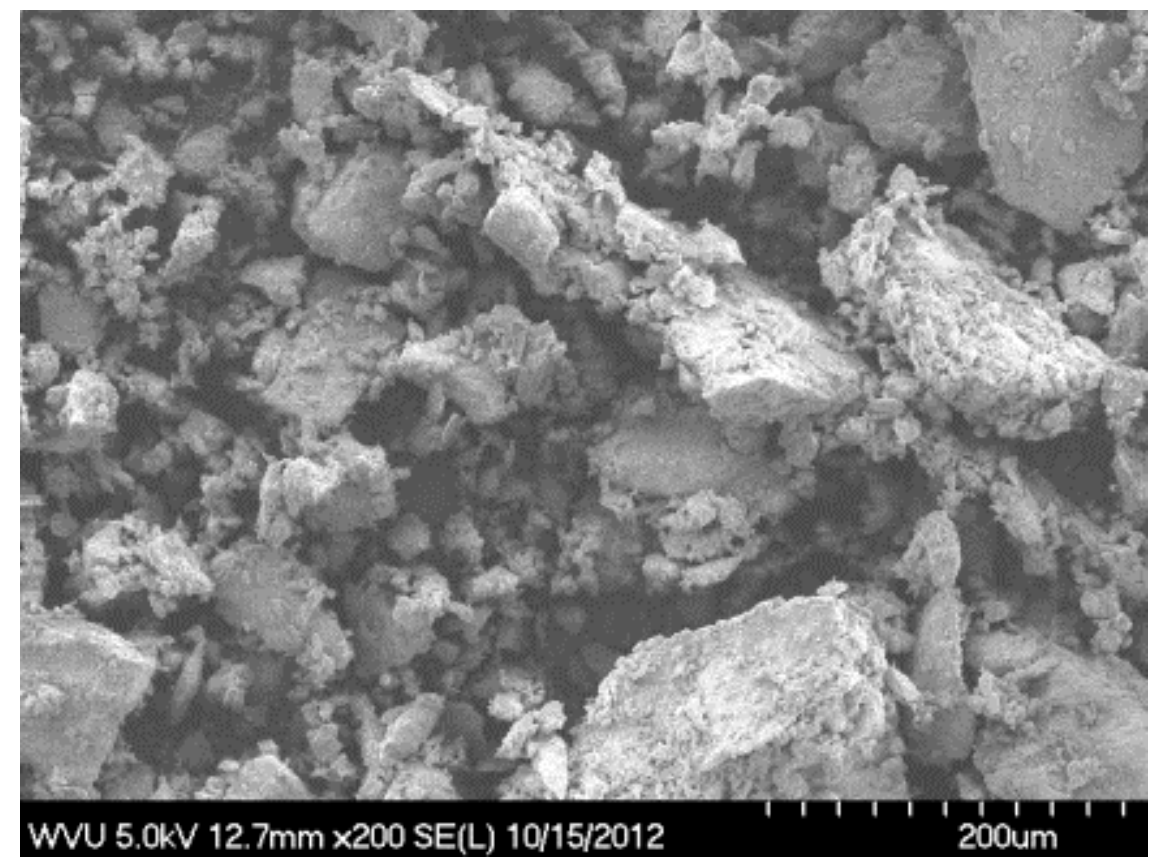

Figure 4-21: SEM image of treated clay with APTMS magnified 200 times, with a working distance of $12.7 \mathrm{~mm}$, using $5.0 \mathrm{kV}$ and the lower detector

Figures 4-22-23 are representative images of the treated clay particles at higher magnifications. In Figure 4-22 the smallest particle that could be imaged and measured was $177 \mathrm{~nm}$. This indicates that treatment with APTMS did not separate the clay platelets when dried, crushed in a mortar and pestle and imaged in the SEM. It was difficult to determine individual particles at low magnification. The largest particle seen in the SEM with a magnification of 350 times was $86.7 \mu \mathrm{m}$. The smallest and largest particles seen while imaging the clay treated with APTMS tend to be larger than the untreated clay. 


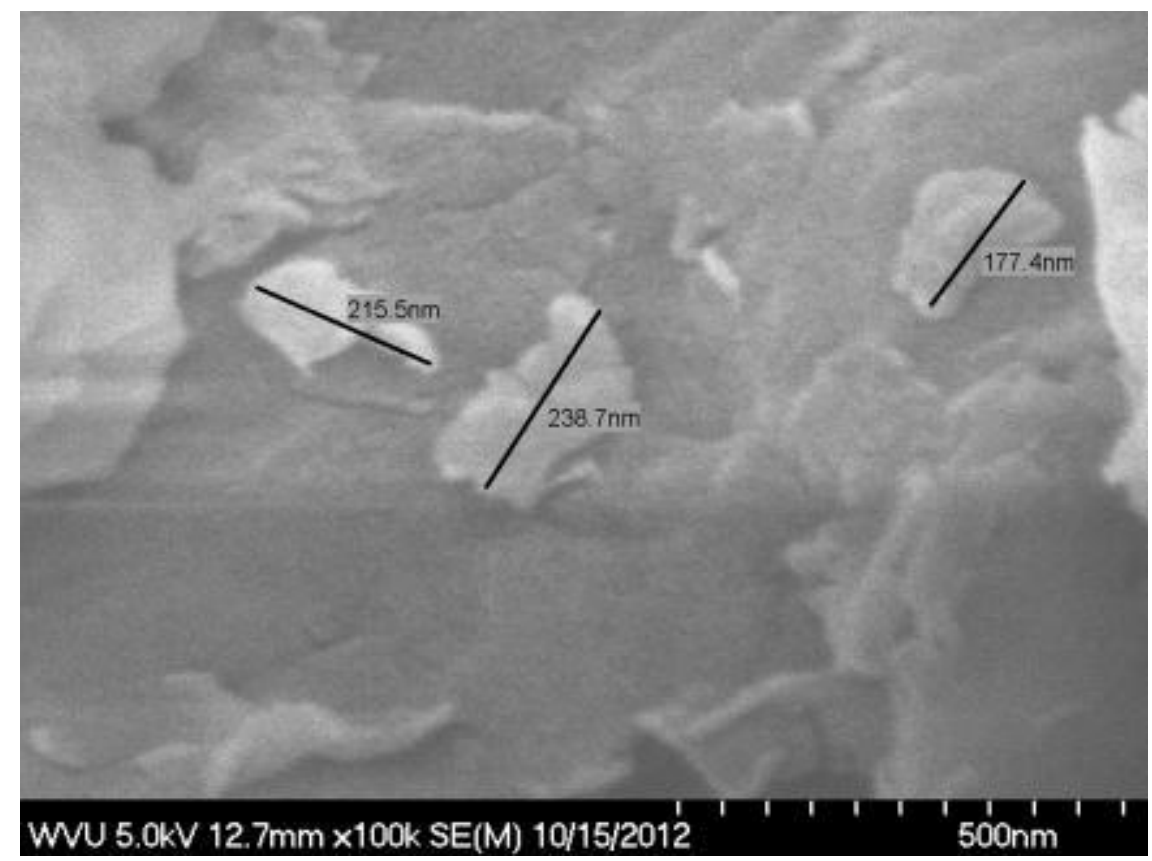

Figure 4-22: SEM image of treated clay with APTMS magnified 100,000 times, with a working distance of $12.7 \mathrm{~mm}$, using $5.0 \mathrm{kV}$ and the both detectors

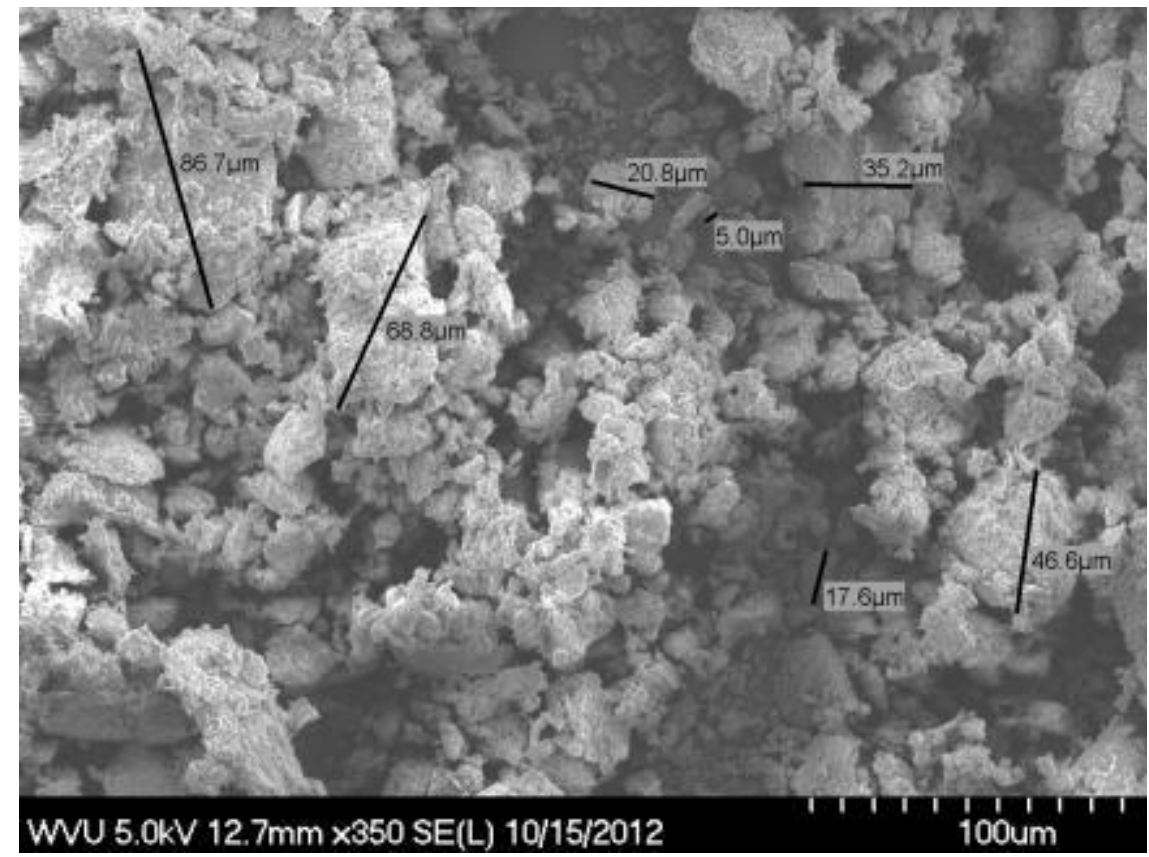

Figure 4-23: SEM image of treated clay with APTMS magnified 350 times, with a working distance of $12.7 \mathrm{~mm}$, using $5.0 \mathrm{kV}$ and the lower detector 
The clay samples treated with APTMS appear to have a rough layer covering the surface of the material that is probably due to the APTMS on the surface. The particles are also in general larger than the particles in the untreated clay. Other than those differences, the particles generally look the same when treated with APTMS. When looking at them with the naked eye this is also the case. The particles appear to be slightly larger than the untreated particles, but are of the same color and consistency.

The clay samples loaded with $50 \% \mathrm{PEI}$ are still a powder but tend to stick together. There is a noticeable difference in appearance and consistency when looking at samples treated with PEI. A low magnification of nanoclay treated with $50 \%$ PEI is shown in Figure 4-24.

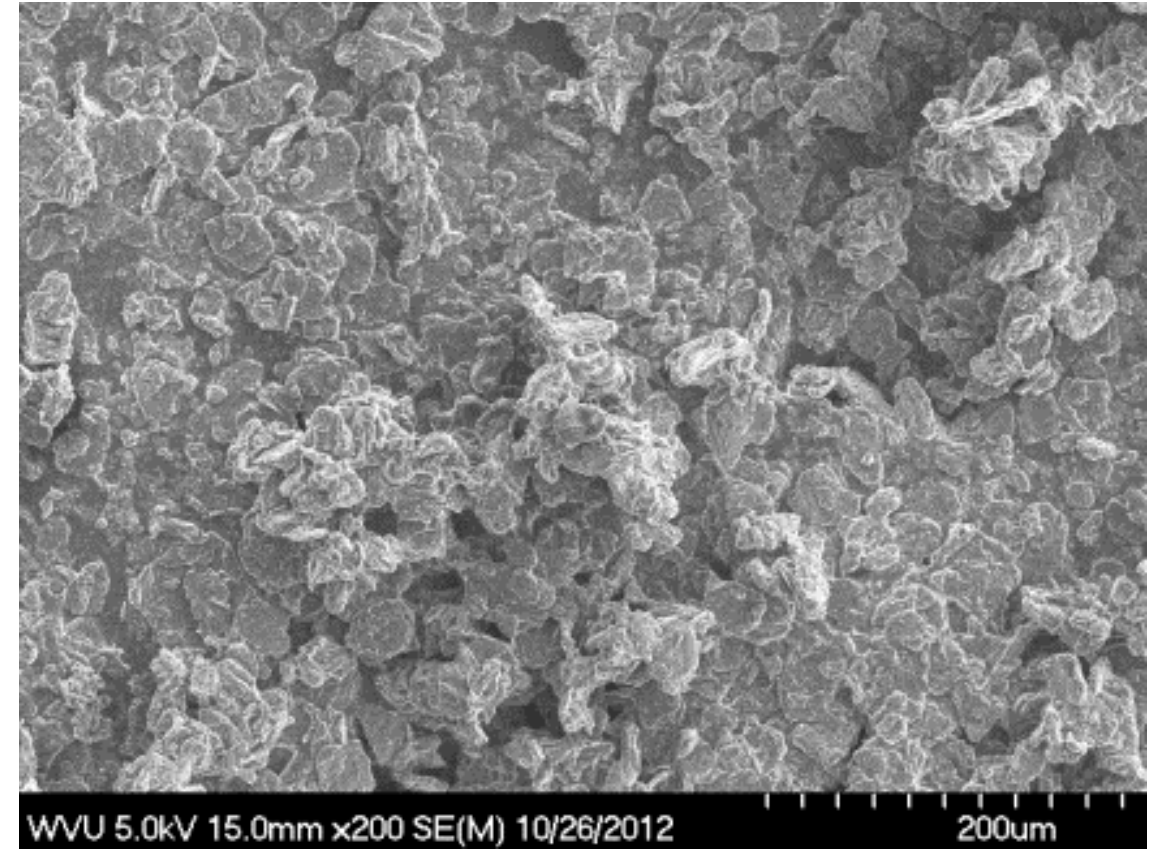

Figure 4-24: SEM image of treated clay with 50\% PEI magnified 200 times, with a working distance of $15.0 \mathrm{~mm}$, using $5.0 \mathrm{kV}$ and both detectors

In Figure 4-24 it can be seen that the general morphology of the nanoclay treated with PEI is completely different from that of the nanoclay treated with APTMS. In Figure 4-24 the 
particles are apparently coated with a layer of PEl and seem to form an almost continuous matrix of PEI with the nanoclay underneath. The clay particles can be seen in Figure 4-24 and appear to be completely covered with PEI. This indicates that the PEl is completely covering the clay surface. A higher magnification image of the clay treated with PEI is shown in Figure 4-25. Since the PEI was completely covering the surface, it was difficult to get dimensions of the clay particles. Using a higher magnification used in Figure 4-25, some of the particles could be measured. The particle size range in Figure $4-25$ is $1-32 \mu \mathrm{m}$. This is just a very general representation of the size of the particles since generally the separate particles could not be distinguished from each other, which is seen in Figure 4-24.

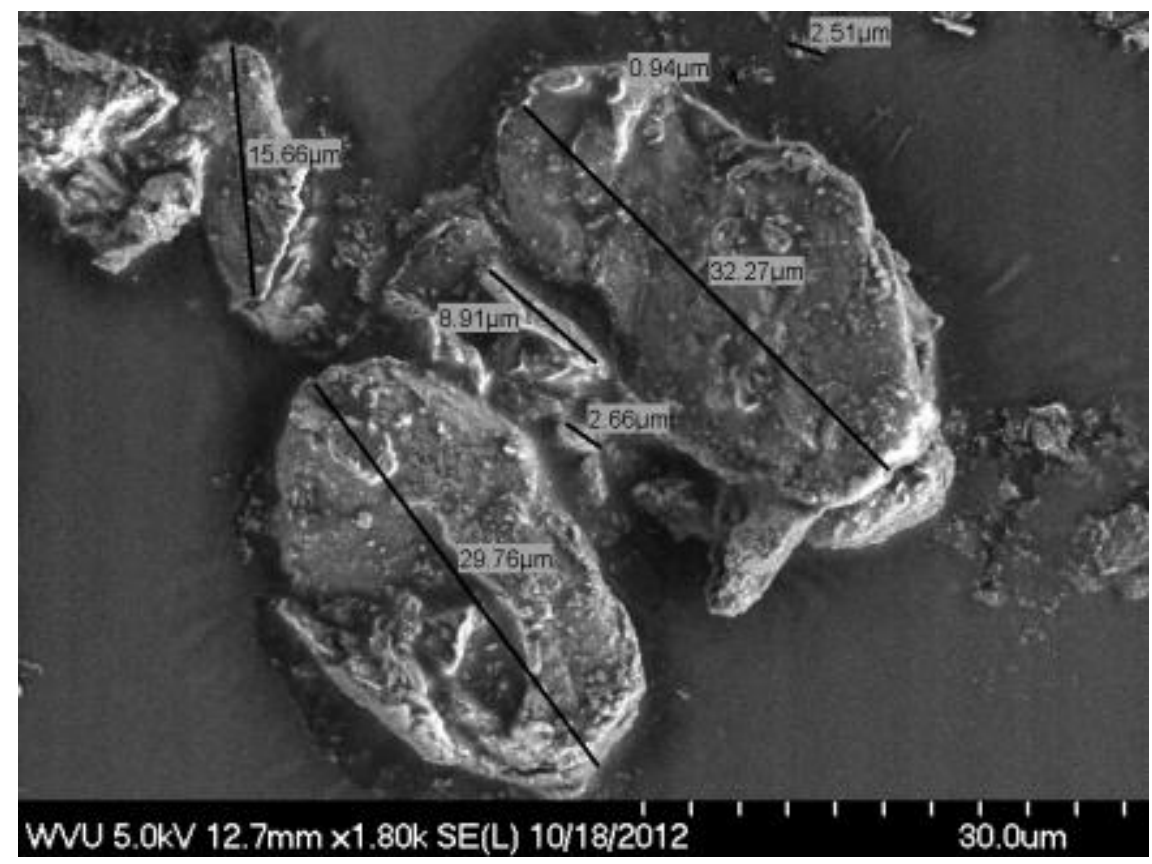

Figure 4-25: SEM image of treated clay with $50 \%$ PEI magnified 1,800 times, with a working distance of $12.7 \mathrm{~mm}$, using $5.0 \mathrm{kV}$ and the lower detector

The consistency of the samples treated with APTMS and PEI in general had more of a paste like consistency than a powder, but varied apparently on how well they mixed together. 
Figure 4-26 is a low magnification image of a sample treated with both APTMS and PEI, in which the consistency was more paste like.

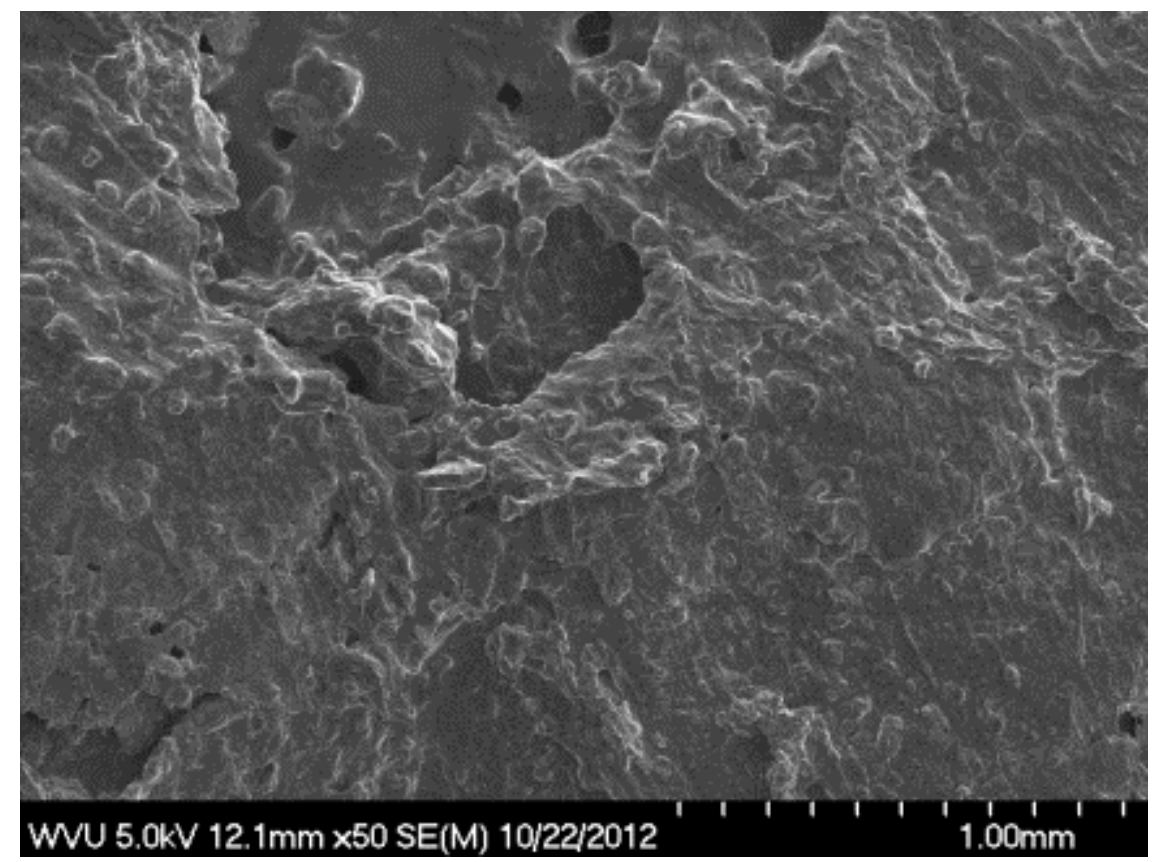

Figure 4-26: SEM image of 20 treated clay with APTMS and 50\% PEI magnified 50 times, with a working distance of $12.1 \mathrm{~mm}$, using $5.0 \mathrm{kV}$ and both detectors.

In Figure 4-26 the clay particles cannot be seen clearly indicating that with the combination of APTMS and PEI, the clay is completely covered with amines and forms a more paste like consistency. In Figures 4-27 and 4-28 a different sample, 2L, of clay treated with APTMS and PEI was imaged. This sample was less paste like than the earlier sample, and very large particles can be seen. 


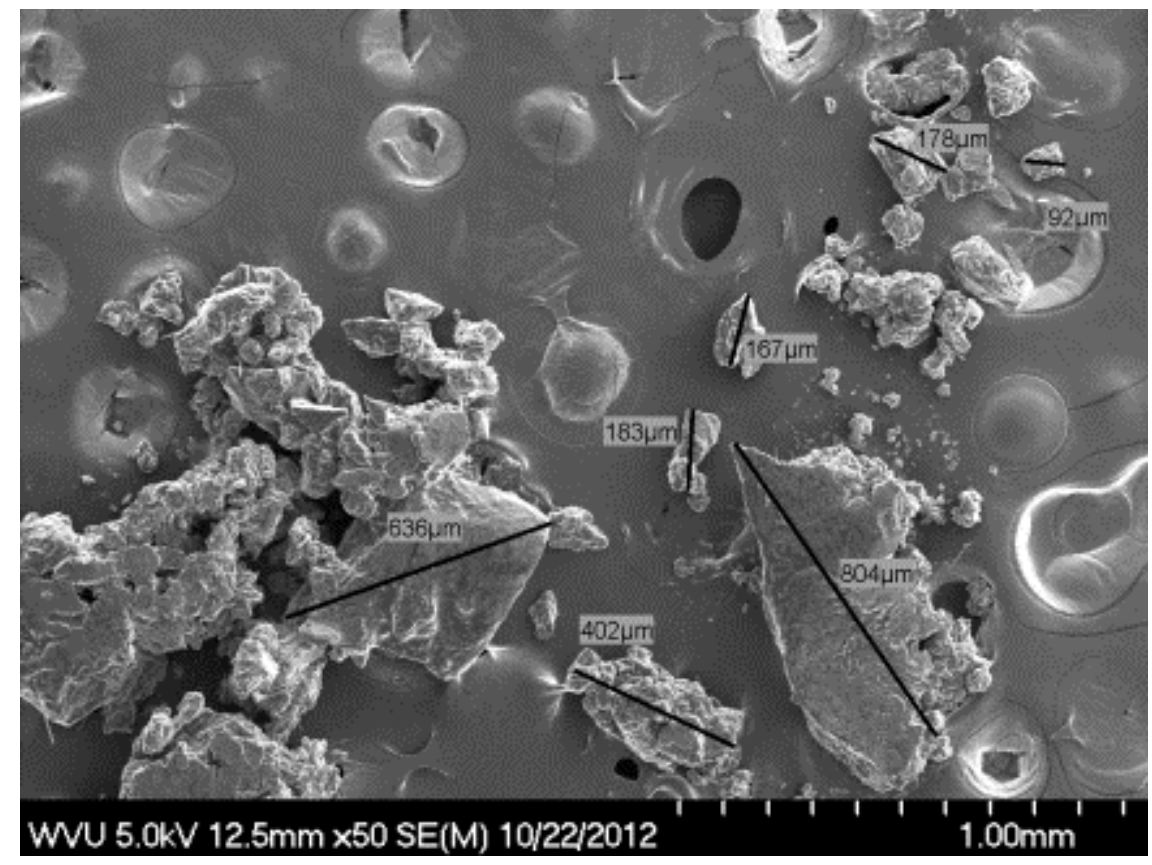

Figure 4-27: SEM image of 2L treated clay with APTMS and 50\% PEI magnified 50 times, with a working distance of $12.5 \mathrm{~mm}$, using $5.0 \mathrm{kV}$ and both detectors. The blisters and holes are due to the carbon tape not the sample

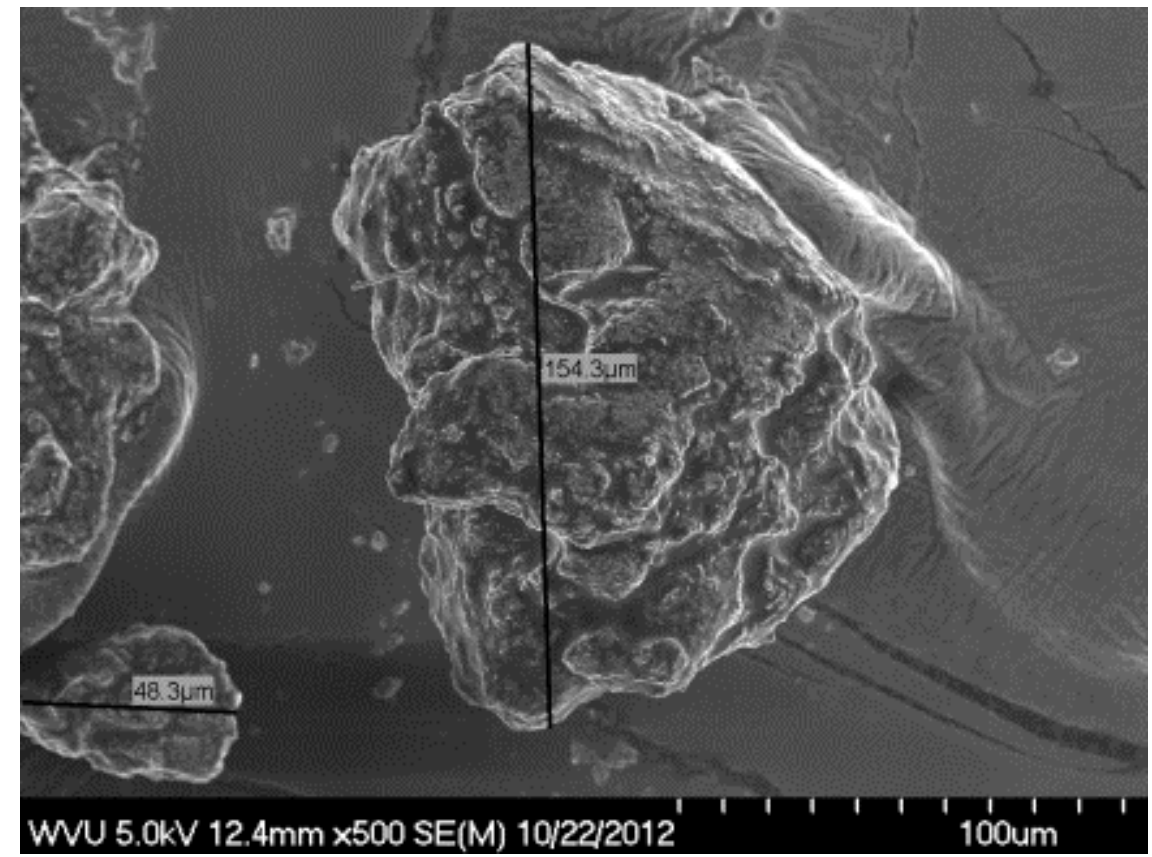

Figure 4-28: SEM image of 2L treated clay with APTMS and 50\% PEI magnified 500 times, with a working distance of $12.4 \mathrm{~mm}$, using $5.0 \mathrm{kV}$ and both detectors 


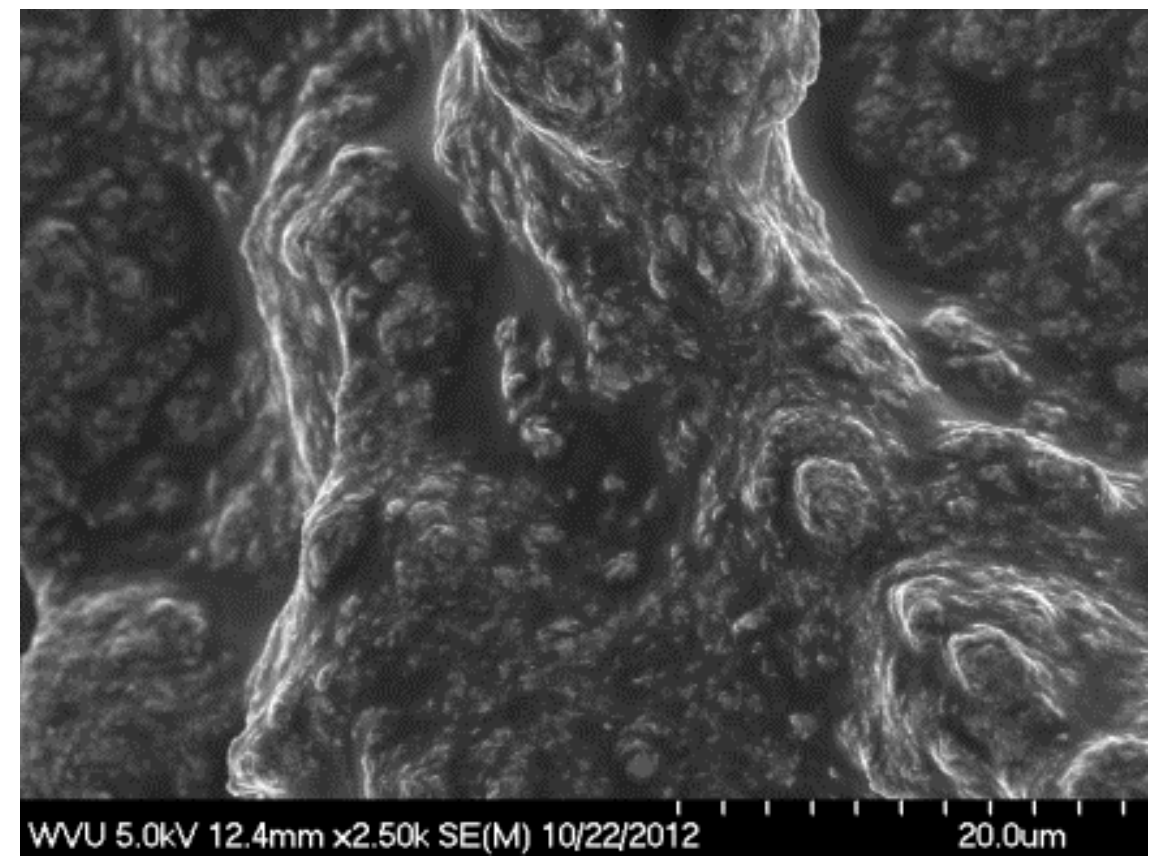

Figure 4-29: SEM image of 20 treated clay with APTMS and 50\% PEI magnified 2,500 times, with a working distance of $12.4 \mathrm{~mm}$, using $5.0 \mathrm{kV}$ and both detectors

Figure 4-29 is a high magnification image of sample 20, clay treated with APTMS and 50\% PEI. In Figure 4-29 the clay particles cannot be easily distinguished, but there is obviously a surface roughness that is most likely caused by the clay particles underneath the PEI.

Using the SEM it can be clearly seen that the amine treatments change the size and morphology of the untreated clay. The samples treated with only APTMS looked similar and had similar consistency to the untreated clay with the naked eye and at low magnification in the SEM, but generally formed larger particle sizes. The samples treated with PEI, and the combination of PEI and APTMS had a more paste like consistency than the untreated clay and the PEI seemed to be completely covering the surface of the clay. 


\section{Chapter 5}

\section{5. $\mathrm{CO}_{2}$ Adsorption and Desorption}

In order to determine the adsorption capacity of the sorbents at different temperatures and at atmospheric conditions, a series of experiments using a TGA was conducted. The initial experiments used pure $\mathrm{CO}_{2}$ and nitrogen to determine the $\mathrm{CO}_{2}$ adsorption capacity and the ability of the sorbent to desorb $\mathrm{CO}_{2}$. Experiments using a mixed gas of $10 \% \mathrm{CO}_{2}$ and nitrogen were also used to determine the ability of the adsorbent to adsorb $\mathrm{CO}_{2}$ from mixed gases. Desorption experiments were also conducted and included using sweep gases of pure nitrogen, pure $\mathrm{CO}_{2}$ and $\mathrm{CO}_{2}$ containing water. $\mathrm{CO}_{2}$ adsorption at high pressure was conducted using a pressure vessel and pure $\mathrm{CO}_{2}$. Pressure Tests for $\mathrm{CO}_{2}$ adsorption were conducted to determine the effect of pressure and possible applications to pre-combustion adsorption. Regeneration using vacuum and water vapor test were also conducted.

\subsection{Pure $\mathrm{CO}_{2}$ Adsorption using TGA}

Pure $\mathrm{CO}_{2}$ was used to determine if the sorbents would adsorb any $\mathrm{CO}_{2}$. In order to establish a baseline for each sorbent, the procedure was to heat the sample to $100^{\circ} \mathrm{C}$ in pure nitrogen for 30 minutes and then cool the reactor to the desired $\mathrm{CO}_{2}$ reaction temperature. Initial experiments used 60 minutes of nitrogen at $100^{\circ} \mathrm{C}$, but after a few experiments it was determined that 30 minutes was sufficient to achieve a stable sample weight for the carbon dioxide weight gain experiments. A representative TGA graph from the Thermo Cahn Thermax 500 apparatus is shown in Figure 5-1 for untreated clay. In Figure 5-1 it can be seen that the weight is reduced to about $94 \%$ of the starting value during the drying step in nitrogen. This decrease in weight is attributed to the loss of water from the sample. After the sample weight 
becomes stabile, the reaction temperature is reduced to $85^{\circ} \mathrm{C}$ for the adsorption of $\mathrm{CO}_{2}$ onto the sample. Once the reaction gas is switched to $\mathrm{CO}_{2}$, there is a dip in the weight which is due to buoyancy effects. The percent carbon dioxide adsorbed is measured by taking the weight difference at the point when the reaction gas is switched to $\mathrm{CO}_{2}$ and the weight gained during the adsorption time. An adsorption time of approximately 90 minutes was used to compare the sample treatments.

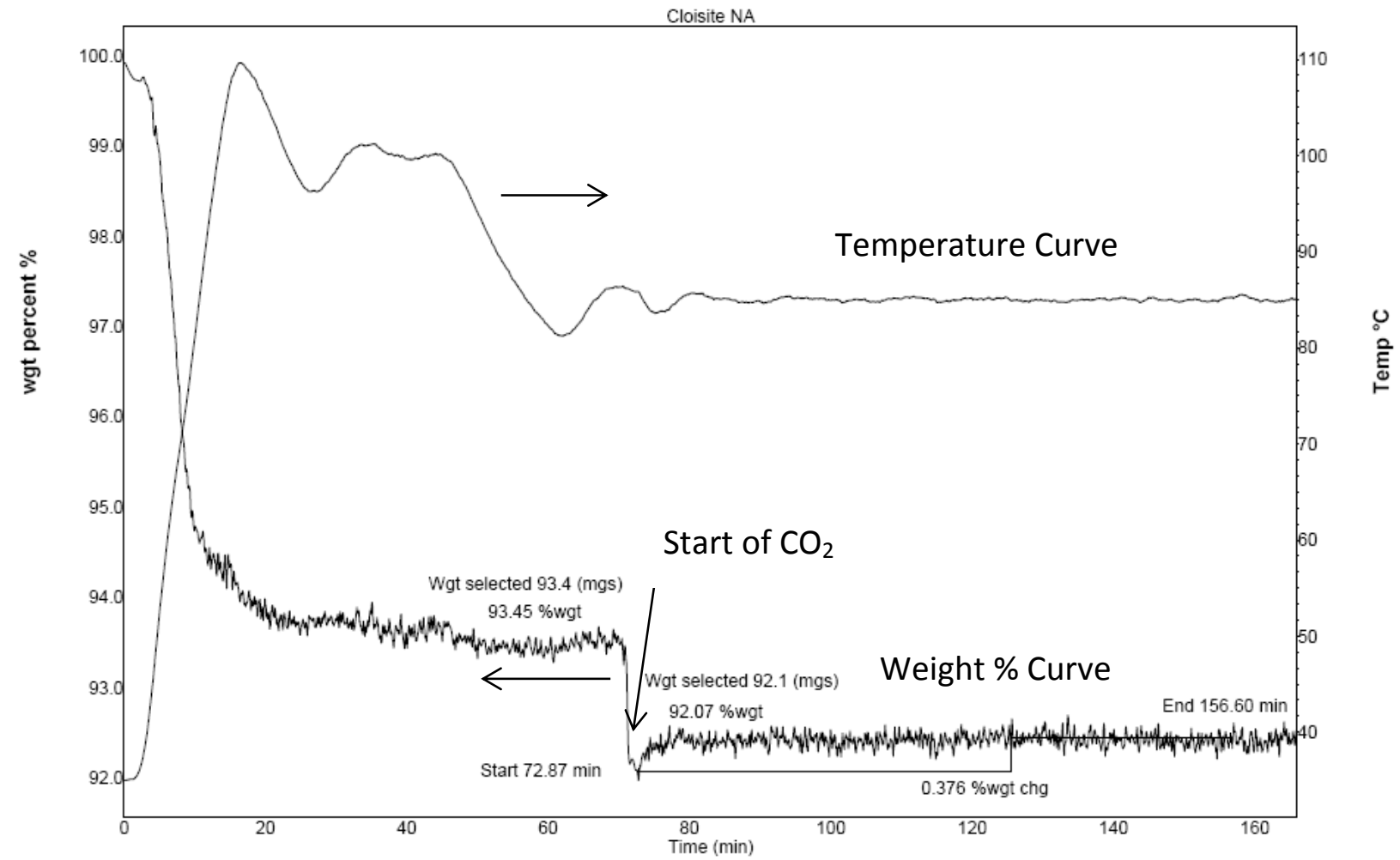

Figure 5-1: TGA graph of untreated clay for $\mathrm{CO}_{2}$ adsorption at $85^{\circ} \mathrm{C}$ in pure $\mathrm{CO}_{2}$

Figure 5-1 shows that there is very little $\mathrm{CO}_{2}$ adsorbed on the untreated clay.

Additionally, the noise in the weight percent curve can clearly be seen. After the reaction gas is switched to $\mathrm{CO}_{2}$ the weight is quickly stabilized, indicating that there is no $\mathrm{CO}_{2}$ being adsorbed or diffused into the untreated clay. 
Figure 5-2 shows a TGA curve using the TA-Q500 TGA for clay treated with PEI. Using this TGA, it can be seen that there is significantly less noise in the weight percent curve. With the loading of PEI onto the clay, it can be clearly seen in Figure 5-2 that $\mathrm{CO}_{2}$ is adsorbed onto the sorbent. The $\mathrm{CO}_{2}$ adsorption is rapid when the reaction gas is first switched to $\mathrm{CO}_{2}$; this is followed by a slow adsorption step as time continues.

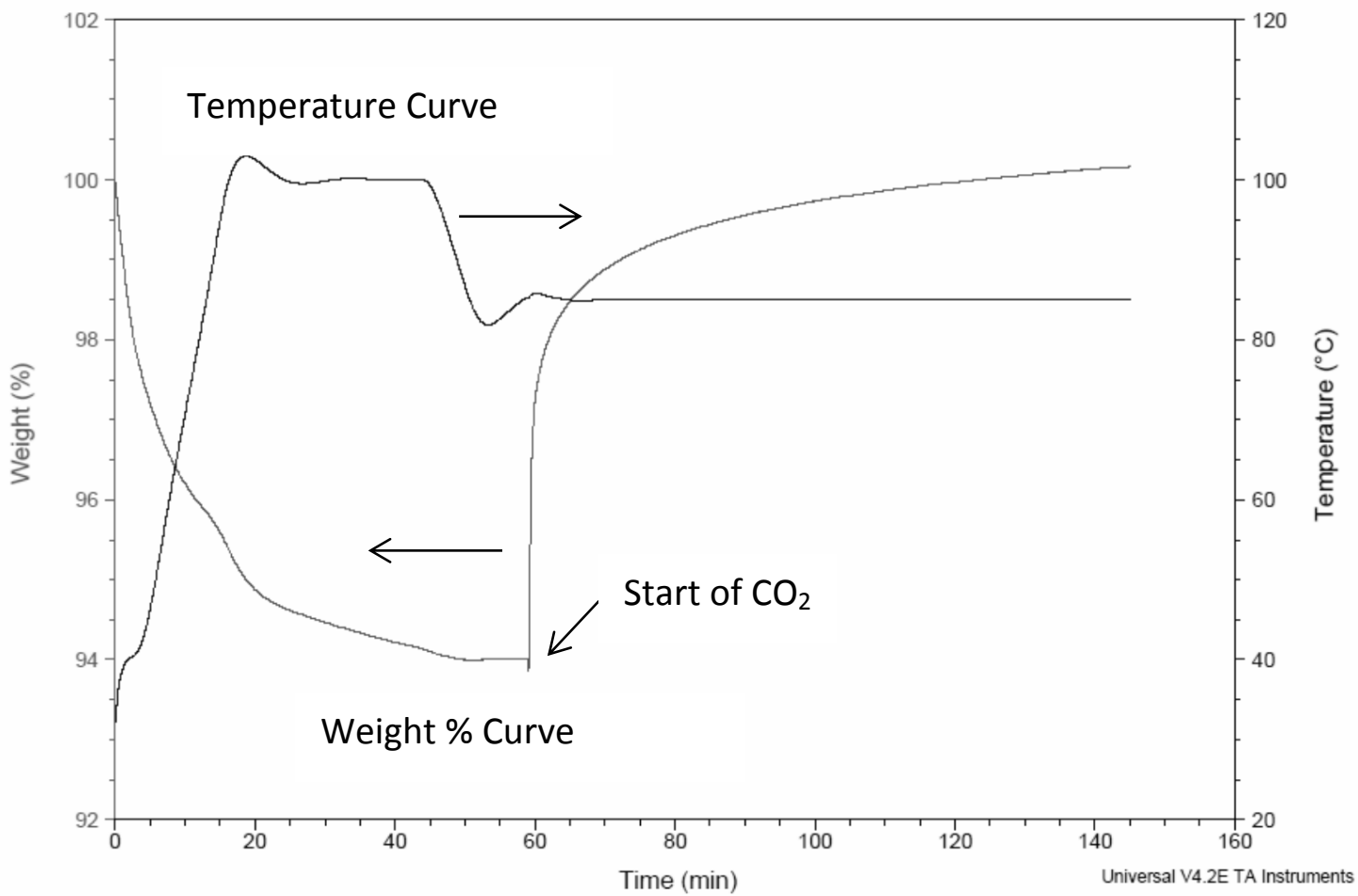

Figure 5-2: TGA graph of clay treated with $\mathrm{PEI}$, pure $\mathrm{CO}_{2}$ adsorption at $85^{\circ} \mathrm{C}$

A TGA graph with clay treated with APTMS is shown in Figure 5-3. Again it can be seen that there is a significant amount of $\mathrm{CO}_{2}$ adsorption compared to the untreated clay. The adsorption profile for the clay treated with APTMS has a rapid adsorption step followed by little to no weight gain. This is attributed to $\mathrm{CO}_{2}$ reacting with the APTMS and having very little diffusion limitations. 


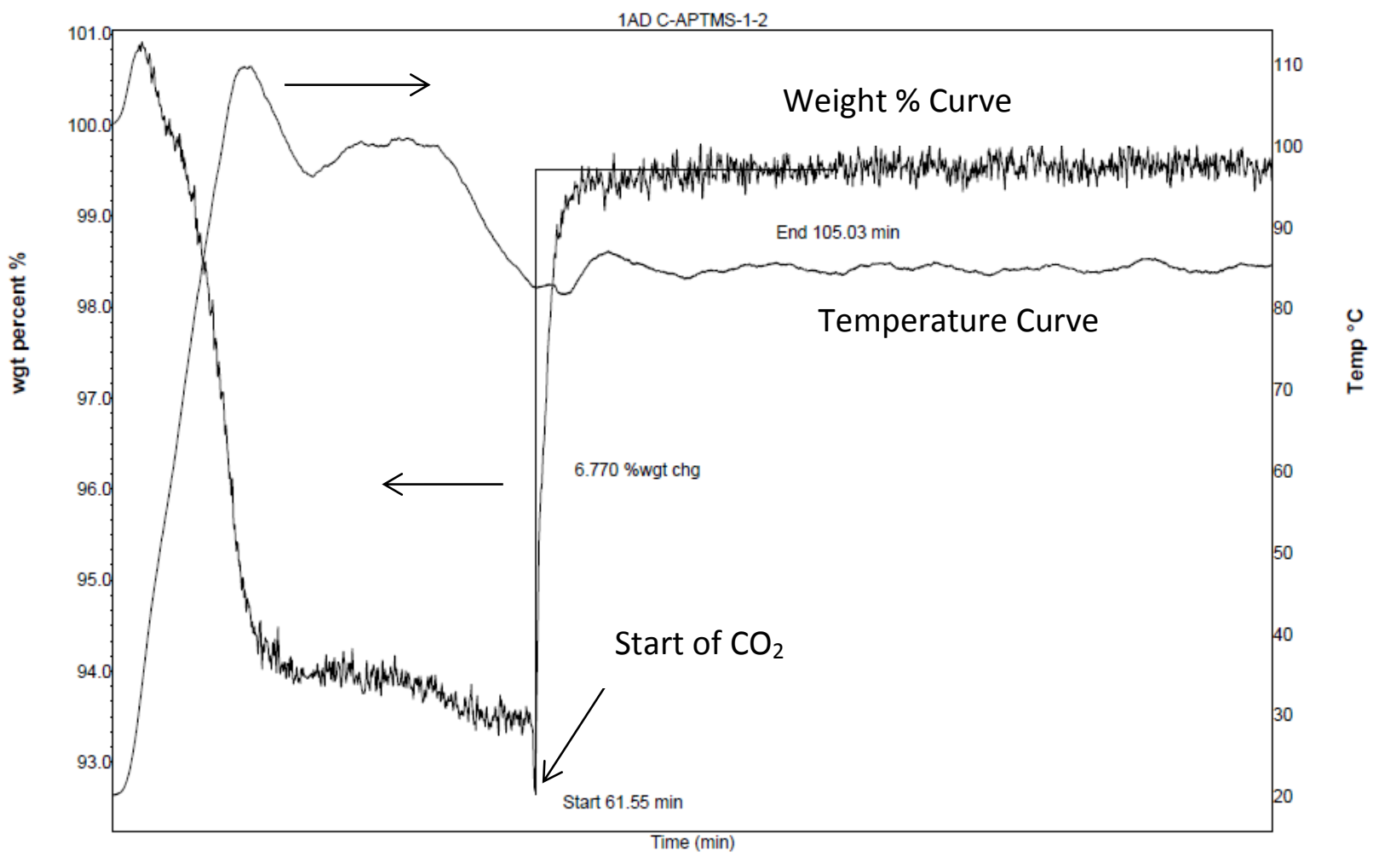

Figure 5-3: TGA graph of clay treated with APTMS, $\mathrm{CO}_{2}$ adsorption at $85^{\circ} \mathrm{C}$

Figure 5-4 is a TGA graph of clay treated with the combination of APTMS and PEI. The $\mathrm{CO}_{2}$ adsorption profile in Figure 5-4 appears to follow the same adsorption profile as the clay treated with only PEI. This is expected since the PEI is covering the majority of the clay surface, and this would cause the same diffusion limitations in the adsorption profile. To determine the temperature dependence of the carbon dioxide adsorption capacity of the adsorbent, experiments were conducted at multiple adsorption temperatures. Results are shown in Figure 5-5. 


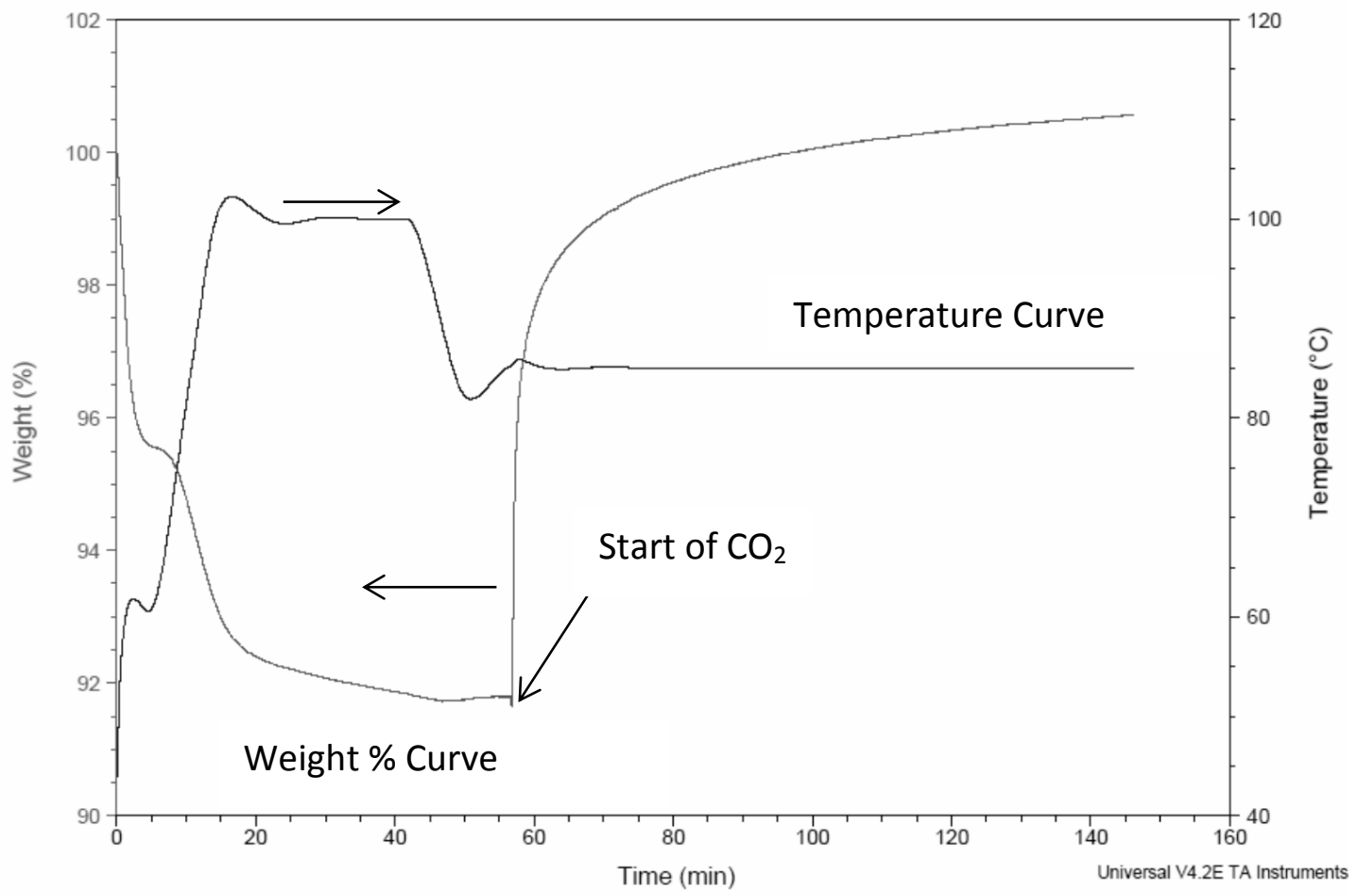

Figure 5-4: TGA graph of clay treated with APTMS and PEI, $\mathrm{CO}_{2}$ adsorption at $85^{\circ} \mathrm{C}$

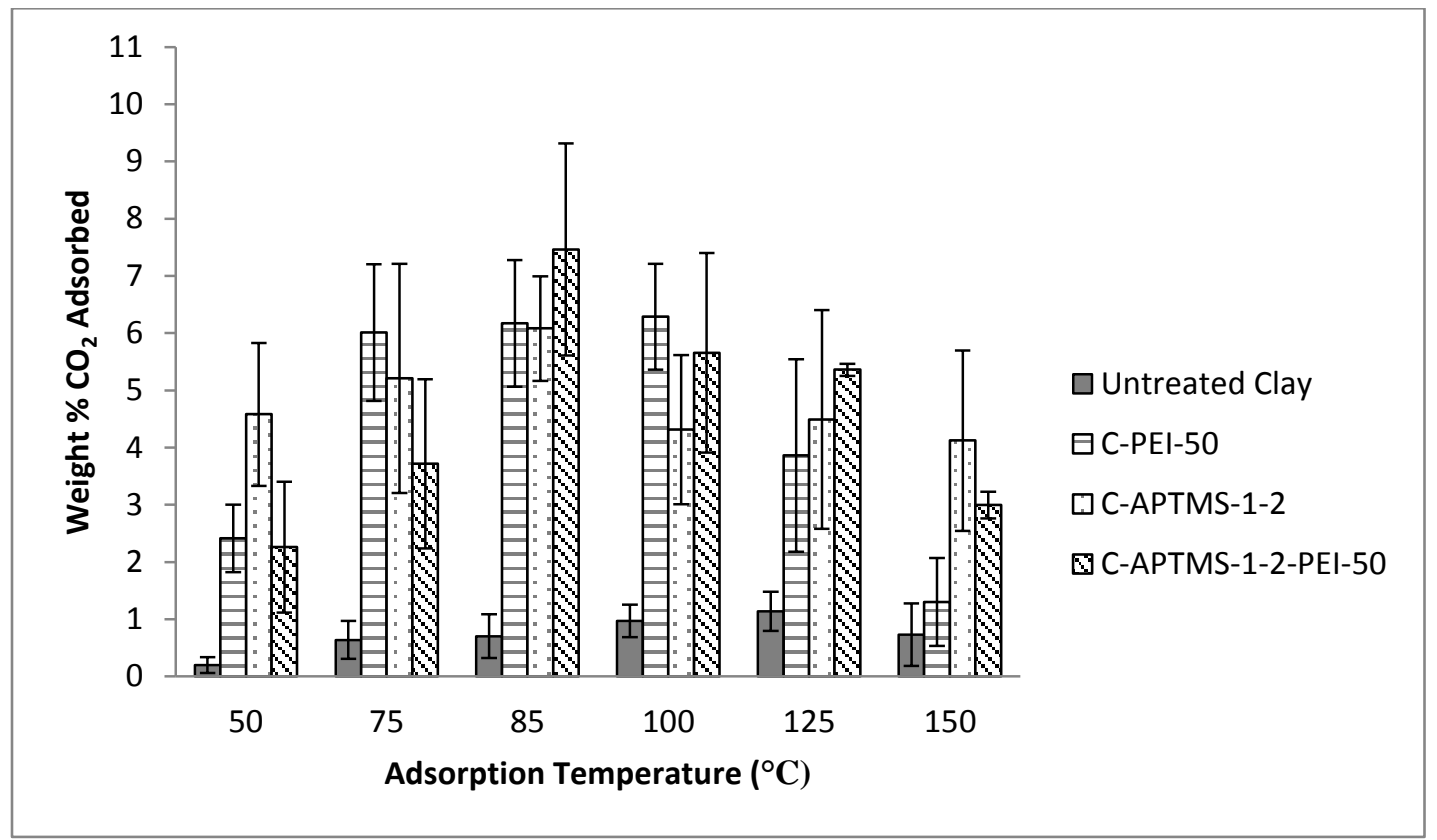

Figure 5-5: Carbon dioxide adsorption capacity as a function of adsorption temperature at atmospheric pressure in the TGA 
Figure 5-5 is a comparison of the $\mathrm{CO}_{2}$ adsorption capacities of untreated clay, clay treated with APTMS, PEI, and APTMS+PEI. Unless it is otherwise stated, the PEI used in the experiments was Mn 423. From Figure 5-5 it can be seen that the adsorption capacity for the treated samples increases from $50^{\circ} \mathrm{C}$ to $75^{\circ} \mathrm{C}$. The temperature range with the highest adsorption was $75^{\circ} \mathrm{C}-100^{\circ} \mathrm{C}$, with the highest adsorption rate being at $85^{\circ} \mathrm{C}$ for clay treated with APTMS+PEI. Therefore, the majority of the other experiments conducted used an adsorption temperature of $85^{\circ} \mathrm{C}$.

Additionally, Figure 5-5 shows that, as the temperature is increased above $100^{\circ} \mathrm{C}$, the adsorption of carbon dioxide is reduced for the samples treated with PEI. The $\mathrm{CO}_{2}$ adsorption capacity for clay treated with APTMS decreased when the temperature was above $85^{\circ} \mathrm{C}$. The untreated clay adsorption capacity does not change significantly with increasing temperature. This is attributed to the reaction of $\mathrm{CO}_{2}$ with amines being exothermic; therefore, as the temperature rises, the equilibrium of the reaction will tend to go towards the reactant side of the equation according to LeChậtelier's principle. One reason for the increase in adsorption capacity from $50^{\circ} \mathrm{C}$ to $85^{\circ} \mathrm{C}$ for the clay samples treated with $\mathrm{PEI}$ is that, with the higher temperature, the PEI molecule can expand giving more access to the amine reaction sites for the $\mathrm{CO}_{2}$. At lower temperatures, the $\mathrm{CO}_{2}$ reacts with surface $\mathrm{PEI}$ molecules, and the $\mathrm{CO}_{2}$ adsorption is limited due to diffusion. Other researchers have also seen this phenomenon using PEI and other supports. ${ }^{[44]}$

When the reaction temperature is $150^{\circ} \mathrm{C}$, the adsorption with APTMS+PEI is less than the adsorption with APTMS alone. This is due to the fact that there is more PEI attached to the 
clay as compared to APTMS and since the PEI adsorbs very little $\mathrm{CO}_{2}$ at this elevated temperature the adsorption capacity of APTMS+PEI is also reduced.

The rate at which the adsorbent can adsorb $\mathrm{CO}_{2}$ is very important when doing calculations for reactor design, and other future design calculations. It was qualitatively observed that clay treated with APTMS alone exhibited rapid adsorption of $\mathrm{CO}_{2}$ and reached near equilibrium very quickly. The clay treated with PEI and the combination of PEI and APTMS showed a quick adsorption followed by a slow adsorption profile. Samples reacted at $85^{\circ} \mathrm{C}$, and these had the highest adsorption capacities, were used in calculating the adsorption times. The times were measured by assuming 100 percent adsorption at 90 minutes, and then measuring the time at $50,75,90$, and 95 percent $\mathrm{CO}_{2}$ adsorption. At least four runs were used to measure the adsorption times at each percent adsorption. The results are shown in Figure 5-6.

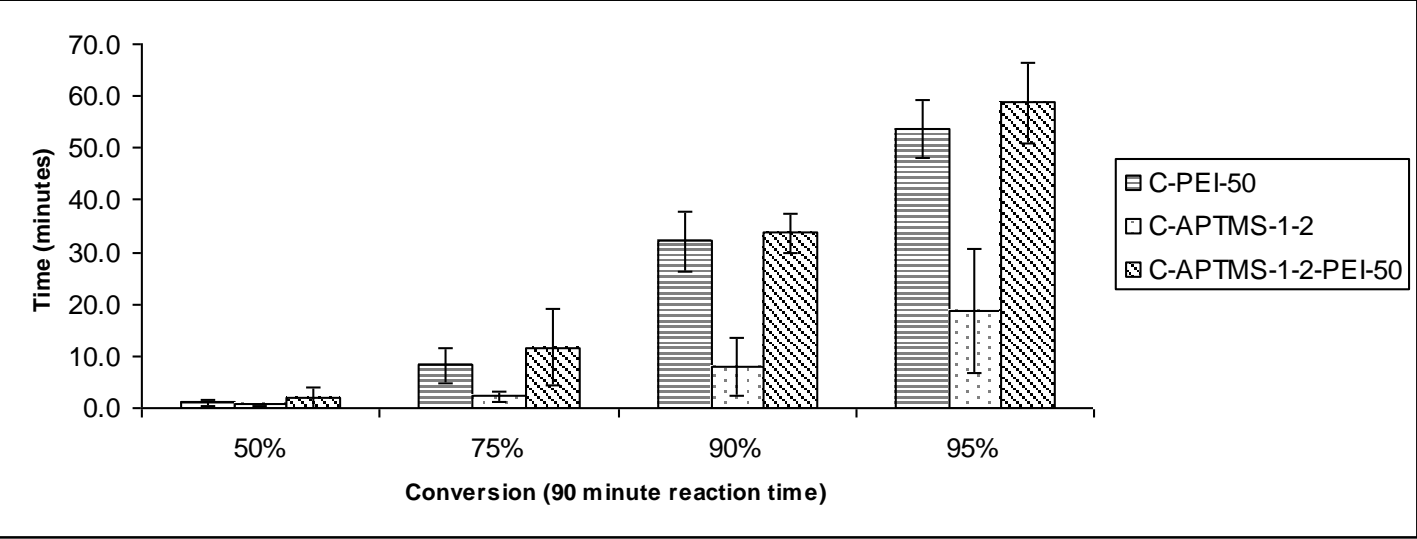

Figure 5-6: Time versus percent $\mathrm{CO}_{2}$ adsorbed based on a 90 minute adsorption run

In Figure 5-6 it can be seen that the adsorption rate of clay treated with only PEI closely follows the adsorption rate for clay treated with the combination of APTMS and PEI. This confirms the observation that the reaction rates appeared to be similar when studying the TGA curves qualitatively. Additionally it can be seen that the clay treated with APTMS achieves 90 percent 
of its adsorption capacity under 10 minutes and 95 percent adsorption capacity around 20 minutes. The data can also be viewed in Table 5- 1

Table 5-1: Time to reach different $\mathrm{CO}_{2}$ adsorption percentages based on a 90 minute adsorption time

\begin{tabular}{|c|c|c|c|c|}
\hline Percent Adsorption & $50 \%$ & $75 \%$ & $90 \%$ & $95 \%$ \\
\hline Clay+PEI (minutes) & 1.1 & 8.2 & 32.2 & 53.8 \\
\hline Clay+APTMS (minutes) & 0.7 & 2.2 & 8.1 & 18.7 \\
\hline Clay+APTMS+PEI (minutes) & 2.0 & 11.7 & 33.8 & 58.8 \\
\hline
\end{tabular}

The results shown in Figure 5-6 and Table 5-1 confirm that the $\mathrm{CO}_{2}$ adsorption rate for samples treated with only PEI and the combination of APTMS and PEI have very similar adsorption profiles. This is to be expected since the PEI is covering the surface of the untreated clay and the clay treated with APTMS. The samples treated with only APTMS showed quick $\mathrm{CO}_{2}$ uptake, which is also expected when looking at the TGA graphs. This also may indicate that although the adsorption capacity for the samples treated with PEI and the combination of APTMS and PEI have a slightly higher adsorption capacity than the samples treated with only APTMS, the clay treated with APTMS might be a better adsorbent because of it fast adsorption kinetics.

To compare the behavior of different molecular weight PEI on the adsorption of $\mathrm{CO}_{2}$, a loading of 50 weight percent PEI onto the surface of clay was employed using the same wet impregnation that is described in the experimental section. The appearance and consistency of the sample using PEI Mn 1200 closely resembled the samples made using PEI Mn 423. The sample made with PEI Mn 60,000, however, formed clumps of material instead of a powder; this is probably due to the large increase in the molecular weight as compared to either Mn 423 
or $\mathrm{Mn}$ 1200. Figure 5-7 and Figure 5-8 are representative TGA graphs for $\mathrm{CO}_{2}$ adsorption on samples made with clay treated with PEI Mn 1200 and Mn 60,000.

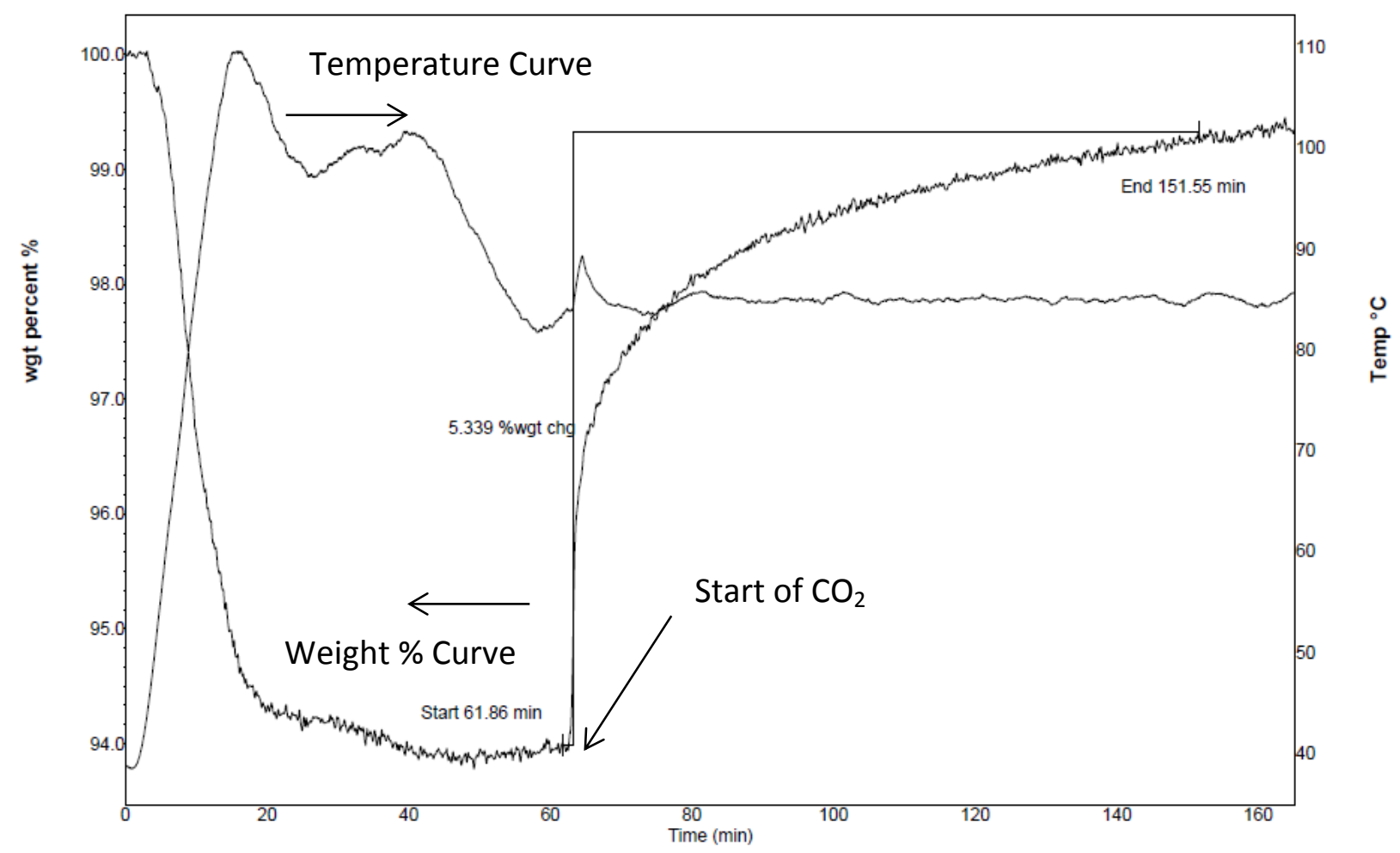

Figure 5-7: $\mathrm{TGA} \mathrm{CO}_{2}$ adsorption graph at $85^{\circ} \mathrm{C}$ of clay loaded with $50 \%$ PEI Mn 1200 


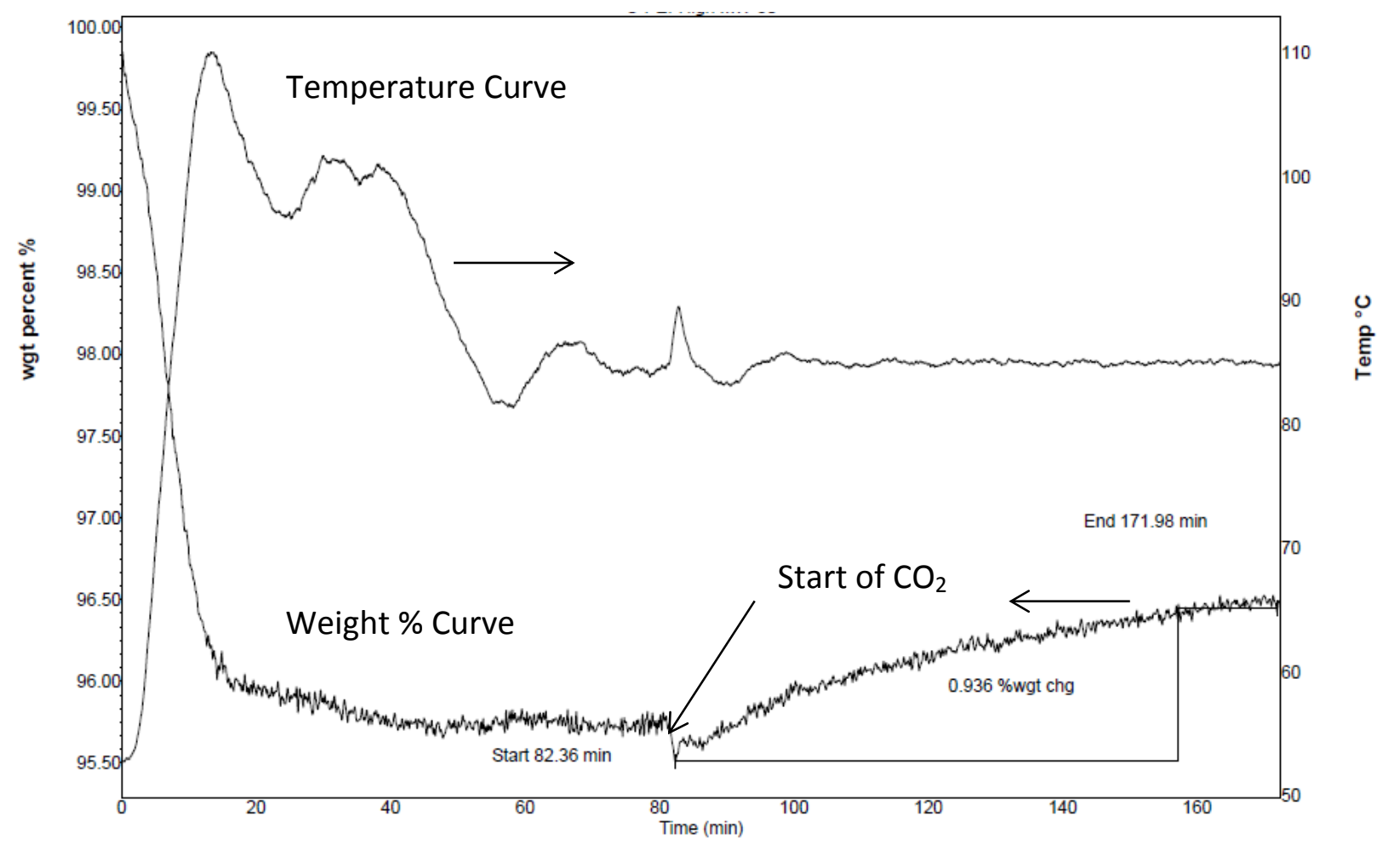

Figure 5-8: $\mathrm{TGA} \mathrm{CO}_{2}$ adsorption graph at $85^{\circ} \mathrm{C}$ for clay loaded with $50 \%$ PEI Mn 60,000

The adsorption capacity and profile for $\mathrm{CO}_{2}$ adsorption on clay treated with PEI Mn 1200 was very similar to the adsorption capacity of PEI Mn 423. The adsorption capacity and profile for $\mathrm{CO}_{2}$ adsorption using high molecular weight PEI had a greatly reduced adsorption capacity and seemed to show a more diffusion-controlled mechanism. This indicates that the amine sites on the high molecular weight PEI are not easily accessed at $85^{\circ} \mathrm{C}$. Figure $5-9$ is a graph of the comparison of the adsorption capacity of three different molecular weight PEls when 50 percent PEI was loaded onto the clay support. 


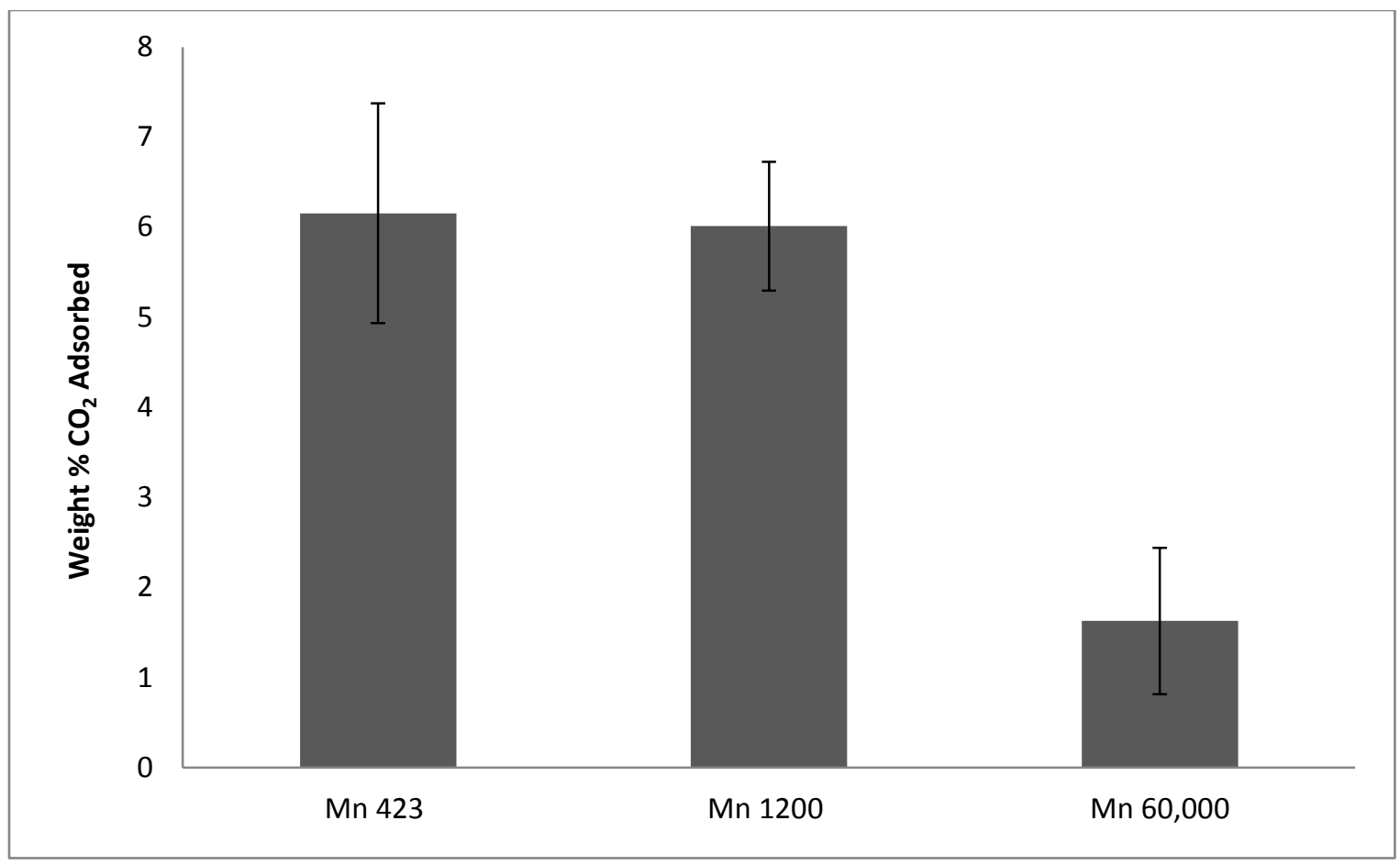

Figure 5-9: $\mathrm{CO}_{2}$ adsorption for clay loaded with PEI at $85^{\circ} \mathrm{C}$

Supports treated with $\mathrm{PEI}$ in the literature for $\mathrm{CO}_{2}$ adsorption were typically prepared using a $50 \%$ loading. This was because this loading value showed the best overall $\mathrm{CO}_{2}$ adsorption per gram of PEI. ${ }^{[4]}$ A study using a loading of $33 \%, 50 \%$ and $66 \%$ loading based on the concentrations used in the wet impregnation method was studied for the $\mathrm{CO}_{2}$ adsorption capacity at $85^{\circ} \mathrm{C}$ in a TGA. The results are presented in Figure $5-10$ and these show that, with the increased loading of PEI from $50 \%$ to $66 \%$, the adsorption capacity did not change. The adsorption capacity did increase when the loading was increased from $33 \%$ to $50 \%$.

Additionally, with the higher loadings, the sample turned into a more paste like consistency. This observation would indicate that a loading of more than $50 \%$ PEI does not significantly increase the amount of $\mathrm{CO}_{2}$ adsorbed onto the adsorbent. 


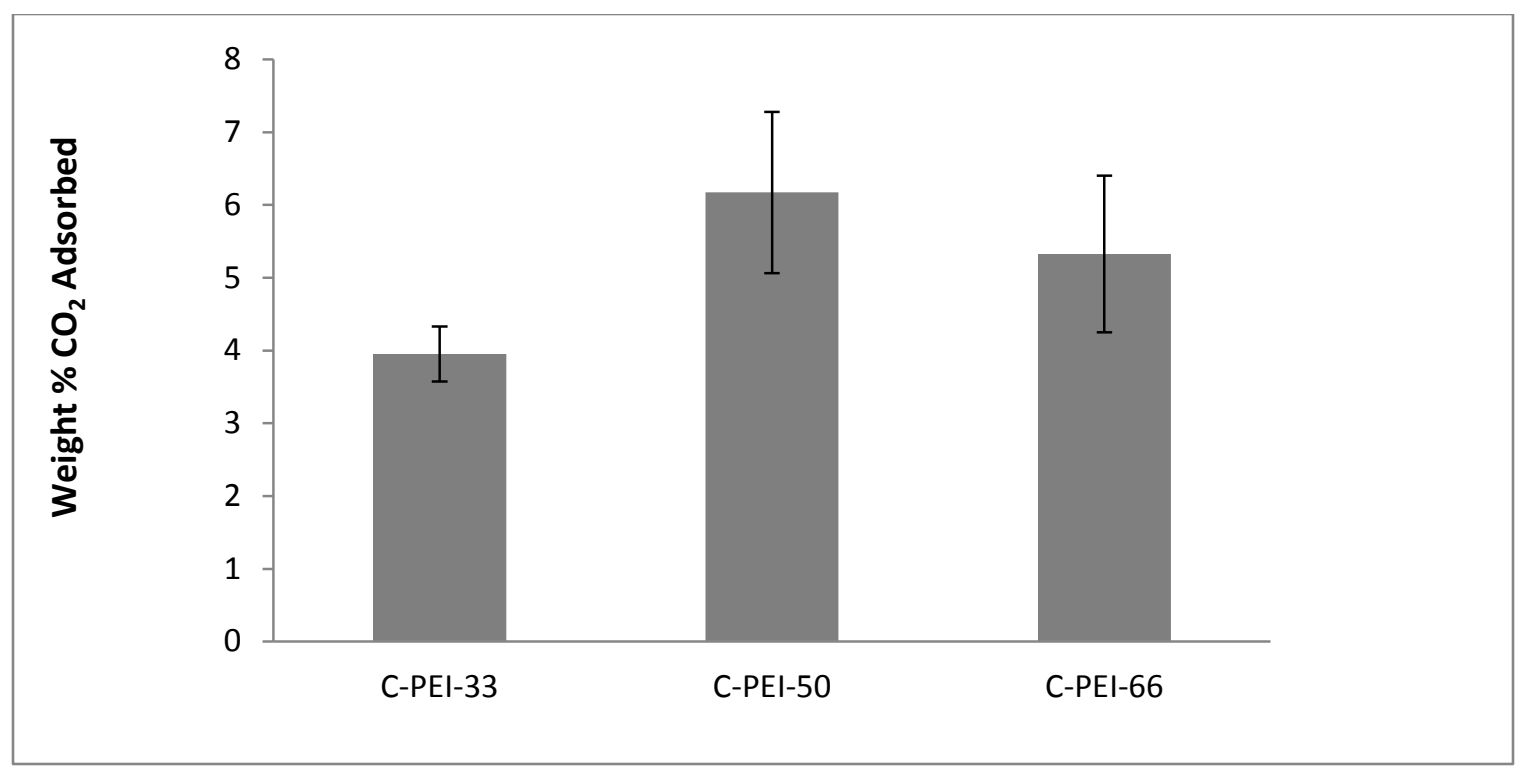

Figure 5-10: Comparison of PEl loading on $\mathrm{CO}_{2}$ adsorption capacity at $85^{\circ} \mathrm{C}$

The data collected during these experiments using pure $\mathrm{CO}_{2}$ at atmospheric conditions showed that the best adsorption temperatures were in the range of $75^{\circ} \mathrm{C}-100^{\circ} \mathrm{C}$ for all of the treated adsorbents. The untreated clay did not adsorb significant $\mathrm{CO}_{2}$ at any temperature. An adsorption temperature of $85^{\circ}$ is in the middle of this range, and it showed the best adsorption results and was, therefore, used for the majority of the other experiments. A study using different molecular weight PEI showed that the best PEI for adsorption at $85^{\circ} \mathrm{C}$ using pure $\mathrm{CO}_{2}$ in a TGA was the lowest molecular weight studied, PEI Mn 423. Studying the different loadings of PEI showed that a loading of $50 \%$ appeared to be enough to achieve the maximum amount of $\mathrm{CO}_{2}$ adsorption at $85^{\circ} \mathrm{C}$ using pure $\mathrm{CO}_{2}$.

\subsection{Adsorption from a Mixed Gas Containing $10 \% \mathrm{CO}_{2}$}

In order to test the adsorbents in a more realistic flue gas stream, a gas cylinder containing $10 \% \mathrm{CO}_{2}$ with the balance being nitrogen was ordered from Airgas and used in the TGA experiments at $85^{\circ} \mathrm{C}$ for $\mathrm{CO}_{2}$ adsorption. The adsorption temperature of $85^{\circ} \mathrm{C}$ was used because previous results using pure $\mathrm{CO}_{2}$ showed that the highest $\mathrm{CO}_{2}$ adsorption capacity was 
attained at $85^{\circ} \mathrm{C}$. Figure $5-11$ is a representative graph of the adsorption of $\mathrm{CO}_{2}$ in this mixed gas stream using a sample of clay treated with APTMS. In Figure 5-11 it can be seen that the adsorption of $\mathrm{CO}_{2}$ followed the same profile as the adsorption in pure $\mathrm{CO}_{2}$ with comparable adsorption capacities. Additionally, there is a cycle step using pure nitrogen at $100^{\circ} \mathrm{C}$ to insure cycling was still possible when using $10 \% \mathrm{CO}_{2}$ reaction stream. The same adsorption profile that occurred in pure $\mathrm{CO}_{2}$ was also evident with the samples of clay treated with PEI and APTMS+PEI. This indicated that $\mathrm{CO}_{2}$ can be adsorbed in a reaction stream that has a significantly lower percentage of $\mathrm{CO}_{2}$.

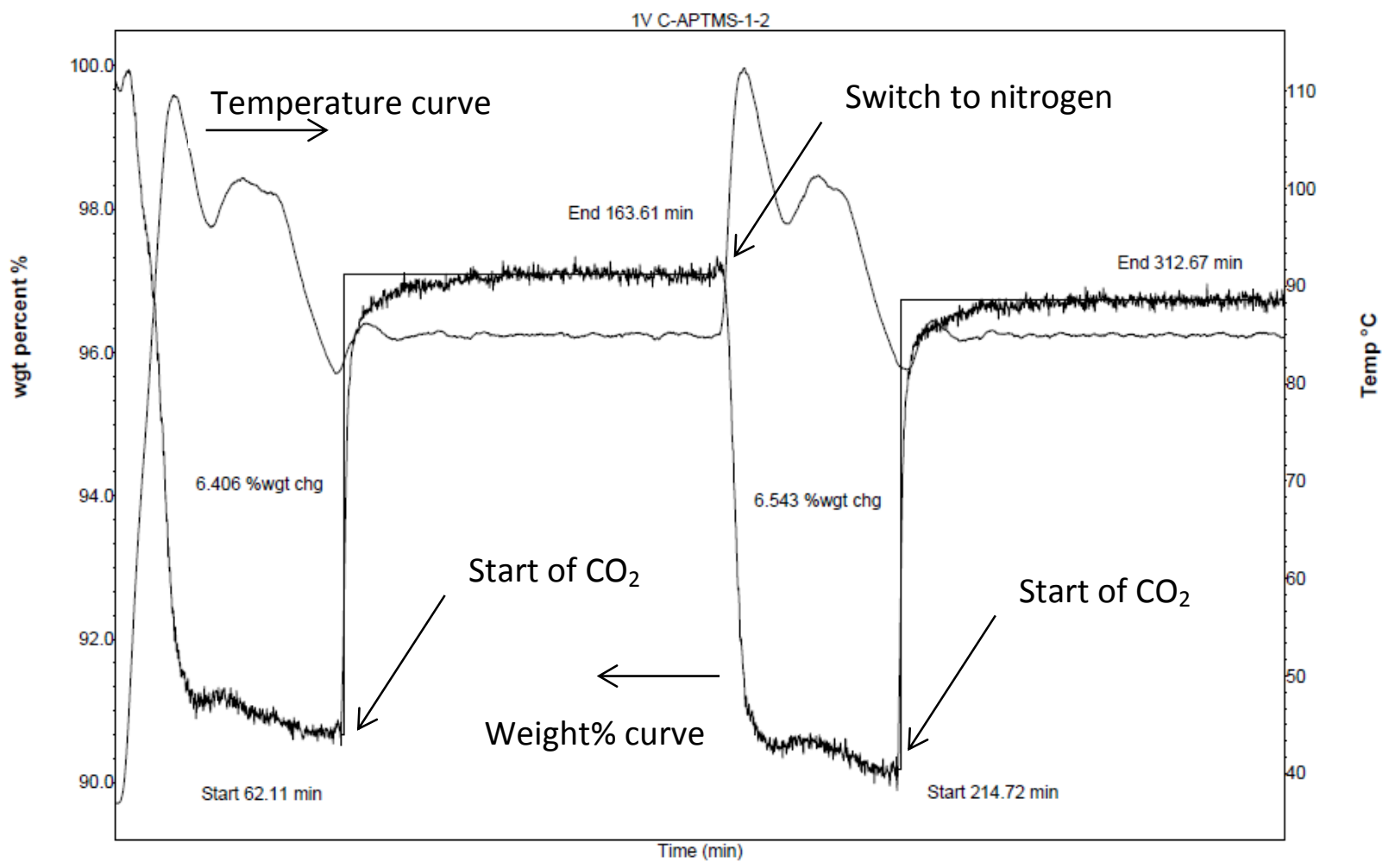

Figure 5-11: $\mathrm{CO}_{2}$ adsorption using $10 \% \mathrm{CO}_{2}$ and $90 \% \mathrm{~N}_{2}$, clay treated with APTMS 


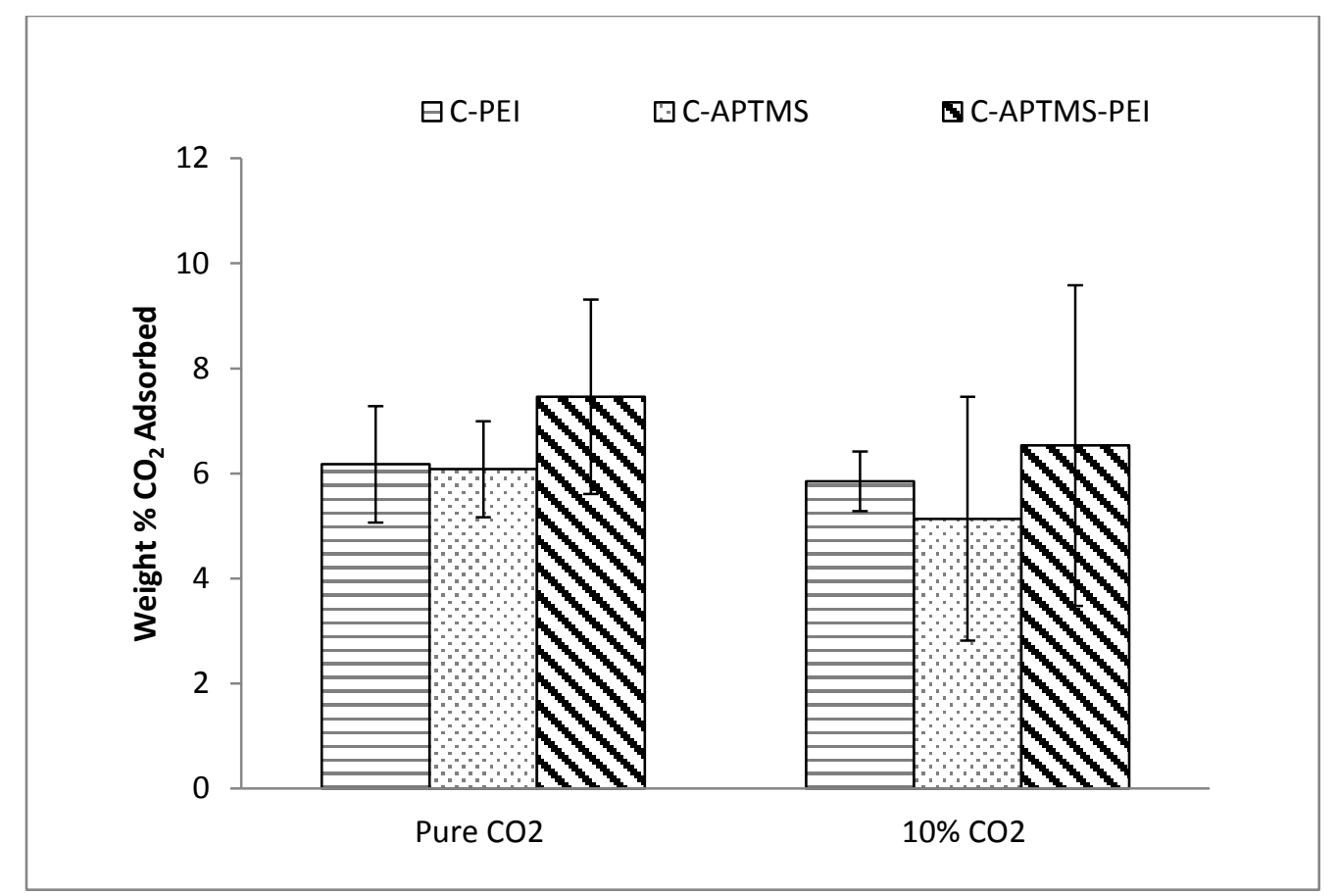

Figure 5-12: $\mathrm{CO}_{2}$ adsorption capacity in pure $\mathrm{CO}_{2}$ and $10 \% \mathrm{CO}_{2}$ balanced with nitrogen

Comparison of the results for all of the amine treatments for a pure $\mathrm{CO}_{2}$ reaction stream and a reaction stream containing $10 \% \mathrm{CO}_{2}$ and $90 \% \mathrm{~N}_{2}$ can be seen in Figure $5-12$. From this it is evident that the adsorption capacity for all of the amine treatments was approximately the same for $\mathrm{CO}_{2}$ adsorption in $10 \% \mathrm{CO}_{2}$ as it was with $\mathrm{CO}_{2}$ adsorption in pure carbon dioxide. This indicates that the adsorption of $\mathrm{CO}_{2}$ is not hindered by the presence of nitrogen. Additionally, this indicates that the adsorption of $\mathrm{CO}_{2}$ in more realistic flue gases is possible. The ability to adsorb $\mathrm{CO}_{2}$ in a mostly nitrogen stream is a basic requirement for all solid sorbents for postcombustion capture. The adsorbents produced in this research showed that this is possible with approximately the same adsorption capacity as in pure $\mathrm{CO}_{2}$ stream.

\subsection{Regeneration of Adsorbents using Pure Nitrogen}

Regeneration of the adsorbents using nitrogen is one of the easiest ways to determine if $\mathrm{CO}_{2}$ can be desorbed using a TGA and is one of the most widely used techniques in the 
literature. Regeneration using nitrogen was carried out by heating the sample after $\mathrm{CO}_{2}$

adsorption to $100^{\circ} \mathrm{C}$ for 30 minutes. Table $5-2$ portrays the data for 1 cycle using nitrogen as the sweep gas. From the data in this table, it is concluded that cycling is possible with samples of clay treated with APTMS using nitrogen at $100^{\circ} \mathrm{C}$, but the regeneration of clay treated with PEI and clay treated with the combination of APTMS and PEI lost some of its original $\mathrm{CO}_{2}$ adsorption capacity on average when the samples were regenerated with nitrogen at $100^{\circ} \mathrm{C}$.

Table 5-2: Regeneration using nitrogen at $100^{\circ} \mathrm{C}$ in a TGA

\begin{tabular}{|l|c|c|c|}
\hline & $\begin{array}{l}\text { Initial } \mathrm{CO}_{2} \\
\text { adsorption }\end{array}$ & $\begin{array}{l}\text { First cycle } \\
\text { adsorption }\end{array}$ & $\begin{array}{l}\text { Percent } \\
\text { regeneration }\end{array}$ \\
\hline C-PEI-50 Average & 5.8 & 5.5 & $94 \%$ \\
\hline C-PEI-50 Standard deviation & 0.9 & 0.7 & $4.3 \%$ \\
\hline C-APTMS-1-2 Average & 6.0 & 6.0 & $101 \%$ \\
\hline C-APTMS-1-2 Standard deviation & 1.1 & 1.0 & $2.4 \%$ \\
\hline C-APTMS-1-2-PEI-50 Average & 7.6 & 7.3 & $97 \%$ \\
\hline $\begin{array}{l}\text { C-APTMS-1-2-PEI-50 Standard } \\
\text { deviation }\end{array}$ & 2.0 & 1.9 & $3.9 \%$ \\
\hline
\end{tabular}

Figure 5-13 shows the same data in Table 5-2 in a graph for a better comparison of the results. In Figure 5-13 it can clearly be seen that some of the samples had a near 100 percent regeneration in nitrogen, but on average the sample treated with PEI and APTMS+PEI had a decrease in its carbon dioxide adsorption capacity when regenerated with nitrogen. 


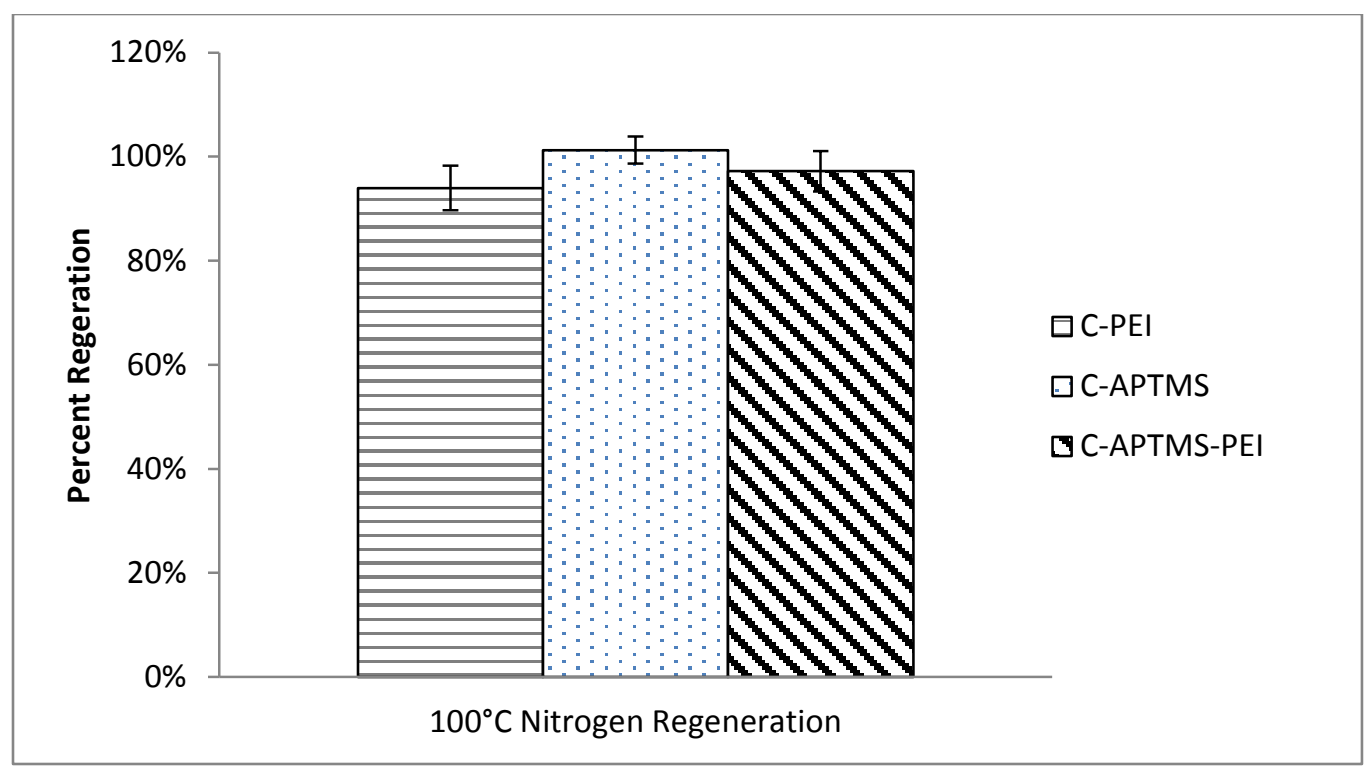

Figure 5-13: Percent regeneration using pure nitrogen at $100^{\circ} \mathrm{C}$ in a TGA

The regeneration of the adsorbents using pure nitrogen at $100^{\circ} \mathrm{C}$ showed that regeneration of the adsorbents was possible. Samples treated with only APTMS showed the best cycling capabilities with the use of pure nitrogen at $100^{\circ} \mathrm{C}$. The loss in adsorption capacity of the samples treated with PEI could be from loss of PEI due to evaporation of the amine, or the slow formation of stable urea onto the adsorbent.

In order to determine the effects of multiple cycles using nitrogen as the sweep gas, an experiment with 10 cycles was conducted for each treatment. Three runs using samples with high $\mathrm{CO}_{2}$ adsorption capacities were conducted. Figure 5-14 shows the $\mathrm{CO}_{2}$ adsorption capacity for each treatment over 10 cycles using nitrogen at $100^{\circ} \mathrm{C}$ for regeneration. 


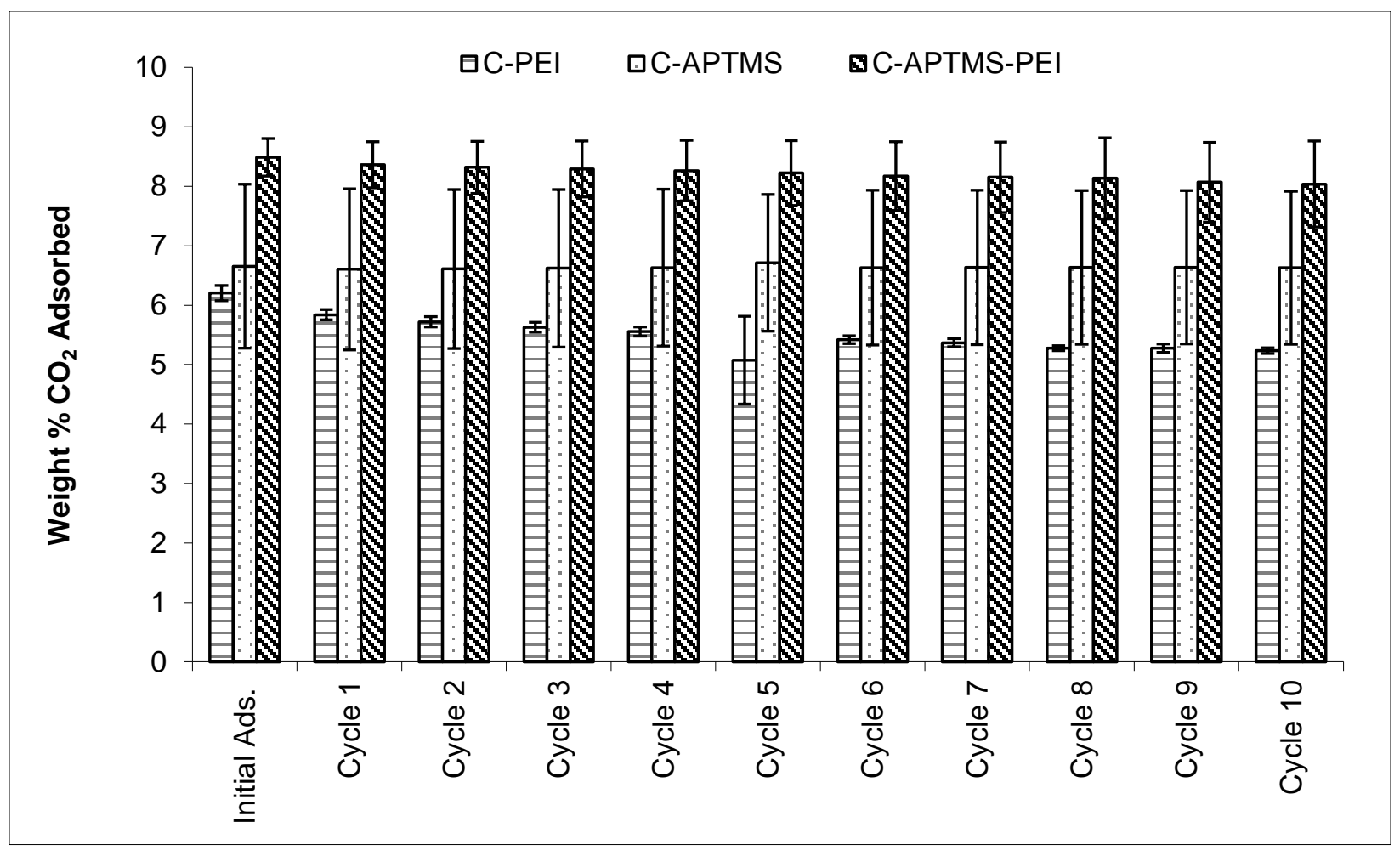

Figure 5-14: $\mathrm{CO}_{2}$ adsorption capacity over 10 cycles

Figure 5-14 shows that there is a slight loss in the average $\mathrm{CO}_{2}$ adsorption capacity for each treatment after the initial adsorption. The adsorption capacity for each treatment over ten cycles is reasonably constant. This would indicate that cycling of the amine treated adsorbents with little loss of $\mathrm{CO}_{2}$ adsorption capacity is possible.

\subsection{Regeneration of Adsorbents using $\mathrm{CO}_{2}$ and ${\mathrm{Humid} \mathrm{CO}_{2}}$}

One of the problems with using nitrogen as a sweep gas during regeneration is that it is not very realistic in an actual commercial setting. This is because the flue gas for a coal-fired power plant consists of a large amount of nitrogen and $\mathrm{CO}_{2}$. Regeneration using nitrogen basically leaves one with the same composition as the initial flue stream. If a different sweep gas is to be used, one possibility is low pressure steam, which can be easily removed from the $\mathrm{CO}_{2}$ by condensing out the water. Another possibility would be using pure $\mathrm{CO}_{2}$ as the sweep 
gas. Using $\mathrm{CO}_{2}$ as a sweep gas would require heating the sorbent to a temperature were $\mathrm{CO}_{2}$ is released from the sorbent. The problem with using dry $\mathrm{CO}_{2}$ to regenerate the sorbent is that it has been reported that dry $\mathrm{CO}_{2}$ can react with amines at high temperature to produce urea, which is difficult to remove. ${ }^{[60]}$ This would reduce the amount of $\mathrm{CO}_{2}$ adsorbed in subsequent cycles. The first experiment conducted was a temperature test on a clay sample treated with APTMS. In this test the sample was heated in pure nitrogen to $100^{\circ} \mathrm{C}$ for 30 minutes and then cooled to $30^{\circ} \mathrm{C}$. The reaction gas was then switched to $\mathrm{CO}_{2}$ and the temperature was increased at $2^{\circ} \mathrm{C} /$ minute until $350^{\circ} \mathrm{C}$. Figure $5-15$ is a TGA graph of this procedure.

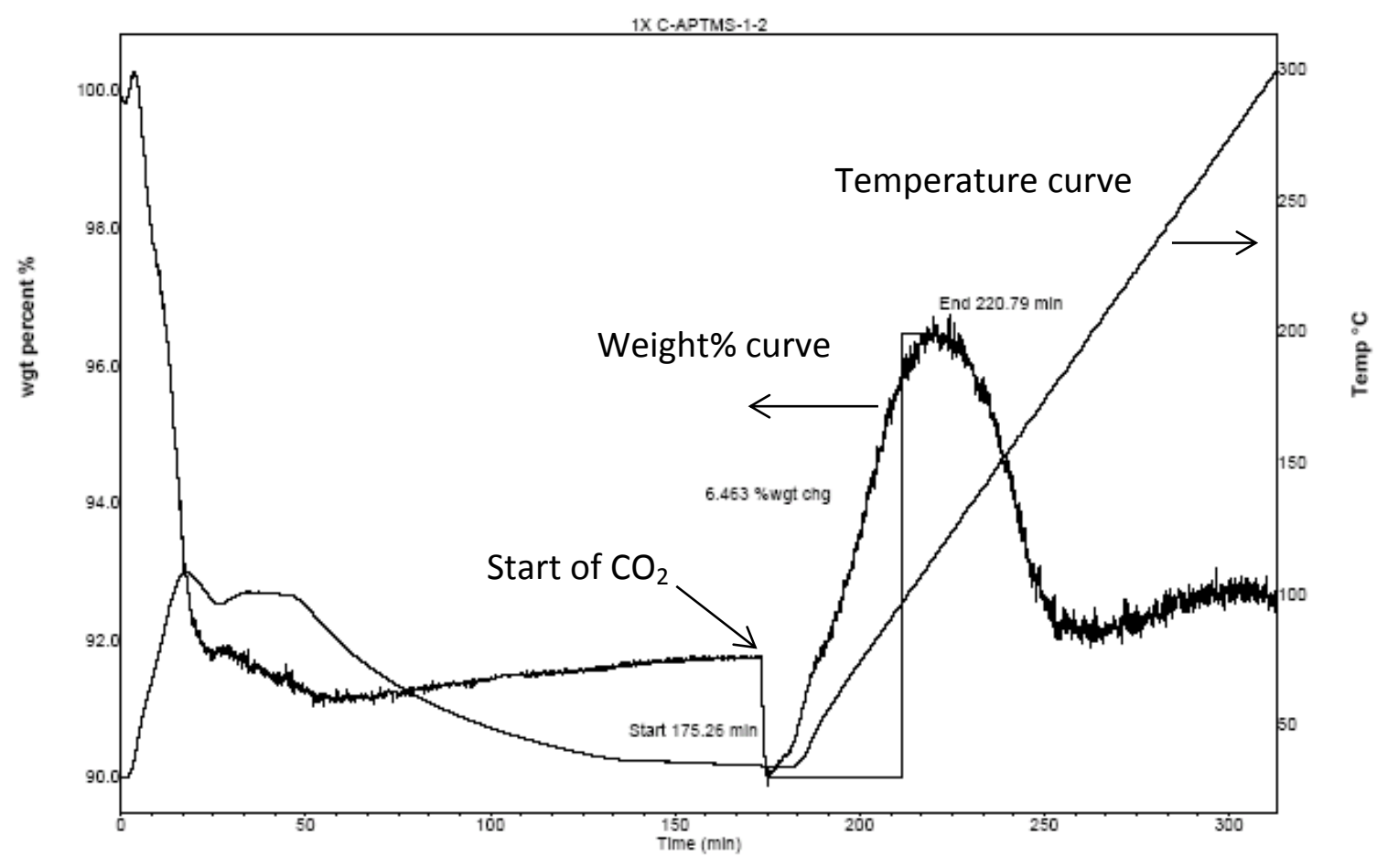

Figure 5-15: TGA graph clay treated with APTMS pure $\mathrm{CO}_{2}$ temperature study

In Figure 5-15 the $\mathrm{CO}_{2}$ adsorbed increased with temperature until about $100^{\circ} \mathrm{C}$ and then started to decrease, but eventually leveled out before returning back to the starting $\mathrm{CO}_{2}$ adsorption weight. This would indicate that there is an irreversible reaction taking place where 
some of the $\mathrm{CO}_{2}$ that was reacted did not desorb. This phenomenon has been reported by other researchers using amines on solid sorbents. ${ }^{[60]}$ This test was also conducted on a sample of clay treated with PEI, and the results are shown in the TGA curve in Figure 5-16.

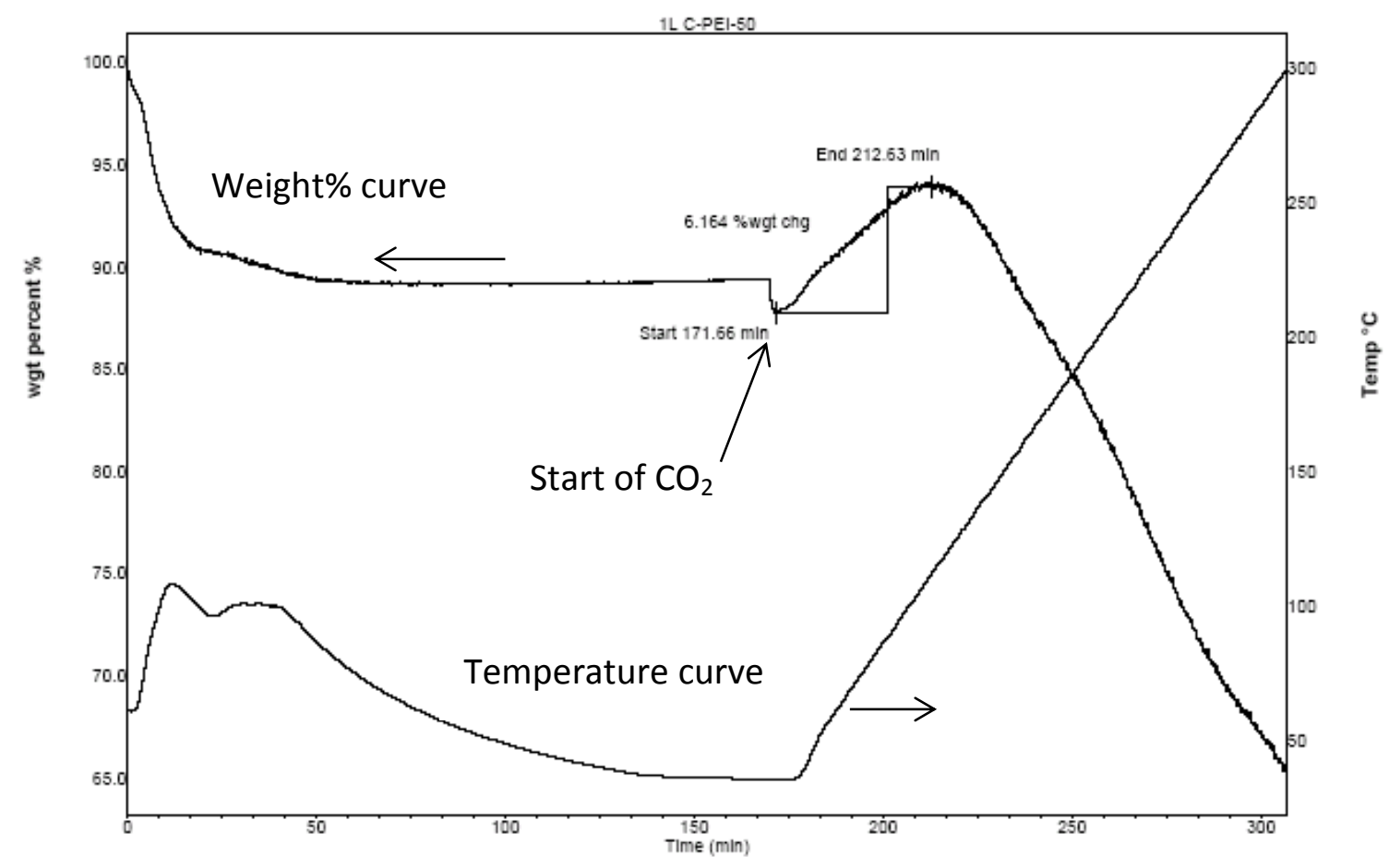

Figure 5-16: Clay treated with $\mathrm{PEI}$ pure $\mathrm{CO}_{2}$ temperature study

It can be seen that the graph in Figure 5-16 differs from the graph generated with clay treated with APTMS. Once the weight begins to decrease, indicating the removal of $\mathrm{CO}_{2}$, the weight continues to decrease with increasing temperature, without leveling. This is probably due to the loss of PEI from the sample as the temperature increases. In Figure 5-16 the temperature at which the weight loss is greater than the $\mathrm{CO}_{2}$ adsorbed is about $155^{\circ} \mathrm{C}$. Therefore, for the regeneration study in $\mathrm{CO}_{2}$ the regeneration temperature used was $155^{\circ} \mathrm{C}$.

The procedure to test the regeneration of the sorbents in pure $\mathrm{CO}_{2}$ involved heating the sample in nitrogen to $100^{\circ} \mathrm{C}$ and, keeping the temperature isothermal for 30 minutes to get a 
good baseline for $\mathrm{CO}_{2}$ adsorption. The reactor was then cooled to $85^{\circ} \mathrm{C}$, and the reaction gas was switched to $\mathrm{CO}_{2}$. After the adsorption of $\mathrm{CO}_{2}$, the reactor was heated to $155^{\circ} \mathrm{C}$ for 30 minutes under pure $\mathrm{CO}_{2}$ to regenerate the adsorbent. The reactor was then cooled to $85^{\circ} \mathrm{C}$ for the first cycle of $\mathrm{CO}_{2}$ adsorption. The amount of $\mathrm{CO}_{2}$ adsorbed initially was then compared to the amount adsorbed at the end of the first cycle. Figure 5-17 is a TGA graph of sample 1AT, clay treated with PEI, using this procedure. In Figure 5-17, the initial $\mathrm{CO}_{2}$ adsorption is 6.8 weight percent, but the amount desorbed is only 5.3 weight percent. When the temperature was reduced back to $85^{\circ} \mathrm{C}$, the weight increased by $5.6 \%$. This reduction in carbon dioxide adsorption indicates that all of the $\mathrm{CO}_{2}$ was not removed from the sample.

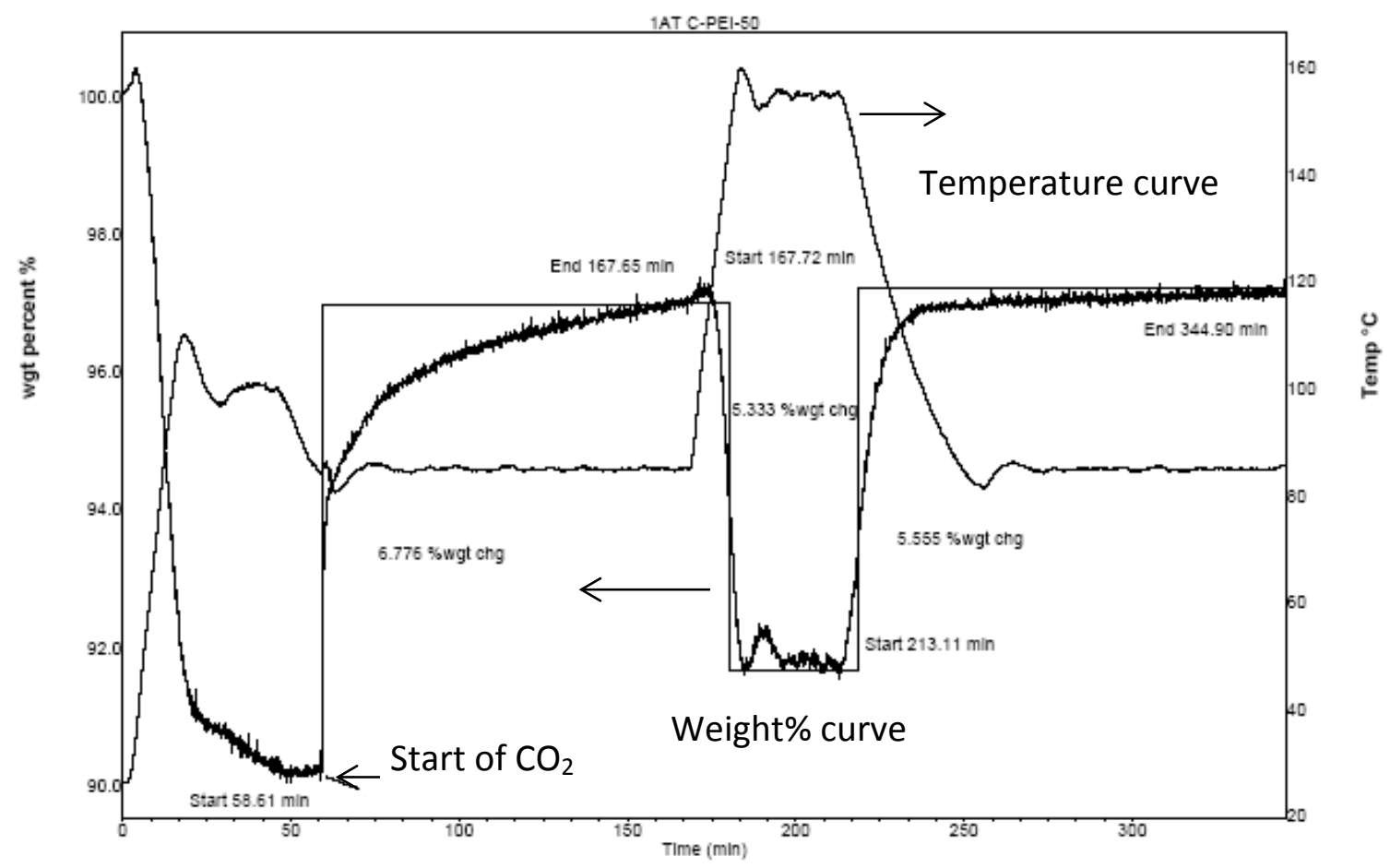

Figure 5-17: Clay treated with PEI, initially in pure nitrogen at $100^{\circ} \mathrm{C}$ then switched to pure $\mathrm{CO}_{2}$ for adsorption at $85^{\circ} \mathrm{C}$ and desorption at $155^{\circ} \mathrm{C}$ 
Cycling in pure $\mathrm{CO}_{2}$ for all three treatments was conducted using a temperature of $155^{\circ} \mathrm{C}$ for 30 minutes, with an adsorption temperature of $85^{\circ} \mathrm{C}$. The same initial step of ramping the sample to $100^{\circ} \mathrm{C}$ in nitrogen was still performed. The results of this experiment are given in Figure 5-18. For all three treatments, the $\mathrm{CO}_{2}$ adsorption capacity went down with the second cycling. If this trend continued and did not stabilize after a couple cycles, which has been shown to happen in the literature with solid amine adsorbents, ${ }^{[59],[57]}$ this technique would not be recommended if hundreds or thousands of regenerations were needed.

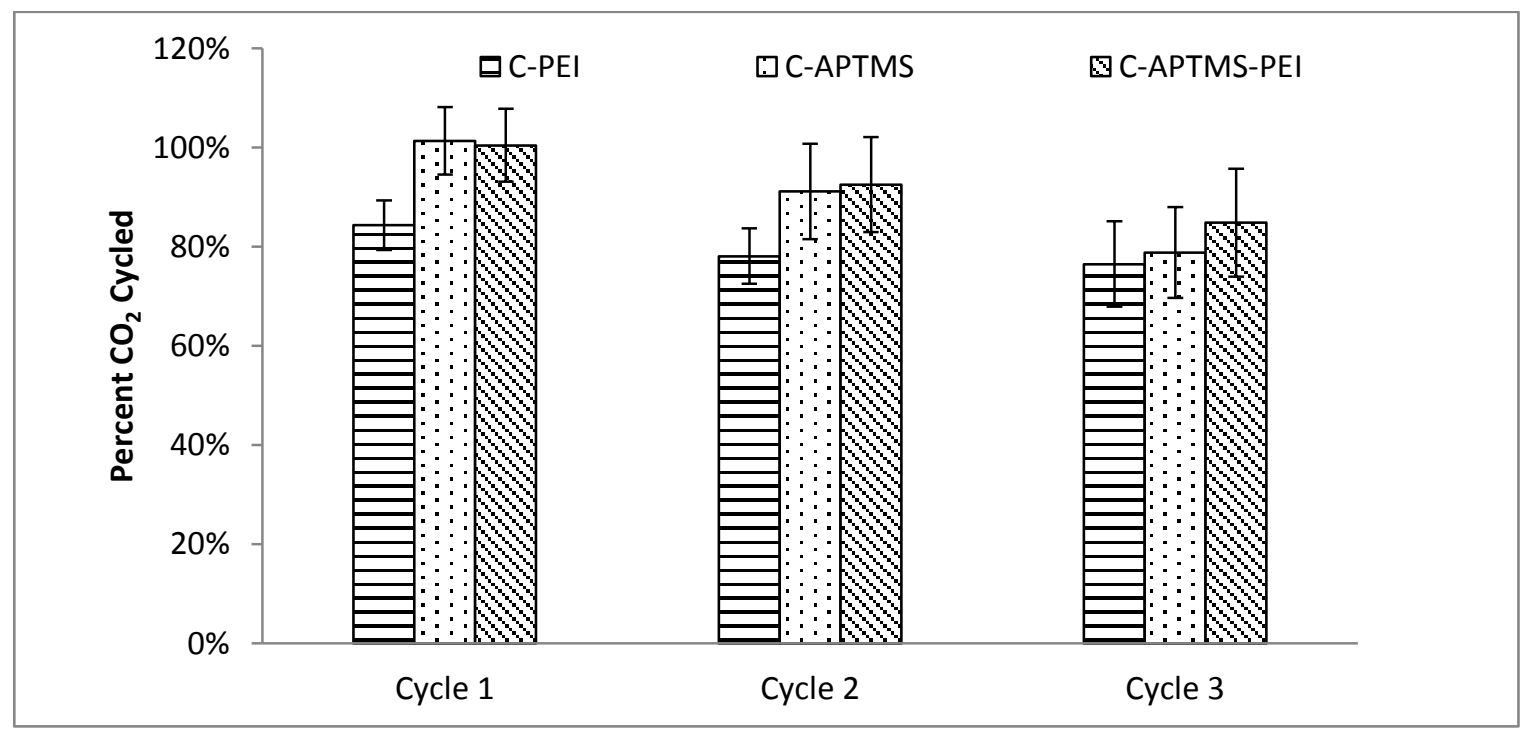

Figure 5-18: Percent carbon dioxide cycled at $85^{\circ} \mathrm{C}$ in the TGA using pure $\mathrm{CO}_{2}$ at $155^{\circ} \mathrm{C}$ for 30 minutes for regeneration

The results in Figure 5-18 show that there is a reduction in the $\mathrm{CO}_{2}$ adsorption capacity when cycling in pure $\mathrm{CO}_{2}$. This would indicate that cycling in pure $\mathrm{CO}_{2}$ is not the most ideal way to regenerate the adsorbent.

The regeneration using humid $\mathrm{CO}_{2}$ was conducted by bubbling the reaction gas through a beaker of deionized water. The amount of water in the reaction gas was assumed by 
calculating the vapor pressure at room temperature using the Antoine equation shown in Equation 5-1.

$$
\log _{10}(P)=A-\frac{B}{C+T}
$$

The pressure $P$ is in $\mathrm{mmHg}$ and the temperature $T$ is in degrees Celsius. $A, B$, and $C$ are constants for water, which are $8.07131,1730.63$, and 233.426 respectively. Using this equation, the vapor pressure for water at an average room temperature of $22^{\circ} \mathrm{C}$ can be calculated to be $2.63 \mathrm{kPa}$, assuming atmospheric pressure and pure $\mathrm{CO}_{2}$, the amount of water added to the reaction stream is $2.6 \%$ with the balance being $\mathrm{CO}_{2}$. Figure 5-19 is a schematic of the setup for the addition of water to the reaction stream.

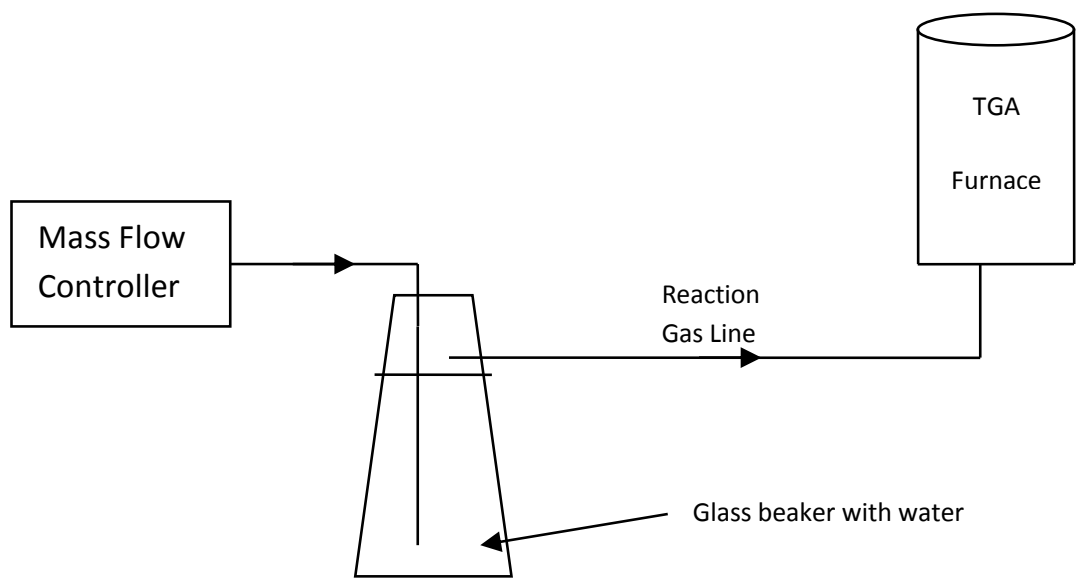

Figure 5-19: Schematic of the addition of water to the reaction gas

The regeneration of the adsorbent using humid $\mathrm{CO}_{2}$ employed humid $\mathrm{CO}_{2}$ over the entire run, and it was conducted at the same conditions as the regeneration using pure $\mathrm{CO}_{2}$, which is desorption at $155^{\circ} \mathrm{C}$ for 30 minutes. The results for the regeneration of clay treated with APTMS, PEI, and APTMS+PEI are shown in Figure 5-20. The regeneration for clay treated 
with APTMS averaged 95\% regeneration over two cycles. The regeneration for clay treated with PEI also showed good results with a cycling of $95 \%$ and $92 \%$ for the first and second cycle respectively. The regeneration of samples treated with both APTMS+PEI went down to $92 \%$ over two cycles.

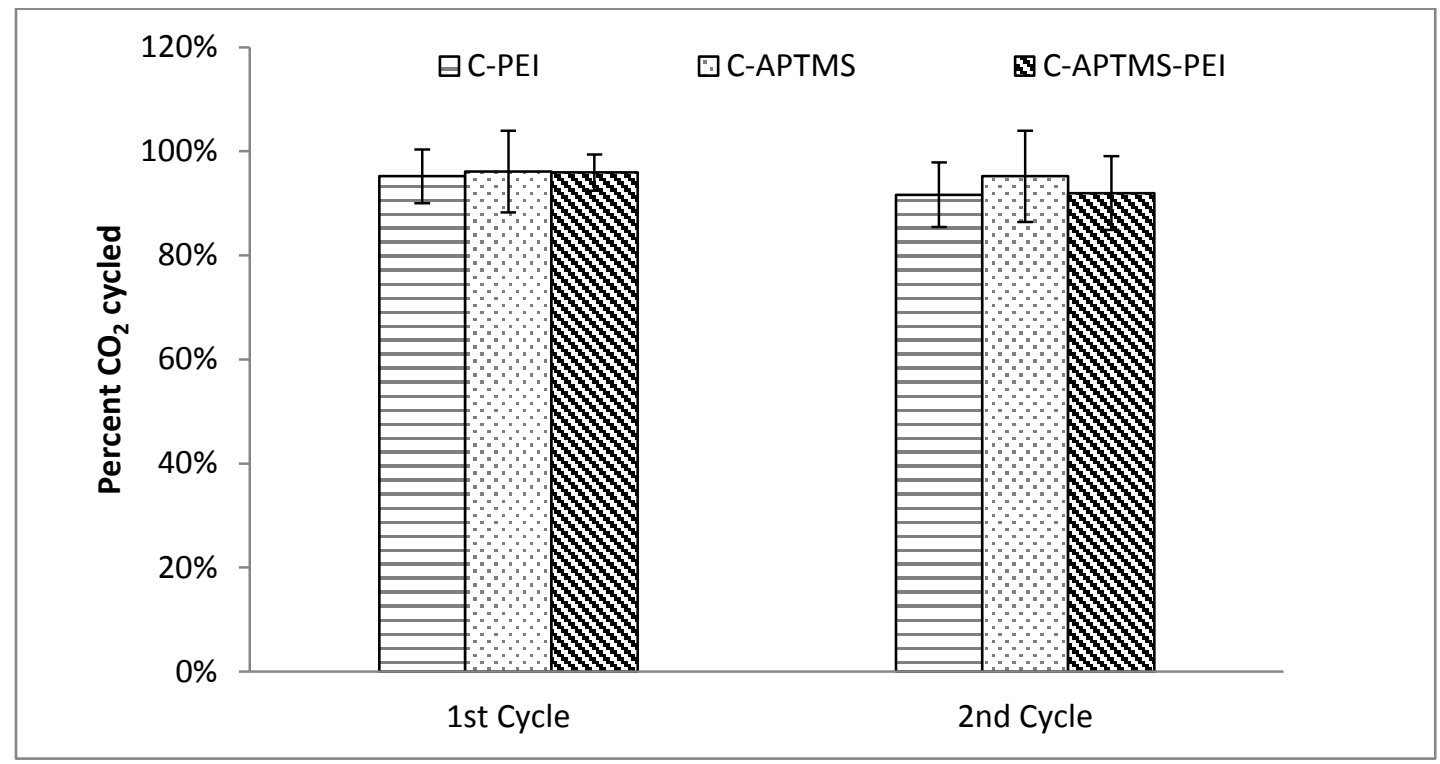

Figure 5-20: Percent $\mathrm{CO}_{2}$ cycled using humid $\mathrm{CO}_{2}$ at $155^{\circ} \mathrm{C}$ for 30 minutes

The regeneration using humid $\mathrm{CO}_{2}$ showed some promising results. Although there was still some degradation to the adsorption capacity, the amount of water in the reaction stream was very low and increasing the percentage of water in the reaction gas might show better results similar to the literature. ${ }^{[57]}$ The use of humid $\mathrm{CO}_{2}$ showed results that are apparently better than cycling with pure $\mathrm{CO}_{2}$, although there is some degradation to the $\mathrm{CO}_{2}$ adsorption capacity with samples treated with PEI. This degradation could be attributed to the loss of PEI on the sample from the regeneration temperature being too close to the temperature were PEI starts to be removed from the sample. 


\subsection{Regeneration of Adsorbents using Vacuum}

Vacuum desorption is one conceivable way to desorb a solid adsorbent in real world applications. Therefore, experiments were done to test to see if vacuum, at the same temperature as the $\mathrm{CO}_{2}$ adsorption temperature $\left(85^{\circ} \mathrm{C}\right)$, could remove all of the $\mathrm{CO}_{2}$ that was adsorbed onto the adsorbent.

The first test of this hypothesis was conducted using Thermo Cahn Thermax 500 in pure $\mathrm{CO}_{2}$ and $\mathrm{N}_{2}$ streams. A sample of clay treated with APTMS, $1 \mathrm{AK}$, was placed into the TGA, and the regular $\mathrm{CO}_{2}$ adsorption test at $85^{\circ} \mathrm{C}$ was conducted. This entails a drying step in pure $\mathrm{N}_{2}$ at $100^{\circ} \mathrm{C}$ for 30 minutes, then reducing the temperature to $85^{\circ} \mathrm{C}$ and switching the gas to $\mathrm{CO}_{2}$. The weight gained during the adsorption step is used to calculate the weight percent $\mathrm{CO}_{2}$ gained.

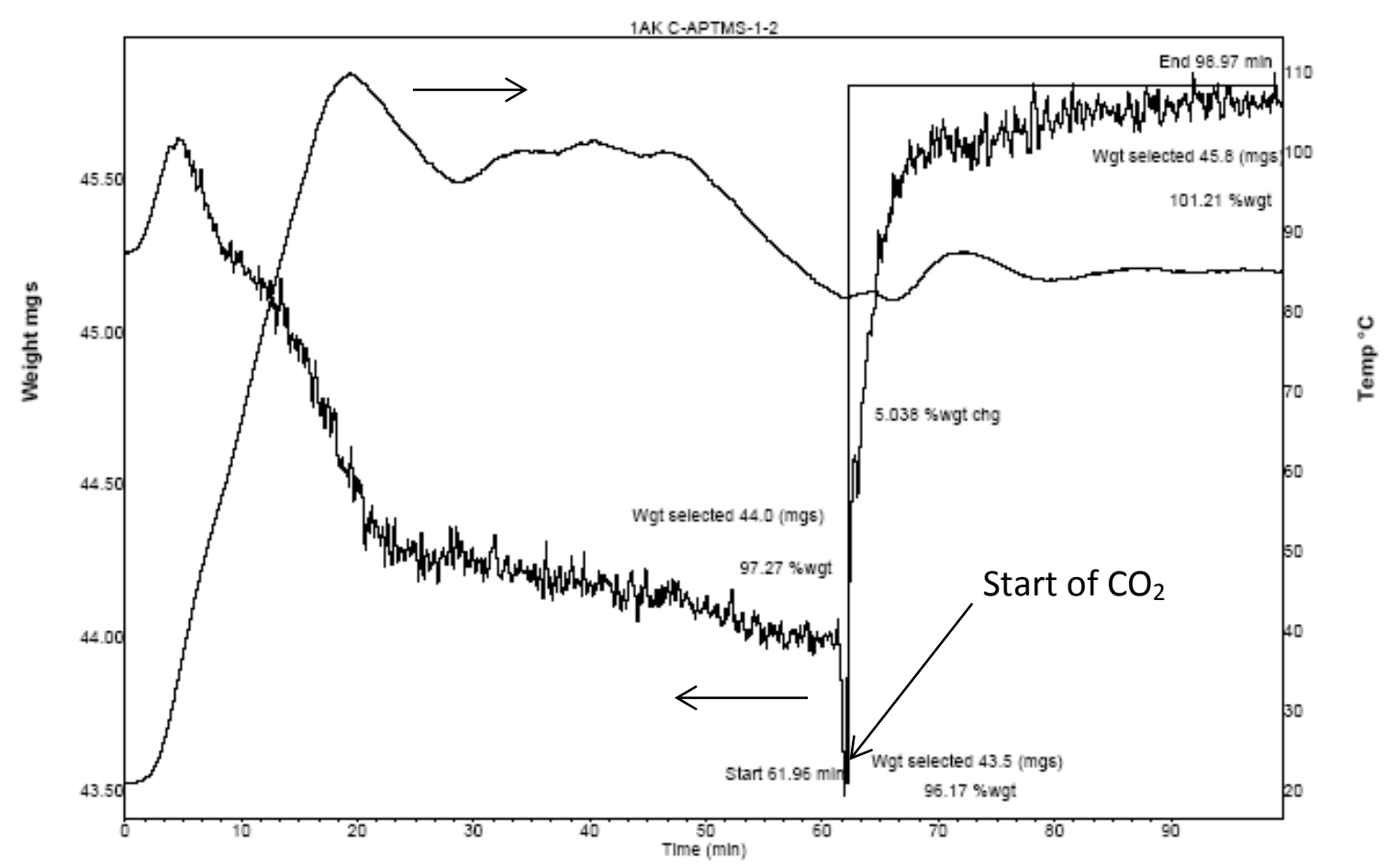

Figure 5-21: Clay treated with APTMS initial $\mathrm{CO}_{2}$ adsorption run for vacuum study 
In Figure 5-21, there is a 5.0wt\% gain of $\mathrm{CO}_{2}$ which is in the standard deviation range of samples of clay treated with APTMS at $85^{\circ} \mathrm{C}$. The run was stopped because an apparent equilibrium had been reached. The sample was then removed and weighed in the balance to confirm the weight after the TGA run. The sample was then placed into the vacuum oven at $85^{\circ} \mathrm{C}$ for 1 hour under vacuum with a gauge reading of $93 \mathrm{kPa}$. Table $5-3$ shows the results of the weight of the sample before and after the TGA run and after vacuum at $85^{\circ} \mathrm{C}$ for 1 hour. The weight after the drying step in $\mathrm{N}_{2}$ is assumed to be the weight of the adsorbent that has no $\mathrm{CO}_{2}$ adsorbed onto it. Therefore, the target weight after removing the sample from the vacuum oven was $44.0 \mathrm{mg}$. The weight after removing the sample from the vacuum oven was $43.27 \mathrm{mg}$. The weight of the sample after removing from the vacuum oven however was rising very quickly and the weight after only 1 minute was 43.84 . This rapid increase in the weight is thought to come from water condensing onto the sample or the pan as it cools to room temperature. The sample was then placed into the TGA for adsorption of $\mathrm{CO}_{2}$ to determine the $\mathrm{CO}_{2}$ adsorption capacity after vacuum desorption of the sample.

Table 5-3: Weight of clay treated with APTMS during different steps of the vacuum study

\begin{tabular}{|l|c|}
\hline & Weight $(\mathrm{mg})$ \\
\hline Initial Sample Weight & 45.256 \\
\hline Sample weight after $\mathrm{N}_{2}$ drying step in TGA & 44.0 \\
\hline Sa. Wt. after gas switch to $\mathrm{CO}_{2}$ in TGA & 43.5 \\
\hline Sa. Wt. after $\mathrm{CO}_{2}$ adsorption reached Eq. & 45.8 \\
\hline Sa. Wt. 1 min after $1^{\text {st }}$ vacuum desorption & 43.84 \\
\hline Weight after gas switched to $\mathrm{CO}_{2} 2^{\text {nd }}$ TGA run & 43.7 \\
\hline Weight after $\mathrm{CO}_{2}$ adsorption $2^{\text {nd }}$ TGA run & 45.35 \\
\hline
\end{tabular}

After the sample was run in the TGA it was then weighed again in the balance to confirm the weight in the TGA. Again the weight was increasing quickly on the balance. After 10 minutes 
the sample was weighed again and placed back into the vacuum oven at $85^{\circ} \mathrm{C}$ and $93 \mathrm{kPa}$ overnight for 17 hours. The sample was then weighed in the balance to compare and measure the decrease in weight during the vacuum regeneration step. This long desorption time was conducted for more than one reason. First to simulate the effects of many regenerations of the sample using vacuum regeneration, and second to see if the longer desorption time removed any more $\mathrm{CO}_{2}$ or $\mathrm{H}_{2} \mathrm{O}$ that could have reduced the $\mathrm{CO}_{2}$ capacity of the sample after the first vacuum run of 1 hour. To determine if any desorption was taking place in the TGA not attributed to the desorption in the vacuum, the weights of sample when it was initially placed into the TGA were compared to the weight just before the reaction gas was switched to $\mathrm{CO}_{2}$. Figure 5-22 is a TGA graph of a sample of clay treated with APTMS, 1AK, after the second vacuum desorption step of 17 hours at $85^{\circ} \mathrm{C}$.

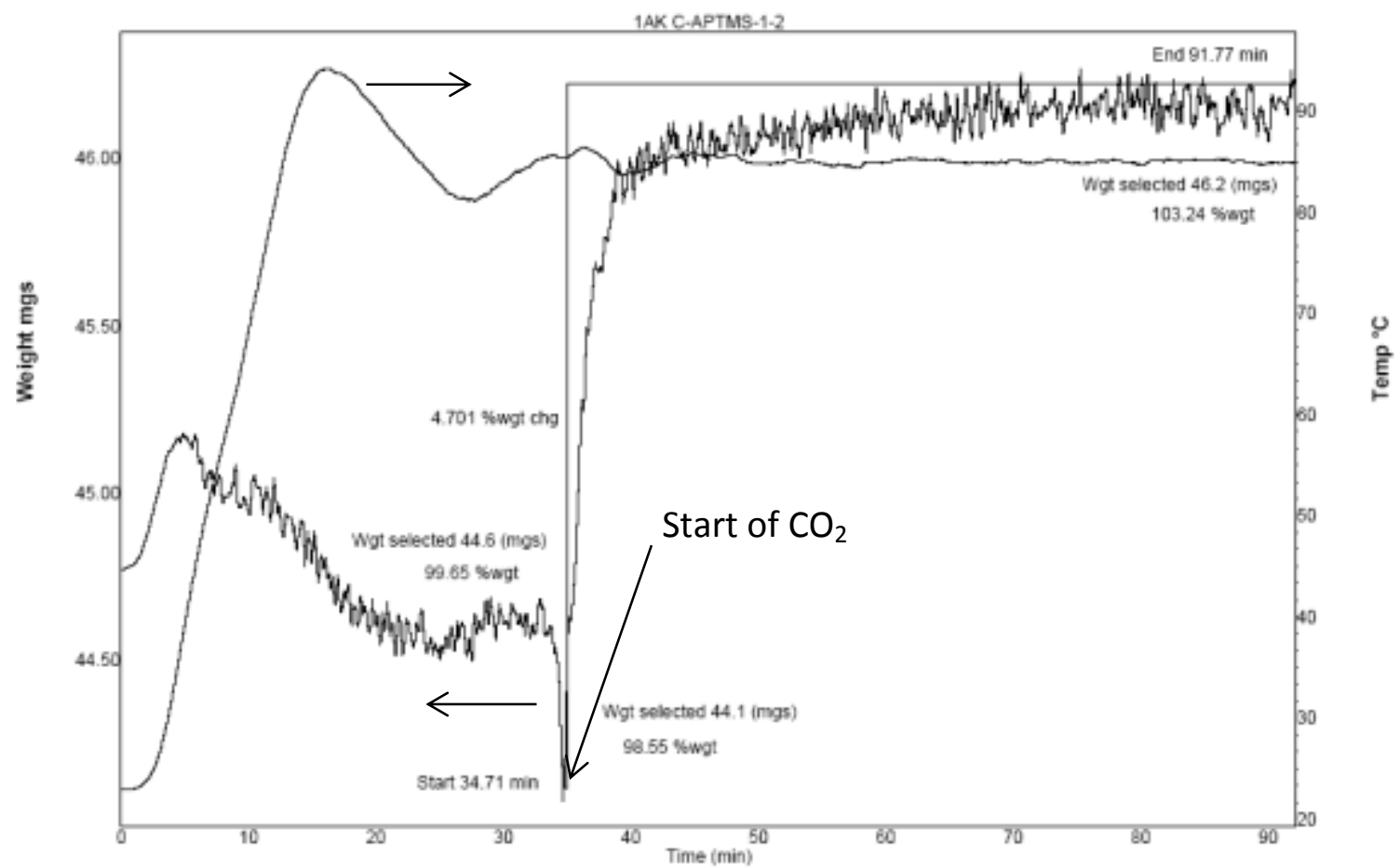

Figure 5-22: TGA graph of clay treated with APTMS after the $2^{\text {nd }}$ vacuum desorption step 
In Figure 5-22 it can be seen that there is very little weight loss during the ramping step to the reaction temperature of $85^{\circ} \mathrm{C}$. This indicates that all of the $\mathrm{CO}_{2}$ desorption occurred during the vacuum desorption step and not in the TGA.

The second sample that was studied was clay treated with PEI. The same procedure was performed on this sample. There was an initial TGA run conducted with a drying step in $\mathrm{N}_{2}$ at $100^{\circ} \mathrm{C}$, then the temperature was reduced to $85^{\circ} \mathrm{C}$ and the reaction gas was switched to $\mathrm{CO}_{2}$ to calculate the amount of $\mathrm{CO}_{2}$ adsorbed onto the sample. The sample was then weighed and placed into the vacuum oven at $85^{\circ} \mathrm{C}$ and $93 \mathrm{kPa}$ for 1 hour. The sample weight was recorded and the sample was placed into the TGA with a $\mathrm{N}_{2}$ purge.

The TGA procedure after the first and second vacuum was the same for this sample and consisted of ramping the sample in $\mathrm{N}_{2}$ to $85^{\circ} \mathrm{C}$ then switching the reaction gas to $\mathrm{CO}_{2}$. Table $5-4$ is a comparison of the weight of the sample at the beginning of the run compared to the weight of the sample right before the reaction gas was switched to $\mathrm{CO}_{2}$.

Table 5-4: Comparison of the beginning TGA weight with the TGA weight right before the reaction gas was switched to $\mathrm{CO}_{2}$

\begin{tabular}{|l|l|l|}
\hline C-PEI-50 & $\begin{array}{l}\text { Beginning TGA } \\
\text { weight }(\mathrm{mg})\end{array}$ & $\begin{array}{l}\text { TGA weight (mg) before switching } \\
\text { to } \mathrm{CO}_{2}\end{array}$ \\
\hline $1^{\text {st }}$ TGA run base run & 39.4 & $36.5(93 \%$ of beginning TGA wt $)$ \\
\hline $2^{\text {nd }}$ TGA run after $1^{\text {st }}$ vac $1 \mathrm{hr}$ & 34.6 & $34.6(100 \%$ of beginning TGA $w t)$ \\
\hline $3^{\text {rd }}$ TGA run after $2^{\text {nd }}$ vac $17 \mathrm{hr}$ & 33.2 & $33.2(100 \%$ of beginning TGA wt $)$ \\
\hline
\end{tabular}

In Table $5-4$, the weight in the $1^{\text {st }}$ TGA run is reduced by $7 \%$ before the reaction gas is switched to $\mathrm{CO}_{2}$ this is expected because it is assumed that water and or $\mathrm{CO}_{2}$ is adsorbed onto the sample while it is stored before the TGA run. Also, in the base run the sample is 
intentionally dried at $100^{\circ} \mathrm{C}$ in $\mathrm{N}_{2}$ for 30 minutes to establish a baseline for $\mathrm{CO}_{2}$ adsorption. In the TGA runs after the vacuum desorption studies, one would not want any drying or desorption occurring while the TGA is ramping to the reaction temperature of $85^{\circ} \mathrm{C}$, because the effect of desorption due to vacuum is being studied. Therefore, since there is no overall reduction or gain in weight during the ramping to $85^{\circ} \mathrm{C}$ in $\mathrm{N}_{2}$, one can assume that the TGA procedure is a relatively good one to study the effects of vacuum desorption. Table 5-5 is a comparison of the $\mathrm{CO}_{2}$ adsorption capacities of a sample of clay treated with PEI during the vacuum study.

Table 5-5: Sample of clay loaded with 50\% PEI comparison of $\mathrm{CO}_{2}$ adsorption capacities

\begin{tabular}{|l|c|}
\hline C-PEI-50 & $\mathrm{CO}_{2}$ adsorption capacity (wt \%) \\
\hline $1^{\text {st }}$ TGA run base run & 5.2 \\
\hline $2^{\text {nd }}$ TGA run after $1^{\text {st }}$ vac $1 \mathrm{hr}$ & $5.4(104 \%$ of initial) \\
\hline $3^{\text {rd }}$ TGA run after $2^{\text {nd }}$ vac $17 \mathrm{hr}$ & $4.7(90 \%$ of initial) \\
\hline
\end{tabular}

The $\mathrm{CO}_{2}$ adsorption capacity after the first vacuum run compares very well with the initial value indicating that the vacuum completely desorbs all of the $\mathrm{CO}_{2}$ from the sample. The $\mathrm{CO}_{2}$ adsorption capacity after 17 hour vacuum treatment is reduce to $90 \%$ of the initial capacity indicating there might be some degradation to the sample, probably due to loss of amine or some other mechanism. Figures 5-23 and 5-24 are the TGA graphs for sample clay treated with PEI during the vacuum study. Figure 5-23 shows then initial $\mathrm{CO}_{2}$ adsorption at $85^{\circ} \mathrm{C}$ for clay treated with PEI. Figure 5-24 shows the $\mathrm{CO}_{2}$ adsorption of clay treated with PEI after one hour vacuum desorption at $85^{\circ} \mathrm{C}$. Figure $5-24$ shows very little weight difference of the sample during the heating to $85^{\circ} \mathrm{C}$ in nitrogen. This indicates that all of the desorption was due to the vacuum desorption step. 


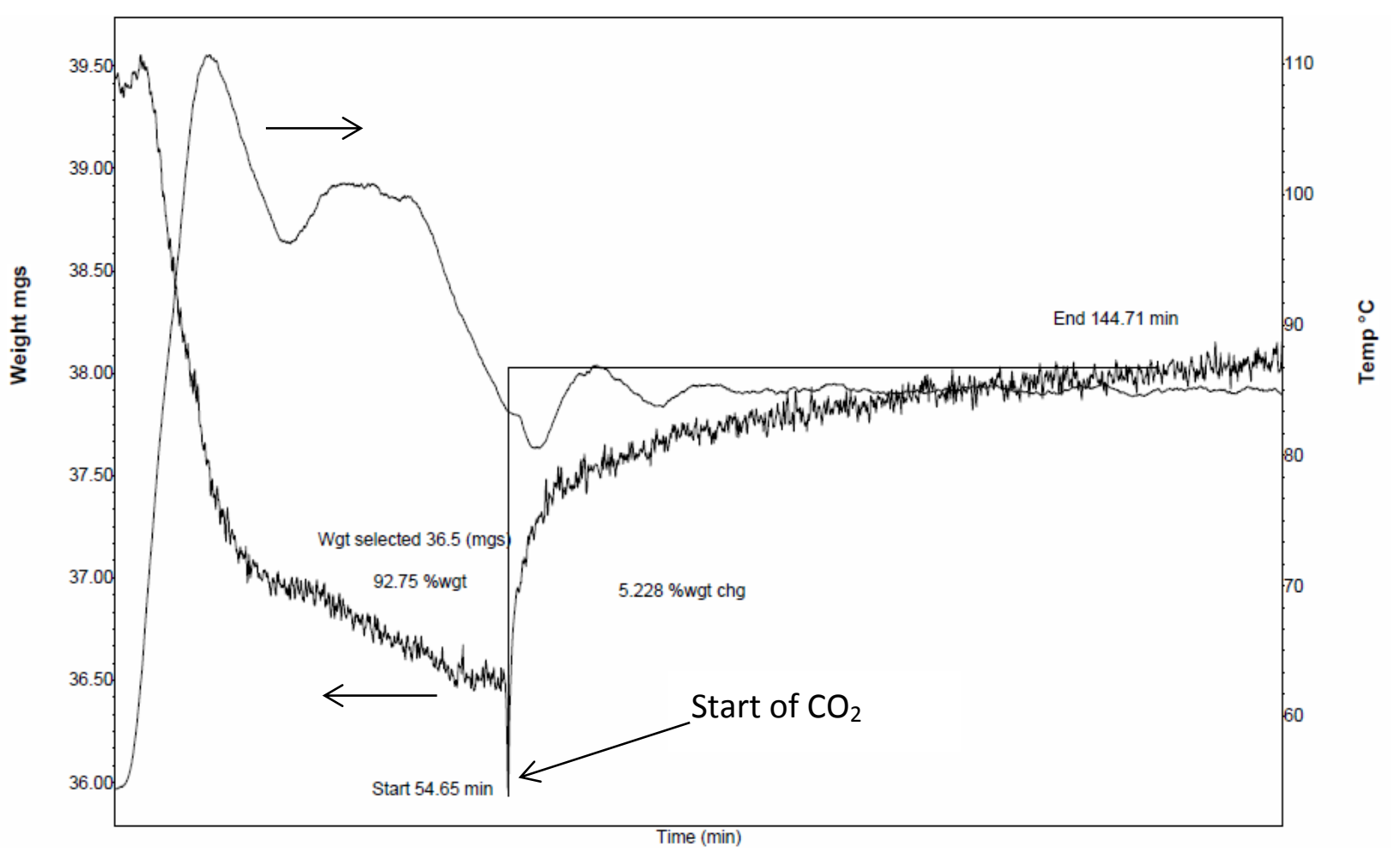

Figure 5-23: TGA graph of clay treated with PEI initial $\mathrm{CO}_{2}$ adsorption at $85^{\circ} \mathrm{C}$

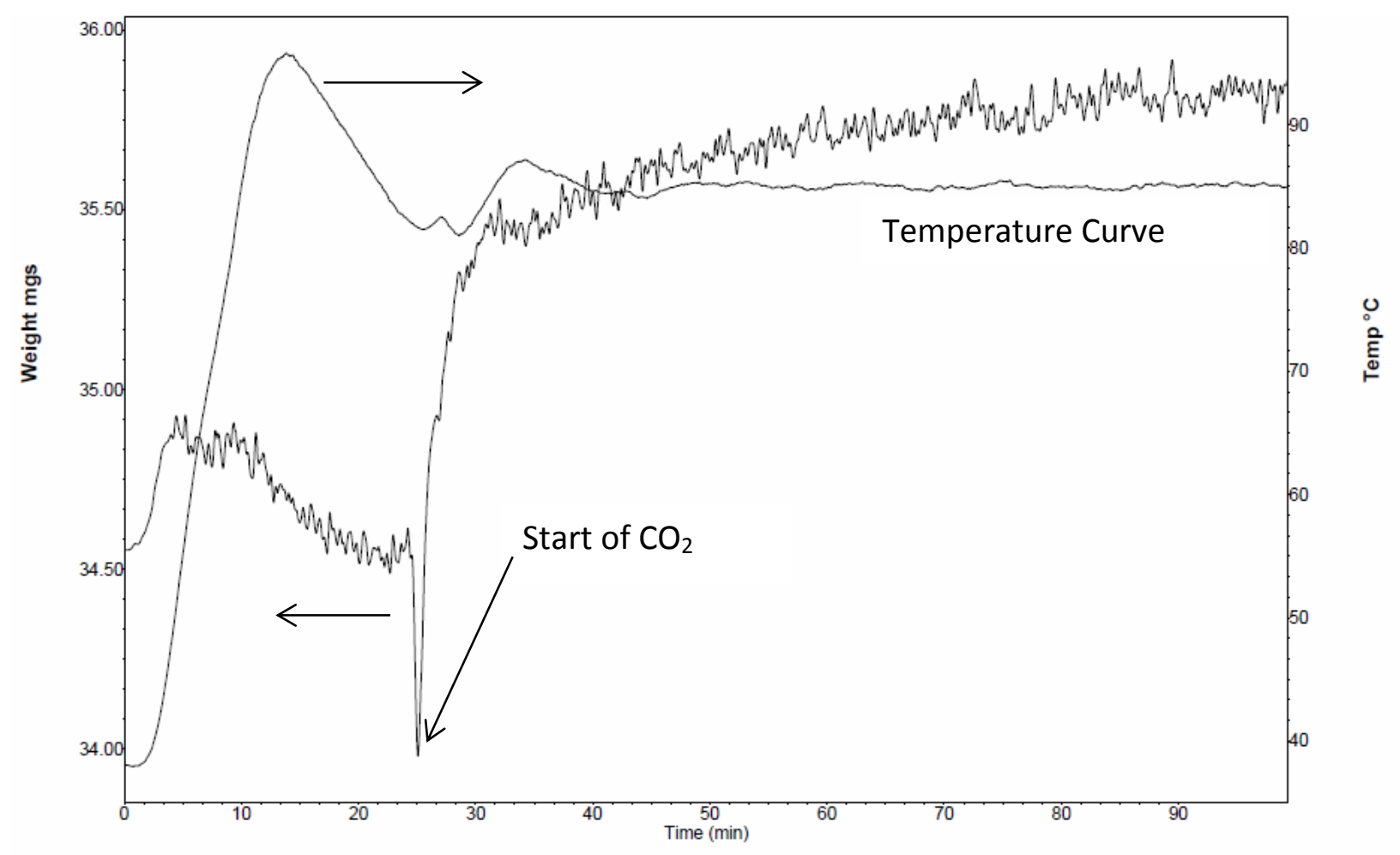

Figure 5-24: TGA graph of clay treated with PEI after first vacuum desorption step 
This procedure was utilized on all of the treated samples to confirm the data. Figure 525 is a graphical representation of the regeneration using vacuum desorption with $\mathrm{CO}_{2}$ adsorption at $85^{\circ} \mathrm{C}$ in the TGA. It shows that regeneration with vacuum at $85^{\circ} \mathrm{C}$ and $93 \mathrm{kPa}$ is possible for cycling the treated adsorbents. After the first regeneration using vacuum at 1 hour, it can be seen that there is apparently very little degradation for the treated samples. The $\mathrm{CO}_{2}$ adsorption capacity for the samples treated with APTMS decreased the most. Two reasons for this are that the desorption time in the vacuum was not long enough to desorbed all of the $\mathrm{CO}_{2}$ or the samples are being degraded. After the 17 hour vacuum desorption step the $\mathrm{CO}_{2}$ adsorption capacity for the samples treated with APTMS went up. This indicates that the desorption time might need to be increased above 1 hour for samples treated with APTMS to achieve the best cycling $\mathrm{CO}_{2}$ adsorption capacity. Additionally, this indicates that samples treated with APTMS are possibly stable to vacuum desorption for potentially 17 cycles. The samples treated with PEI and the combination of APTMS and PEI had a decrease in the $\mathrm{CO}_{2}$ adsorption capacity after the 17 hour vacuum desorption step. This means there is probably some degradation to the samples probably caused by the loss of amines from the support. For clay treated with only PEI the sample showed very little degradation during the first one hour vacuum cycle, but after 17 hours the regeneration was only $86.6 \%$ indicating that the sample does not return to its original $\mathrm{CO}_{2}$ adsorption capacity over 17 hours vacuum at $85^{\circ} \mathrm{C}$. This is not completely unexpected since the PEI is not covalently attached to the clay as APTMS is. 


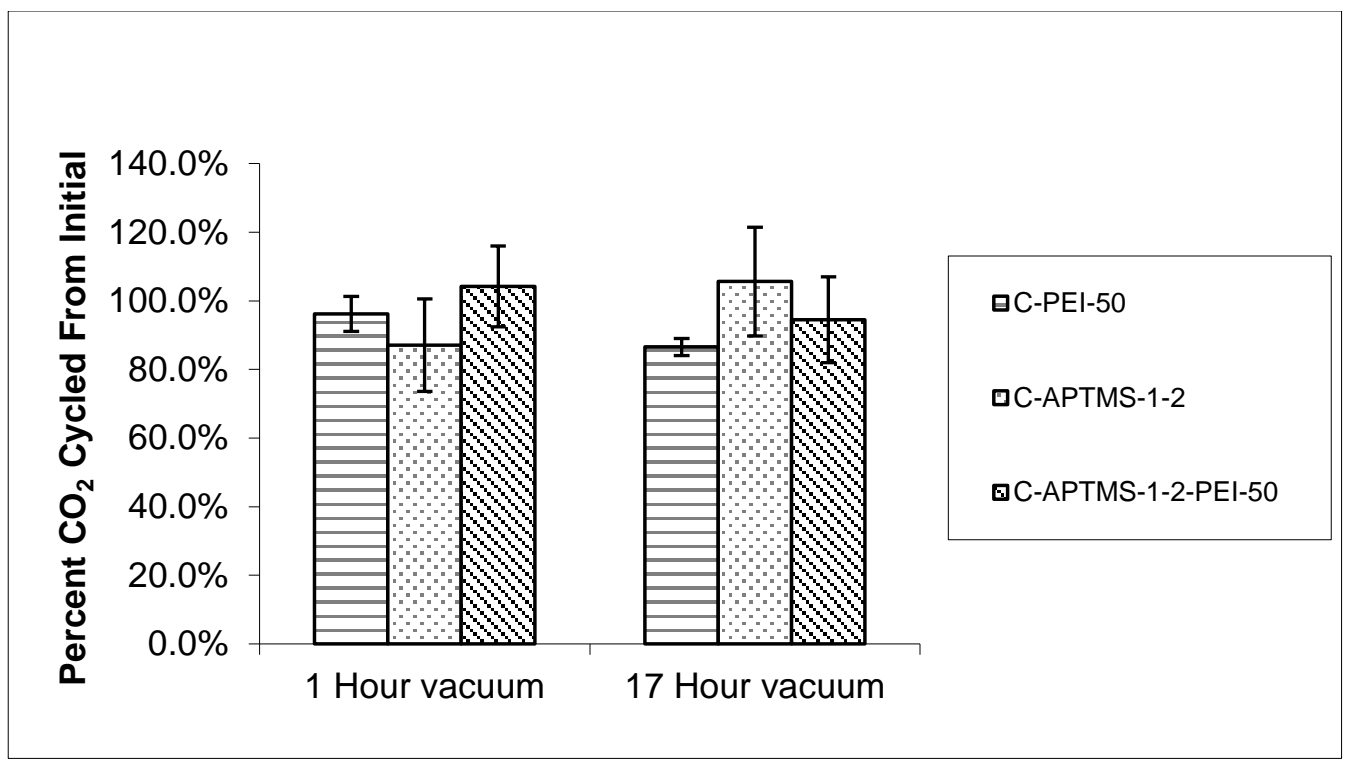

Figure 5-25: Vacuum regeneration results for $85^{\circ} \mathrm{C}$ vacuum desorption in the vacuum oven In summary, vacuum desorption at $85^{\circ} \mathrm{C}$ and $93 \mathrm{kPa}$ showed some interesting results for the amine treated clays. Clay treated with APTMS was interesting in the fact that the first regeneration showed a reduction in $\mathrm{CO}_{2}$ capacity to $87.1 \%$ of the original, but after 17 hours the $\mathrm{CO}_{2}$ capacity went above $100 \%$ of the original capacity. This would indicate that the regeneration time of 1 hour might not be enough time for the sample to fully regenerate, and the sample is not degraded by a desorption time of 17 hours in the vacuum oven. Samples treated with PEI and the combination of PEI and APTMS had a cycle adsorption capacity near $100 \%$ after the first vacuum desorption for 1 hour, but had an average decrease in the $\mathrm{CO}_{2}$ adsorption capacity after the 17 hour vacuum step. This indicates that there might be some loss of the amines or degradation to the sample during long vacuum regeneration at $85^{\circ} \mathrm{C}$

\section{6 $\quad \mathrm{CO}_{2}$ Adsorption at High Pressure}

$\mathrm{CO}_{2}$ adsorption at an elevated pressure was also conducted to see if an increase in pressure had any effect on the adsorption capacity of the adsorbent. If there is enhanced adsorption capacity or different properties at different pressures, there could be other possible 
applications for the treated adsorbents. The procedure for the pressure vessel tests were described in the experimental procedures section. The pressure that was used was varied from 40 psi to 300 psi. 300 psi was chosen because it is close to the pressure that is used in IGCC processes. The lower pressures were chosen to determine the pressure were the adsorption of $\mathrm{CO}_{2}$ reaches a maximum and is no longer dependent on pressure increases. A soak time of 2, 16 , and 24 hours was used to determine the effect of adsorption time on the adsorption capacity and to insure that equilibrium was reached.

The results for clay treated with APTMS are given in Figure 5-26. In Figure 5-26 it can be seen that within experimental error, that, the adsorption capacity is not significantly affected by the pressure or the adsorption time. This would indicate that a two hour adsorption time is sufficient to achieve the maximum $\mathrm{CO}_{2}$ adsorption on the sample treated with APTMS.

Additionally, the $\mathrm{CO}_{2}$ adsorption capacity for all of the different pressures and time averages to 6.93 weight percent which is only slightly higher than the average adsorption capacity of the clay treated with APTMS in the TGA at $85^{\circ} \mathrm{C}$. This would indicate that the sorption of $\mathrm{CO}_{2}$ on clay treated with APTMS is not physically absorbed but is chemical reacted onto the sample. Figures 5-26 and 5-27 are the results for untreated clay, clay treated with PEI and clay treated with APTMS+PEI. 


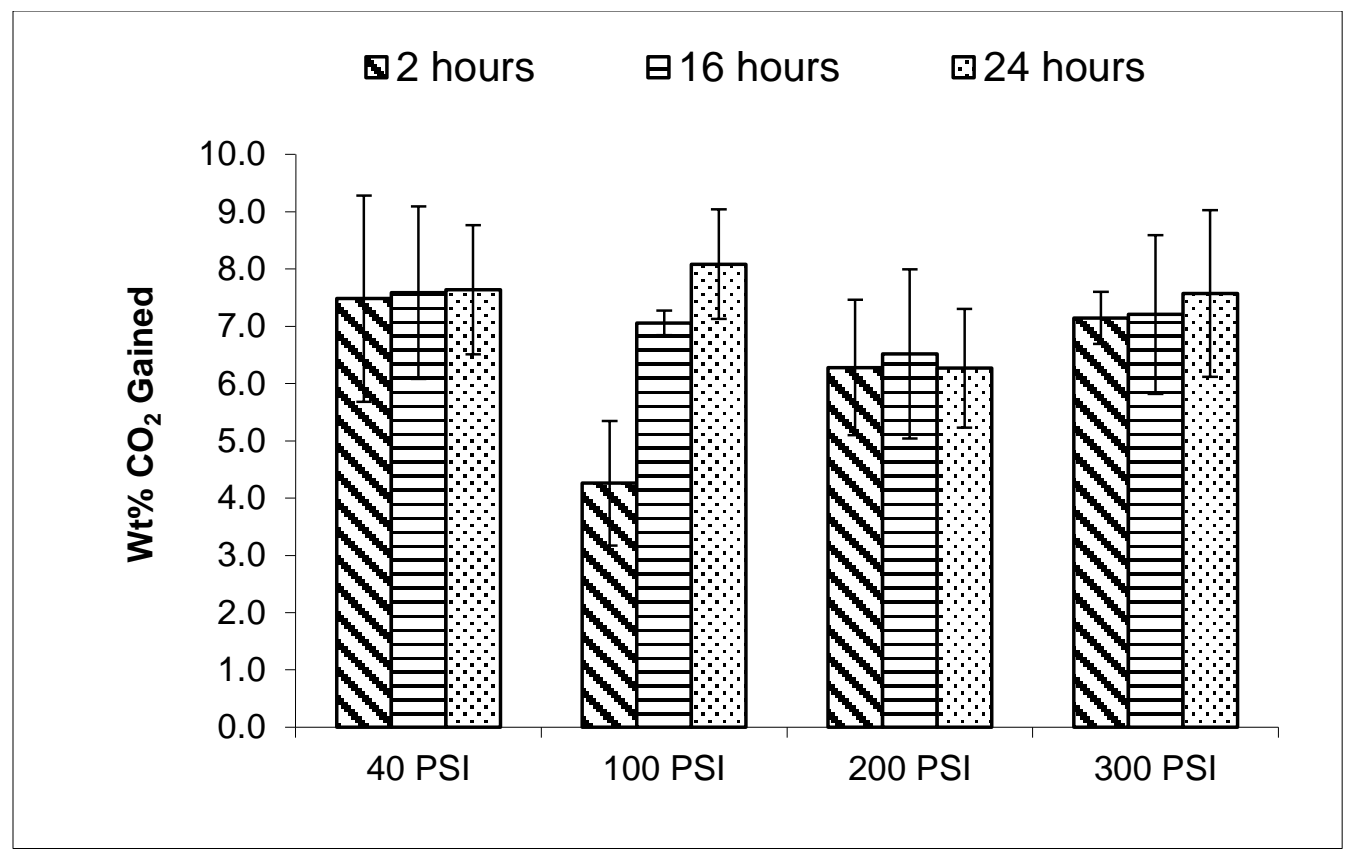

Figure 5-26: $\mathrm{CO}_{2}$ sorption at pressure using clay treated with APTMS

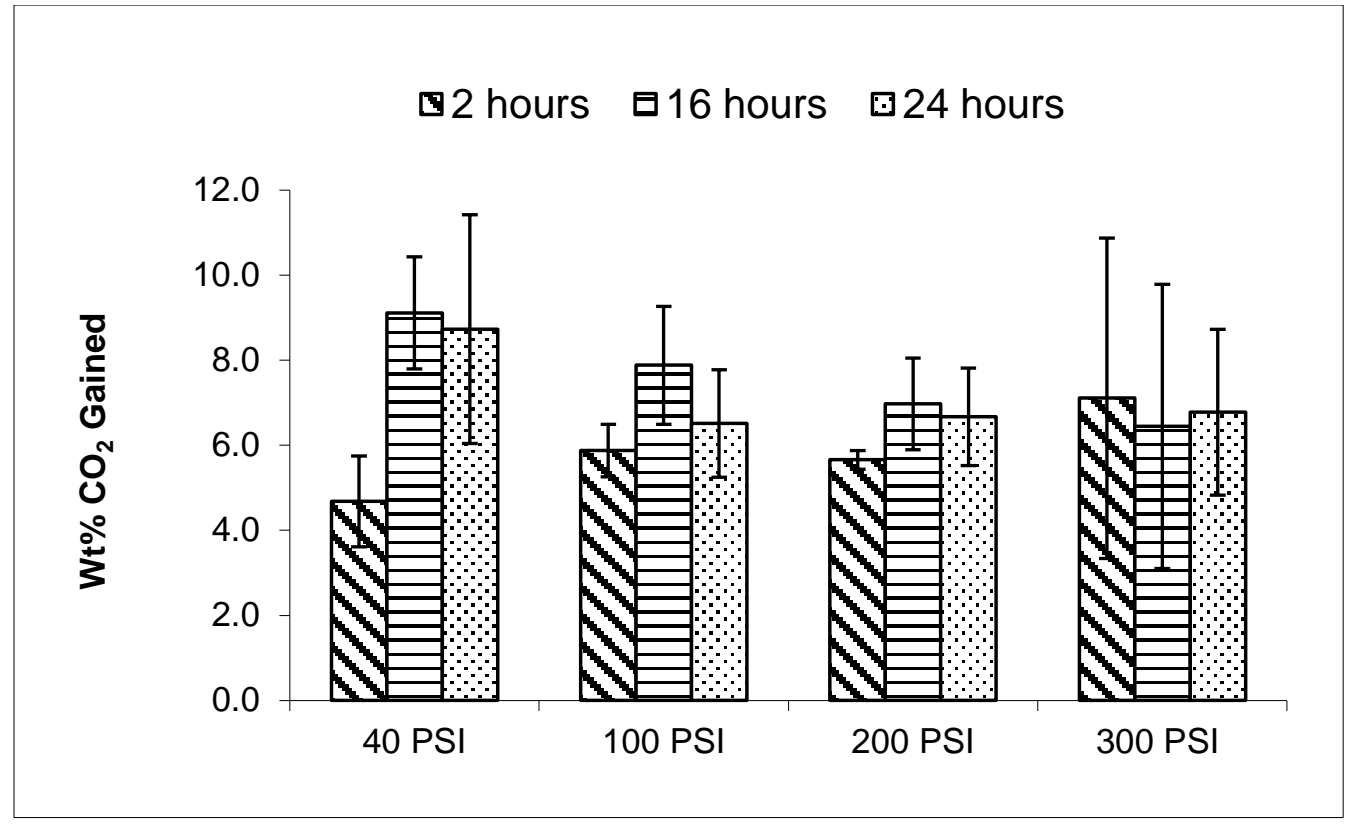

Figure 5-27: $\mathrm{CO}_{2}$ sorption at pressure using clay treated with PEI

Figure 5-27 shows the $\mathrm{CO}_{2}$ adsorption at pressures from 40-300psi with adsorption times of 2-24 hours. Again there is not a significant difference in the amount of the overall $\mathrm{CO}_{2}$ adsorption capacity with the changing of pressure and soak time. This is somewhat surprising 
since in the TGA adsorption profile for samples of clay treated with PEl there seemed to be some diffusion controlled reactions towards the end of the adsorption step. In Figure 5-28 the adsorption of pure $\mathrm{CO}_{2}$ at high pressure can be seen for samples treated with the combination of APTMS and PEI. Similarly to the samples treated with only APTMS and PEI, there is not a significant difference in the adsorption capacity with the change in pressure. There is possibly a change in the $\mathrm{CO}_{2}$ adsorption capacity at 40psi with increasing adsorption times. This would indicate that the $\mathrm{CO}_{2}$ adsorption equilibrium might not be reached with only a 2 hour adsorption time.

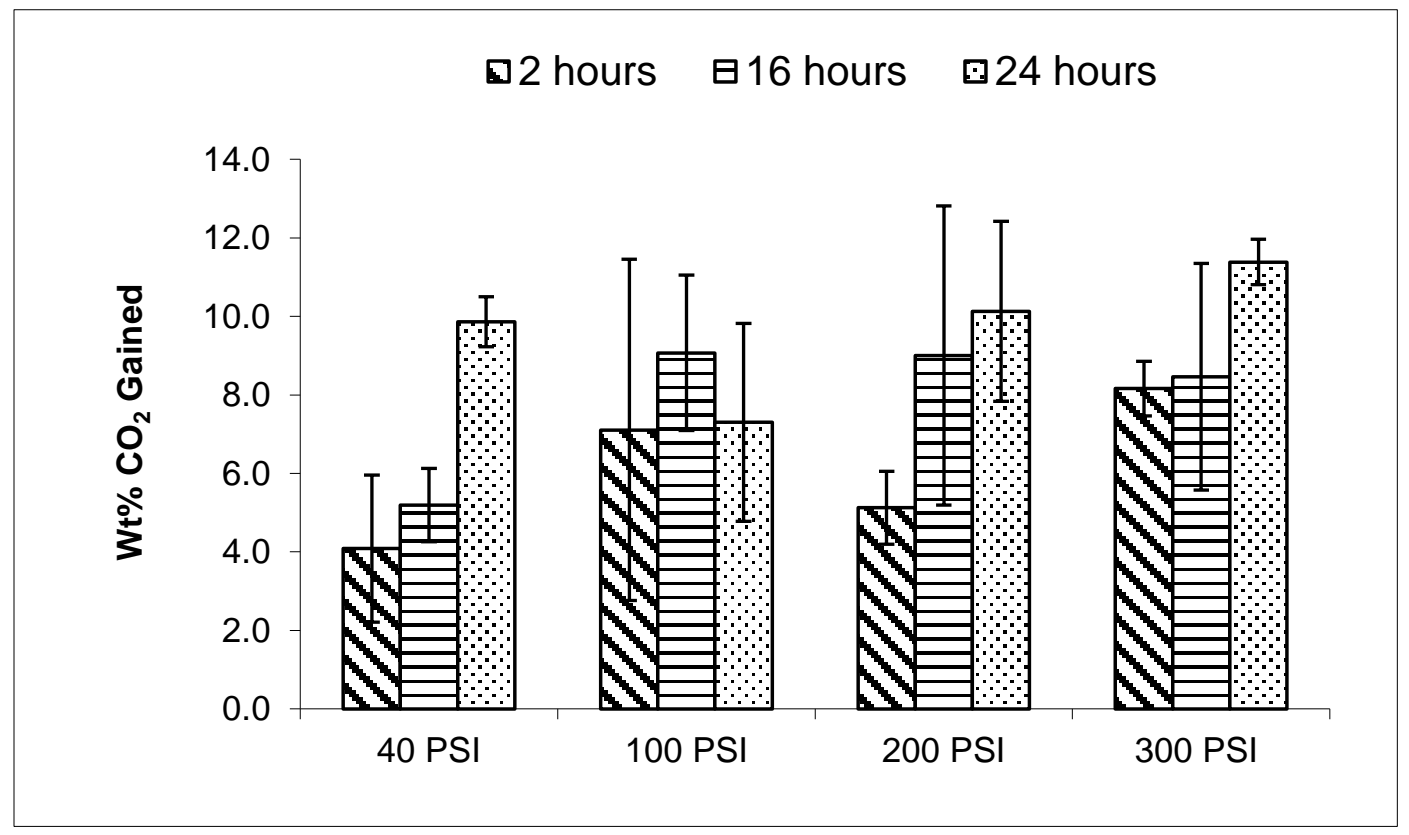

Figure 5-28: $\mathrm{CO}_{2}$ sorption at pressure using clay treated with APTMS+PEI 


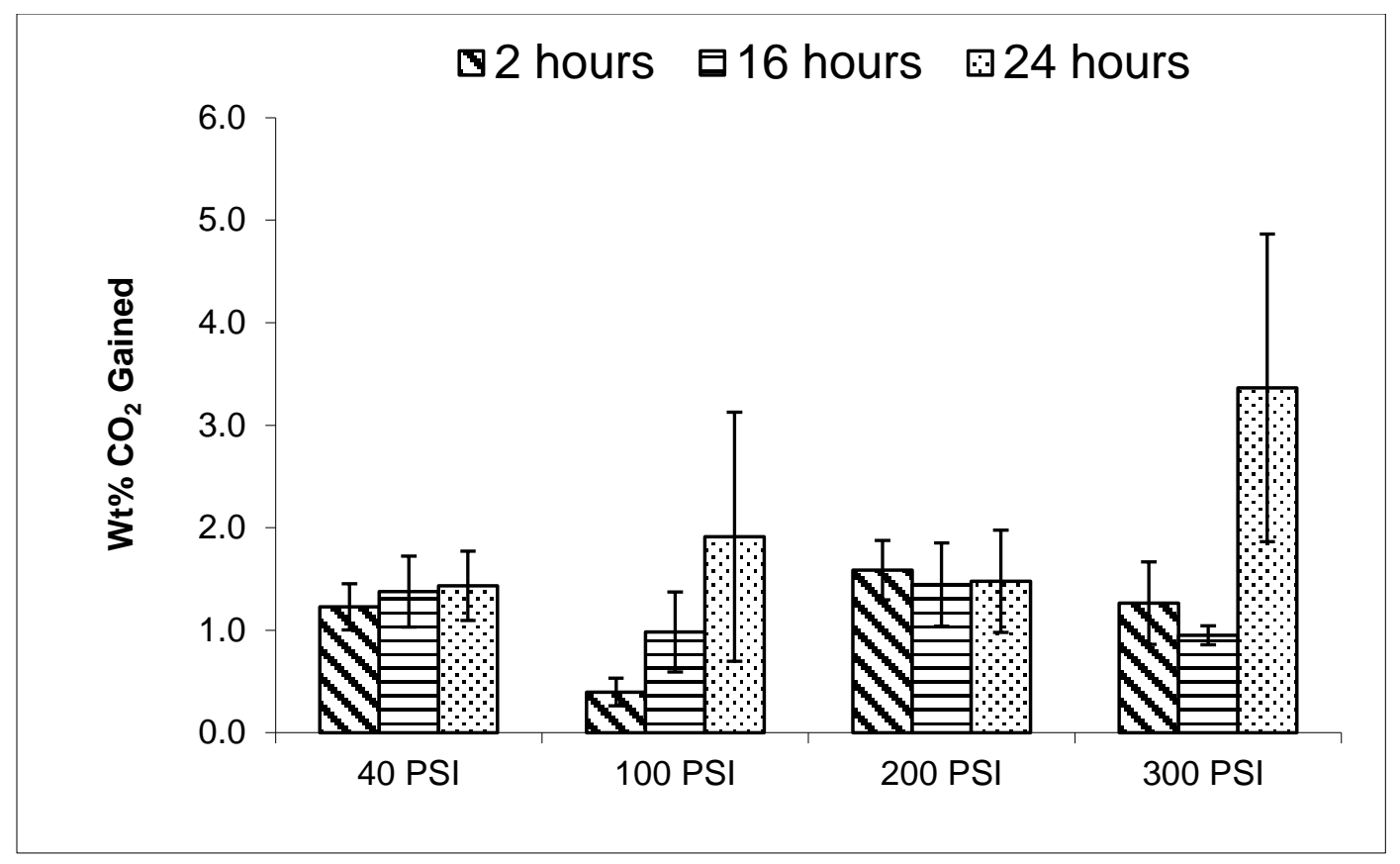

Figure 5-29: $\mathrm{CO}_{2}$ sorption at pressure using untreated clay

Similarly to the TGA results, the untreated clay adsorbed very little $\mathrm{CO}_{2}$; see Figure 5-29

this would suggest that the amine treatments had an important role in increasing the $\mathrm{CO}_{2}$

adsorption capacity of the clay. The results for each treatment showed that using this method

for testing the $\mathrm{CO}_{2}$ adsorption capacity at elevated pressure, there is not significant

dependence on the pressure of the $\mathrm{CO}_{2}$ to the adsorption capacity of the adsorbent. $\mathrm{A}$

comparison of all the clay treatments at 24 hours is given in Figure 5-30. 


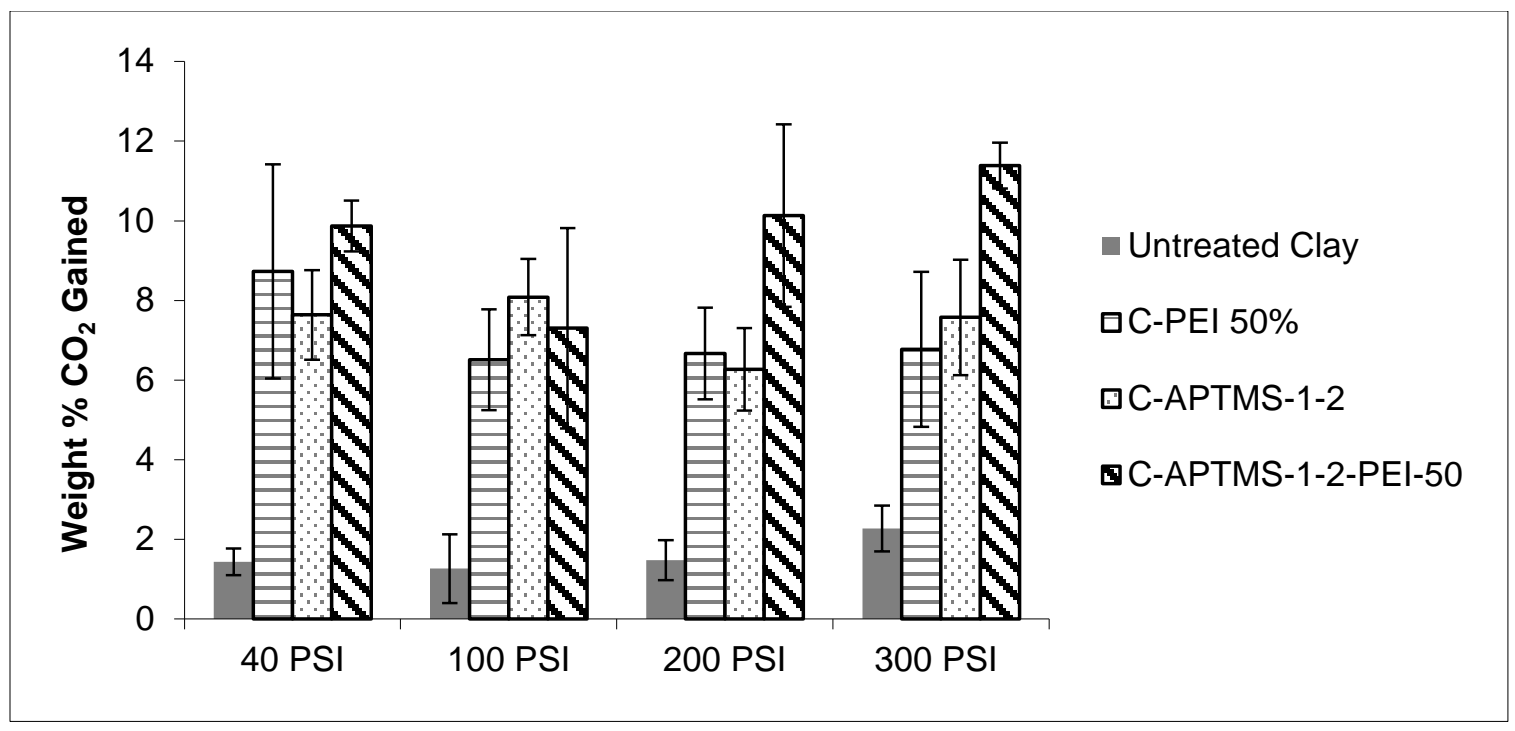

Figure 5-30: $\mathrm{CO}_{2}$ sorption at different pressures with 24 hours adsorption time

The results shown in Figure 5-30 demonstrate that the highest average adsorption capacity is obtained with the clay treated with APTMS+PEI at 300 psi. The adsorption capacity is 11.36 weight percent and is higher than the adsorption capacity of clay treated with APTMS+PEI at $85^{\circ} \mathrm{C}$, which averaged 7.2 weight percent with a maximum adsorption capacity of 9.7 weight \%. The adsorption results show that there is a slight increase in the adsorption capacity of $\mathrm{CO}_{2}$ in pure $\mathrm{CO}_{2}$ at high pressure, but does not indicate that there is a significant increase in sorption capacity with increasing pressure. This indicates that the increase in $\mathrm{CO}_{2}$ capacity due to the physical absorption at high pressures is small.

\subsection{1 $\mathrm{CO}_{2}$ Adsorption at High Pressure with Increasing Temperature}

The TGA results suggested that there was an increase in the $\mathrm{CO}_{2}$ adsorption capacity with an increase in temperature to $85^{\circ} \mathrm{C}$. Therefore, it was decided to study the effects of temperature on the adsorption capacity at a pressure of 300psi for 24 hours. This time and pressure were chosen because 300 psi is close to the adsorption pressure of an IGCC plant and a 24 hour adsorption time would help ensure that equilibrium was reached. 
The detailed procedure for conducting the experiments is described in the experimental section. Using the ideal gas law, the pressure vessel was calculated to have a final pressure of 300psi. The modified ideal gas law used to calculate the pressure is shown in Equation 5-2

$$
\frac{P_{2}}{T_{2}} T_{1}=P_{1}
$$

Where $P_{2}$ is the pressure in the pressure vessel at the adsorption temperature. $T_{2}$ is the adsorption temperature studied, $T_{1}$ is the room temperature, and $P_{1}$ is the calculated pressure that is placed into the pressure vessel.

The samples were placed into the pressure vessel and the then the pressure vessel was placed into a water bath in the oven at a set temperature. The water bath was used to better maintain a constant temperature. The first temperature studied was $50^{\circ} \mathrm{C}$ to determine if temperature had any effect. The results of this experiment are shown in Figure 5-31.

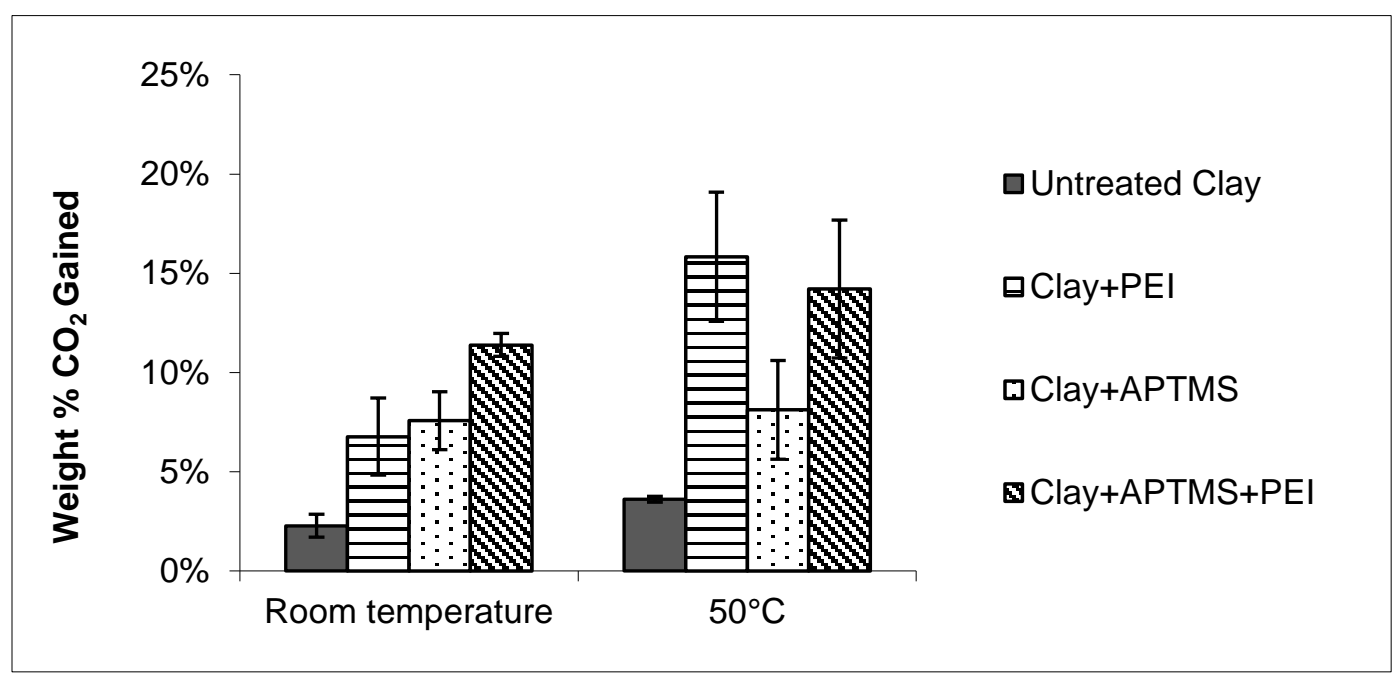

Figure 5-31: $\mathrm{CO}_{2}$ adsorption at $300 \mathrm{psi}$ for 24 hours at room temperature and at $50^{\circ} \mathrm{C}$

The results indicate that there is an increase in the adsorption capacity of the samples treated with PEI, and this is similar to the results obtained at atmospheric pressure using TGA. 
The adsorption capacity of the untreated clay and the clay treated with APTMS was not significantly affected by the increase in temperature. Additionally, there is not a significant difference in the $\mathrm{CO}_{2}$ adsorption capacity in the samples treated with the combination of PEI and APTMS over the samples treated with PEI. The increase in adsorption capacity for the samples treated with PEI is assumed to be due to the same reason as the increase shown in the TGA. In the literature, it is suggested that the $\mathrm{CO}_{2}$ reacts with the surface PEI but then there is resistance to the amount of $\mathrm{CO}_{2}$ that can diffuse into the PEI. Increasing the temperature helps expand the PEI and promote diffusion which increases the $\mathrm{CO}_{2}$ adsorption capacity. Therefore, even at 300psi for 24 hours increasing the temperature increases the $\mathrm{CO}_{2}$ adsorption capacity.

Since the adsorption capacity increased for samples treated with PEI, tests were conducted at $75^{\circ} \mathrm{C}$ and $85^{\circ} \mathrm{C}$ to determine if there is a higher increase in the $\mathrm{CO}_{2}$ adsorption capacity. Figure 5-32 displays the results of the $\mathrm{CO}_{2}$ adsorption capacities at higher temperatures using 300psi and a 24 hour adsorption time.

In Figure 5-32 it can be seen that the adsorption capacity for the untreated clay and the clay treated with APTMS had very little change in the adsorption capacity with increasing temperature. The adsorption capacity for clay treated with PEI and the combination of PEI had an increased adsorption capacity for at $50-85^{\circ} \mathrm{C}$ compared to room temperature. The difference in adsorption capacity between $50^{\circ} \mathrm{C}, 75^{\circ} \mathrm{C}$ and $85^{\circ} \mathrm{C}$ was small compared to the difference at room temperature. This would indicate that with increasing the adsorption temperature above $50^{\circ} \mathrm{C}$ there is not a significant increase in the $\mathrm{CO}_{2}$ adsorption capacity. 


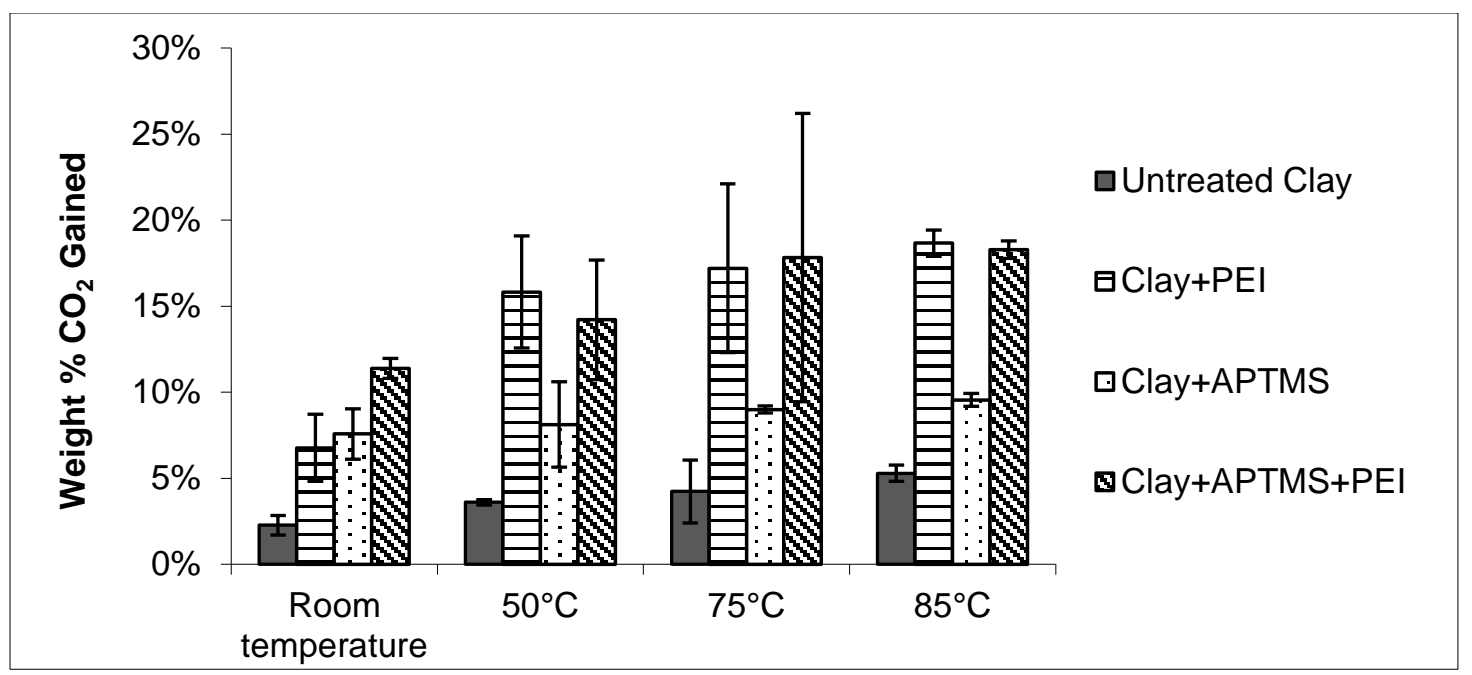

Figure 5-32: Temperature comparison at 300psi for a 24 hours adsorption time

The results for the $\mathrm{CO}_{2}$ adsorption capacity with increasing temperatures at $300 \mathrm{psi}$ and a 24 hours adsorption time showed that there was an increase in the adsorption capacity for samples treated with PEI. The adsorption capacity did not significantly change for the untreated clay and the clay treated with APTMS. This was expected since there seemed to be no diffusion issues with APTMS treated samples and the untreated clay has very little $\mathrm{CO}_{2}$ adsorption capacity. The samples treated with only PEI had approximately the same amount of $\mathrm{CO}_{2}$ adsorption as the samples treated with the combination of APTMS and PEI. There also was not a significant difference in the adsorption capacities when increasing the temperature above $50^{\circ} \mathrm{C}$. This would indicate that the increase in the diffusion of $\mathrm{CO}_{2}$ with increasing temperature, as previously seen in the TGA results, does not have a significant effect in the high pressure results. This would suggest that at 300psi and a 24 hour adsorption time at temperatures above $50^{\circ} \mathrm{C}$ there is not a signification additional amount of $\mathrm{CO}_{2}$ that can diffusive into the $\mathrm{PEI}$ and react with amines. 


\subsubsection{Regeneration Using Vacuum}

Three samples of clay treated with APTMS, PEI, and APTMS+PEI were weighed and placed into the vacuum oven for 2 hours at $85^{\circ} \mathrm{C}$ at $93 \mathrm{kPa}$ in order to get a baseline weight for vacuum regeneration. The samples were then removed and placed into the pressure vessel. Pure $\mathrm{CO}_{2}$ at 300 psi was contacted with these samples for 2 hours. The amount of $\mathrm{CO}_{2}$ adsorbed was calculated by measuring the weight difference between the sample weight before and after the exposure to $\mathrm{CO}_{2}$. The samples were then placed back into the vacuum oven to study desorption of the $\mathrm{CO}_{2}$ in the vacuum oven. The samples were subsequently weighed and placed into the $\mathrm{CO}_{2}$ pressure vessel. The amount of $\mathrm{CO}_{2}$ adsorbed was then compared to the original amount of $\mathrm{CO}_{2}$ adsorbed. Figure 5-33 shows the $\mathrm{CO}_{2}$ adsorption capacity of the samples tested in this manner. The adsorption capacities for each treatment are in the range that was calculated during the adsorption tests. The percent weight that is desorbed in the vacuum oven compared well to the initial $\mathrm{CO}_{2}$ adsorption, but after calculating the amount of $\mathrm{CO}_{2}$ that is adsorbed after the vacuum regeneration onto the sample, the capacity for $\mathrm{CO}_{2}$ adsorption was found to have gone down for all three treatments. 


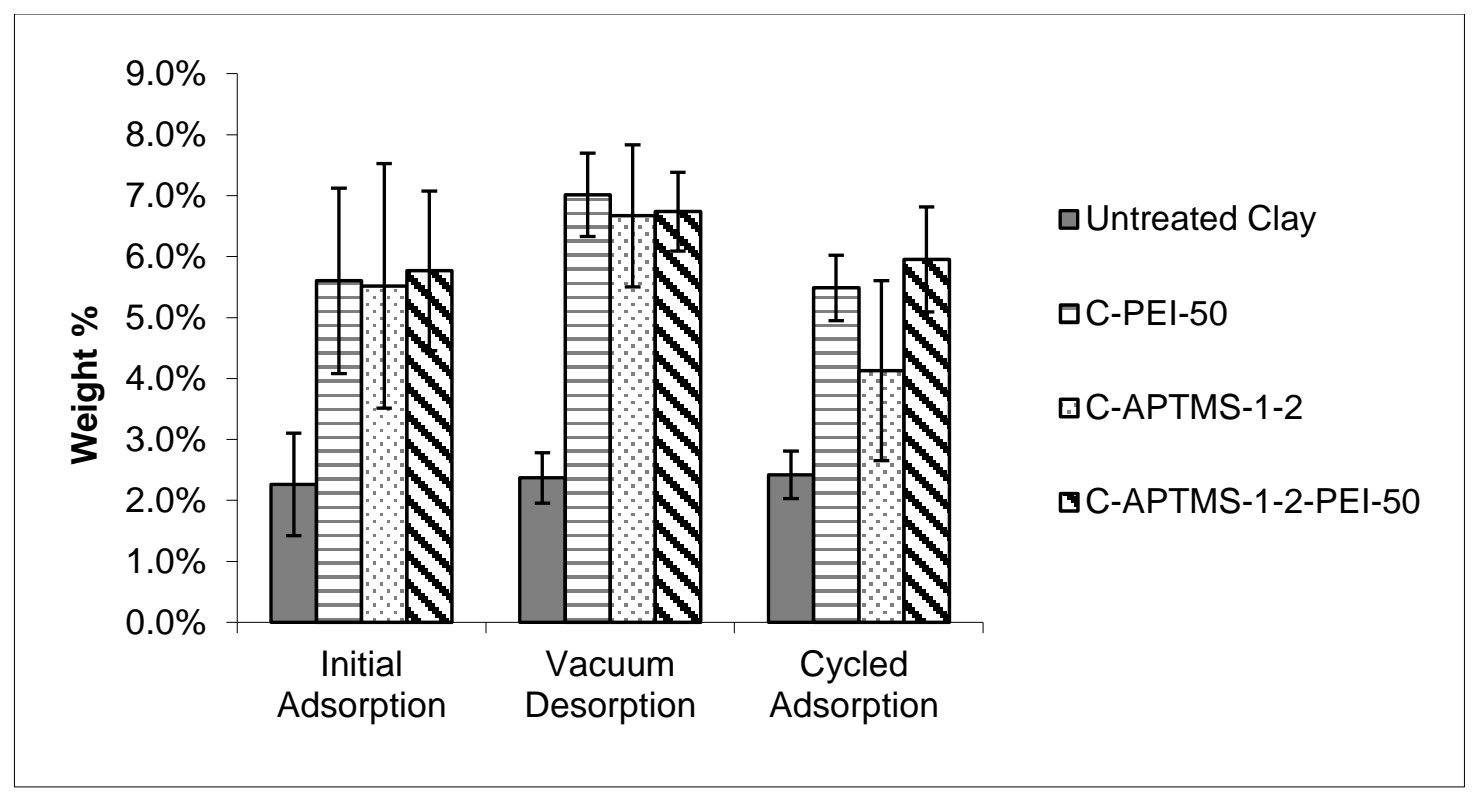

Figure 5-33: Weight percent $\mathrm{CO}_{2}$ adsorbed at 300 psi for at least 2 hours and weight percent desorbed under vacuum at $85^{\circ} \mathrm{C}$ at $93 \mathrm{kPa}$

In Figure 5-33 one can see that the weight desorbed was greater than the amount of weight gained during the initial $\mathrm{CO}_{2}$ adsorption. This would indicate that all of the $\mathrm{CO}_{2}$ was removed during the vacuum regeneration. Additionally, the second $\mathrm{CO}_{2}$ adsorption capacity should be the same as the initial adsorption capacity. However, the second $\mathrm{CO}_{2}$ adsorption was not equal to the initial adsorption capacity, indicating that some degradation of the sample is occurring or all of the $\mathrm{CO}_{2}$ on the sample is not being removed. It is also interesting to note that the clay treated with the combination of APTMS and PEI preformed the best in terms of the $\mathrm{CO}_{2}$ cycling. The decrease in the adsorption for clay treated with PEI might be because some of the $\mathrm{PEI}$ is being evaporated during the vacuum cycling step. The untreated clay had a small amount of $\mathrm{CO}_{2}$ adsorption but did have the same amount of $\mathrm{CO}_{2}$ adsorption after the vacuum regeneration. 
Vacuum regeneration was also tried on the samples exposed to $\mathrm{CO}_{2}$ at $50^{\circ} \mathrm{C}$ and $300 \mathrm{psi}$ for 24 hours. This was done to confirm that increased $\mathrm{CO}_{2}$ adsorption capacity seen for the PEI samples at $50^{\circ} \mathrm{C}$ could also be regenerated. The same vacuum regeneration procedure was used as before with 1 hour desorption at $85^{\circ} \mathrm{C}$ in the vacuum oven. The results are shown in Figure 5-34. The concern with exposing the treated clay samples to $50^{\circ} \mathrm{C}$ pure $\mathrm{CO}_{2}$ at $300 \mathrm{psi}$ for 24 hours was the possible formation of urea that could not be regenerated using vacuum at these conditions. This would cause a reduction in the adsorption capacity during cycles.

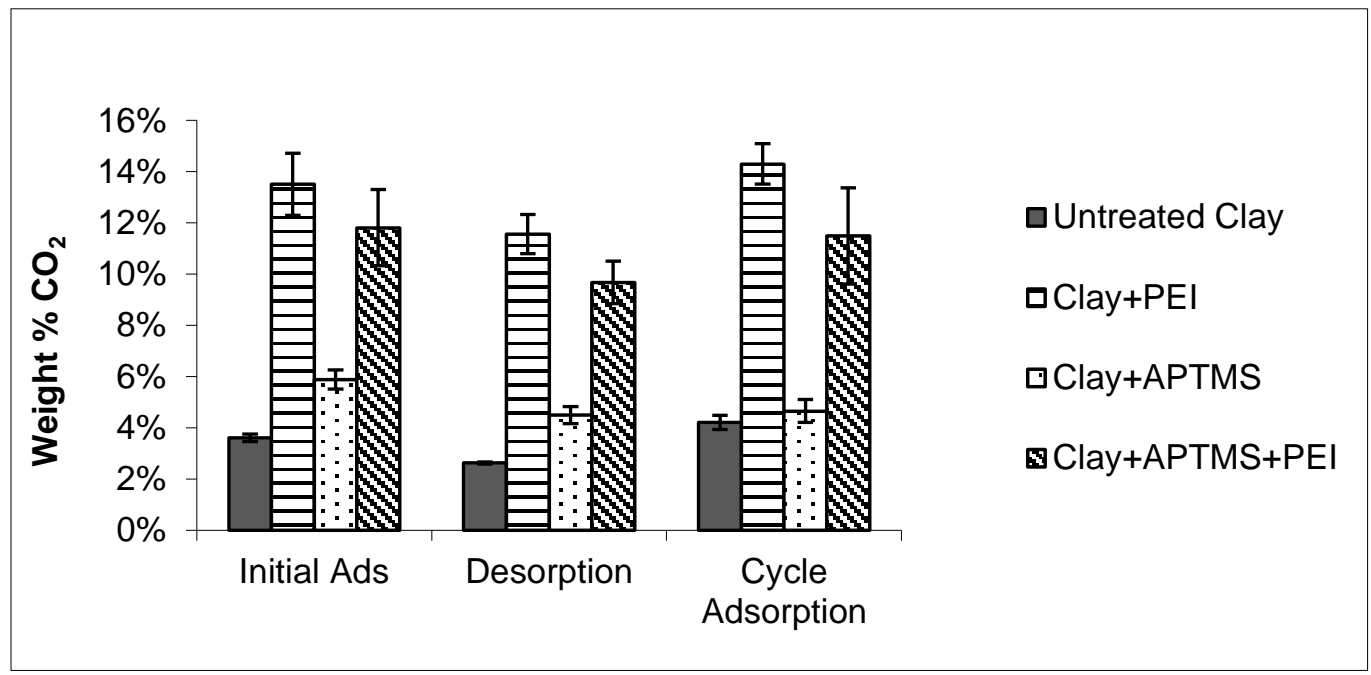

Figure 5-34: Vacuum regeneration with adsorption at $50^{\circ} \mathrm{C}$ at $300 \mathrm{psi}$

The results shown in Figure 5-34 demonstrate that vacuum can desorb the $\mathrm{CO}_{2}$ after exposure to $50^{\circ} \mathrm{C}$ pure $\mathrm{CO}_{2}$ at 300 psi for 24 hours. The adsorption capacity did not change significantly during the second adsorption after the vacuum desorption step. These results show that vacuum desorption is a possible regeneration method for samples exposed to high pressure $\mathrm{CO}_{2}$. 


\subsection{Stability of the Adsorbent after Long Exposure to Water Vapor}

In order for a $\mathrm{CO}_{2}$ adsorbent to be applicable to real flue gas adsorption applications, the adsorbent must be regenerated numerous times. This has been studied in the previous sections using temperature swing adsorption (TSA) and nitrogen as a sweep gas. Using nitrogen as a sweep gas is an easy technique in the lab to study feasibility, but to have an industrially relevant adsorbent, the sweep gas has to be something that can be easily removed from $\mathrm{CO}_{2}$ so that the $\mathrm{CO}_{2}$ outlet stream can be pure enough for sequestration. $\mathrm{CO}_{2}$ and low pressure steam, so far, are the two prospective sweep gases. Low pressure steam can easily be removed from the $\mathrm{CO}_{2}$ stream after regeneration by condensing out the water vapor. The problem with using $\mathrm{CO}_{2}$ as a sweep stream is the formation of urea instead of carbamate that has been reported to happen at high regeneration temperatures. The formation of urea is slow, but since it does not regenerate at the typical regeneration temperature, the adsorbent progressively loses $\mathrm{CO}_{2}$ adsorption capacity.

Therefore, the effects of low pressure steam on our adsorbents should be studied. Other researchers ${ }^{[54]}$ have simulated steam regeneration by using an autoclave purged with nitrogen or air and then exposing the adsorbent with steam at temperatures ranging from $105^{\circ} \mathrm{C}-180^{\circ} \mathrm{C}$ for 24 hours to simulate many regeneration cycles. The steam was generated by placing a flask with $30 \mathrm{ml} \mathrm{DI}$ water in an autoclave and heating to the desired temperature. The results showed a significant decrease in the $\mathrm{CO}_{2}$ adsorption capacity even at the lowest temperature of $105^{\circ} \mathrm{C}$. The adsorbent was mesoporous silica made in house that was similar to commercial MCM-48 and SBA-15 but had thinner pore walls, which is one of the reasons that 
was offered for the reduction of the pore volume, surface area and $\mathrm{CO}_{2}$ adsorption capacity after steam treatment. ${ }^{[54]}$

The present was carried out by placing the samples in an environmental chamber at 66$67^{\circ} \mathrm{C}$ and $\sim 98.4$ relative humidity for 24 hours. The lower temperature was considered to be less severe than $105^{\circ} \mathrm{C}$, but it is unknown what the degradation of the sample will be if condensation occurs on the sample. The other researchers who had conducted their experiments in an autoclave reported no apparent condensation on the sample bottles or samples.

The experiment used approximately $40 \mathrm{mg}$ of sample, and it was placed into the environmental chamber for 24 hours. The bottles were then removed from the chamber after 24 hours and weighed shortly thereafter; the samples had to be moved into a different lab with a balance. The bottles had no lids and were bound together in a bundle using a rubber band. Six different samples were used in this study each having a duplicate for repeat analysis. The samples included clay reacted with APTMS, clay impregnated with PEl loadings of $33 \%, 50 \%$, $66 \%$, and clay reacted with APTMS and then impregnated with PEI 50\% loading. Two samples of clay-APTMS were immediately tested in the TGA without drying. The remaining samples were placed in a vacuum oven at $60^{\circ} \mathrm{C}$ overnight to dry.

All of the bottles had obvious condensation on and in the bottle, indicating that not only did water vapor come into contact with the samples but also liquid water. The samples that had PEI in them were actually sitting in a pool of water. The clay reacted with APTMS samples looked damp, but there was no standing water. The amount of water appeared to increase with 
increased PEI loading, meaning that the cloisite-PEI-33 had the least amount of water while the PEI-66 appeared to have the most. The liquid water being in contact with the clay-APTMS samples was a concern because of the possibility that the powdered samples would turn into a solid clump of material affecting the mass transfer to the amine sites and possibly requiring another grinding step in a mortar and pestle. Removing the dried clay-APTMS samples from the bottles and putting them into the TGA crucible broke up the sample into a powder without any intentional crushing. The two wet samples that were not dried before the TGA experiment broke apart easily into a powder when touched after the adsorption experiment indicating that the sample did not strongly agglomerate together, which would probably have greatly reduced the accessibility of the amine sites. The C-PEI-50 and C-PEI-33 sample did form a solid clump of material in the bottle, but this was partially broken up in the process of transferring it to the TGA pan. The C-PEI-66 also formed a solid mass of material, but when transferring the sample to the TGA pan, the solid was more of a dry paste-like consistency than a powder. This is one of the reasons why almost all of our work has been done using 50\% PEI loaded samples instead of 66\% PEI loaded samples. The C-APTMS-PEI-50 sample formed a solid mass of material that had to be broken to be removed from the bottle and placed into the TGA pan.

$\mathrm{CO}_{2}$ adsorption was studied by ramping the instrument at $5^{\circ} \mathrm{C}$ per minute in $\mathrm{N}_{2}$ to $100^{\circ} \mathrm{C}$ for 30 minutes then reducing the temperature to $85^{\circ} \mathrm{C}$ for adsorption in pure $\mathrm{CO}_{2}$ in the Thermo Cahn TGA. Table 5-6 shows the results for the $\mathrm{CO}_{2}$ adsorption TGA experiment. For the clay treated with APTMS, the $\mathrm{CO}_{2}$ adsorption capacity was greatly reduced after being exposed to the $66-67^{\circ} \mathrm{C}$ and $\sim 98 \%$ relative humidity environment chamber. Sample $1 \mathrm{AD}$ and $1 \mathrm{AJ}$, clay reacted with APTMS, $\mathrm{CO}_{2}$ adsorption capacities reduce to an average of $65 \%$ of their original 
capacity. Since the wet sample had a significant amount of water in the sample, the sample weight for the $\mathrm{CO}_{2}$ weight percent calculation was taken when the sample weight reached an approximate equilibrium during the initial $\mathrm{N}_{2}$ desorption step at $100^{\circ} \mathrm{C}$.

The sample weight is manually put into the Thermo Cahn TGA and not measured by the TGA before the run begins, this may cause some error due to the sample drying in the $\mathrm{N}_{2}$ purge that is running through the reactor while the experiment is being set up. This most likely would not cause a big error when the samples have been dried and have been sitting in a sealed bottle before running the experiments. However, with a very water-saturated sample that may be rapidly drying in the $\mathrm{N}_{2}$ purge, there could be more error.

The clay treated with PEI samples were expected to perform worse than the clay treated with APTMS because PEI is soluble in water and is not expected to be covalently attached to the sample, but electrostatically attached to the negative surface of the clay. Clay loaded with $33 \%$ $\mathrm{PEI}$ exposed to the $66^{\circ} \mathrm{C}$ water vapor adsorbed 99 percent of its initial carbon dioxide adsorption capacity. This is unexpected intuitively, but there have been other reports that show that mesoporous silica impregnated with PEI showed similar results when exposed to water vapor. Clay loaded with $66 \%$ PEI showed an increase in its adsorption capacity. The C-PEI-50 sample showed a slight decrease but was better than the C-APTMS samples. The C-APTMS-PEI sample also had a similar adsorption capacity to the samples not exposed to the environmental chamber. Although the adsorption capacity was not as high as other C-APTMS-PEI samples made in the past. Table 5-6 shows the data collected for the samples after exposure to the environmental chamber. Figure 5-35 is a comparison of the initial adsorption capacity with the 
weight capacity of the samples after the exposure in the environmental chamber for samples of clay treated with $50 \%$ PEI, APTMS and APTMS+PEI. Figure 5-36 is a comparison of the 3 different loadings of PEI onto the clay. From Figures 5-35 and 5-36 it can be seen that the sample of clay treated with APTMS performed the worst of all of the treatments. Figures 5-3738 are some representative TGA graphs for the data collected.

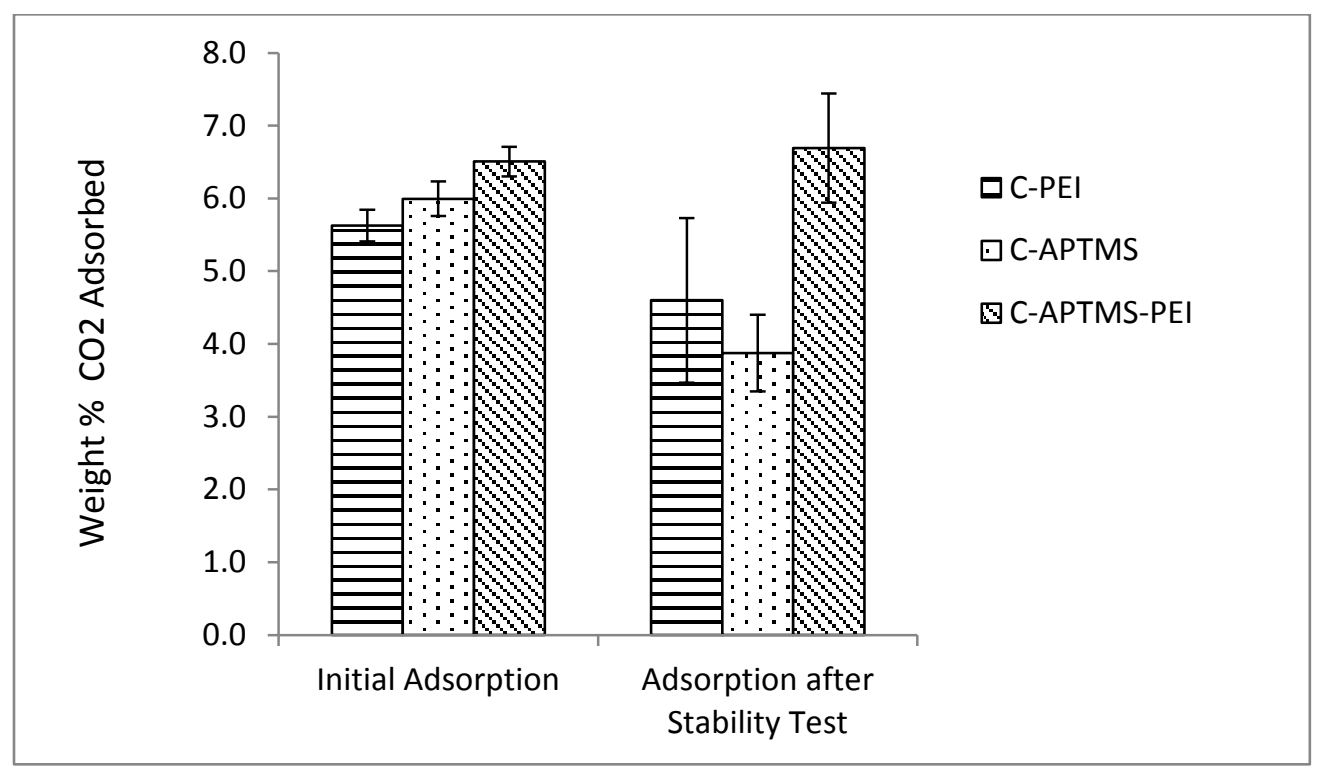

Figure 5-35: Comparison of amine treatments on $\mathrm{CO}_{2}$ adsorption

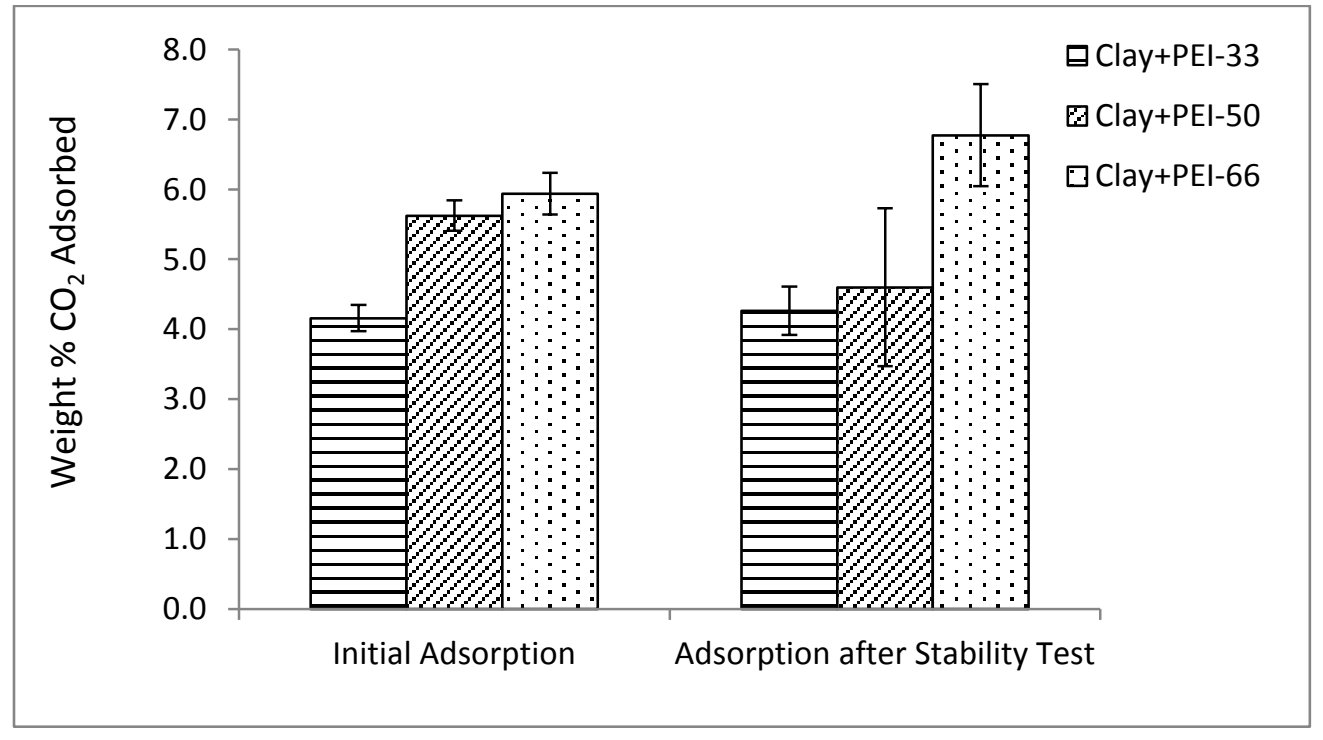

Figure 5-36: Comparison of the PEl loading on $\mathrm{CO}_{2}$ adsorption 
Table 5-6: $\mathrm{CO}_{2}$ adsorption capacity after exposure to the environmental chamber

\begin{tabular}{|l|l|l|l|l|}
\hline Sample & $\begin{array}{l}\text { Weight } \\
(\mathrm{mg})\end{array}$ & $\begin{array}{l}\text { Weight (After 66-67 }{ }^{\circ} \mathrm{C} \\
\text { Env. Chamber) } 24 \mathrm{hr}\end{array}$ & $\begin{array}{l}60^{\circ} \mathrm{C} \text { vacuum } \\
\text { dried weight }\end{array}$ & $\begin{array}{l}\text { After 66-67 }{ }^{\circ} \mathrm{C} \text { Env. } \\
\text { Chamber } \mathrm{CO}_{2} \text { Capacity }\end{array}$ \\
\hline $\begin{array}{l}\text { C-APTMS } \\
(1 \mathrm{AD})\end{array}$ & 37.735 & $\begin{array}{l}79.237 \mathrm{mg} \\
(210 \mathrm{wt} \%)\end{array}$ & $\begin{array}{l}\text { NA } \\
\text { Did not Dry }\end{array}$ & $3.4 \mathrm{wt} \%$ \\
\hline $\begin{array}{l}\text { C-APTMS } \\
(1 \mathrm{AD})\end{array}$ & 45.016 & $\begin{array}{l}84.445 \mathrm{mg} \\
(188 \mathrm{wt} \%)\end{array}$ & $3.9 \mathrm{wt} \%$ \\
\hline $\begin{array}{l}\text { C-APTMS } \\
(1 \mathrm{AJ})\end{array}$ & 42.306 & $\begin{array}{l}80.023 \mathrm{mg} \\
(189 \mathrm{wt} \%)\end{array}$ & $\begin{array}{l}\text { NA } \\
\text { Did not Dry }\end{array}$ & $3.6 \mathrm{wt} \%$ \\
\hline $\begin{array}{l}\text { C-APTMS } \\
(1 \mathrm{AJ})\end{array}$ & 44.653 & $\begin{array}{l}86.751 \mathrm{mg} \\
(194 \mathrm{wt} \%)\end{array}$ & $\begin{array}{l}41.320 \mathrm{mg} \\
(93 \mathrm{wt} \%)\end{array}$ & $4.6 \mathrm{wt} \%$ \\
\hline $\begin{array}{l}\text { C-PEI-33 } \\
(1 \mathrm{AE})\end{array}$ & 30.124 & $\begin{array}{l}91.295 \mathrm{mg} \\
(303 \mathrm{wt} \%)\end{array}$ & $\begin{array}{l}30.713 \mathrm{mg} \\
(102 \mathrm{wt} \%)\end{array}$ & $4.51 \mathrm{wt} \%$ \\
\hline $\begin{array}{l}\text { C-PEI-33 } \\
(1 \mathrm{AE})\end{array}$ & 38.536 & $\begin{array}{l}113.353 \mathrm{mg} \\
(294 \mathrm{wt} \%)\end{array}$ & $\begin{array}{l}39.444 \mathrm{mg} \\
(102 \mathrm{wt} \%)\end{array}$ & $4.02 \mathrm{wt} \%$ \\
\hline $\begin{array}{l}\text { C-PEI-50 } \\
(1 \mathrm{AG})\end{array}$ & 45.696 & $\begin{array}{l}135.532 \mathrm{mg} \\
(297 \mathrm{wt} \%)\end{array}$ & $\begin{array}{l}42.082 \mathrm{mg} \\
(92 \mathrm{wt} \%)\end{array}$ & $5.4 \mathrm{wt} \%$ \\
\hline $\begin{array}{l}\text { C-PEI-50 } \\
(1 \mathrm{AG})\end{array}$ & 53.434 & $\begin{array}{l}153.625 \mathrm{mg} \\
(288 \mathrm{wt} \%)\end{array}$ & $\begin{array}{l}51.190 \mathrm{mg} \\
(96 \mathrm{wt} \%)\end{array}$ & $3.8 \mathrm{wt} \%$ \\
\hline C-PEI-66 & 36.719 & $\begin{array}{l}136.532 \mathrm{mg} \\
(370 \mathrm{wt} \%)\end{array}$ & $\begin{array}{l}37.257 \mathrm{mg} \\
(101 \mathrm{wt} \%)\end{array}$ & $7.29 \mathrm{wt} \%$ \\
\hline $\begin{array}{l}142.174 \mathrm{mg} \\
(343 \mathrm{wt} \%)\end{array}$ & $\begin{array}{l}41.897 \mathrm{mg} \\
(101 \mathrm{wt} \%)\end{array}$ & $6.26 \mathrm{wt} \%$ \\
\hline $\begin{array}{l}\text { C-APT-66 } \\
\text { PEI }(2 \mathrm{~N})\end{array}$ & 41.459 & $\begin{array}{l}34.002 \mathrm{mg} \\
(98 \mathrm{wt} \%)\end{array}$ & $6.16 \mathrm{wt} \%$ \\
\hline $\begin{array}{l}\text { C-APTMS- } \\
\text { PEI }(2 \mathrm{~N})\end{array}$ & $38.316 \mathrm{mg}$ & $\begin{array}{l}36.935 \mathrm{mg} \\
(97 \mathrm{wt} \%)\end{array}$ & $7.22 \mathrm{wt} \%$ \\
\hline & 34.554 & $\begin{array}{l}157.267 \mathrm{mg} \\
(413 \mathrm{wt} \%)\end{array}$ & & \\
\hline
\end{tabular}




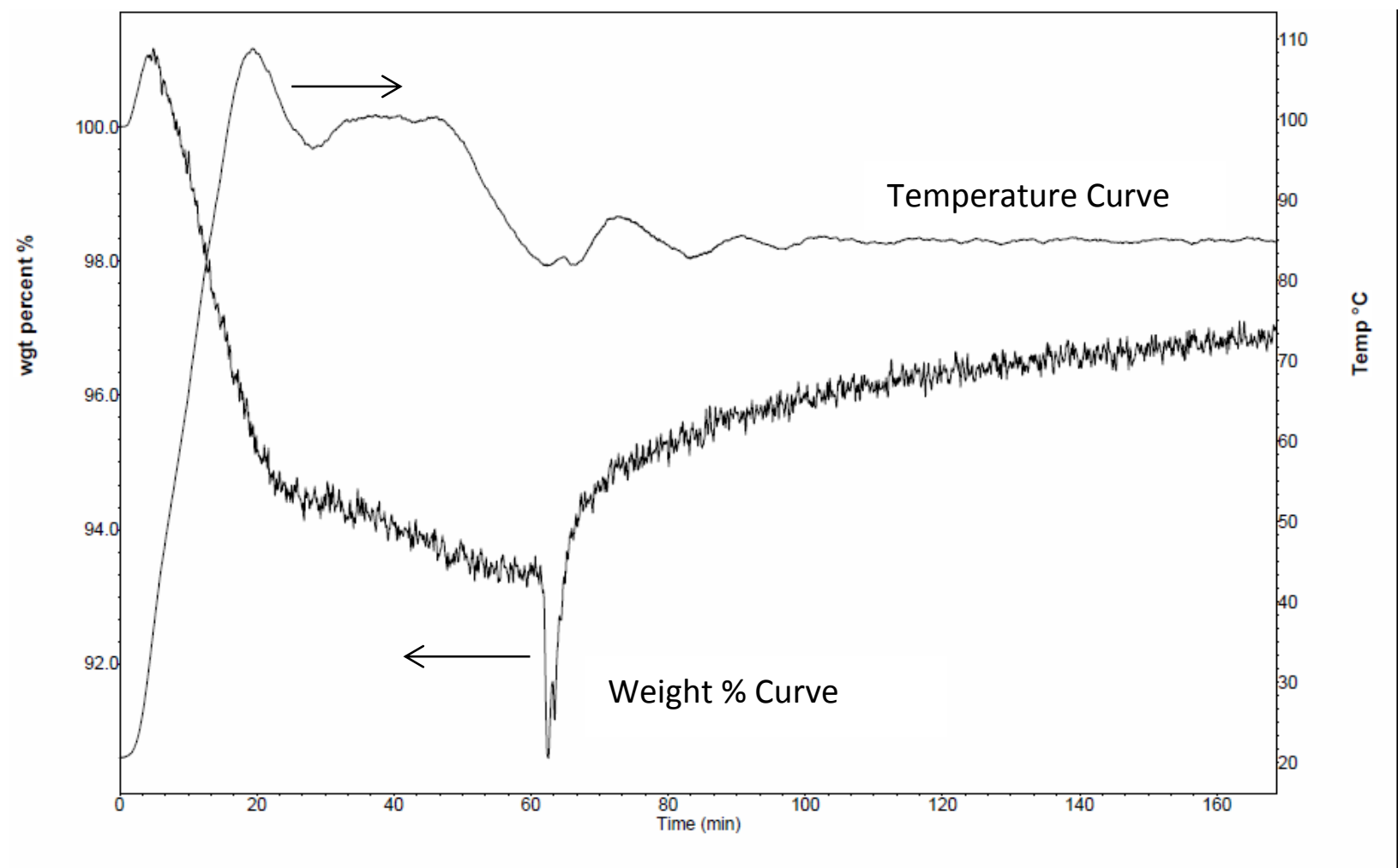

Figure 5-37: $\mathrm{CO}_{2}$ adsorption of clay loaded with $66 \% \mathrm{PEI}$ after exposure to the environment chamber

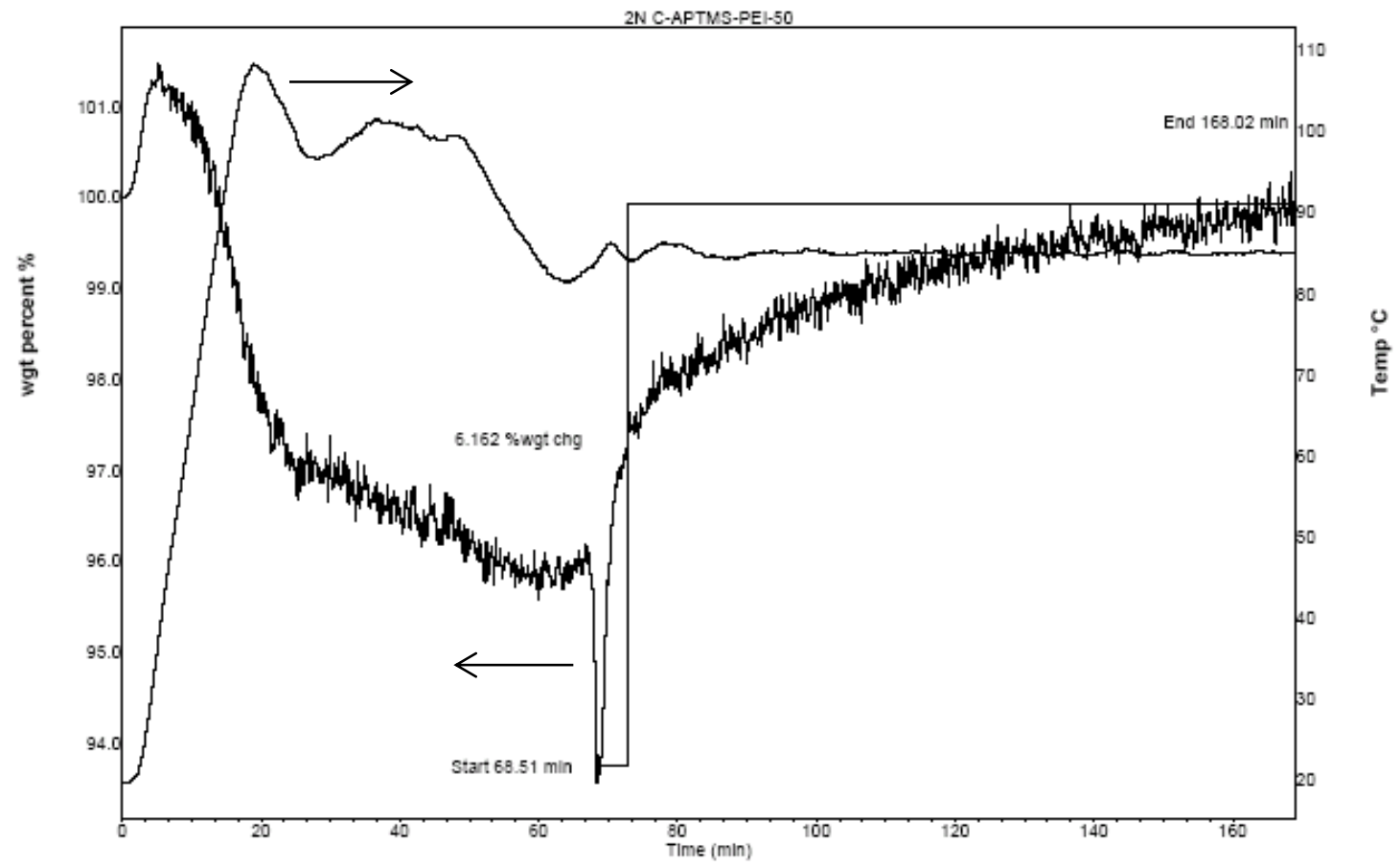

Figure 5-38: $\mathrm{CO}_{2}$ adsorption for clay treated with APTMS and PEI after exposure to the environment chamber 
From Figures 5-37-38, it can be seen that the same $\mathrm{CO}_{2}$ adsorption profile is observed for the adsorption of $\mathrm{CO}_{2}$ before and after exposure to the environmental chamber at $66-67^{\circ} \mathrm{C}$ and $98 \% \mathrm{RH}$ for 24 hours. This was also true for all of the other samples tested. The data collected here suggest that the use of steam for the regeneration of samples treated with only APTMS would not be an ideal way for regeneration. Although the decrease in adsorption capacity for samples treated with APTMS could have been due to the condensation of water directly onto the sample, which probably would not occur to the degree that it did in the environmental chamber when using low pressure steam. The stability of samples treated with PEI and APTMS+PEl showed good resilience to the environmental chamber and therefore lowpressure steam might be a good candidate for regeneration of these samples.

\subsection{Activation Energy Results}

The stability of amines on solid supports is a big concern for the applicability of the amine solid adsorbents in commercial applications. Therefore the activation energy of the degradation of APTMS and PEI on montmorillonite was studied using a TGA technique

described in a paper by Friedman. ${ }^{[66]}$ Additionally, other papers on TGA activation energy assumed a very general kinetic equation. ${ }^{[67],[68]}$ The method is used for decomposition kinetics of polymers using different heating rates through its decomposition region. After heating the material at different heating rates, the temperatures for a constant decomposition level are determine. Equation 5-3 is a general kinetic equation used to calculate activation energy. 


$$
\left(-\frac{1}{\omega_{o}}\right)\left(\frac{d \omega}{d t}\right)=A e^{-\frac{\Delta E}{R T}} f\left(\frac{\omega}{\omega_{o}}\right)
$$

Where $\omega=$ weight of organic material, $\omega_{o}=$ original weight, $\mathrm{t}=$ time (in hours), $A=$ preexponential factor of rate constant (per hour), $\Delta E=$ activation energy of rate constant, (in calories $/$ mole $) R=$ gas constant $\left(1.987 \mathrm{cal} . /{ }^{\circ} \mathrm{K}\right.$. mole $), T=$ absolute temperature, and $f\left(\frac{\omega}{\omega_{0}}\right)=\mathrm{a}$ function of the weight of organic material. ${ }^{[66]}$ By taking logarithms of both sides of Equation 53, one can obtain Equation 5-4.

$$
\ln \left[\left(-\frac{1}{\omega_{o}}\right)\left(\frac{d \omega}{d t}\right)\right]=\ln A+\ln f\left(\frac{\omega}{\omega_{o}}\right)-\frac{\Delta E}{R T}
$$

It is assumed that $f\left(\frac{\omega}{\omega_{o}}\right)$ is a constant for constant values of $\left(\frac{\omega}{\omega_{o}}\right)$. Values of $\left(-\frac{1}{\omega_{o}}\right)\left(\frac{d \omega}{d t}\right)$ and $\frac{1}{T}$ were determined for each $\left(\frac{\omega}{\omega_{o}}\right)$ for each TGA experimental run and plotted against each other. The slope of each line is equal to $-\frac{\Delta E}{R}$, while the intercept is $\ln \left[A f\left(\frac{\omega}{\omega_{o}}\right)\right]$. Flynn, et. al. used a similar equation, Equation $5-5$, and graphed the negative logarithm of the heating rate $(-\log (B))$ versus $1 / \mathrm{T}$.

$$
E \cong-4.35(d \log B) /\left(d \frac{1}{T}\right)
$$

Were $B$ is the ramping or heating rate for each TGA run. A sample of clay treated with PEI was first tested using heating rates of $5,10,15$, and $20^{\circ} \mathrm{C}$ per minute in pure nitrogen. Figure 5-39 shows the TGA graph of sample clay treated with PEI at these heat rates. Figure $5-40$ shows a plot of $-\log B$ vs. $1 / T$ from the data in Figure 5-39 


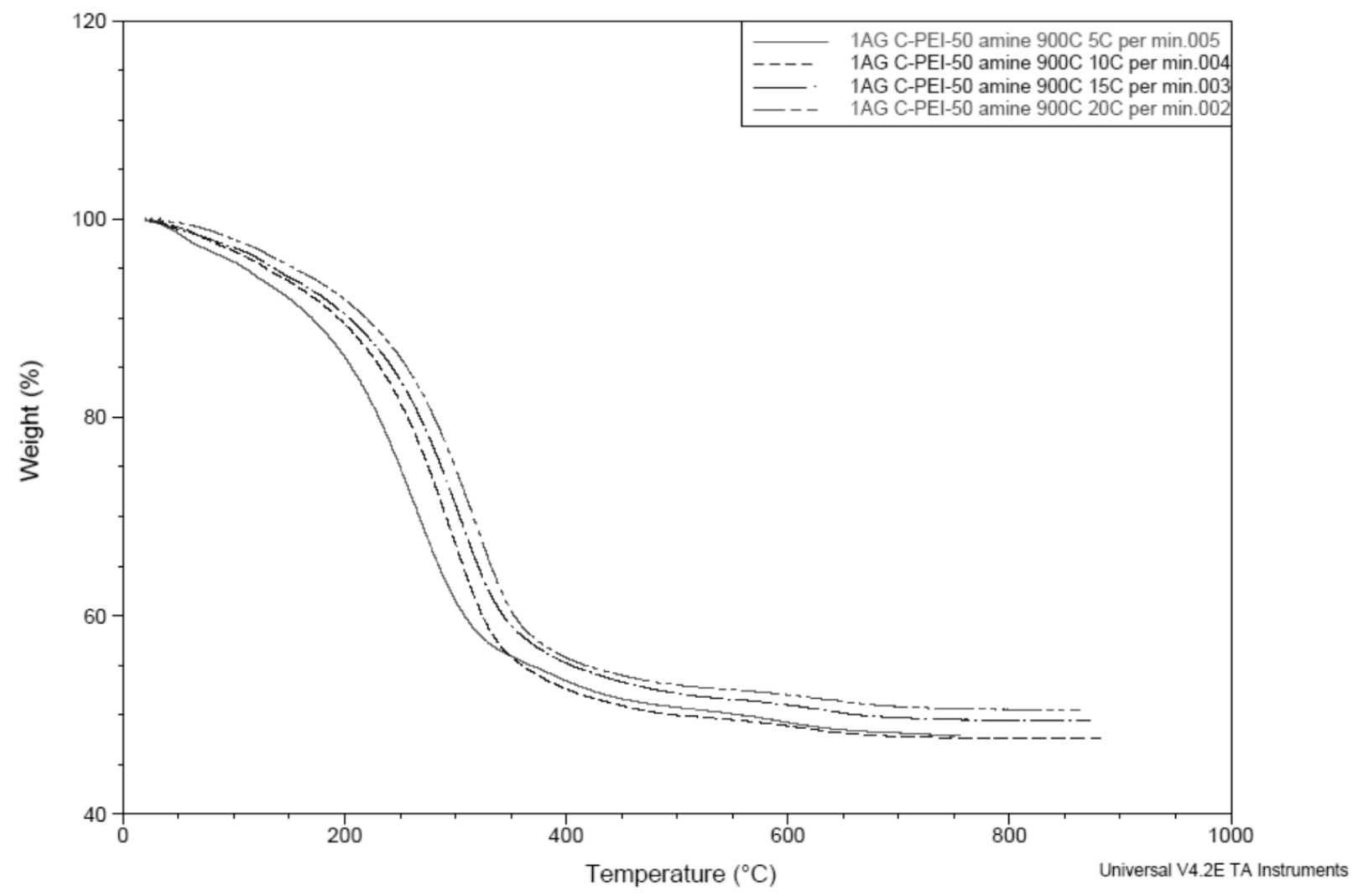

Figure 5-39: TGA overlay graph of sample clay treated with PEI

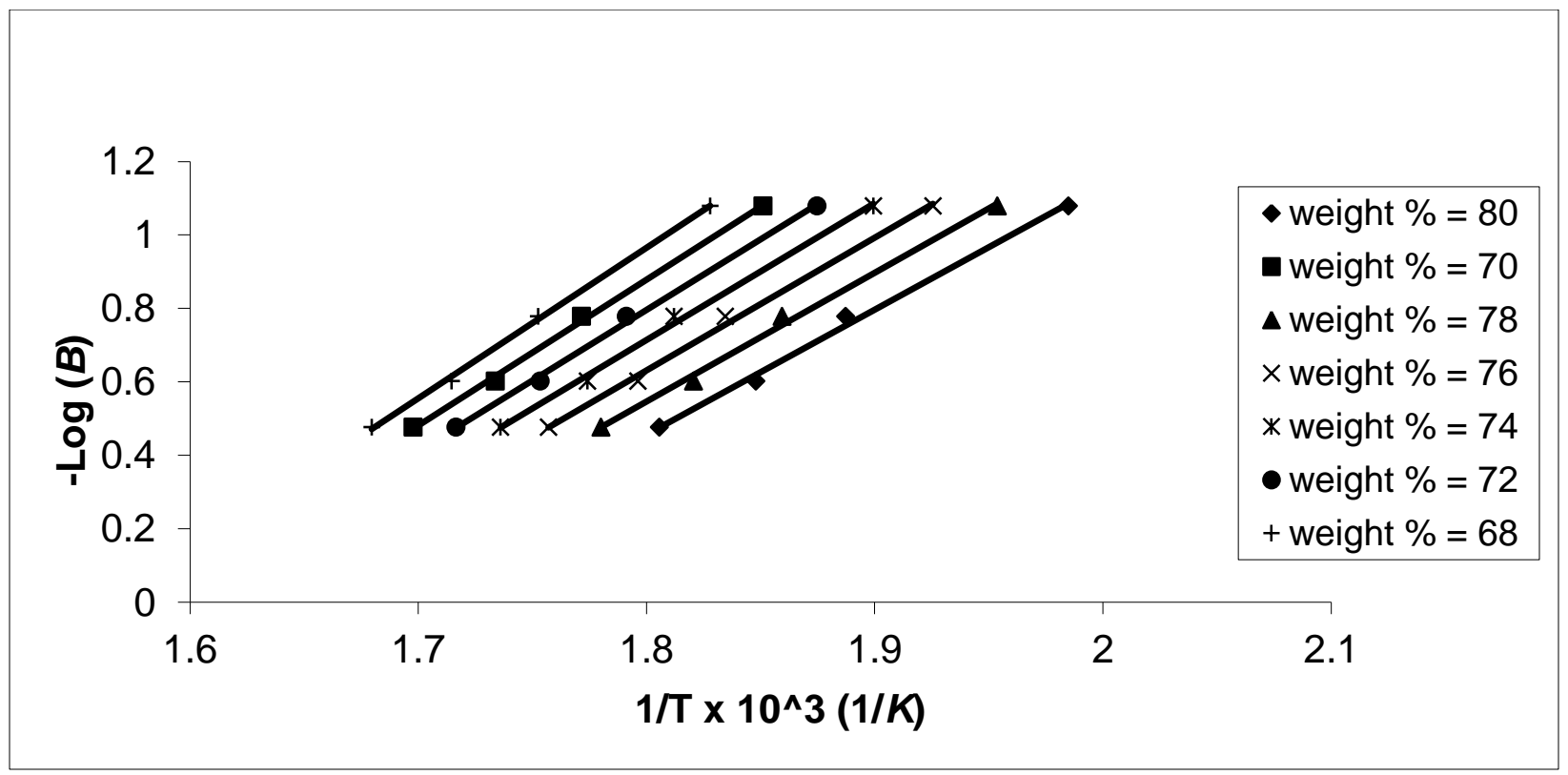

Figure 5-40: Logarithm of heating rate vs. reciprocal absolute temperature 
From Figure 5-39 values of 1/T were calculated at different weight percentages during the constant weight loss process. By using the equation by Flynn, the activation energy can be calculated at each weight percent for an average value of $16.26 \mathrm{Kcal} / \mathrm{mole}$ with a standard deviation of 1.1. Figure 5-41 is a graph of the activation energy versus residual fraction $\left(\frac{\omega}{\omega_{o}}\right)$

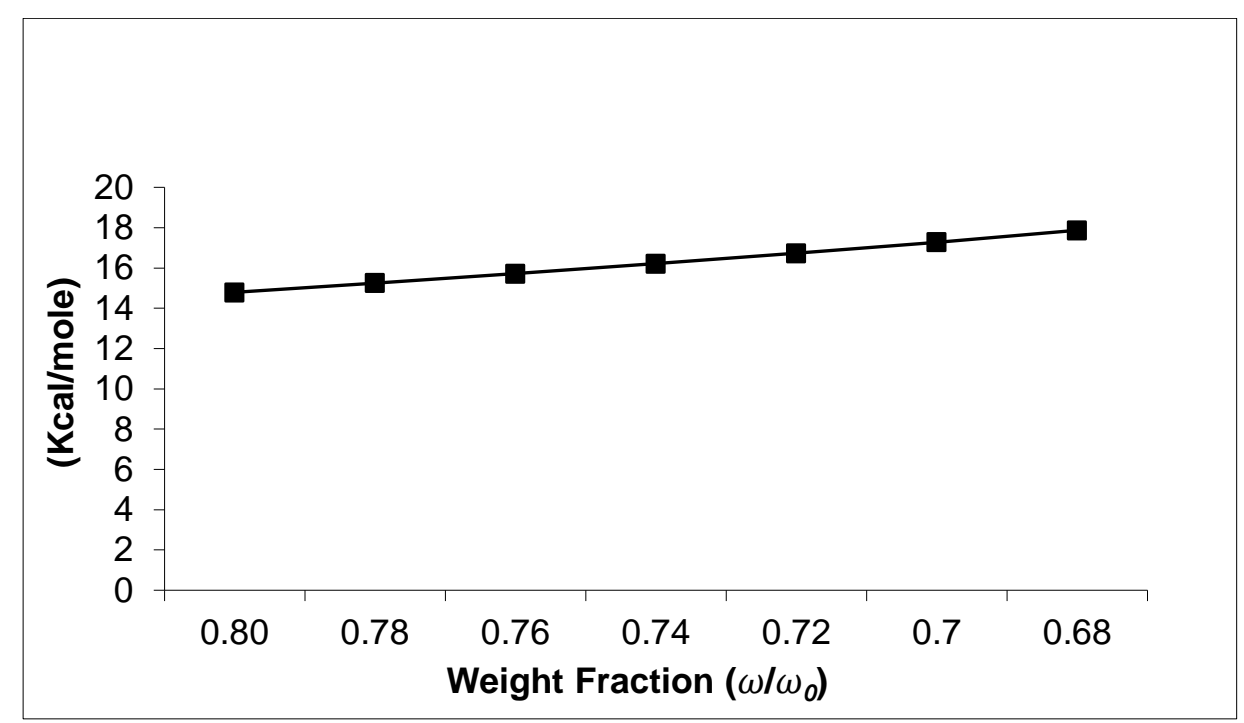

Figure 5-41: Activation energy of clay treated with PEI versus weight fraction

Figure 5-42 is an overlay graph of clay treated with APTMS. The TGA data did not form a very ideal decomposition graph and the calculated activation energy had a very big standard deviation. The calculated decomposition activation energy was $45.4 \mathrm{Kcal} / \mathrm{mole}$ with a standard deviation of $20.1 \mathrm{Kcal} / \mathrm{mole}$. 


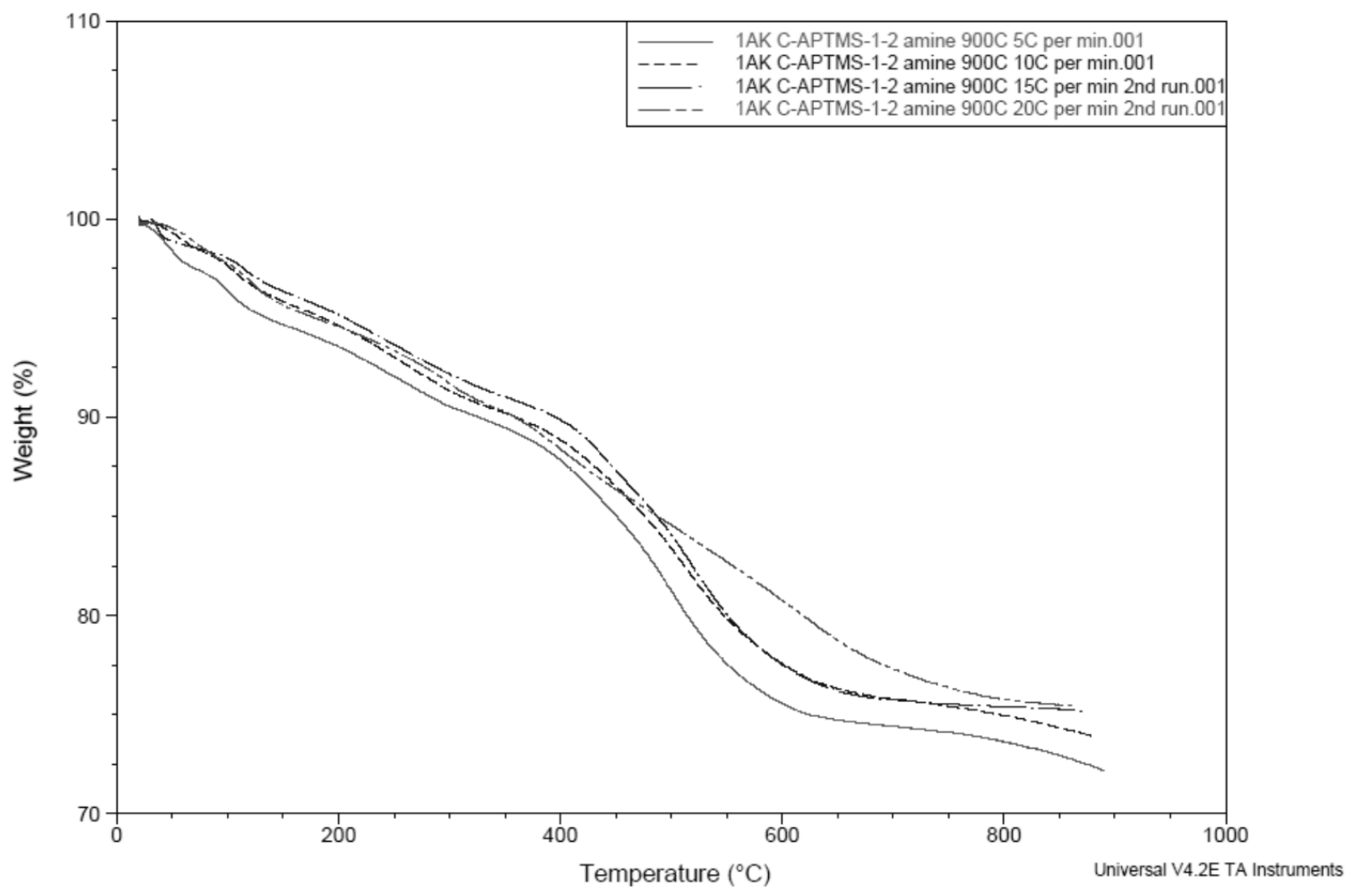

Figure 5-42: Clay treated with APTMS overlay TGA graph

Figure 5-43 is a graph of the decomposition activation energy versus the residual weight fraction.

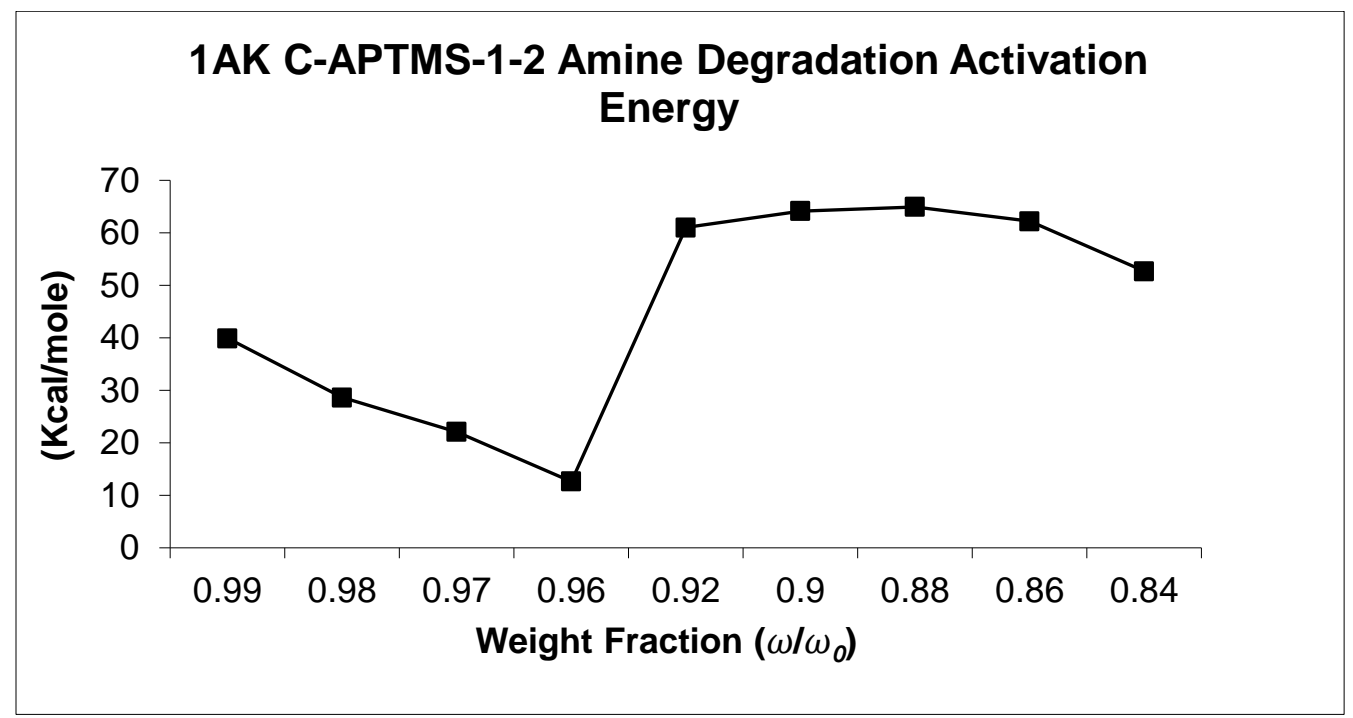

Figure 5-43: Clay treated with APTMS activation energy versus weight fraction 
Figures 5-42 and 5-43 show that this method for calculating the activation energy for the degradation of APTMS on clay is poor.

Clay treated with the combination of APTMS and PEI was also studied using this method. Similar to the clay treated with APTMS, the clay treated with the combination of APTMS and PEI did not give good results for an accurate calculation of the degradation activation energy.

The goal of this study was not only to better understand the degradation of the amine on the clay, but also try to use this technique to study the desorption of $\mathrm{CO}_{2}$ from the adsorbents. Therefore, the activation energy of desorption of $\mathrm{CO}_{2}$ was studied using a similar procedure to the decomposition of the amines. The TGA procedure for the desorption of $\mathrm{CO}_{2}$ was to react $\mathrm{CO}_{2}$ to the adsorbent at $85^{\circ} \mathrm{C}$ then cool the sample in $\mathrm{CO}_{2}$ to $30^{\circ} \mathrm{C}$. Once the sample was at $30^{\circ} \mathrm{C}$ the reaction gas was switched to nitrogen and the heating rate was varied to achieve graphs similar to the decomposition graphs. Figure 5-44 is a TGA overlay graph of desorption of $\mathrm{CO}_{2}$ on clay treated with APTMS. The curves were adjusted to be equal at the start of decomposition. 


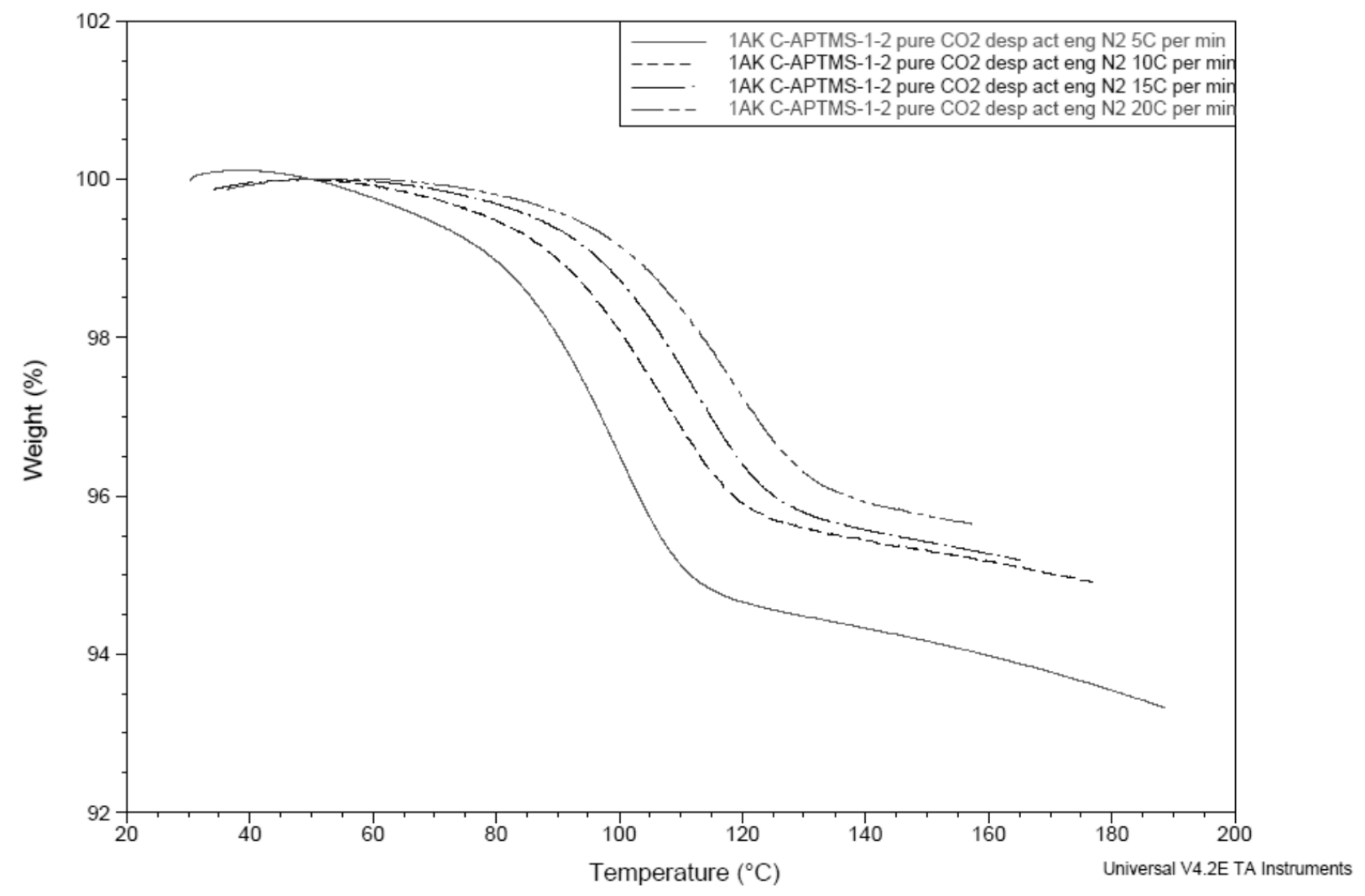

Figure 5-44: Desorption of $\mathrm{CO}_{2}$ on clay treated with APTMS in nitrogen

By using the same procedure to calculate activation energy as before, the activation energy was $15.4 \mathrm{Kcal} / \mathrm{mole}$ with a standard deviation of $0.76 \mathrm{Kcal} / \mathrm{mole}$. While the calculated standard deviation is small, it can be seen that the ending weight percent for the different heating rates is significantly different. This is not expected since the same amount of $\mathrm{CO}_{2}$ is eventually expected to desorb, independent of the heating of the heating rate. Therefore, this procedure to calculate desorption activation energy for $\mathrm{CO}_{2}$ did not seem very accurate.

The degradation activation of polymers using this TGA technique has been conducted for many years. The results obtained using this technique on the adsorbents studied did not seem to give very accurate results. Additionally, trying the use this technique to study desorption of $\mathrm{CO}_{2}$ also seemed to give inconclusive results. 


\section{Chapter 6}

\section{Conclusions and Future Work}

\subsection{Conclusions}

The research completed in this project shows that untreated nanoclay adsorbs very little $\mathrm{CO}_{2}$ at atmospheric pressure and at pressures up to $300 p s i$ at various temperatures. Clay treated with APTMS and PEI was able to adsorb significant $\mathrm{CO}_{2}$. Additionally, the amine treated clay was able to adsorb $\mathrm{CO}_{2}$ at different pressures and temperatures, even when using a gas mixture of $10 \% \mathrm{CO}_{2}$ and $90 \% \mathrm{~N}_{2}$. The highest adsorption capacities at atmospheric pressure were observed to occur at temperatures between $75^{\circ} \mathrm{C}$ and $100^{\circ} \mathrm{C}$. This phenomenon has been seen in the literature using PEI and is attributed to diffusion limitations at lower temperatures.

The combination of APTMS reacted to the edge hydroxyl groups and PEl attached to the clay surface showed an increased adsorption capacity at $85^{\circ} \mathrm{C}$ in the TGA at atmospheric pressure over samples treated with PEI or APTMS alone. The adsorption capacity at high pressures and room temperature also showed an increased adsorption capacity for the combination for APTMS and PEI. At increased temperatures and high pressure, samples treated with $\mathrm{PEI}$ showed a big increase in $\mathrm{CO}_{2}$ adsorption, while samples treated with APTMS did not have a significant increase in $\mathrm{CO}_{2}$ adsorption capacity. Similar to $\mathrm{CO}_{2}$ adsorption at atmospheric pressure, this was attributed to the reduction in diffusion resistance when the sample is heated. 
FTIR, TGA, and SEM studies showed that APTMS and PEI were successfully attached to the nanoclay. The attachment of amines to the nanoclay reduced the surface area according to the BET surface area analysis. The surface area of the dry untreated clay was significantly lower than the expected surface area for completely separated platelets. The APTMS treated samples also showed a decrease in the BET surface area over the untreated clay. It is suspected that if the clay platelets were completely separated during $\mathrm{CO}_{2}$ adsorption the $\mathrm{CO}_{2}$ adsorption capacity would increase because more amine groups would be easily available for reacting to $\mathrm{CO}_{2}$.

The regeneration of amine treated adsorbents was initially studied using pure nitrogen, and showed that the sorbents could be regenerated in nitrogen at $100^{\circ} \mathrm{C}$. Over ten cycles there was a small of loss of $\mathrm{CO}_{2}$ adsorption capacity for all of the treated samples. This indicated the possibility for cycling of the sorbents. Other regeneration schemes using pure and humid $\mathrm{CO}_{2}$ at $155^{\circ} \mathrm{C}$ also showed that regeneration using these sweep gases was possible. Loss of the $\mathrm{CO}_{2}$ adsorption capacity was observed when using pure $\mathrm{CO}_{2}$ at $155^{\circ} \mathrm{C}$ and indicated that the ability for the cycling of the adsorbent over hundreds or thousands of cycles should be investigated further. Vacuum regeneration of the adsorbents also indicated that this could be a possible mechanism for cycling. Vacuum desorption also showed that there is some loss of $\mathrm{CO}_{2}$ adsorption capacity over multiple cycles.

The stability of the adsorbents in water vapor at mild temperatures was studied and indicated that the adsorption capacity of APTMS treated samples could be greatly reduced with long exposures to water vapor at mild temperatures. It is important to note that liquid 
water was observed on these samples and could have possibly affected the $\mathrm{CO}_{2}$ adsorption capacity more than water vapor. The samples treated with PEI surprisingly showed little to no degradation after exposure to water vapor at mild temperatures. Although this is surprising, this has also been seen in the literature.

In summary, a nanoclay treated with commercially available amines has been shown to adsorb $\mathrm{CO}_{2}$. Although the $\mathrm{CO}_{2}$ adsorption capacity is not as high as the highest reported amine treated adsorbents, it is still within the range being employed for scale up studies. The advantage of these adsorbents is the use a support that is relatively cheap and available in huge quantities. This work has shown that the possibility of $\mathrm{CO}_{2}$ capture from a coal-fired power plant using an amine treated nanoclay is possible. 


\subsection{Future Work}

Future work for this project would be cycling tests using humid $\mathrm{CO}_{2}$ at $155^{\circ} \mathrm{C}$ over hundreds of cycles to determine the stability or degradation rate of the adsorbent. Additionally, the regeneration over hundreds of cycles using vacuum should be further investigated.

The degradation due to $\mathrm{SO}_{\mathrm{x}}$ and $\mathrm{NO}_{\mathrm{x}}$ is a big concern for solid amine adsorbents over thousands of adsorption and desorption cycles. The degradation due to these acid gases is expected to slightly degrade the solid amine adsorbents developed in this study. The rate of degradation and stability of the adsorbents when exposed to these acid gases should be studied. To study these properties, an actual or simulated coal-fired slipstream should be used as an adsorption gas.

The stability of the adsorbents to water vapor was tested using an environmental chamber that could not get to temperatures of low pressure steam. Since low pressure steam could be a likely candidate for regeneration of solid amine adsorbents, the stability of the adsorbents should be examined using low pressure steam or similar conditions. Additionally, cycling experiments using steam would be interesting.

Determining the energy for desorption of $\mathrm{CO}_{2}$ using different cycling techniques is an important property needed to design a commercial process. Therefore, futures studies are needed to determine the energy need to desorb $\mathrm{CO}_{2}$ from the adsorbents studied. Use more conclusive characterization tests to determine if a reaction of $\mathrm{CO}_{2}$ with the attached amine occurs as predicted. 


\section{References:}

[1] Plasynski, "Progress and New developments in Carbon Capture and Storage," Critical Reviews in Plant Sciences, vol. 28, no. 3, pp. 123-138, 2009.

[2] International Energy Agency, " $\mathrm{CO}_{2}$ Emissions from fuel Combustion," International Energy Agence and the Organisation for Economic Co-operation and Development, Paris, 2011.

[3] L. Parker and P. Folger, "Capturing $\mathrm{CO}_{2}$ from Coal-Fired Power Plants: Challenges for a Comprehensive Strategy," Congressional Research Service Reports, Washington, DC, 2010.

[4] U.S. Energy Information Administration, "Electricity generation from coal and natural gas both increased with summer heat," U.S. Department of Energy, Washington, DC, 2012.

[5] W. Liu, "Critical Material and Process Issues for $\mathrm{CO}_{2}$ Separation from Coal-Powered Plants," Minerals, Metals and Materials Society, vol. 61, no. 4, pp. 36-44, 2009.

[6] J. Ciferno, J. Litynski, S. Plasynski, J. Murphy, G. Vaux, R. Munson and J. Marano, "DOE/NETL Carbon Dioxide Capture and Storage RD\&D Roadmap," US DOE National Energy Technology Laboratory, Pittsburgh, 2010.

[7] D. Connell, "Carbon Dioxide Capture Options for Large Point Sources in the Midwestern United States," 2005.

[8] J. Bradshaw, S. Bachu, D. Bonijoly, R. Burruss, S. Holloway, N. P. Christensen and O. M. Mathiassen, " $\mathrm{CO}_{2}$ storage capacity estimation: issues and development of standards," International Journal of Greenhouse Gas Control, vol. 1, pp. 62-68, 2007.

[9] USDOE/National Energy Technology Laboratory, "Carbon Dioxide Enhanced Oil Recovery," USDOE/ National Energy Technology Laboratory, 2010.

[10] USDOE/National Energy Technology Laboratory, "Carbon Sequestration Atlas of the United States and Canada Third edition," United States Department of Energy/ National Energy Technology Laboratory, 2010.

[11] H. W. Pennline, D. R. Luebke, B. I. Morsi, Y. J. Heintz, K. L. Jones and J. B. Ilconich, "Carbon Dioxide Capture and Separation Techniques for Advanced Power Generation Point Sources," U.S. Department of Energy/NETL, Pittsburgh, 2006.

[12] C. M. White, B. R. Strazisar, E. J. Granite, J. S. Hoffman and H. W. Pennline, "Separation and Capture of $\mathrm{CO}_{2}$ from Large Stationary Sources and Sequestration in Geological Formations," Journal of Air and Waste Management Association, vol. 53, no. 6, pp. 645$715,2003$.

[13] A. Yazaydin and R. Snurr, "Screening of Metal-Organic Framewroks for Carbon Dioxide Capture from Flue Gas Using a Combined Experimental and Modeling Approach," Journal of American Chemical Society, vol. 131, pp. 18198-18199, 2009.

[14] D. Britt, H. Furukawa, B. Wang, T. G. Glover and O. M. Yaghi, "Highly efficient separation of carbon dioxide by a metal-organic framework replete with open metal sites," Proc Natl Acad Sci USA, vol. 106, pp. 20637-20640, 2009.

[15] S. R. Caskey, A. G. Wong-Foy and A. J. Matzger, "Dramatic Tuning of Carbon Dioxide Uptake via Metal Sustitution in a Coordination Polymer with Cylindrical Pores," Journal of the American Chemical Society, vol. 130, pp. 10870-10871, 2008.

[16] D. Wu, Q. Yang, C. Zhong, D. Liu, H. Huang, W. Zhang and G. Maurin, "Revealing the 
Structure-Property Relationships of Metal-Organic Frameworks for $\mathrm{CO}_{2}$ Capture from Flue Gas," Langmuir, vol. 28, pp. 12094-12099, 2012.

[17] S. A. S. Talesh, S. Fatemi, S. Hashemi and M. Ghasemi, "Effect of Si/Al Ratio on $\mathrm{CO}_{2}-\mathrm{CH}_{4}$ Adsorption and Selectivity in Synthesized SAPO-34," Separation Science and Technology, vol. 45, pp. 1295-1301, 2010.

[18] D. Ko, r. Siriwardane and L. T. Biegler, "Optimization of a Pressure-Swing Adsorption Process Using Zeolite $13 \mathrm{X}$ for $\mathrm{CO}_{2}$ Sequestration," Ind. Eng. Chem. Res. , vol. 42, pp. 339348, 2003.

[19] M. Tatlier and A. Erdem-Senatalar, "Fractal dimension of zeolite surfaces by calculation," Chaos, Solitons and Fractals, vol. 12, pp. 1145-1155, 2001.

[20] F. Brandani and D. M. Ruthven, "The Effect of Water on teh Adsorption of $\mathrm{CO}_{2}$ and $\mathrm{C}_{3} \mathrm{H}_{8}$ on Type X Zeolites," Ind. Eng. Chem. Res. , vol. 43, pp. 8339-8344, 2004.

[21] B. Castellani, M. Filipponi, S. Rinaldi and F. Rossi, "Capture of Carbon Dioxide Using Gas Hydrate Technology," in The 25th International Conference on Efficiency, Cost, Optimization, Simulation and Environmental Impact of Energy Systems, Peruglia, Italy, 2012.

[22] H. Yang, Z. Xu, M. Fan, F. Gupta, R. B. Slimane, A. E. Bland and I. Wright, "Progress in carbon dioxide separtion and capture: A review," Journal of Environmental Sciences, vol. 20, no. 1, pp. 14-27, 2008.

[23] L.-S. Fan and F. Li, "Chemical Looping Technology and Its Fossil Energy Conversion Applications," Industrial \& Engineering Chemistry Research, vol. 49, no. 21, pp. 1020010211, 2010.

[24] C. A. Scholes, S. E. Kentish and G. W. Stevens, "Carbon Dioxide Separation through Polymeric Membrane Systems for Flue Gas Applications," Recent Patens on Chemical Engineering, vol. 1, pp. 52-66, 2008.

[25] J. C. Hicks, J. H. Drese, D. J. Fauth, M. L. Gray, G. Qi and C. W. Jones, "Designing Adsorbents for $\mathrm{CO}_{2}$ Capture From Flue Gas-Hyperbranched Aminosilicas Capable of Capturing $\mathrm{CO}_{2}$ Reversibly," Journal of the American Chemical Society, vol. 130, no. 10, pp. 2902-2903, 2008.

[26] M. T. Ho, G. W. Allinson and D. E. Wiley, "Reducing the Cost of $\mathrm{CO}_{2}$ Capture from Flue Gases Using Pressure Swing Adsorption," Industrial \& Engineering Chemistry Research, vol. 47, no. 14, pp. 4883-4890, 2008.

[27] J. H. Drese, S. Choi, R. P. Lively, W. J. Koros, D. J. Fauth, M. L. Gray and C. W. Jones, "Synthesis-Structure-Property Relationships for Hyperbranced Aminosilica $\mathrm{CO}_{2}$ Adsorbents," Advanced Functional Materials, vol. 19, pp. 3821-3832, 2009.

[28] L. Gray, Y. Soong, K. Champagne, H. Pennline, J. Baltrus, R. S. Jr., R. Dhatri, S. Chuang and T. Filburn, "Improved immobilized carbon dioxide capture sorbents," Fuel Processing Technology, vol. 86, no. 14-15, pp. 1449-1455, 2005.

[29] X. Xu, C. Song, R. Wincek, J. M. Andresen, B. G. Miller and A. W. Scaroni, "Separation of $\mathrm{CO}_{2}$ from Power Plant Flue Gas Using a Novel $\mathrm{CO}_{2}$ "Molecular Basket" Adsorbent," Energy and Fuels, vol. 13, pp. 1463-1469, 2002.

[30] X. Xu, C. Song, J. M. Andresen, B. G. Miller and A. W. Scaroni, "Preparation and characterization of novel $\mathrm{CO}_{2}$ "molecular basket" adsorbents based on polymer-modifed 
mesoporous molecular sieve MCM-41," Microporous and Mesoporous Materials, vol. 62, pp. 29-45, 2003.

[31] X. Xu, C. Song, B. G. Miller and A. W. Scaroni, "Influence of Moisture on $\mathrm{CO}_{2}$ Separation from Gas Mixture by a Nanoporous Adsorbent Based on Polyethylenimine-Modified Molecular Sieve MCM-41," Industrial and Engineering Chemisty Research, vol. 21, no. 44, pp. 8113-8119, 2005.

[32] X. Xu, C. Song, B. G. Miller and A. W. Scaroni, "Adsorption separation of carbon dioxide from flue gas of natural gas-fired boiler by a novel nanoporous "molecular basket" adsorbent," Fuel Processing Technology, vol. 86, pp. 1457-1472, 2005.

[33] X. Wang, X. Ma, V. Schwartz, J. C. Clark, S. H. Overbury, S. Zhao, X. Xu and C. Song, "A solid molecular basket sorbent for $\mathrm{CO}_{2}$ capture from gas streams with low $\mathrm{CO}_{2}$ concentration under ambient conditions," Physical Chemisty Chemical Physics, vol. 14, pp. 1485-1492, 2012.

[34] P. J. Harlick and A. Sayari, "Applications of Pore-Expanded Mesoporous Silicas. 3. triamine silane grafting for Enhanced $\mathrm{CO}_{2}$ adsorption," Industrial \& Engineering Chemistry Research, vol. 9, no. 45, pp. 3248-3255, 2006.

[35] A. Sayari and P. J. Harlick, "Applications of Pore-Expanded Mesoporous Silica. 5. Triamine Grafted Material with Exceptional $\mathrm{CO}_{2}$ dynamic and Equilibrium Adsorption Performance," Industrial \& Engineering Chemistry Research, vol. 46, pp. 446-458, 2007.

[36] Y. Belmabkhout, R. Serna-Guerrero and A. Sayari, "Adsorption of $\mathrm{CO}_{2}$-Containing Gas Mixtures over Amine-Bearing Pore-Expanded MCM-41 Silica: Application for Gas Purification," Industrial \& Engineering Chemistry Research, vol. 49, pp. 359-365, 2010.

[37] Y. Belmabkhout, R. Serna-Guerrero and A. Sayari, "Adsorption of $\mathrm{CO}_{2}$-containing gas mixtures over amine-bearing pore-expanded MCM-41 silica: application for $\mathrm{CO}_{2}$ separtion," Chemistry and Materials Science, vol. 17, no. 2, pp. 395-401, 2011.

[38] J. C. Hicks, J. H. Drese, D. J. Fauth, M. L. Gray, G. Qi and C. W. Jones, "Designing Adsorbents for $\mathrm{CO}_{2}$ Capture from Flue Gas-Hyperbranched Aminosilicas Capable of Capturing $\mathrm{CO}_{2}$ Reversibly," Journal of the American Chemical Society, vol. 130, pp. 29022903, 2008.

[39] J. H. Drese, S. Choi, R. P. Lively, W. J. Koros, D. J. Fauth, M. L. Gray and C. W. Jones, "Synthesis-Structure-Property Relationships for Hyperbranched Aminosilica $\mathrm{CO}_{2}$ adsorbents," Materials Views, vol. 19, no. 23, pp. 3821-3832, 2009.

[40] W. Li, S. Choi, J. H. Drese, M. Hornbostel, G. Krishnan, P. M. Eisenberger and C. W. Jones, "Steam-Stripping for Regeneration of Supported Amine-Based $\mathrm{CO}_{2}$ Adsorbents," ChemSusChem, vol. 3, no. 8, pp. 899-903, 2010.

[41] X. Yan, L. Zhang, Y. Zhang, G. Yang and Z. Yan, "Amine-Modified SBA-15: Effect of Pore Structure on the Performance for $\mathrm{CO}_{2}$ Capture," Industrial \& Engineering Chemistry Research, vol. 50, pp. 3220-3226, 2011.

[42] N. Hiyoshi, K. Yogo and T. Yashima, "Adsorption of Carbon Dioxide on Amine Modified SBA-15 in the Presence of Water Vapor," Chemistry Letters, vol. 33, pp. 510-511, 2004.

[43] A. Sayari, Y. Belmabkhout and R. Serna-Guerrero, "Flue gas treatment via $\mathrm{CO}_{2}$ adsorption," Chemical Engineering Journal, vol. 171, no. 3, pp. 760-774, 2011.

[44] X. Xu, C. Song, J. M. Andresen, B. G. Miller and A. W. Scaroni, "Novel Polyethylenimine- 
Modified Mesoporous Molecular Sieve of MCM-41 Type as High-Capacity Adsorbent for $\mathrm{CO}_{2}$ Capture," Energy \& Fuels, vol. 16, pp. 1463-1469, 2002.

[45] P. Bollini, S. Choi, J. H. Drese and C. W. Jones, "Oxidative Degradation of Aminosilica Adsorbents Relevant to Postcombustion $\mathrm{CO}_{2}$ capture," Energy \& Fuels, vol. 25, pp. 24162425, 2011.

[46] O. Leal, C. Bolivar, C. Ovalles, J. J. Gracia and Y. Espidel, "Reversible adsorption of carbon dioxide on amine surface-bonded silica gel," Inorganica Chimica Acta, vol. 240, pp. 183-189, 1995.

[47] G. P. Knowles, J. V. Graham, S. W. Delaney and A. L. Chaffee, "Aminopropylfunctionalized mesoporous silicas as $\mathrm{CO}_{2}$ adsorbents," Fuel Processing Technology, vol. 86, pp. 1435-1448, 2005.

[48] G. P. Knowles, S. W. Delaney and A. L. Chaffee, "Diethylenetriamine[propyl(silyl)]Functionalized (DT) Mesoporous Silicas as $\mathrm{CO}_{2}$ Adsorbents," Industrial \& Engineering Chemistry Research, vol. 45, no. 8, pp. 2626-2633, 2006.

[49] C. Knofel, J. Descarpentries, A. Benzaouia, V. Zelenak, S. Mornet, P. Llewelyn and V. Hornebecq, "Functionalised micro-/mesoporous silica for the adsorption of carbon dioxide," Microporous and Mesoporous Materials, vol. 99, no. 1-2, pp. 79-85, 2007.

[50] H. Y. Yang and F. T. Huang, "Amine-Grafted MCM-48 and Silica Xerogel as Superior Sorbents for Acidic Gas Removal from Natural Gas," Industrial \& Engineering Chemistry Research, vol. 42, no. 12, pp. 2427-2433, 2003.

[51] W. Linfang, M. Lei, W. Aiquin, L. Qian and Z. Tao, " $\mathrm{CO}_{2}$ adsorption on SBA-15 Modified by Aminosilane," Chinese Journal of Catalysis, vol. 28, no. 9, pp. 805-810, 2007.

[52] N. Hiyoshi, K. Yogo and T. Yashima, "Adsorption characterisitcs of carbon dioxide on organically functionalized SBA-15," Microporous and Mesoporous Materials, vol. 84, pp. 357-365, 2005.

[53] P. Bollini, S. Choi, J. H. Drese and C. W. Jones, "Oxidative Degradation of Aminosilica Adsorbents Relevant to Postcombustion $\mathrm{CO}_{2}$ capture," Energy \& Fuels, vol. 25, pp. 24162425, 2011.

[54] W. Li, P. Bollini, S. A. Didas, S. Choi, J. H. Drese and C. W. Jones, "Structural Changes of Silica Mesocellular Foam Supported Amine-Functionalized $\mathrm{CO}_{2}$ adsorbents Upon Exposure to Steam," Applied Materials \& Interfaces, vol. 2, no. 11, pp. 3363-3372, 2010.

[55] O. Leal, C. Bolivar, C. Ovalles, J. J. Gracia and Y. Espidel, "Reversible adsorption of carbon dioxide on amine surface-bonded silica gel," Inorganica Chimica Acta, vol. 240, pp. 183-189, 1995.

[56] R. A. Khatri, S. S. C. Chuang, Y. Soong and M. Gray, "Thermal and Chemical Stability of Regenerable Solid Amine Sorbent for $\mathrm{CO}_{2}$ Capture," Energy \& Fuels, vol. 20, pp. 15141520, 2006.

[57] A. Sayari and Y. Belmabkhout, "Isothermal versus Non-isothermal Adsorption-Desorption Cycling of Triamine-Grafted Pore-Expanded MCM-41 Mesoporous Silica for $\mathrm{CO}_{2}$ Capture from Flue Gas," Energy \& Fuels, vol. 24, pp. 5273-5280, 2010.

[58] J. H. Drese, S. Choi, S. A. Didas, P. Bollini, M. L. Gray and C. W. Jones, "Effect of support structure on $\mathrm{CO}_{2}$ adsoorption properties of pore-expanded hyperbranced aminosilicas," Microporous and Mesoporous Materials, vol. 151, pp. 231-240, 2012. 
[59] A. Heydari-Gorji, Y. Belmabkhout and A. Sayari, "Polyethylenimine-Impregnated Mesoporous Silica: Effect of Amine Loading and Surface Alkyl Chains on $\mathrm{CO}_{2}$ Adsorption," Langmuir, vol. 27, pp. 12411-12416, 2011.

[60] A. Sayari and Y. Belmabkhout, "Stabilization of Amine-Containing $\mathrm{CO}_{2}$ Adsorbents; Dramatic Effect of Water Vapor," Journal of the American Chemical Society, vol. 18, no. 132, pp. 6312-6314, 2010.

[61] T. Drage, A. Arenillas, K. Smith and C. Snape, "Thermal stability of polyethylenimine based carbon dioxide adsorbents and its influence on selection of regeneration strategies," Microporous and Mesoporous Materials, vol. 116, pp. 504-512, 2008.

[62] C. Biqiong, J. R. G. Evans, H. C. Greenwell, P. Boulet, P. V. Coveney, A. A. Bowden and A. Whiting, "A critical appraisal of polymer-clay nanocomposites," Chemical Society Reviews, vol. 37, pp. 568-594, 2008.

[63] F. Hussain and M. Hojjati, "Polymer-matrix Nanocomposites, Processing, Manufacturing and Application: an Overview," Composite Materials, vol. 40, pp. 1511-1575, 2006.

[64] F. Bergaya and B. Theng, Handbook of Clay materials, Elsevier, 2006, pp. 1-109.

[65] K. Wang, L. Wang, J. Wu, L. Chen and C. He, "Preparation of Highly Exfoliated Epoxy/Clay Nanocomposites by "Slurry Compounding": Process and Mechanisms," American Chemical Society, vol. 21, pp. 3613-3618, 2005.

[66] H. L. Friedman, "Kinetics of Thermal Degradation of char-forming plastics from thermogravimetry. Application to a phenolic plastic," Polymer Science, no. 6, pp. 183-195, 1964.

[67] J. H. Flynn and L. A. Wall, "A Quick, direct method for the determination of activation energy from thermogravimetric data," Journal of Polymer Science Part B; Polymer Letters, vol. 4, no. 5, pp. 323-328, 1966.

[68] S. Gill and S. P., "Decomposition Kinetics using TGA," TA Instruments, New Castle, DE, 1994.

[69] O. Monticelli, Z. Musina, A. Frache, F. Bellucci, G. Camino and S. Russo, "Influence of compatibilizer degradation on fromation and properties of PA6/organoclay nanocomposites," Polymer Degradation and Stability 92 , vol. 92, pp. 370-378, 2007.

[70] J. L. Bishop, C. M. Pieters and J. O. Edwards, "Infrared Spectroscopic Analyses on the Nature of Water in Montmorillonite," Clays and Clay Minerals, vol. 42, no. 6, pp. 702-716, 1994.

[71] A. Danon, P. C. Stair and E. Weitz, "FTIR Study of $\mathrm{CO}_{2}$ Adsorption on Amine-Grafted SBA-15: Elucidation of Adsorbed Species," Physical Chemistry, vol. 115, pp. 11540-11549, 2011.

[72] X. Wang, V. Schwartz, J. C. Clark, X. Ma, S. H. Overbury, X. Xu and C. Song, "Infrared Study of $\mathrm{CO}_{2}$ Sorption over "Molecular Basket" Sorbent Consisting of PolyethylenimineModified Mesoporous Molecular Sieve," Physical Chemistry, vol. 17, no. 113, pp. 72607268, 2009.

[73] A. C. C. Chang, S. S. Chuang, M. Gray and Y. Soong, "In-situ Infrared Study of $\mathrm{CO}_{2}$ Adsorption on SBA-15 Grafted with (Aminopropyl)triethoxsilane," Energy \& Fuels, vol. 17, pp. 468-473, 2003. 


\section{Appendix A: Tabulated Data for Graphs}

Table A-1: Data for Figure 4-5, Comparison of "dry method" versus "slurry method"

\begin{tabular}{|l|c|c|}
\hline Concentration (g APTMS/ g Clay) & 0.4 & 0.8 \\
\hline "Dry Method" Percent Amine (wt.\%) & 14.8 & 17.4 \\
\hline $\begin{array}{l}\text { "Dry Method" Standard Deviation } \\
\text { (STDEV) (wt.\%) }\end{array}$ & 0.1 & 0.9 \\
\hline "Slurry Method" Percent Amine (wt.\%) & 19.8 & 19.1 \\
\hline "Slurry Method" STDEV (wt.\%) & 1.6 & 1.1 \\
\hline
\end{tabular}

Table A-2: Data for Figure 4-6, Percent amine grafted versus the concentration of APTMS "slurry method"

\begin{tabular}{|l|l|l|l|l|l|}
\hline Concentration (g APTMS/ g Clay) & 0.4 & 0.6 & 0.8 & 1.0 & 1.2 \\
\hline Percent Amine (wt.\%) & 14.2 & 13.6 & 12.0 & 16.7 & 15.7 \\
\hline STDEV (wt.\%) & 1.6 & 1.1 & 1.6 & 0.2 & 1.9 \\
\hline
\end{tabular}

Table A-3: Data for Figure 4-8, Comparison of amount amine grafted versus treatment

\begin{tabular}{|l|c|c|}
\hline & Weight Percent Amine & STDEV (wt.\%) \\
\hline C-PEI-50 & 37.4 & 1.5 \\
\hline C-APTMS-1-2 & 15.7 & 1.9 \\
\hline C-APTMS-PEI & 40.5 & 2.1 \\
\hline
\end{tabular}

Table A-4: Data for Figure 5-5, Carbon dioxide adsorption capacity as a function of adsorption temperature at atmospheric pressure in the TGA

\begin{tabular}{|l|c|c|c|c|c|c|}
\hline \multicolumn{1}{|c|}{ Adsorption Temperature } & $50^{\circ} \mathrm{C}$ & $75^{\circ} \mathrm{C}$ & $85^{\circ} \mathrm{C}$ & $100^{\circ} \mathrm{C}$ & $125^{\circ} \mathrm{C}$ & $150^{\circ} \mathrm{C}$ \\
\hline Untreated Clay (wt.\%) & 0.2 & 0.6 & 0.7 & 1.0 & 1.1 & 0.7 \\
\hline Untreated Clay (STDEV wt.\%) & 0.1 & 0.3 & 0.4 & 0.3 & 0.3 & 0.5 \\
\hline C-PEI (wt.\%) & 2.4 & 6.0 & 6.2 & 6.3 & 3.9 & 1.3 \\
\hline C-PEI (STDEV wt.\%) & 0.6 & 1.2 & 0.9 & 0.9 & 1.7 & 0.8 \\
\hline C-APTMS (wt.\%) & 4.6 & 5.2 & 6.1 & 4.3 & 4.5 & 4.1 \\
\hline C-APTMS (STDEV wt.\%) & 1.2 & 2.0 & 0.9 & 1.3 & 1.9 & 1.6 \\
\hline C-APTMS-PEI (wt.\%) & 2.3 & 3.7 & 7.5 & 5.7 & 5.4 & 3.0 \\
\hline C-APTMS-PEI (STDEV wt.\%) & 1.1 & 1.5 & 1.9 & 1.7 & 0.1 & 0.2 \\
\hline
\end{tabular}


Table A-5: Data for Figure 5-6, Time versus percent $\mathrm{CO}_{2}$ adsorbed based on a 90 minute adsorption run

\begin{tabular}{|l|c|c|c|c|}
\hline \multicolumn{1}{|c|}{ Percent Adsorption } & $50 \%$ & $75 \%$ & $90 \%$ & $95 \%$ \\
\hline C-PEI (minutes) & 1.1 & 8.2 & 32.2 & 53.8 \\
\hline C-PEI (STDEV minutes) & 0.6 & 3.2 & 5.7 & 5.6 \\
\hline C-APTMS (minutes) & 0.7 & 2.2 & 8.1 & 18.7 \\
\hline C-APTMS (STDEV minutes) & 0.2 & 1.0 & 5.6 & 12.1 \\
\hline C-APTMS-PEI (minutes) & 2.0 & 11.7 & 33.8 & 58.8 \\
\hline C-APTMS-PEI (STDEV minutes) & 1.9 & 7.4 & 3.7 & 7.7 \\
\hline
\end{tabular}

Table A-6: Data for Figure 5-9, $\mathrm{CO}_{2}$ adsorption for clay loaded with PEI at $85^{\circ} \mathrm{C}$

\begin{tabular}{|c|c|c|c|}
\hline PEI & Mn 423 & Mn 1200 & Mn 60,000 \\
\hline $\mathrm{CO}_{2}$ adsorption (wt.\%) & 6.2 & 6.0 & 1.6 \\
\hline STDEV (wt.\%) & 0.9 & 0.7 & 0.8 \\
\hline
\end{tabular}

Table A-7: Data for Figure 5-10, Comparison of PEI loading versus $\mathrm{CO}_{2}$ adsorption capacity at $85^{\circ} \mathrm{C}$

\begin{tabular}{|c|c|c|c|}
\hline PEI loading & $33 \%$ & $50 \%$ & $66 \%$ \\
\hline $\mathrm{CO}_{2}$ adsorption (wt.\%) & 4.0 & 6.2 & 5.3 \\
\hline STDEV (wt.\%) & 0.4 & 0.9 & 1.1 \\
\hline
\end{tabular}

Table A-8: Data for Figure 5-12, $\mathrm{CO}_{2}$ adsorption capacity in pure $\mathrm{CO}_{2}$ and $10 \% \mathrm{CO}_{2}$ balanced with nitrogen

\begin{tabular}{|l|c|c|c|}
\hline & C-PEI & C-APTMS & C-APTMS-PEI \\
\hline Pure $\mathrm{CO}_{2}$ (wt.\%) & 6.2 & 6.1 & 7.5 \\
\hline Pure $\mathrm{CO}_{2}$ (STDEV wt.\% & 0.9 & 0.9 & 1.9 \\
\hline $10 \% \mathrm{CO}_{2}$ (wt.\%) & 5.9 & 5.1 & 6.5 \\
\hline $10 \% \mathrm{CO}_{2}$ (STDEV wt.\%) & 0.6 & 2.3 & 3.1 \\
\hline
\end{tabular}


Table A-9: Data for Figure 5-13, Percent regeneration using pure nitrogen at $100^{\circ} \mathrm{C}$

\begin{tabular}{|l|c|c|c|}
\hline & $\begin{array}{c}\mathrm{CO}_{2} \text { adsorption } \\
(w \mathrm{t} . \%)\end{array}$ & $\begin{array}{c}1^{\text {st }} \text { Cycle } \mathrm{CO}_{2} \\
\text { adsorption (wt.\%) }\end{array}$ & $\begin{array}{c}\text { Percent regeneration } \\
\text { based on 1st cycle } \\
\text { adsorption }\end{array}$ \\
\hline C-PEI (wt.\%) & 5.8 & 5.5 & $94.0 \%$ \\
\hline C-PEI (STDEV wt.\%) & 0.9 & 0.7 & $4.3 \%$ \\
\hline C-APTMS (wt.\%) & 6.0 & 6.0 & $101.2 \%$ \\
\hline C-APTMS (STDEV wt.\%) & 1.1 & 1.0 & $2.6 \%$ \\
\hline C-APTMS-PEI (wt.\%) & 7.6 & 7.3 & $97.2 \%$ \\
\hline C-APTMS-PEI (STDEV wt.\%) & 2.0 & 1.9 & $3.9 \%$ \\
\hline
\end{tabular}

Table A-10: Data for Figure 5-14, $\mathrm{CO}_{2}$ adsorption capacity over 10 cycles

\begin{tabular}{|l|c|c|c|c|c|c|c|c|c|c|c|}
\hline \multicolumn{1}{|c|}{ Cycle } & 0 & 1 & 2 & 3 & 4 & 5 & 6 & 7 & 8 & 9 & 10 \\
\hline C-PEI (wt.\%) & 6.2 & 5.8 & 5.7 & 5.6 & 5.6 & 5.1 & 5.4 & 5.4 & 5.3 & 5.3 & 5.2 \\
\hline C-PEI (STDEV wt.\%) & 0.1 & 0.1 & 0.1 & 0.1 & 0.1 & 0.7 & 0.1 & 0.1 & 0.0 & 0.1 & 0.0 \\
\hline C-APTMS (wt.\%) & 6.7 & 6.6 & 6.6 & 6.6 & 6.6 & 6.7 & 6.6 & 6.6 & 6.6 & 6.6 & 6.6 \\
\hline C-APTMS (STDEV wt.\%) & 1.4 & 1.4 & 1.3 & 1.3 & 1.3 & 1.2 & 1.3 & 1.3 & 1.3 & 1.3 & 1.3 \\
\hline C-APTMS-PEI (wt.\%) & 8.5 & 8.4 & 8.3 & 8.3 & 8.3 & 8.2 & 8.2 & 8.2 & 8.1 & 8.1 & 8.0 \\
\hline C-APTMS-PEI (STDEV wt.\%) & 0.3 & 0.4 & 0.4 & 0.5 & 0.5 & 0.5 & 0.6 & 0.6 & 0.7 & 0.7 & 0.7 \\
\hline
\end{tabular}

Table A-11: Data for Figure 5-18, Percent $\mathrm{CO}_{2}$ cycled using pure $\mathrm{CO}_{2}$ at $155^{\circ} \mathrm{C}$ for 30 minutes for regeneration

\begin{tabular}{|l|c|c|c|}
\hline \multicolumn{1}{|c|}{ Cycle } & 1 & 2 & 3 \\
\hline C-PEI (Percent $\mathrm{CO}_{2}$ cycled) & $84 \%$ & $78 \%$ & $77 \%$ \\
\hline C-PEI (STDEV) & $5 \%$ & $6 \%$ & $9 \%$ \\
\hline C-APTMS (Percent $\mathrm{CO}_{2}$ cycled) & $101 \%$ & $91 \%$ & $79 \%$ \\
\hline C-APTMS (STDEV) & $7 \%$ & $10 \%$ & $9 \%$ \\
\hline C-APTMS-PEI (Percent $\mathrm{CO}_{2}$ cycled) & $100 \%$ & $93 \%$ & $85 \%$ \\
\hline C-APTMS-PEI (STDEV) & $7 \%$ & $10 \%$ & $11 \%$ \\
\hline
\end{tabular}

Table A-12: Data for Figure 5-20, Percent $\mathrm{CO}_{2}$ cycled using humid $\mathrm{CO}_{2}$ at $155^{\circ} \mathrm{C}$ for 30 minutes for regeneration

\begin{tabular}{|l|c|c|}
\hline \multicolumn{1}{|c|}{ Cycle } & 1 & 2 \\
\hline C-PEI (Percent $\mathrm{CO}_{2}$ cycled) & $95 \%$ & $92 \%$ \\
\hline C-PEI (STDEV) & $5 \%$ & $6 \%$ \\
\hline C-APTMS (Percent $\mathrm{CO}_{2}$ cycled) & $96 \%$ & $95 \%$ \\
\hline C-APTMS (STDEV) & $8 \%$ & $9 \%$ \\
\hline C-APTMS-PEI (Percent $\mathrm{CO}_{2}$ cycled) & $96 \%$ & $92 \%$ \\
\hline C-APTMS-PEI (STDEV) & $3 \%$ & $7 \%$ \\
\hline
\end{tabular}


Table A-13: Data for Figure 5-25, Vacuum regeneration results for $85^{\circ} \mathrm{C}$ vacuum desorption in the vacuum oven

\begin{tabular}{|l|c|c|}
\hline & 1 hour vacuum & 17 hour vacuum \\
\hline C-PEI (Percent $\mathrm{CO}_{2}$ cycled) & $96 \%$ & $87 \%$ \\
\hline $\mathrm{C}-\mathrm{PEI}(\mathrm{STDEV})$ & $5 \%$ & $3 \%$ \\
\hline $\mathrm{C}$-APTMS (Percent $\mathrm{CO}_{2}$ cycled) & $87 \%$ & $106 \%$ \\
\hline $\mathrm{C}$-APTMS (STDEV) & $14 \%$ & $16 \%$ \\
\hline C-APTMS-PEI (Percent $\mathrm{CO}_{2}$ cycled) & $104 \%$ & $95 \%$ \\
\hline C-APTMS-PEI (STDEV) & $12 \%$ & $13 \%$ \\
\hline
\end{tabular}

Table A-14: Data for Figures 5-26-30, Pure $\mathrm{CO}_{2}$ adsorption at pressure

\begin{tabular}{|l|c|c|c|c|c|c|c|c|c|c|c|c|}
\hline Pressure (PSI) & $\mathbf{4 0}$ & $\mathbf{4 0}$ & $\mathbf{4 0}$ & $\mathbf{1 0 0}$ & $\mathbf{1 0 0}$ & $\mathbf{1 0 0}$ & $\mathbf{2 0 0}$ & $\mathbf{2 0 0}$ & $\mathbf{2 0 0}$ & $\mathbf{3 0 0}$ & $\mathbf{3 0 0}$ & $\mathbf{3 0 0}$ \\
\hline Time (hours) & $\mathbf{2}$ & $\mathbf{1 6}$ & $\mathbf{2 4}$ & $\mathbf{2}$ & $\mathbf{1 6}$ & $\mathbf{2 4}$ & $\mathbf{2}$ & $\mathbf{1 6}$ & $\mathbf{2 4}$ & $\mathbf{2}$ & $\mathbf{1 6}$ & $\mathbf{2 4}$ \\
\hline C-PEI (wt.\%) & 4.7 & 9.1 & 8.7 & 5.9 & 7.9 & 6.5 & 5.7 & 7.0 & 6.7 & 6.4 & 6.4 & 6.8 \\
\hline C-PEI STDEV & 1.1 & 1.3 & 2.7 & 0.6 & 1.4 & 1.3 & 0.2 & 1.1 & 1.1 & 2.8 & 3.3 & 1.9 \\
\hline C-APTMS (wt.\%) & 7.5 & 7.6 & 7.6 & 4.3 & 7.1 & 8.1 & 6.3 & 6.5 & 6.3 & 6.0 & 7.2 & 7.6 \\
\hline C-APTMS STDEV & 1.8 & 1.5 & 1.1 & 1.1 & 0.2 & 1.0 & 1.2 & 1.5 & 1.0 & 1.8 & 1.4 & 1.5 \\
\hline C-APTMS-PEI (wt. \%) & 4.1 & 5.2 & 9.9 & 7.1 & 9.1 & 7.3 & 5.1 & 9.0 & 10.1 & 7.3 & 8.5 & 11.4 \\
\hline C-APMTS-PEI STDEV & 1.9 & 0.9 & 0.6 & 4.3 & 2.0 & 2.5 & 0.9 & 3.8 & 2.3 & 0.8 & 2.9 & 0.6 \\
\hline Untreated Clay (wt.\%) & 0.9 & 1.4 & 1.4 & 0.4 & 1.0 & 1.3 & 1.6 & 1.4 & 1.5 & 2.0 & 1.0 & 2.3 \\
\hline Untreated Clay STDEV & 0.6 & 0.3 & 0.3 & 0.1 & 0.4 & 0.9 & 0.3 & 0.4 & 0.5 & 0.8 & 0.1 & 0.6 \\
\hline
\end{tabular}

Table A-15: Data for Figures 5-31-32, Pure $\mathrm{CO}_{2}$ adsorption at pressure and temperature

\begin{tabular}{|l|c|c|c|c|}
\hline Adsorption for 24 hours at 300 PSI & Room Temperature & $50^{\circ} \mathrm{C}$ & $75^{\circ} \mathrm{C}$ & $85^{\circ} \mathrm{C}$ \\
\hline C-PEI (wt.\%) & 6.8 & 15.8 & 17.2 & 18.7 \\
\hline C-PEI STDEV & 1.9 & 3.3 & 4.9 & 0.8 \\
\hline C-APTMS (wt.\%) & 7.6 & 8.1 & 9.0 & 9.6 \\
\hline C-APTMS STDEV & 1.5 & 2.5 & 0.2 & 0.4 \\
\hline C-APTMS-PEI (wt. \%) & 11.4 & 14.2 & 17.8 & 18.3 \\
\hline C-APMTS-PEI STDEV & 0.6 & 3.5 & 8.4 & 0.5 \\
\hline Untreated Clay (wt.\%) & 2.3 & 3.6 & 4.2 & 5.3 \\
\hline Untreated Clay STDEV & 0.6 & 0.1 & 1.8 & 0.5 \\
\hline
\end{tabular}


Table A-16: Data for Figure 5-33, $\mathrm{CO}_{2}$ adsorption and vacuum desorption results

\begin{tabular}{|l|c|c|c|}
\hline Pure $\mathrm{CO}_{2}$ adsorption at 300 PSI and 2 Hours & $\begin{array}{c}\text { Initial } \\
\text { Adsorption }\end{array}$ & $\begin{array}{c}\text { Vacuum } \\
\text { Desorption }\end{array}$ & $\begin{array}{c}\text { Cycled } \\
\text { Adsorption }\end{array}$ \\
\hline C-PEI (wt.\%) & 5.6 & 7.0 & 5.5 \\
\hline C-PEI (STDEV wt.\%) & 1.5 & 0.7 & 0.5 \\
\hline C-APTMS (wt.\%) & 5.5 & 6.7 & 4.1 \\
\hline C-APTMS (STDEV wt.\%) & 2.0 & 1.2 & 1.5 \\
\hline C-APTMS-PEI (wt.\%) & 5.8 & 6.7 & 6.0 \\
\hline C-APTMS-PEI (wt.\%) & 1.3 & 0.6 & 0.9 \\
\hline Untreated Clay (wt.\%) & 2.3 & 2.4 & 2.4 \\
\hline Untreated Clay STDEV & 0.8 & 0.4 & 0.4 \\
\hline
\end{tabular}

Table A-17: Data for Figure 5-34, $\mathrm{CO}_{2}$ adsorption and vacuum desorption results

\begin{tabular}{|l|c|c|c|}
\hline Pure $\mathrm{CO}_{2}$ adsorption at 300 PSI, 2 Hours and $50^{\circ} \mathrm{C}$ & $\begin{array}{c}\text { Initial } \\
\text { Adsorption }\end{array}$ & $\begin{array}{c}\text { Vacuum } \\
\text { Desorption }\end{array}$ & $\begin{array}{c}\text { Cycled } \\
\text { Adsorption }\end{array}$ \\
\hline C-PEI (wt.\%) & 13.5 & 11.6 & 14.3 \\
\hline C-PEI (STDEV wt.\%) & 1.2 & 0.8 & 0.8 \\
\hline C-APTMS (wt.\%) & 5.9 & 4.5 & 4.7 \\
\hline C-APTMS (STDEV wt.\%) & 0.4 & 0.3 & 0.4 \\
\hline C-APTMS-PEI (wt.\%) & 11.8 & 9.7 & 11.5 \\
\hline C-APTMS-PEI (wt.\%) & 1.5 & 0.8 & 1.9 \\
\hline Untreated Clay (wt.\%) & 3.6 & 2.6 & 4.2 \\
\hline Untreated Clay STDEV & 0.1 & 0.0 & 0.3 \\
\hline
\end{tabular}

Table A-18: Data for Figures 5-35-36, $\mathrm{CO}_{2}$ adsorption before and after water stability test

\begin{tabular}{|l|c|c|}
\hline Water stability test & Initial Adsorption & Adsorption After Stability Test \\
\hline C-PEI-33 (wt.\%) & 4.2 & 4.3 \\
\hline C-PEI-33 (STDEV wt.\%) & 0.2 & 0.4 \\
\hline C-PEI-50 (wt.\%) & 5.6 & 4.6 \\
\hline C-PEI-50 (STDEV wt.\%) & 0.2 & 1.1 \\
\hline C-PEI-66 (wt.\%) & 5.9 & 6.8 \\
\hline C-PEI-66 (STDEV wt.\%) & 0.3 & 0.7 \\
\hline C-APTMS (wt.\%) & 6.0 & 3.9 \\
\hline C-APTMS (STDEV wt.\%) & 0.2 & 0.5 \\
\hline C-APTMS-PEI (wt.\%) & 6.5 & 6.7 \\
\hline C-APTMS-PEI (wt.\%) & 0.2 & 0.8 \\
\hline
\end{tabular}

